\title{
ITINERARIOS DE ACCESO/ADMISIÓN A LA EDUCACIÓN SUPERIOR. UN ANÁLISIS COMPARADO EN LOS SISTEMAS EDUCATIVOS DE ESPAÑA, FRANCIA Y FINLANDIA
}

\section{David Revesado Carballares Dirigida por Dr. D. Leoncio Vega Gil}

\section{Tesis Doctoral}

Facultad de Educación

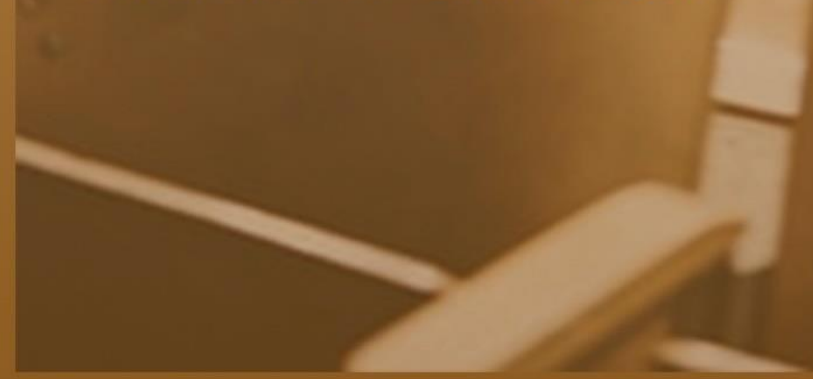

VNIVERSIDAD BSALAMANCA CAMPUS DE EXCELENCIA INTERNACIONAL

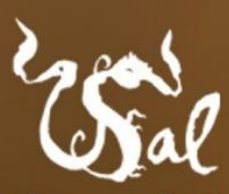
800 Año) 1218 -2018 


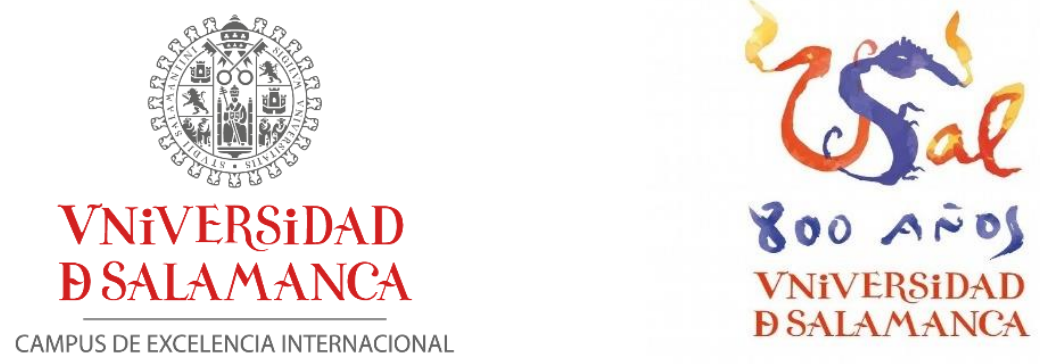

\section{UNIVERSIDAD DE SALAMANCA}

FACULTAD DE EDUCACIÓN

TESIS DOCTORAL

\section{ITINERARIOS DE ACCESO/ADMISIÓN A LA EDUCACIÓN SUPERIOR. UN ANÁLISIS COMPARADO EN LOS SISTEMAS EDUCATIVOS DE ESPAÑA, FRANCIA Y FINLANDIA.}

Autor:

DAVID REVESADO CARBALLARES

Director:

Dr. LEONCIO VEGA GIL

Salamanca, 2020 



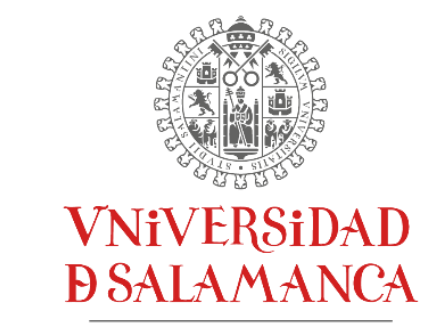

CAMPUS DE EXCELENCIA INTERNACIONAL

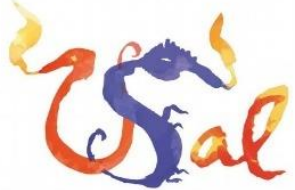

800 Años

VNIVERSIDAD

BSALAMANCA

\section{UNIVERSIDAD DE SALAMANCA}

FACULTAD DE EDUCACIÓN

TESIS DOCTORAL

\section{ITINERARIOS DE ACCESO/ADMISIÓN A LA EDUCACIÓN SUPERIOR. UN ANÁLISIS COMPARADO EN LOS SISTEMAS EDUCATIVOS DE ESPAÑA, FRANCIA Y FINLANDIA.}

\section{Autor}

Firmado por REVESADO

CARBALLARES DAVID -

$52413932 z$ el día 11/07/2020

con un certificado emitido

David Revesado Carballares
Director

VEGA GIL Firmado digitalmente LEONCIO - $\begin{aligned} & \text { por VEGA GIL } \\ & \text { LEONCIO- }-404539916\end{aligned}$ $40453991 \mathrm{G}$ Fecha: 2020.06 .28

\section{Leoncio Vega Gil}



Estos son mis principios.

Si no le gustan ... tengo otros. 



\section{AGRADECIMIENTOS}



No es una tarea sencilla ponerse frente a la pantalla del ordenador y mostrar mi más sincero agradecimiento a todas y cada una de las personas que, directa o indirectamente, me han ayudado en el desarrollo de este trabajo. Y digo que no es una tarea sencilla, porque son muchas las personas que han puesto su granito de arena para ayudarme a crecer desde el punto de vista académico y, sobre todo, personal.

Hace diez años llegue a esta universidad, sin saber que iba a permanecer en ella más tiempo de lo esperado. Una serie de cambios en el acceso universitario (de ahí el gran interés que suscita para mi este tema) me llevaron a la Facultad de Educación, un poco "de rebote". Tengo que reconocer que, en ese momento, mi vocación hacia la Pedagogía era prácticamente nula. No tenía muy claro cuál era la función social que desempeñaba, ni sus salidas profesionales. Sin embargo, me embarque en esa nueva aventura, y hasta la fecha, creo que no he tomado una decisión más acertada en mi vida. En buena medida, esto es gracias a todas y cada una de las personas que he conocido en Canalejas durante la última década, que han hecho que, poco a poco, cambiara mi visión sobre la Pedagogía. Por ello, quiero dar las gracias a toda esa gente que me han ayudado durante todo este tiempo.

En primer lugar, como no podía ser de otro modo, me gustaría comenzar los agradecimientos de esta tesis doctoral dándole las gracias al profesor Leoncio Vega Gil, director, tutor, pero, sobre todo, compañero. Gran parte de este trabajo es suyo. Gracias por tu dedicación, por tu esfuerzo, por tu paciencia y, sobre todo, por tu plena confianza en mí. De una forma totalmente altruista has dedicado a este trabajo tantas horas como las que le he dedicado yo, y eso es de alabar. Gracias por ayudarme a crecer académica pero, sobre todo, personalmente. Por tener siempre la puerta de tu despacho abierta para mí. Estoy convencido de que cinco años atrás, no era ni una caricatura de lo que soy ahora mismo, y eso es gracias a ti.

En segundo lugar, a mi familia, tanto los que están, como los que por desgracia ya no (en especial, mi abuelo y mi tía). A todos y a cada uno de ellos, 
gracias. Pero por encima del resto, a mis padres, a mi hermana, a mis tíos y a mi abuela, que son mi núcleo fundamental de mi vida. Sin su apoyo es inimaginable que yo hoy pudiera estar aquí. Seguramente, no sean los mejores tiempos para investigar. Dedicar los últimos cinco años de mi vida a esta investigación, de forma totalmente gratuita, quizás no haya sido la mejor idea desde el punto de vista económico o laboral. De hecho, hay muchas personas que ni siquiera lo comprenden. Sin embargo, ellos nunca lo han puesto en duda y, así, todo es mucho más sencillo, de verdad ¡MUCHAS GRACIAS POR TODO!

A mis amigos de Vitigudino. No podría enumerarlos a todos porque se haría muy largo, pero me gustaría darles las gracias a todos y cada uno de ellos. Por estar siempre al pie del cañón cuando más lo necesitas. Por tener siempre un plan que te saque de casa. Por cada fiesta y cada cena juntos. Por todas las noches de café y cerveza. En definitiva, ¡Gracias por todo! Para ellos ya hace tiempo que soy el doctor del grupo, seguro que a más de uno le sorprenderá saber que, ahora, por fin, estoy cerca de conseguirlo.

Por otro lado, al Grupo de Investigación Reconocido de Educación Comparada y Políticas Educativas de la Universidad de Salamanca, que me acogió como uno más desde el primer día, cuando tan solo era un estudiante de Máster en prácticas. Y particularmente, a cada uno de sus miembros. A Eva, que dejo de ser mi profesora, para ser mi compañera y, finalmente, mi amiga. Durante estos años has sido la persona que más consejos me ha dado y, sin duda alguna, una de las personas que más me ha ayudado durante todo este tiempo. A Juan Carlos, que fue la primera persona que me acompañó en este proceso de investigación, tras dirigir mi Trabajo Fin de Grado y mi Trabajo Fin de Máster. Siempre que he podido, he intentado aprovecharme de ti y de tus ideas. De hecho, no te quepa duda de que muchas de ellas están plasmadas en este trabajo. A Víctor, compañero de despacho (y fatigas) durante mucho tiempo, y por encima de todo, amigo. Tener una persona como tu al lado, me 
ha facilitado mucho las cosas. Iniciar una tesis doctoral no es algo sencillo, y poder compartir tus inquietudes con alguien que está en una situación similar a la tuya, es algo muy tranquilizador. Por último, también me gustaría acordarme de Yadir y Marta, así como todos los compañeros internacionales que han pasado por nuestra universidad, y que, en algún momento, me han prestado su ayuda.

También me gustaría darle las gracias a Charo y a Laura. La sonrisa de una y la locura de la otra han hecho que todo sea mucho más fácil desde que os conozco. Hemos hecho un gran equipo, nos hemos ayudado mutuamente cuando más lo necesitábamos pero, sobre todo, hemos forjado una gran amistad que, desde luego, no termina aquí. Y, cómo no, a Natalia y a María, que aunque más tarde, han llegado con una energía y un positivismo que se contagia. Sin un mal gesto, siempre tratando de sumar. Me alegro de que también forméis parte de este grupo.

A mi amigo Alfonso. Seguramente sea la persona con la que más tiempo he compartido durante estos años en la Facultad de Educación. No conozco a nadie más positivo que tú. Siempre bromeando, siempre de buen humor. Además, un fijo cada 27 de Noviembre, nunca fallas en las fiestas de Educación.

Al proyecto de Tutoría entre Compañeros de la Facultad de Educación, especialmente, en su vertiente internacional, en la que he podido participar durante los últimos cuatro años. Al profesor José Antonio Cieza, que es el gran artífice de este proyecto y, de una forma más particular, a todos y cada uno de los profesores y alumnos con los que he podido trabajar durante estos años.

Al Programa de Doctorado de Educación y a su equipo de trabajo. Siempre tratando de ayudarnos, en colaboración con la Escuela de Doctorado.

A la Universidad de Salamanca, y de una forma más particular, a la Facultad de Educación, y como no podía ser de otro modo, a todos y cada uno de sus 
trabajadores. Gracias por vuestra ayuda, por vuestras facilidades, por vuestra dedicación... en definitiva, gracias por todo.

También me gustaría mostrar mi agradecimiento a la Fundación SM. Gracias a su colaboración, pude disfrutar de una estancia en uno de los centros de investigación de referencia en el ámbito nacional, como es el Centro Internacional de Cultura Escolar (CEINCE). Y, particularmente, al profesor Agustín Escolano, por su acogida y familiaridad durante esa semana.

Y, por último, gracias a todas aquellas personas que haya podido olvidar en este pequeño preámbulo, que seguro son muchas. A todo aquel que me haya prestado su ayuda durante estos cinco intensos años. 


\section{INDICE}

\section{1) INTRODUCCIÓN Y JUSTIFICACIÓN DEL TEMA OBJETO DE}

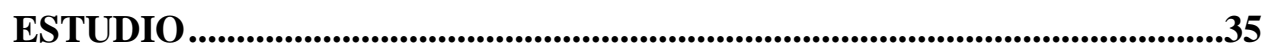

1.1) Justificación de los sistemas educativos objeto de estudio..........................39

1.1.1) Sistema educativo español...........................................................42

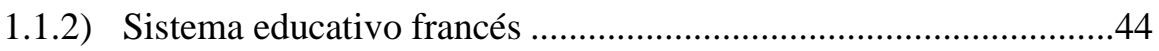

1.1.3) Sistema educativo finlandés ...........................................................46

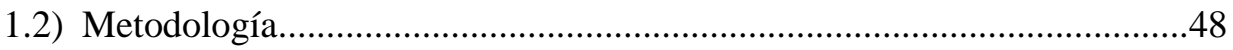

1.2.1) Antecedentes y construcción histórica de la educación comparada

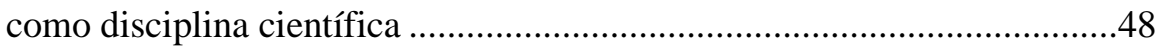

1.2.1.1) Comparación y Comparabilidad ............................................. 49

1.2.2) Método clásico de comparación ....................................................50

1.2.2.1) Cambio de paradigma en la Educación Comparada. Nuevas

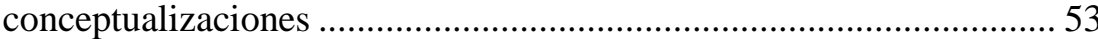

1.2.3) Aplicación y desarrollo del método comparado en nuestro estudio.

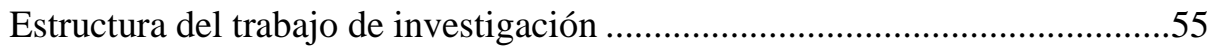

1.3) Hipótesis de la investigación ...............................................................58

1.4) Objetivos que persigue la investigación ....................................................59

1.5) Recogida de la información...................................................................60

2) CATEGORÍAS O VARIABLES DE ANÁLISIS QUE CONCURREN EN EL ACCESO/ADMISIÓN A LA EDUCACIÓN SUPERIOR..................................63

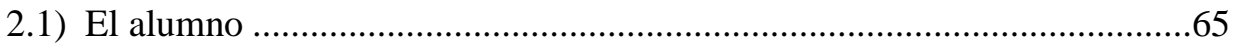

2.1.1) Características académicas del alumno .......................................66

2.1.2) Rendimiento competencial en pruebas de acceso...........................67

2.1.2.1) ¿Garantizan estas pruebas la adquisición de una serie de

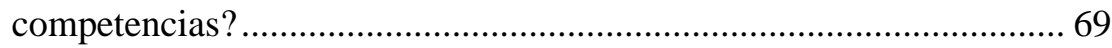


2.1.2.2) ¿Qué relación existe entre el rendimiento competencial de los alumnos y su posterior elección universitaria? ..................................... 70

2.1.3) Origen social de los alumnos que acceden a la educación superior .70

2.1.3.1) Origen social y educación..................................................... 71

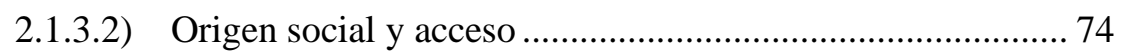

2.2) Los procesos de organización y gestión .....................................................75

2.2.1) Competencias organizativas del acceso, ¿a quién corresponden?.75

2.2.2) ¿Qué papel desempeñan los centros de secundaria en el proceso de transición? .76

2.2.3) Requisitos necesarios para el acceso/admisión a estudios de

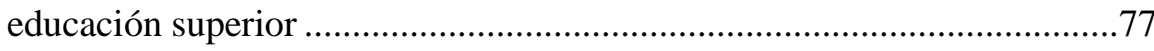

2.3) La regulación. Sistema educativo y modelos de organización....................78

2.3.1) Tipología de los modelos de acceso/admisión................................79

2.3.1.1) Binomio derecho a la educación - igualdad de oportunidades 80

2.3.1.2) Distintos modelos de acceso/admisión a la educación superior 81

2.3.2) Importancia de los modelos de acceso/admisión en la elección de

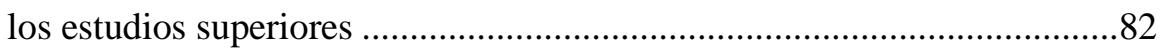

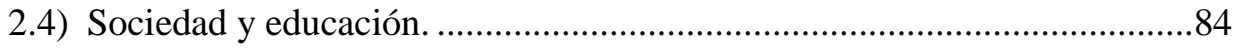

2.4.1) Indicadores culturales y acceso a la educación superior ................84

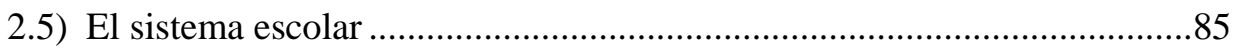

2.5.1) Sistemas de orientación en los centros de educación secundaria y su relación con el acceso/admisión hacia la educación superior ......................85

2.5.1.1) Objetivos y funciones que persigue la orientación ............... 86

2.5.1.2) Orientación en las transiciones ........................................... 87 
2.5.2) Acción tutorial en los alumnos de educación secundaria y su relación con el acceso/admisión hacia la educación superior .......................88

2.5.2.1) ¿Qué entendemos por acción tutorial?.................................. 89

2.5.2.2) Objetivos y principios de la acción tutorial ........................... 89

2.5.2.3) Destinatarios de la acción tutorial........................................ 90

3) EL ACCESO/ADMISIÓN A LA EDUCACIÓN SUPERIOR EN ESPAÑA, FRANCIA Y FINLANDIA. CONTEXTO SOCIO HISTÓRICO, POLÍTICO

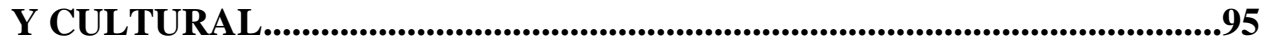

3.1) Contexto socio histórico, político y cultural en España ..............................96

3.1.1) Cultura histórica del sistema educativo español............................96

3.1.1.1) Construcción del sistema educativo en España (1812-1874) .. 97

3.1.1.2) La educación en la restauración (1874-1931)....................... 98

3.1.1.3) La educación en la segunda república española (1931-1939). 99

3.1.1.4) La educación durante el franquismo (1939-1975)............. 100

3.1.1.5) La restauración democrática y la educación ........................ 103

3.1.2) Cultura escolar en el sistema educativo español...........................106

3.1.2.1) Fundamentación teórica y contenido ................................... 106

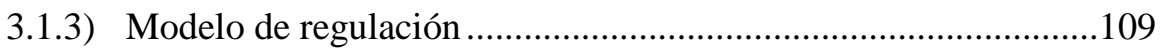

3.1.3.1) Conceptualización de modelo de regulación y formas de

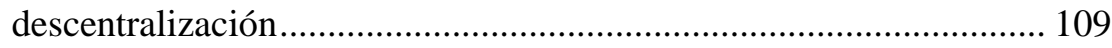

3.1.3.2) El sistema educativo español descentralizado /regionalizado .

3.1.4) Organización y funcionamiento del sistema educativo ................114

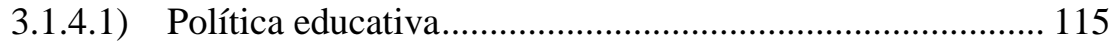

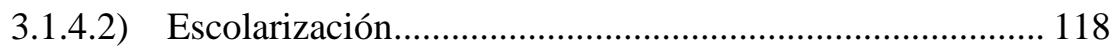

3.1.4.3) Abandono escolar temprano ............................................... 119 
3.1.4.4) Estructura del sistema educativo ....................................... 121

3.1.4.5) Titularidad de los centros educativos ............................... 124

3.1.5) Eficacia del sistema educativo..................................................127

3.2) Contexto socio histórico, político y cultural en Francia............................131

3.2.1) Cultura histórica del sistema educativo francés ...........................131

3.2.1.1) La Revolución Francesa como punto de partida del sistema

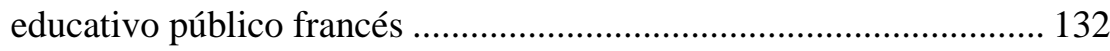

3.2.1.2) El Imperio Napoleónico: en busca de una educación nacional 132

3.2.1.3) Restauración (1814-1830): inicio de la enseñanza primaria....

3.2.1.4) La monarquía de Julio (1830-1848) .................................. 133

3.2.1.5) La II República francesa (1848-1851)............................. 134

3.2.1.6) El II Imperio (1852-1870) ……………......................... 135

3.2.1.7) III República: las leyes Ferry como punto de partida de la

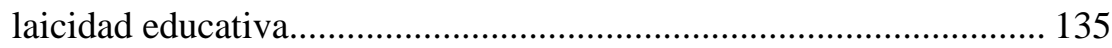

3.2.1.8) Ruptura definitiva entre Iglesia y Estado........................... 137

3.2.1.9) Política educativa francesa entre 1943-1958 .................... 137

3.2.1.10) Política educativa francesa entre 1958-1973 .................. 138

3.2.1.11) Política educativa francesa de finales del s. XX.............. 139

3.2.1.12) La política educativa a principios del siglo XXI ............. 140

3.2.2) Cultura escolar del sistema educativo francés ..............................142

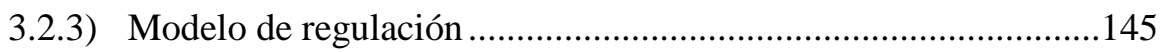

3.2.4) Organización y funcionamiento del sistema educativo ................147

3.2.4.1) Política educativa................................................................ 147

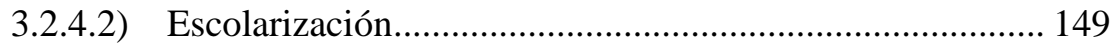

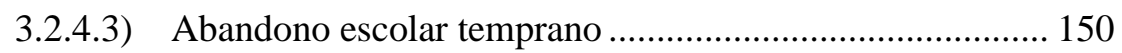

3.2.4.4) Estructura del sistema educativo ....................................... 151 
3.2.4.5) Titularidad de los centros educativos ................................ 154

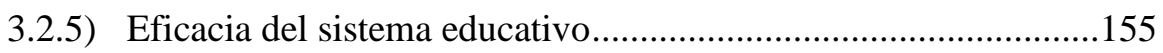

3.3) Contexto socio histórico, político y cultural en Finlandia........................157

3.3.1) Cultura histórica del sistema educativo finlandés ........................158

3.3.1.1) Independencia de Finlandia. Constitución de 1919........... 158

3.3.1.2) La situación después de la Segunda Guerra Mundial ........ 160

3.3.1.2.1) El sistema comprensivo finlandés ............................... 161

3.3.1.2.2) Contexto socio político de la reforma........................ 161

3.3.1.2.3) Las fases de la reforma ........................................... 162

3.3.1.3) Reforma de la educación secundaria superior (1985)........ 163

3.3.1.3.1) Desarrollo económico de Finlandia........................... 163

3.3.1.3.2) Nueva política de educación secundaria..................... 163

3.3.1.3.3) Lanzamiento de la reforma ......................................... 164

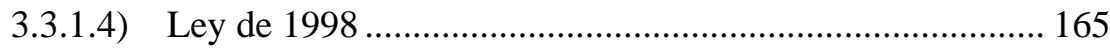

3.3.2) Cultura escolar del sistema educativo finlandés...........................165

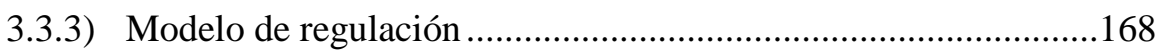

3.3.4) Organización y funcionamiento del sistema educativo ................169

3.3.4.1) Política educativa.................................................................. 169

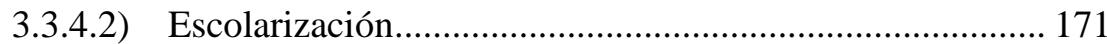

3.3.4.3) Abandono escolar temprano ............................................. 173

3.3.4.4) Estructura del sistema educativo ..................................... 174

3.3.4.5) Titularidad de los centros educativos ............................... 178

3.3.5) Eficacia del sistema educativo.................................................179

4) ¿CÓMO ACTÚAN LOS MODELOS DE ACCESO/ADMISIÓN A LA EDUCACIÓN SUPERIOR?.........................................................................187

4.1) Análisis individualizado del proceso de transición hacia la educación superior en España, Francia y Finlandia .......................................................187 
4.1.1) Características académicas de los alumnos que están en disposición de acceder a los estudios de educación superior ......................................188

4.1.1.1) Sistema educativo español ................................................ 188

4.1.1.2) Sistema educativo francés ................................................... 194

4.1.1.3) Sistema educativo finlandés ............................................ 203

4.1.2) Rendimiento competencial en las pruebas de acceso ..................206

4.1.2.1) Sistema educativo español................................................. 206

4.1.2.2) Sistema educativo francés ................................................ 213

4.1.2.3) Sistema educativo finlandés ............................................. 218

4.1.3) Origen social de los alumnos que están en disposición de acceder a los estudios de educación superior.........................................................220

4.1.3.1) Sistema educativo español .............................................. 220

4.1.3.2) Sistema educativo francés ................................................ 224

4.1.3.3) Sistema educativo finlandés ............................................. 226

4.1.4) Competencia organizativa del acceso, ¿a quién corresponde? ....228

4.1.4.1) Sistema educativo español................................................ 228

4.1.4.2) Sistema educativo francés ................................................. 230

4.1.4.3) Sistema educativo finlandés .............................................. 231

4.1.5) ¿Qué papel desempeñan los centros de secundaria en el proceso de

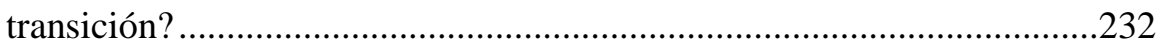

4.1.5.1) Sistema educativo español................................................ 232

4.1.5.2) Sistema educativo francés ................................................. 233

4.1.5.3) Sistema educativo finlandés ............................................ 233

4.1.6) Requisitos necesarios para el acceso/admisión a los estudios de

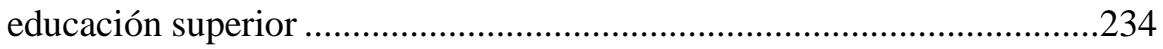

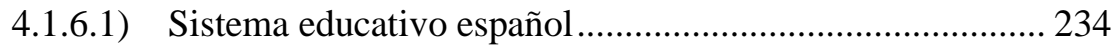

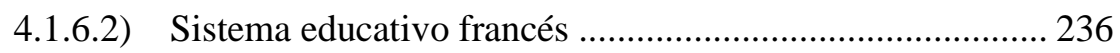

4.1.6.3) Sistema educativo finlandés ............................................. 238 
4.1.7) Sistema educativo y modelos de acceso/admisión .239

4.1.7.1) Sistema educativo español.............................................. 239

4.1.7.2) Sistema educativo francés .................................................. 241

4.1.7.3) Sistema educativo finlandés ............................................. 242

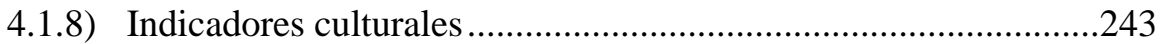

4.1.8.1) Sistema educativo español................................................ 243

4.1.8.2) Sistema educativo francés ................................................. 246

4.1.8.3) Sistema educativo finlandés .............................................. 248

4.1.9) Sistemas de orientación en los centros de educación secundaria y su relación con el acceso/admisión a los estudios de educación superior ....250

4.1.9.1) Sistema educativo español................................................ 250

4.1.9.2) Sistema educativo francés ................................................ 253

4.1.9.3) Sistema educativo finlandés ............................................. 255

4.1.10) Acción tutorial en los alumnos de educación secundaria y su relación con el acceso/admisión hacia los estudios de educación superior

4.1.10.1) Sistema educativo español.............................................. 258

4.1.10.2) Sistema educativo francés ............................................... 259

4.1.10.3) Sistema educativo finlandés ............................................ 260

4.2) El proceso de transición hacia la educación superior en España, Francia y Finlandia: convergencias y divergencias ....................................................261

5) LA COMPARACIÓN CONTEXTUAL DEL ACCESO/ADMISIÓN A LA EDUCACIÓN SUPERIOR. LA RACIONALIDAD COMO VEHÍCULO PARA LA COMPRENSIÓN ....................................................................271

5.1) Explicación de las semejanzas y diferencias en el acceso/admisión a la educación superior en España, Francia y Finlandia.........................................274

5.1.1) Características académicas de los alumnos que están en disposición de acceder a los estudios de educación superior ........................................274 
5.1.2) Rendimiento competencial en pruebas de acceso.

5.1.3) Origen social de los alumnos que están en disposición de acceder a los estudios de educación superior. .280

5.1.4) Competencia organizativa del acceso, ¿a quién corresponde? ....283

5.1.5) ¿Qué papel desempeñan los centros de secundaria en el proceso de transición?... 285

5.1.6) Requisitos necesarios para el acceso/admisión a los estudios de educación superior .287

5.1.7) Sistema educativo y modelos de acceso/admisión ........................290

5.1.8) Indicadores culturales .293

5.1.9) Sistemas de orientación en los centros de educación secundaria y su relación con el acceso/admisión a la educación superior. .296 5.1.10) Acción tutorial en los alumnos de educación secundaria y su relación con el acceso/admisión a la educación superior .300

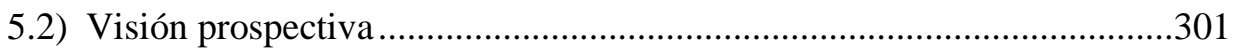

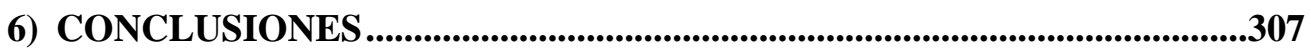

6.1) Fortalezas y debilidades de nuestro estudio ………….............................316

6.2) Futuras líneas de investigación.................................................................319

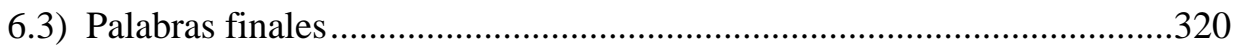

REFERENCIAS BIBLIOGRÁFICAS .......................................................323

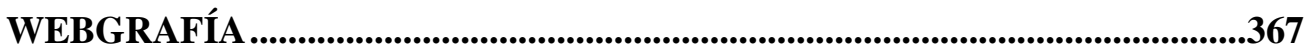

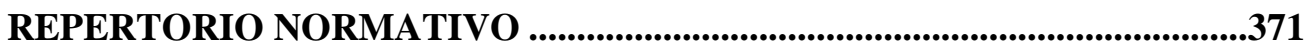

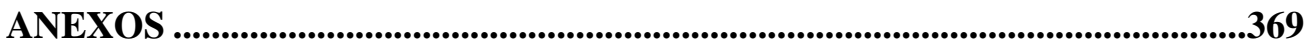




\section{INDICE DE TABLAS}

Tabla 1. Rendimiento en competencia científica (PISA 2015) de los alumnos adscritos a centros de titularidad pública de los sistemas educativos de España, Francia y Finlandia, según el índice ESCS. ..........................................................................72

Tabla 2. Modelos de acceso/admisión hacia la educación superior ............................82 Tabla 3. Etapas en el proceso de transferencia de competencias educativas en España 113

Tabla 4. Puntuaciones obtenidas por los alumnos españoles en las diferentes áreas de conocimiento evaluadas por PISA

Tabla 5. Puntuaciones obtenidas por los alumnos franceses en las diferentes áreas de conocimiento evaluadas por PISA 156

Tabla 6. Puntuaciones obtenidas por los alumnos finlandeses en las diferentes áreas de conocimiento evaluadas por PISA 180

Tabla 7. Número de alumnos matriculados en Ciclos Formativos de Grado Superior, atendiendo a la variable género y familia profesional (2019) 193

Tabla 8. Número de alumnos matriculados en educación secundaria superior general y tecnológica, atendiendo a la variable género, titularidad del centro y especialidad cursada (2019) .196

Tabla 9. Número de alumnos matriculados en educación secundaria superior profesional (sector producción), atendiendo a la variable género, titularidad del centro y familia profesional (2019) .198

Tabla 10. Número de alumnos matriculados en educación secundaria superior profesional (sector servicios), atendiendo a la variable género, titularidad del centro y familia profesional (2019) 200 
Tabla 11. Número de alumnos matriculados, presentados y aprobados en la prueba de acceso a la universidad, por comunidades autónomas (2017) 209

Tabla 12. Origen social de los alumnos que están en disposición de acceder a los estudios de educación superior en España, Francia y Finlandia. .263

Tabla 13. Acceso hacia los estudios de educación superior en España, Francia y Finlandia .265

Tabla 14. Admisión hacia los centros de educación superior en España, Francia y Finlandia .266

Tabla 15. Asesoramiento y acción tutorial en los sistemas educativos de España, Francia y Finlandia. .267 


\section{INDICE DE GRÁFICOS}

Gráfico 1. Transición desde la educación secundaria superior hacia la educación superior en España, Francia y Finlandia

Gráfico 2. Evolución (\%) de la tasa de abandono escolar temprano en España durante el s. XXI 120

Gráfico 3. Estructura del sistema educativo español. .121

Gráfico 4. Porcentaje de alumnos matriculados en centros de titularidad pública (PISA, 2015). 126

Gráfico 5. Evolución de las puntuaciones obtenidas por los estudiantes españoles, en las diferentes áreas de conocimiento evaluadas por PISA

Gráfico 6. Evolución (\%) de la tasa de abandono escolar temprano en Francia durante el s. XXI .151

Gráfico 7. Estructura del sistema educativo francés 154

Gráfico 8. Evolución de las puntuaciones obtenidas por los estudiantes franceses, en las diferentes áreas de conocimiento evaluadas por PISA

Gráfico 9. Evolución (\%) de la tasa de abandono escolar temprano en Finlandia durante el s. XXI 174

Gráfico 10. Estructura del sistema educativo finlandés 178

Gráfico 11. Evolución de las puntuaciones obtenidas por los estudiantes finlandeses, en las diferentes áreas de conocimiento evaluadas por PISA. .181

Gráfico 12. Evolución del número de alumnos matriculados en bachillerato 190

Gráfico 13. Evolución (\%) de los alumnos de bachillerato atendiendo a la titularidad del centro al que están adscritos .191 
Gráfico 14. Evolución del número de alumnos matriculados en estudios de formación profesional (Modalidad presencial)

Gráfico 15. Evolución del número de alumnos matriculados en educación secundaria superior general y tecnológica

Gráfico 16. Evolución del número de alumnos matriculados en educación secundaria superior profesional 195

Gráfico 17. Evolución del número de alumnos matriculados en educación secundaria superior general y tecnológica, atendiendo a la titularidad del centro .202

Gráfico 18. Evolución del número de alumnos matriculados en educación secundaria superior profesional, atendiendo a la titularidad del centro 202

Gráfico 19. Evolución del número de alumnos matriculados en educación secundaria superior general .203

Gráfico 20. Evolución del número de alumnos matriculados en educación secundaria superior profesional .204

Gráfico 21. Evolución del número de alumnos presentados a la prueba de acceso a la universidad (convocatoria ordinaria y extraordinaria) .210

Gráfico 22. Evolución del número de alumnos presentados a la fase específica de la prueba de acceso a la universidad 211

Gráfico 23. Evolución del número de alumnos presentados a las distintas pruebas de acceso a la universidad .212

Gráfico 24. Evolución del número de alumnos presentados a la prueba del Bac....216 Gráfico 25. Evolución del número de alumnos matriculados en educación secundaria superior, atendiendo a la especialidad cursada .217

Gráfico 26. Evolución de la tasa de finalización de estudios en educación secundaria superior general 219 


\section{ABREVIATVRAS Y SIGLAS}

AES - Adult Education Survey

BAC - Baccalauréat

CAP - Certificat d'Aptitude Professionelle

CC. AA - Comunidades Autónomas

$\mathbf{C E}$ - Constitución Española

CEG - Collèges d’Enseignement General

CES - Collège d' Enseignement Secondaire

CFEPS - Certificat de fin d'études professionnelles secondaires

CFES - Certificat de fin d'études secondaires

CFETS - Certificat de fin d'études technologiques secondaires

CIMO - Center for International Mobility and Cooperation

CINE - Clasificación Internacional Normalizada de la Educación

CIO - Centres d'information et d'orientation

CNL - Centre National du Livre

COP - Conseillers d'Orientation-Psychologues

CPE - Conseiller Principal en Éducation

DZHW - German Centre for Higher Education Research and Science Studies 
EBAU - Evaluación de Bachillerato para el Acceso a la Universidad

ECTS - European Credit Transfer and Acumulation System

EEES - Espacio Europeo de Educación Superior

ES - Itinerario Educación Secundaria Superior Económico y Social

ESCS - Economic, Social and Cultural Status

ESO - Enseñanza Secundaria Obligatoria

ESPE - Écoles Supérieures du Professorat et de l'Éducation

FGEE - Federación de Gremios de Editores de España

FNAE - Finnish National Agency for Education

FNBE - Finnish National Board of Education

FP - Formación Profesional

FSFS - Finnish Society for Future Studies

FSO - Swiss Federal Statistical Office

IES - Institutos de Enseñanza Secundaria

IHS - Institute for Advanced Studies

ILE - Institución Libre de Enseñanza

INSPE - Instituts Nationaux Supérieurs du Professorat et de l’Éducation

L - Itinerario de Educación Secundaria Superior Literario

LGE - Ley General de Educación 
LOCE - Ley Orgánica de Calidad de la Educación

LODE- Ley Orgánica del Derecho a la Educación

LOE - Ley Orgánica de Educación

LOECE- Ley Orgánica por la que se regula los Estatutos de los Centros Escolares

LOGSE - Ley de Ordenación General del Sistema Educativo

LOMCE - Ley Orgánica para la Mejora de la Calidad de la Educación

LOMLOE - Ley Orgánica por la que se Modifica la Ley Orgánica de Educación

LRU - Loi relative aux libertés et responsabilités des universités

MESR - Ministère de l'Enseignement Supérieur et de la Recherche

NCFHE - Maltese National Commission for Further and Higher Education

NEE - Necesidades educativas especiales

OCDE - Organización para la Cooperación y el Desarrollo Económico

OI - Organismos Internacionales

PAAU - Pruebas de Aptitud para el Acceso a la Universidad

PAC - Plan Anual de Centro

PAT - Plan de Acción Tutorial

PAU - Prueba de Acceso a la Universidad

PCE - Proyecto Curricular de Etapa

PEC - Proyecto Educativo de Centro 
PIB - Producto Interior Bruto

PISA - Programme for International Student Assessment

PP - Partido Popular

PSOE - Partido Socialista Obrero Español

ROF - Reglamento de Organización y Funcionamiento

S - Itinerario de Educación Secundaria Superior Científico

ST2S - Sciences et Technologies de la Santé et du Social

STD2A - Sciences et Technologies du Design et des Arts Appliqués

STHR - Sciences et Technologies de l'hôtellerie et de la Restauration

STI2D - Sciences et Technologies de l'industrie et du Développement Durable

STL - Sciences et Technologies de Laboratoire

STMG - Sciences et Technologies du Management et de la Gestión

TALIS - Teaching and Learning International Survey

TMD - Techniques de la Musique et de la Danse

U. E. - Unión Europa 


\section{ÍNDICE DE ANEX○S}

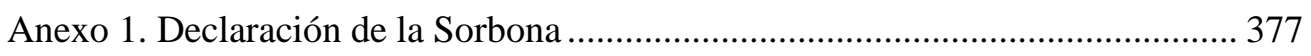

Anexo 2. Espacio Europeo de Enseñanza Superior................................................ 381

Anexo 3. Proyecto de resolución del consejo y de los representantes de los gobiernos de los estados miembros reunidos en el seno del consejo sobre el fortalecimiento de las políticas, sistemas y prácticas en materia de orientación permanente en europa. 385

Anexo 4. Proyecto de resolución del consejo y de los representantes de los gobiernos de los estados miembros, reunidos en consejo, de 21 de noviembre de 2008, titulada «incluir mejor la orientación permanente en las estrategias permanentes de educación y formación permanente 395 



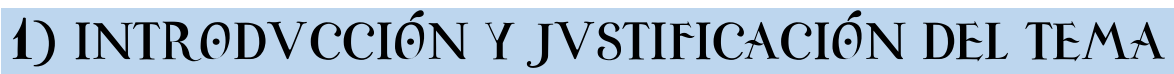

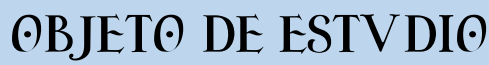

2) CATEGORÍAS $\odot$ VARIABLES DE ANÁLISIS DEL ACCESO/ADMISIÓN A LA EDVCACIÓN SVPERIOR

3) EL ACCESの/ADMISIÓN A LA EDVCACIÓN SVPERIOR EN ESPANAA, FRANCIA Y

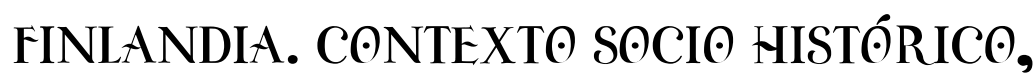
POLÍTICe Y CVLTVRAL

4) ¿CÓM@ ACTV́AN LOS MODELOS DE ACCESO/ADMISIÓN HACIA LA EDVCACIÓN SVPERIOR?

5) LA COMPARACIÓN CONTEXTVAL DEL ACCES@/ADMISIÓN A LA EDVCACIÓN SVPERIOR. EL CARÁCTER FVNCIONAL DE LAS TRANSICIONES

6) CONCLVSI@NES 



\section{1) INTR}

\section{ESTVDI@}

No cabe duda de que, a lo largo de los últimos años, se ha producido un importante crecimiento en la demanda de educación superior, una demanda que se prevé sea aún mayor, llegando incluso a superar las previsiones y posibilidades de los sistemas educativos (Banks, 2001; Meyer y Schofer, 2006). Frente a tal situación, los centros de educación superior están destinados a desempeñar un papel primordial (Luzón, Sevilla y Torres, 2009) en las denominadas sociedades del conocimiento, donde los esquemas clásicos de producción, difusión y aplicación del saber están experimentando profundos cambios (UNESCO, 2005).

Si examinamos de una manera general el contexto de la educación superior ${ }^{1}$ podríamos afirmar que ésta estaría compuesta por tres momentos o etapas clave: acceso, retención/formación y empleabilidad. El acceso exige un conocimiento acerca

\footnotetext{
${ }^{1}$ Cuando utilizamos el término educación superior, estamos aludiendo al nivel 5 y nivel 6 de la Clasificación Internacional Normalizada de la Educación (CINE), elaborada por la UNESCO. De este modo, utilizaremos este término, para referirnos a los programas de educación terciaria de ciclo corto CINE 5- y los grados en educación terciaria o equivalentes -CINE 6- (UNESCO, 2013).
} 
de la oferta de educación superior por parte de los estudiantes, los requisitos para ser admitidos y el proceso de admisión al que deberán enfrentarse; la formación/retención hace referencia a la progresión del estudiante a lo largo del programa de estudios; y, finalmente, la empleabilidad, se refiere al proceso de transición desde la educación superior hacia el mercado laboral (European Commission, 2014).

Nuestra intención a lo largo de este trabajo es centrarnos en la primera vertiente, el acceso, que no solamente hace referencia a la propia educación superior, sino también a la etapa inmediatamente anterior, la educación secundaria superior. De este modo, podemos afirmar que lo que en realidad estamos analizando es un proceso de transición educativa. Sin duda, estamos ante un término que guarda una gran complejidad, ya que tiene multitud de acepciones. Sebastián (2015) las define como momentos críticos de cambio que vive el alumnado al pasar de un ambiente a otro. Mientras tanto, Dockett y Perry (2007) lo definen como un proceso en el que los individuos cambian su rol dentro de la comunidad educativa. Por otro lado, Fabian y Dunlop (2007) las definen como el proceso de cambio que experimentan los alumnos (y sus familias) cuando se trasladan de un escenario a otro. De esta manera, podemos considerar las transiciones educativas (tanto en los niveles obligatorios como postobligatorios) como un proceso inherente en la vida académica del alumno (Azorín, 2019). Además, debemos tener muy presente que en algunas ocasiones (como la que aquí analizamos), los procesos de transición se desarrollan en un nuevo contexto organizativo, educativo y social, que es regulado por normas explícitas e implícitas muy diferentes a la de los sistemas previos (Figuera, Rodríguez y Llanes, 2015).

Por otro lado, también nos gustaría hacer una pequeña alusión a dos términos que debemos conocer y diferenciar para poder entender el devenir de nuestro trabajo, como son: acceso y admisión. Cuando hablamos de acceso nos estamos refiriendo a aquellos requisitos o condiciones necesarias para la entrada hacía unos determinados 
estudios universitarios; por lo general, garantizan que el alumno está en disposición de unas competencias mínimas, que habrá adquirido durante su paso por la educación secundaria y que le permitirán hacer frente a los estudios universitarios de una manera satisfactoria. Mientras que la admisión, se refiere a las condiciones específicas de entrada fijadas desde los propios centros de educación superior (Revesado, 2018); estos procedimientos permitirán que las universidades puedan adecuar los perfiles académicos de sus futuros alumnos, para así localizar a aquellos que potencialmente tienen mayores probabilidades de éxito a la hora de finalizar unos determinados estudios (Egido, 2019). Sin duda alguna, es fundamental comprender y diferenciar ambos términos ya que, a lo largo de nuestro trabajo, aludiremos a ellos constantemente y, aunque tendemos a utilizarlos de manera indistinta, lo cierto es que tienen connotaciones diferentes.

Actualmente, se está generando una gran expectación, tanto a nivel nacional (De Carlos, 2014; Lorenzo, Argos, Hernández y Vera, 2014; Michavila y Esteve, 2011; Revesado, 2018; Rodríguez, Fita y Torrado, 2004; Valle, 2001, 2008) como a nivel internacional (Adelman, Holland y Heidelk, 2017; European Commission, 2014, 2015; Kwiek, 2013; Mabokela y Mlambo, 2017; Van der Wende, 2003; Yang, Borrowman, Tan y New, 2019) por la temática que nosotros presentamos en este trabajo, no solo por lo que este tema representa a nivel académico, sino también desde el punto de vista institucional. Sin duda alguna, los procesos de transición, y especialmente, la transición desde la educación secundaria hacia la educación superior está tomando un papel relevante en nuestra sociedad, generando un gran atractivo para los investigadores educativos, especialmente en la perspectiva internacional o comparada (Revesado, 2018), que es en la que se enmarca nuestro trabajo. Esta relevancia a la que nosotros aludimos está estrechamente relacionada con el aprovechamiento de la calidad universitaria y del ejercicio profesional. Pero esta relación, es aún más interesante si cabe, si tenemos en cuenta alguno de los sistemas 
analizados en el trabajo, como es el finlandés, donde existe una estrecha relación entre la calidad en el acceso, calidad en la formación y la calidad del ejercicio profesional.

Sin embargo, no es esta relevancia que están adquiriendo los procesos de transición la que nos ha llevado a indagar sobre ellos, sino que se trata de una motivación puramente personal. Con antelación, durante el desarrollo de mi Trabajo Fin de Grado y mi Trabajo Fin de Máster, ya había comenzado a indagar acerca del acceso hacia las instituciones de educación superior. Comencé analizando el acceso hacia la titulación de Pedagogía en la Universidad de Salamanca, con el único fin de esclarecer cuales eran los motivos por los que esta titulación tenía tan poca acogida entre los propios alumnos que la estaban cursando. Dado que en este primer trabajo localicé lo que, desde mi punto de vista, eran algunos errores en el proceso de transición, decidí dar un paso más y analizar el acceso universitario en perspectiva nacional, tanto en lo que concierne al plano legislativo como institucional. Todo ello me sembró una serie de dudas que me impulsaron a continuar este proceso de investigación. Sin embargo, en este caso, aposté por continuar trabajando el acceso en perspectiva internacional, llevando a cabo un estudio comparado de nuestro sistema educativo con otros dos sistemas que generaban un gran atractivo para mí, como son el francés y el finlandés. Y es que, conocer el funcionamiento de otros sistemas educativos, favorecerá un mayor y mejor conocimiento sobre el nuestro propio (Bereday, 1968).

Por otro lado, no debemos obviar que un porcentaje significativo de la población ha experimentado este proceso de transición en primera persona, ya que cada vez es mayor el porcentaje de estudiantes que acceden a las instituciones de educación superior. Por ello, no solo los expertos en pedagogía o cualquier ciencia de la educación pueden valorar este proceso educativo, sino que cualquier persona, sea del ámbito que sea, también tendrá una opinión al respecto. Y es que, sin duda alguna, el acceso a la universidad marca un punto de inflexión en nuestras vidas, ya que va a 
condicionar nuestro futuro más inmediato (no solo a nivel académico, sino también a nivel personal) y también, nuestro futuro a largo plazo (en lo que se refiere al plano profesional). Por todo ello, consideramos que esta es una etapa fundamental en nuestra vida y, como tal, debe desarrollarse de la forma más eficaz posible. Este ha sido uno de los principales motivos que me ha llevado a investigar sobre ello, el poder aportar nuevas evidencias sobre este complejo proceso de transición que, espero y deseo, sean útiles en el futuro.

\section{1) Justificación de los sistemas educativos objeto de estudio}

En un entorno social y económico en el que las habilidades y competencias adquiridas a través de la educación superior se están volviendo cada vez más importantes, debe de ser imperativo social ampliar las oportunidades para que exista un mayor y, sobre todo, mejor acceso hacia las instituciones de educación superior (European Commission, 2015). Por todo ello, como acabamos de comentar, hemos decidido examinar el acceso hacia tales estudios en perspectiva internacional, analizando, no solo a nuestro sistema educativo, el español, sino que, además, hemos optado por compararlo con otros dos sistemas, cuyos modelos e itinerarios de transición difieren en gran medida del nuestro, como son el finlandés y el francés.

A continuación, queremos exponer las razones que nos han llevado a elegir estos sistemas educativos para nuestro estudio, y no otros. Y es que, un trabajo como el que estamos presentando, de semejante envergadura, no es fruto de una elección aleatoria. Varios han sido los motivos que nos han llevado a elegir estos tres sistemas educativos para el desarrollo de nuestra investigación. El primero de ellos tiene que ver con el apartado personal, ya que estamos hablando de tres sistemas que conocemos perfectamente y que, además, ya hemos analizado a lo largo de nuestro periplo formativo, puesto que, con anterioridad, hemos realizado algunas investigaciones de menor envergadura. El modelo español es sin duda alguna el que más interés ha 
suscitado para nosotros. En primer lugar, porque se trata de nuestro propio sistema educativo, en el que nos hemos educado y aquel que todos hemos experimentado en primera persona. $Y$ en segundo lugar, debido a que, en el momento en el que iniciamos esta investigación -allá por el año 2015-, España se encontraba inmersa en un momento de transición reformista, que hacía que nuestro sistema educativo fuese muy atractivo para los investigadores educativos tanto nacionales como internacionales. Respecto a Francia, llama la atención su perspectiva tanto histórica como política, y la gran influencia educativa que el país galo ha ejercido sobre numerosos países europeos, en general (Phillips y Ochs, 2004), y sobre el nuestro, en particular, con un fuerte influjo durante el periodo republicano (Fernández Soria, 2005) que, si bien es cierto, adquiría unos mayores tintes políticos e institucionales, que pedagógicos (Monés, 1977). Además, no debemos obviar que, al igual que España, el sistema educativo francés ha consolidado una de las reformas más importantes que se recuerdan en materia de acceso universitario, a través del coloquialmente conocido Bac 2021. A través de esta propuesta, se pretende acabar con la complejidad de esta prueba que, tras más de doscientos años, necesita impulsar una serie de cambios que le permitan adaptarse a las nuevas realidades de la sociedad francesa. Por último, no podíamos olvidar el modelo finlandés, por el que tenemos un especial apego y que, hoy en día, es uno de los sistemas educativos referentes en el panorama internacional, debido a su liderazgo en la sociedad del conocimiento, gracias a su contrastada calidad educativa. Y es que, pese al descenso que el país nórdico ha experimentado en las últimas evaluaciones internacionales, lo cierto es que el sistema educativo finés se mantiene como uno de los grandes atractivos pedagógicos del contexto internacional.

Desde el punto de vista pedagógico, otro de los elementos que justificaría la elección de estos sistemas educativos para nuestro trabajo, es la comprensividad. Este modelo, que tiene sus orígenes en Reino Unido y Suecia, se expande por el contexto europeo a lo largo de los años setenta del pasado siglo. De los tres sistemas analizados, 
Finlandia es que lo manifiesta de una forma más clara, si bien, también está presente en el sistema educativo español y francés; mientras que en España se afianzó de una forma más tardía, durante la década de los años noventa, en Francia se mantiene como un modelo mixto en los College, donde los dos primeros cursos son de carácter comprensivo, mientras que los dos últimos serían diferenciados (Vega, 2011a).

Por último, también es reseñable de cara a comprender la elección de estos sistemas educativos, el hecho de que estamos analizando geográficamente tres países muy diferentes dentro de un mismo contexto, como es el europeo: un sistema de la Europa mediterránea como es el caso de España, otro que podemos denominar centroeuropeo, que sería el caso de Francia y, finalmente, uno nórdico, como es el finlandés. Y es que, "la comparación supone una afinidad o proximidad geográfica e histórica" (Raventós, 1990: 108). En nuestro caso, vamos a llevar a cabo un estudio comparado de tres sistemas educativos que, lógicamente, comparten muchos aspectos en común, pero que también tienen muchas diferencias entre sí, no solo en lo que respecta al ámbito académico y pedagógico -como es evidente-, sino también si atendemos a otros factores que pueden tener gran transcendencia para nuestro estudio desde el punto de vista contextual, como son: cultura histórica, eficacia del sistema educativo, modelos de regulación, etc. Estas variables, junto a alguna otra que hemos considerado oportuna, serán analizadas individualmente a lo largo de nuestro trabajo, ya que entendemos que el contexto es determinante para explicar y fundamentar las semejanzas y diferencias que arroje nuestra investigación. De hecho, son muchos los comparatistas que, a lo largo de los últimos años, han defendido esta tesitura (Astiz, Wiseman y Baker, 2002; Derqui 2001; Holmes, 1981; Noah, 1986; Phillips y Ochs, 2003, 2004). Por ello, sin ánimo de ser exhaustivos, y con el único fin de enriquecer más aún la justificación de esta elección, vamos a hacer una pequeña reseña acerca de algunas variables contextuales de interés en cada uno de los tres sistemas educativos analizados. 


\subsection{1) Sistema educativo español}

Comenzaremos analizando el sistema educativo español. A nivel histórico, debemos reconocer que España, al igual que sus homólogos europeos, no contaba con un sistema educativo público como el que conocemos hoy en día hasta hace relativamente poco tiempo, ya que estos son muy recientes y tan solo cuentan con dos siglos de existencia. En todo lo que antecede a la revolución francesa, en el denominado Antiguo Régimen, podemos hablar de mosaico o aparato escolar, pero de ningún modo de sistema escolar como el que está vigente en la actualidad. Se trataba por tanto de un aparato informal, donde la instrucción era muy escasa, y casi siempre, llevada a cabo por la Iglesia o, en menor medida, por las autoridades municipales (Puelles, 2011). En la construcción histórica del sistema educativo español, debemos diferenciar dos grandes periodos: el primero de ellos, un periodo que fue iniciado con la Constitución de Cádiz (1812) y finalizado con la última Constitución Española (CE) promulgada en el año 1978. Esta etapa estaría caracterizada por la jerarquización y el centralismo, con una fuerte influencia francesa. El segundo ciclo o periodo al que aludimos es el que continua a partir de la $\mathrm{CE}$, momento en el que comienza a llevarse a cabo una democratización de la educación y esta comienza a concebirse como un derecho (Vega, 2013). Con la llegada de la democracia, se instalará en nuestro país una fuerte alteración política, que se verá reflejada en el aparato educativo, con la aprobación de multiplicidad de leyes en un periodo temporal muy corto. Estas leyes carecerán de una estructura vertebradora e integradora, ya que son fruto de una serie de cambios introducidos por gobiernos de diferente signo político (Charro, 2016; Marbán y Rodríguez, 2014).

Otra de las variables que hemos tenido muy presente, y que puede condicionar en gran medida, no solo el acceso hacia los estudios de educación superior, sino todo el proceso educativo, es el modelo de regulación. Nuestro país se rige de una forma totalmente descentralizada, siendo "un principio vertebrador del Estado español y de 
sus administraciones públicas, cuyo sentido es aproximar el ejercicio del poder público a la sociedad" (Caballero, 2014: 45). Esta descentralización, que se manifiesta en forma de regionalización, se verá claramente reflejada en el apartado educativo, donde las Comunidades Autónomas (CC. AA) tendrán un peso específico en la toma de decisiones.

Por último, vamos a hacer referencia a la eficacia del sistema educativo español. La lectura histórica, política y neoliberal de un sistema, debe ir acompañada de las consecuencias del buen o mal funcionamiento del mismo, que distintos Organismos Internacionales (OI), como la Organización para la Cooperación y el Desarrollo Económico (OCDE), a través de diferentes programas, como PISA $^{2}$ y TALIS $^{3}$, se encargan de poner de manifiesto (Vega, 2013). Atendiendo a estas pruebas, podemos afirmar que el rendimiento de nuestro sistema educativo se encuentra en torno a la media internacional, ya que las puntuaciones obtenidas son muy similares a la del resto de participantes. Más adelante, nos detendremos a analizar las puntuaciones obtenidas por España en las pruebas PISA, ya que son las encargadas de evaluar a los estudiantes de secundaria y, por tanto, las que mejor se adaptan a la idiosincrasia de nuestro trabajo. De este modo, podremos esclarecer las diferencias en cuanto al rendimiento académico de los estudiantes lo que, a su vez, nos permitirá vislumbrar la eficacia del sistema educativo.

\footnotetext{
${ }^{2}$ Programme for International Student Assessment. Se trata de un proyecto de la OCDE, cuyo objetivo es el de evaluar a aquellos alumnos que están a punto de finalizar la enseñanza secundaria obligatoria. El programa ha sido concebido como un recurso para ofrecer información útil, que permita a los países miembros adoptar las decisiones y políticas necesarias para la mejora de los niveles educativos.
}

${ }^{3}$ Teaching and Learning International Survey. Este programa internacional, da la oportunidad, tanto a maestros como directores, de valorar diferentes áreas de conocimiento: prácticas de enseñanza y ambiente en el aula, desarrollo y apoyo, liderazgo escolar y autoeficacia, satisfacción en el trabajo, etc. 


\subsection{2) Sistema educativo francés}

En segundo lugar, analizaremos alguna de las causas que nos han llevado a analizar el sistema educativo francés. No cabe duda de que, desde el punto de vista histórico, Francia es uno de los grandes referentes internacionales, habiendo ejercicio una fuerte influencia sobre numerosos sistemas educativos europeos. Dos son los momentos históricos de mayor relevancia, y ambos, se enmarcan a finales del s. XVIII. El primero de ellos, tras la publicación del Emilio de Rousseau (1762), que muestra una nueva pedagogía inspirada en la libertad y el descubrimiento del niño como sujeto de la educación. Y, en segundo lugar, un año más tarde (1763), con la publicación de Essai d'Éducation Nationale de Louis-Rene de Caradeuc de La Chalotais, una obra que apuesta por la secularización de la enseñanza, y donde se le otorga al Estado un papel primordial en el desempeño educativo (Puelles, 2011).

En lo que al apartado legislativo se refiere, destacamos por encima del resto tres leyes que han tenido un mayor impacto sobre el sistema educativo francés a lo largo de su historia. En primer lugar, la ley Guizot ${ }^{4}$ (1833) que, a la postre, ejercería una gran influencia sobre diferentes sistemas educativos del contexto internacional, entre los que se encontraría el español; y es que esta ley fue la antesala de uno de los textos legislativos más importantes en la historia de la educación española, como es la ley Moyano (1857). A través de ella, se impulsaría una serie de mejoras sobre la instrucción primaria francesa que, hasta ese momento, se encontraba en una situación de precariedad absoluta (Weill, 2006). Y, en segundo lugar, ya a finales del s. XIX,

${ }^{4}$ Loi dite Guizot sur l'instruction primaire. (1833). Loi du 28 juin 1833, dite Guizot sur l'instruction primaire (Publiée dans le Journal Officiel de la République Française du 8 juin 1833). 
las leyes Ferry ${ }^{5}$ (1881 y 1882), que tendrán un gran impacto sobre el sistema educativo francés, ya que, gracias a ellas, se instaurará una educación obligatoria, gratuita y laica.

En lo que respecta al plano organizativo, Francia presenta un sistema centralizado que, en muchas ocasiones, dificulta la puesta en marcha de diferentes reformas (Gauthier, 1999). Lógicamente, esta centralización se ve plasmada en el apartado educativo, donde las Académies ejecutan las políticas educativas por delegación del gobierno central, expresando la desconcentración como forma de descentralización. Si bien, resulta, cuanto menos paradójico, que, pese a que el sistema educativo francés se fundamenta en la autonomía otorgada, la capacidad institucional de sus centros educativos es mucho mayor que la de otros contextos.

Respecto a la eficacia del sistema educativo francés, podríamos afirmar que el rendimiento obtenido por sus alumnos se encuentra en torno a la media internacional, siendo ligeramente superior al rendimiento medio de los participantes en esta prueba. Si bien debemos destacar que la situación no es nada halagüeña en el país galo ya que, después de obtener unas buenas puntuaciones durante las primeras ediciones de la prueba, el rendimiento de los estudiantes franceses ha descendido considerablemente, lo que pone en entredicho la eficacia de su sistema educativo. Además, debemos destacar que pese al escepticismo que la sociedad francesa muestra frente a estas pruebas, lo cierto es que, con el paso del tiempo, estas evaluaciones han

\footnotetext{
${ }^{5}$ Loi qui établit la gratuité absolue de l'enseignement primaire dans les écoles publiques. (1881). Loi du 16 juin 1881, qui établit la gratuité absolue de l'enseignement primaire dans les écoles publiques. (Publiée dans le Journal Officiel de la République Française du 17 juin 1881).

Loi qui rend l'Enseignement primaire obligatoire. (1882). Loi $\mathrm{n}^{\circ} 11696$ du 28 mars 1882, qui rend l'Enseignement primaire obligatoire. (Publiée dans le Journal Officiel de la République Française du 29 mars 1882).
} 
comenzado a adquirir un mayor protagonismo en el país galo, sirviendo como justificación frente a alguna de las últimas reformas educativas puestas en marcha.

\subsection{3) Sistema educativo finlandés}

Por último, analizaremos el sistema educativo finlandés, donde pondremos de manifiesto algunas de las variables que nos han llevado a elegir el país nórdico para el desarrollo de nuestra investigación. Históricamente, Finlandia ha recibido una fuerte influencia desde dos sectores: por un lado, desde Suecia y, por otro, desde el Imperio soviético. Y es que, geográficamente, Finlandia es un país un tanto peculiar, ya que se encuentra ubicada en el extremo más septentrional de Europa y, además, marca la frontera entre el ámbito oriental y occidental. Y es que no debemos olvidar que el estado finlandés fue constituido a comienzos del. XIX, bajo los auspicios del Imperio Ruso (García Ruíz, 2010), lo que ha generado que existan una gran cantidad de elementos orientales en la sociedad finlandesa, que van desde las diferentes tradiciones administrativas, hasta la propia herencia genética (Simola, 2005). Este fuerte influjo ha determinado que la sociedad finlandesa adquiera unos rasgos orientales, que se manifiestan en su cultura escolar y que, con casi total seguridad, es uno de los grandes detonantes del éxito educativo finlandés. El ambiente gélido y adverso, predominante en Finlandia, ha forzado la realización de grandes esfuerzos en la sociedad finlandesa, esfuerzos que también son plasmados en la cultura escolar. Además, como ya hemos comentado, existe un fuerte influjo sueco en Finlandia, siendo Suecia un país muy significativo y modélico en el acuñamiento de la política educativa finlandesa, así como en sus reformas.

En lo que respecta al modelo de regulación, podemos percibir como el sistema educativo finlandés se rige por un modelo de descentralización local; si bien es cierto, que algunos autores (véase García Perales y Martín Sánchez, 2012) lo definen como un modelo mixto, ya que defienden que por un lado existe financiación, dirección y 
control estatal, pero, además, las autoridades o entes locales tienen un gran peso en todo lo que concierne a la organización del sistema educativo. Esta parte descentralizada se organiza a partir de la Finnish National Agency for Education (FNAE), creado en el año 1991 bajo la denominación de Finnish National Board of Education (FNBE).

Por último, si hablamos de rendimiento académico, sin duda alguna, el sistema educativo finés es el más eficaz de todos los analizados en este trabajo. Pero es que, además, Finlandia viene siendo considerado desde hace varios años como uno de los grandes referentes educativos, no solo del contexto europeo, sino también internacional, donde, junto a varias economías asiáticas, es uno de los grandes líderes de las pruebas PISA. Cierto es que, en las últimas ediciones, los estudiantes finlandeses han bajado su rendimiento académico, si bien, eso no quita mérito alguno a las excelentes puntuaciones obtenidas, que hacen del sistema finlandés uno de los más atractivos para los investigadores educativos en los últimos años (DarlingHammond, 2017; Gripenberg y Lizarte, 2012; Lie, Linnakylä y Roe, 2003; Linnakylä y Välijärvi, 2006; Simola, 2005, 2013; Simola y Rinne, 2013; Vega, 2005).

Por tanto, como ya anticipamos, los tres países analizados presentan grandes diferencias tanto en la construcción histórica del sistema educativo, como en la eficacia del mismo, donde el rendimiento competencial de los tres países es muy dispar. Además, también existen grandes diferencias en cuanto a los modelos de regulación que rigen estos tres países. Francia es un país fuertemente centralizado, mientras que España y Finlandia son administrados a partir de un modelo descentralizado, de carácter autonómico en el caso español y local en el país nórdico. Por tanto, no solamente estamos frente a países que puedan tener grandes diferencias en lo que respecta al plano geográfico, académico o político, sino también si atendemos a aspectos históricos, sociales y culturales. De este modo, seria inimaginable un análisis comparativo en el que no se plasmara la realidad 
sociocultural en la que se pretende llevar a cabo el análisis comparativo (Raventós, 1990).

\section{2) Metodología}

\subsection{1) Antecedentes y construcción histórica de la educación comparada como disciplina científica}

La educación comparada tiene sus orígenes a finales del s. XVIII y comienzos del s. XIX, gracias a la aparición de los primeros textos científicos y la progresiva emersión de distintas disciplinas del ámbito comparado: anatomía, literatura, antropología, etc. (Vega, 2011b). Si nos centramos estrictamente en la comparación educativa, son varias las etapas que han ayudado a conformar esta disciplina a lo largo de su historia (Vexliard, 1970). En primer lugar, debemos destacar la fase estructural, que se desarrollaría de la mano de Jullien de Paris, gracias a su obra Esquisse d'un ouvrage sur l'education comparée (1817) y que, sin duda alguna, marcará un antes y un después en la evolución de esta disciplina científica. Posteriormente, debemos hacer alusión a la etapa de los «encuestadores» (1830-1914), dominada por aquellos viajeros que se encargaban de elaborar informes que, a la postre, permitirían a los Estados proyectar reformas educativas. Por otro lado, un periodo de gran significación es el que abarca entre la última década del s. XIX y las primeras del s. XX, por cuanto es la etapa de construcción disciplinar de distintas ciencias sociales, como la pedagogía, la psicología y la sociología, que tendrán una gran incidencia sobre los estudios comparados. Más tarde, se desarrollará un periodo de sistematización teórica (19201940), de la mano de autores de gran relevancia, como son Hessen, Kandel, Schneider y Hans. Otra de las etapas a destacar, es la prospectiva, que se llevará a cabo entre los años 50 y 60 del s. XX, y que tendrá una gran relevancia en la conformación de la educación comparada, donde la aparición de diferentes organismos internacionales (UNESCO, OCDE, Consejo de Europa), junto a la proliferación de distintas 
publicaciones del ámbito comparado ${ }^{6}$, proporcionarán un gran empuje a esta disciplina. Finalmente, tendríamos que añadir dos etapas más, en las que, sin duda, se ha producido la mayor progresión de la educación comparada como disciplina científica, al menos en lo que a investigación y desarrollo disciplinar se refiere. Por una parte, la circunscrita a los años 70 y 80 del pasado siglo, que ha sido denominada como positivismo comparado, por ser una etapa de funcionalismo estructural y lógica científica. Y, finalmente, una última etapa que abarca las últimas décadas del s. XX y que vendría definida por el debate entre modernidad tardía y globalización. La nómina de autores, desarrollos institucionales y proyectos curriculares que se han llevado a cabo en estos años, muestran el gran crecimiento que ha experimentado esta disciplina (Vega, 2011b).

\subsubsection{1) Comparación y Comparabilidad}

Nosotros, en nuestro trabajo, vamos a tomar como punto de partida la idea de que la comparación es un fenómeno inevitable. Es más, no sólo no podemos «no comparar», sino que, además, existen pocos factores que nos inviten a alejarnos de la comparación (Sobe, 2018).

A continuación, y dada la idiosincrasia de este trabajo, queremos hacer una pequeña alusión a algunos términos que, creemos es importante conocer. A lo largo de su historia, la educación comparada ha tenido que hacer frente a distintos problemas semánticos que giran en torno a la palabra «comparación». En este sentido, uno de los grandes errores que se cometen, es el de equiparar comparabilidad y semejanza. Bajo esta premisa, solamente sería comparable aquello que guarda similitud, cuando, en realidad, aquello que es diferente también es susceptible de ser

\footnotetext{
${ }^{6}$ Es importante reseñar que, durante esta época (1957), nace la Comparative Education Review, una de las herramientas de divulgación científica más importantes en el ámbito de la educación comparada.
} 
comparado, ya que, en muchas ocasiones, la riqueza de la comparación se encuentra en la diversidad (Farrel, 1990; Vega, 2011b).

Del mismo modo, también debemos entender que los términos comparación y comparabilidad, tienen connotaciones distintas, aunque, a menudo, se usen indistintamente. En este sentido, debemos distinguir la comparación simple, que se centra en los hechos observables, de la comparación compleja, como método científico (Vega, 2011b). Y es que la comparación, no debe de ser entendida como un fin en sí mismo, sino como un método, como una herramienta, que se encuentra al servicio del investigador para hacer frente a sus problemas (Raivola, 1990).

\subsection{2) Método clásico de comparación}

El objetivo que perseguimos a lo largo de nuestro trabajo, no es el de describir de una forma simplista algunas de las variables que concurren en el acceso/admisión hacia los estudios de educación superior, sino que lo que pretendemos, es hacerlo en perspectiva comparada, llevando a cabo un estudio exhaustivo, mediante el método clásico de comparación, con el único fin de esclarecer cuales son las principales semejanzas y diferencias que existen en este proceso de transición en España, Francia y Finlandia; además, trataremos de explicarlas, de una forma coherente y racional.

Para ello, seguiremos las líneas de trabajo marcadas, casi de manera contemporánea, por Hilker $(1964)^{7}$ y Bereday $(1968)^{8}$, a través de sus obras. Si bien hemos de reconocer que, tras ellos, han sido muchos los autores de reconocido prestigio los que han trabajado, e incluso, ampliado, este método comparado de educación y que nos han servido como referentes a la hora de estructurar nuestro trabajo: Altbach y Kelly (1990), García Garrido (1986), Farrel (1990), Ferrer (1990,

\footnotetext{
${ }^{7}$ HILKER, F. (1964). La Pédagogie Comparée. Paris: Institut Pédagogique National.

${ }^{8}$ BEREDAY, G. Z. F. (1968). El método comparativo en pedagogía. Barcelona: Editorial Herder 
2002), Novoa y Yariv-Mashal (2003), Raventós (1990), Steiner (2010), Vega (2011b), etc.

Desde el punto de vista histórico, podemos afirmar que el método clásico de comparación tiene sus raíces en los años 60 del siglo pasado, momento en el que, tal y como ya hemos señalado, se produjo una gran eclosión de los estudios comparados en el ámbito educativo. En sus orígenes, este método centraba su atención en las semejanzas y diferencias existentes entre los diferentes sistemas educativos, si bien, y como veremos a continuación, en los últimos años ha experimentado una gran evolución. Esta disciplina aporta al área de la Pedagogía y de las Ciencias Sociales importantes servicios ya que, conocer el funcionamiento de otros sistemas educativos, favorecerá un mayor y mejor conocimiento sobre el nuestro propio (Bereday, 1968).

Siguiendo las directrices marcadas por estos autores, nosotros, en nuestro trabajo, asentaremos la investigación sobre cuatro fases, claramente definidas: descripción, interpretación, yuxtaposición y comparación. No obstante, debemos señalar que existe una serie de autores (véase Ferrer, 1990) que, a las fases ya señaladas, añaden otras dos que amplían este método clásico de comparación: una al comienzo de la investigación, denominada fase Pre-descriptiva, y otra al final del mismo, denominada fase Prospectiva. La fase Pre-descriptiva se centra en aspectos básicos que han de ser tratados antes de comenzar la investigación propiamente dicha: selección, identificación y justificación del problema, planeamiento de hipótesis, delimitación de la investigación, etc. Mientras que la fase Prospectiva, tiene como misión extraer conclusiones que nos permitan realizar previsiones sobre las tendencias dilucidadas en el estudio, y en consecuencia ofrecer propuestas de mejora, líneas de acción y reformas en todo aquello que consideremos necesario (Caballero, Manso, Matarranz y Valle, 2016). 
El objetivo principal de la primera fase del método comparado, la fase descriptiva, es el análisis y explicación de los ejes vertebradores de la investigación, o lo que es lo mismo, las categorías analíticas con las que nos disponemos a trabajar. Debemos comenzar esta etapa realizando una lectura extensa, donde tendremos que familiarizarnos con los diferentes conceptos que aborden la temática que hemos elegido como objeto de estudio. De este modo, tendremos que recurrir a varias fuentes de información que, al igual que en otras disciplinas, se dividen en: fuentes primarias, fuentes secundarias y fuentes terciarias (Bereday, 1968). Por tanto, el objetivo fundamental de esta primera etapa es el de establecer un marco teórico a partir del cual desarrollaremos nuestra investigación. Es fundamental que la información se presente de manera clara y concisa (Bereday, 1968), para así favorecer el correcto desarrollo de nuestro trabajo.

En la segunda fase, la interpretativa, se pretende «someter» los datos que han sido obtenidos durante la etapa descriptiva. $\mathrm{Y}$ es que, entendemos que existen numerosas interrelaciones entre el sistema educativo y la sociedad en la que este se enmarca. Para su apreciación, es fundamental que los comparatistas educativos usen una terminología común; por ello, todo comparatista debe poseer conocimientos suficientes para trabajar en otras disciplinas afines, de modo que pueda aplicar estos fenómenos educativos, desde el punto de vista sociológico, histórico, económico, etc. (Bereday, 1968). Son muchos los autores (véase Novoa y Yariv-Mashal, 2003) que abogan por la apertura de la educación comparada hacia nuevas áreas, entendiendo este, como uno de los grandes objetivos de la investigación comparativa en el s. XXI. Por tanto, es en esta fase donde los datos recabados anteriormente, serán interpretados atendiendo a las diferentes variables contextuales que puedan inferir en este proceso. Uno de los hándicaps que podemos encontrar en esta fase, y que no debemos obviar es que, en ella, puede ponerse de manifiesto la ideología y subjetividad del autor (Ferrer, 2002). Por todo ello, esta fase también puede ser definida como fase 
«contextual», ya que los diferentes elementos o procesos pedagógicos objeto de análisis, serán vinculados con los contextos sociohistóricos, políticos o culturales en los que se enmarque el sistema educativo.

Durante la tercera fase, la de yuxtaposición, lo que haremos será confrontar los datos que se han obtenido durante la primera etapa y que han sido interpretados posteriormente (Ferrer, 1990). Las variables estudiadas serán cotejadas con el único fin de encontrar semejanzas y diferencias entre los distintos sistemas objeto de análisis. Se trata por tanto de una fase de contrastación y diagnóstico. De este modo, podemos explicarla a través de tres componentes: explicación del contenido de las variables o categorías analíticas, contrastación o cotejo de las variables seleccionadas y presentación de semejanzas y diferencias.

Por último, la cuarta fase que vamos a desarrollar es la comparativa. En ella daremos una explicación razonada de las semejanzas y diferencias encontradas durante la etapa anterior, la de yuxtaposición. El fin último que persigue esta fase es el de servir como instrumento para poder abordar la confirmación o rechazo de las hipótesis planteadas al comienzo de nuestro trabajo (Ferrer, 1990). Además, durante esta última etapa también puede realizarse un plan de mejora de carácter prospectivo, donde se establecerán las tendencias educativas que, posiblemente, seguirán los países analizados, en un futuro a corto o medio plazo.

1.2.2.1) Cambio de paradigma en la Educación Comparada. Nuevas conceptualizaciones

Como ya hemos indicado, históricamente, el método comparado de educación centraba su atención en el estudio y análisis de las semejanzas y diferencias existentes entre sistemas educativos. De este modo, el foco de atención de estos estudios recaía sobre determinados países o áreas geográficas (Halls, 1990; Little, 2000; Manzon, 2011; Rust, Soumare, Pescador y Shibuya, 1999; Wolhuter, 2008). De este modo, a 
lo largo de los últimos años, e incluso décadas, el eje sobre que giraban todos estos estudios era el Estado-Nación, considerado por muchos como la unidad comparativa por excelencia. Sin embargo, con el paso de los años y la irrupción de distintos fenómenos como la globalización y la aparición de las nuevas tecnologías de la información y de la comunicación, se ha producido un cambio de paradigma en torno a esta disciplina, que supone, no solo una revisión, sino también una ampliación de las unidades de comparación. Y es que, la revalorización de la educación comparada pasa, necesariamente, por una puesta en cuestión del Estado-Nación como unidad exclusiva de comparación (Altbach y Kelly, 1990). En los últimos tiempos, han surgido nuevas unidades de análisis en términos de espacios (contextos), que están demandado, cada vez más, una reconceptualización de esta disciplina (Crossley, 2002). En este sentido, uno de los enfoques que está ganando un mayor protagonismo, es la comparación de contextos - contextual comparison-, donde el método comparado servirá de herramienta para conocer todas aquellas circunstancias que rodean una determinada acción pedagógica (Steiner, 2010).

En la actualidad, una nueva corriente de investigadores comparatistas (Kelly y Altbach, 1986; Crossley, 2002; Manzon, 2011; Novoa y Yariv-Mashal, 2003; Clayton, 2004; Steiner, 2010), defienden que la comparación entre países está llegando a su fin, y lo que es más importante, ya no es la única forma legítima de comparar. De este modo, los diferentes fenómenos educativos que se vienen produciendo a lo largo de las últimas décadas, no pueden ser atribuidos a un territorio concreto, y por lo tanto, tampoco a un sistema educativo en particular (Steiner, 2010). Son muchos los autores que, a lo largo de los últimos años, han estudiado la influencia que la globalización está ejerciendo sobre nuestra sociedad y, de una forma más concreta, sobre la educación, intuyendo la presencia de grandes cambios en las unidades de comparación (Carney, 2009; Carnoy, 1999; Pedró y Rolo, 1998; Rust, 1991). Para analizar de una forma más conveniente las implicaciones epistemológicas (Kauko y Wermke, 2018) y metodológicas de la globalización sobre los estudios 
comparativos de educación, es necesario comprender todos aquellos cambios que ha generado la economía global, modificando las relaciones entre los Estados-Nación, lo que ha provocado que las relaciones entre países (y sus instituciones) hayan cambiado (Dale, 2007). Por tanto, debemos liberar la investigación comparativa de las nociones clásicas espacio/lugar, de tal manera que las unidades básicas de comparaciones dejen de ser geografías nacionales (Novoa y Yariv-Mashal, 2003).

\subsection{3) Aplicación y desarrollo del método comparado en nuestro estudio. Estructura del trabajo de investigación}

Tras analizar el método comparado desde el punto de vista histórico, y de una forma un tanto analítica, nos gustaría exponer, de una forma más específica, cómo desarrollaremos esta metodología a lo largo de nuestro trabajo. Para comenzar, debemos tener en cuenta que, en nuestro caso, hemos desestimado incorporar las fases Pre-descriptiva y Prospectiva que algunos autores incorporan, ya que la primera de ellas la hemos llevado a cabo antes de dar comienzo a nuestro trabajo, mientras que la segunda hemos optado por incorporarla en la última fase de nuestra investigación, la comparativa, dado que es la tendencia más normalizada en este tipo de estudios y la que, a nuestro parecer, más se ajusta a nuestro trabajo. Por tanto, limitaremos nuestro estudio a las cuatro fases anteriormente mencionadas: descripción, interpretación, yuxtaposición y comparación. En este sentido, y con el fin de ser lo más pragmáticos posible, hemos optado por dedicar un capítulo a cada una de estas fases. De este modo, entendemos que la estructura del trabajo será más nítida y favorecerá una mayor y mejor comprensión por parte del lector.

En el primero de los capítulos (tras este apartado introductorio), que hace referencia a la parte descriptiva de nuestro trabajo, centraremos nuestra atención en la descripción y fundamentación de diferentes variables o categorías analíticas que puedan tener una cierta relevancia en el acceso/admisión a la educación superior. Para 
fijar estas variables, de una forma previa, hemos seleccionado los principales agentes y actores educativos que participan en este proceso de transición, habiendo escogido los cinco que, a nuestro parecer, tienen una mayor trascendencia en este proceso educativo. El primer actor educativo que hemos seleccionado es «el alumno» que, sin duda alguna, es el principal protagonista en este proceso de transición. En segundo lugar, nos centraremos en el análisis de «los procesos de organización y gestión». Posteriormente, haremos alusión a la «regulación», donde centraremos nuestro análisis en la descripción e interpretación acerca de los diferentes modelos de acceso/admisión hacia la educación superior; los procesos y la administración en el marco institucional. El cuarto agente seleccionado, es la «sociedad» en la que se enmarcan estos sistemas educativos que, en buena lógica, ejercen una fuerte influencia sobre los fenómenos educativos. Por último, analizaremos el «sistema escolar», donde prestaremos una especial atención al asesoramiento pedagógico que recibe el alumno durante la educación secundaria, entendiendo esta, como una etapa transcendental, donde la orientación académica y/o profesional será fundamental.

En lo referente a la segunda fase, se pretende interpretar los datos recogidos en la etapa descriptiva en términos sociohistóricos, políticos y culturales. Esta interpretación se abordará siguiendo algunos de los aspectos contextuales más relevantes en torno a los que giran los procesos de transición, como son la cultura histórica y escolar del sistema educativo, el modelo de regulación vigente, la organización y funcionamiento del sistema educativo y, finalmente, la eficacia del mismo, que será analizada a partir de los datos publicados por las pruebas internacionales de PISA que, sin duda alguna, han adquirido una gran trascendencia a lo largo de las últimas dos décadas. Estamos ante una etapa fundamental en el desarrollo metodológico de nuestro trabajo, ya que nos servirá de apoyo para el análisis comparado, y a la postre, nos ayudará a explicar de una forma racional las semejanzas y diferencias encontradas en nuestra investigación. 
La tercera fase de nuestro trabajo será la de yuxtaposición. En ella, se expondrán, de manera individual, las semejanzas y diferencias encontradas en el acceso/admisión hacia la educación superior de los tres sistemas educativos analizados. Estamos, por tanto, ante una fase analítica, puramente descriptiva, donde, por el momento, no entraremos en valoraciones acerca del porqué de estas convergencias y divergencias.

Por último, entramos en la fase comparativa. Será aquí, donde pasaremos del diagnóstico y el cotejo de las variables, a un análisis mucho más profundo, en donde estas semejanzas y diferencias que hemos encontrado en la fase previa serán explicadas de una forma coherente y racional. Esta cuarta fase del método clásico de comparación nos permitirá aceptar o refutar las hipótesis fijadas al comienzo de nuestro estudio. Además, tal y como ya hemos explicado, en ella incorporaremos un pequeño análisis prospectivo, donde mostraremos las tendencias futuras que los países analizados podrían desarrollar en materia de acceso.

\section{Gráfico 1. Transición desde la educación secundaria superior hacia la educación superior en España, Francia y Finlandia.}

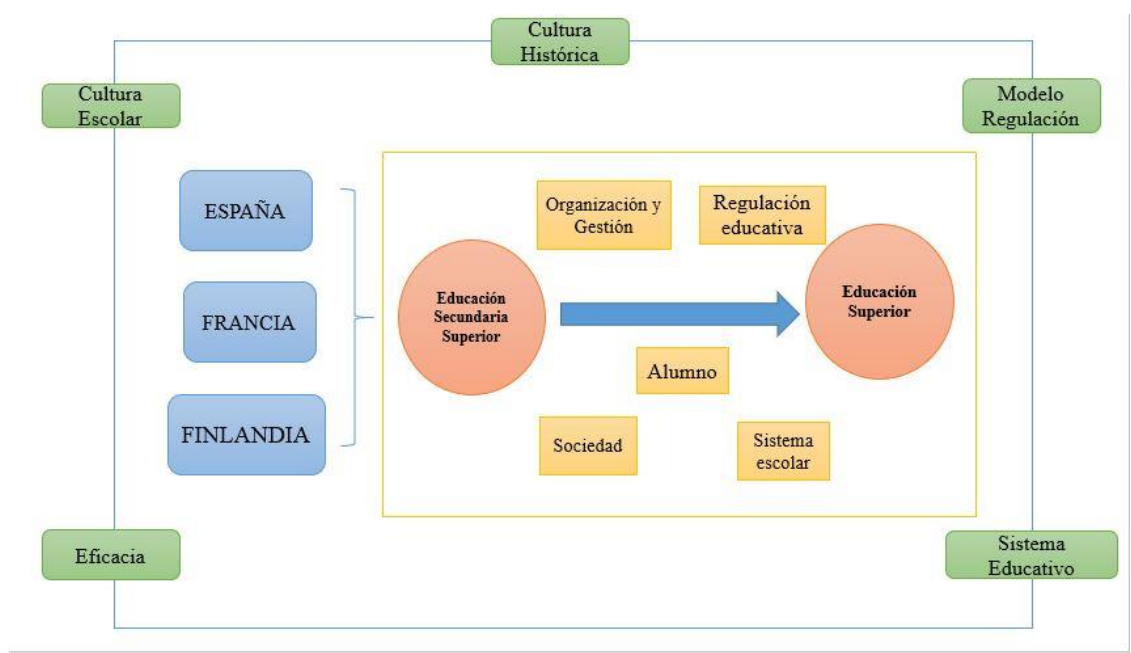

Fuente: Elaboración propia 
Una vez finalizado el análisis comparativo, pondremos sobre la mesa aquellas conclusiones que hemos alcanzado durante el desarrollo de nuestro trabajo. En este sentido, debemos reconocer que estas conclusiones tienen un doble objetivo: por un lado, atender a las aserciones más relevantes de nuestra investigación y, por otro lado, aceptar o refutar las hipótesis de nuestro trabajo, y que vamos a presentar a continuación.

\section{3) Hipótesis de la investigación}

Para el desarrollo de nuestra investigación, partimos de dos hipótesis iniciales, que son las que enumeramos a continuación:

Hipótesis 1. Los itinerarios de acceso/admisión hacia la educación superior en los tres sistemas educativos analizados muestran diferencias desde el punto de vista político, administrativo y pedagógico.

Entendemos que el acceso/admisión hacia los estudios de educación superior en España, Francia y Finlandia presenta grandes diferencias entre sí, debido, fundamentalmente, a las divergencias políticas, administrativas y pedagógicas que presentan los países en los que estos sistemas se enmarcan. Reconocemos, por tanto, la fuerte influencia que ejerce el contexto sobre los sistemas educativos, en general, y sobre los procesos de transición educativa, en particular.

> Hipótesis 2. Las exigencias y requisitos de acceso/admisión a la educación superior dependen de la estructura y organización de los sistemas educativos, de la cultura social y de la tradición escolar, más que de las necesidades y exigencias del sistema productivo.

Los procesos de transición desde la educación secundaria hacia la educación superior no toman en consideración las necesidades y exigencias del sistema 
productivo. Así, el acceso/admisión estaría condicionado a la estructura y organización del sistema educativo, a su cultura social y, sobre todo, a la tradición escolar. De este modo, no existe una interrelación entre el acceso hacia las instituciones de educación superior y su posterior traslado al mercado laboral, un hecho que puede terminar generando una serie de déficits sobre el sistema económicoproductivo.

\section{4) Objetivos que persigue la investigación}

Las metas que nos hemos planteado para el desarrollo de nuestro estudio se enmarcan dentro de un objetivo general:

Objetivo general. Conocer y comprender, desde el punto de vista sociohistórico, político, cultural y pedagógico, los procesos de transición hacia los estudios de educación superior en España, Francia y Finlandia.

Para alcanzar este objetivo general, hemos establecido una serie de objetivos específicos, que guardan una estrecha relación con el desarrollo metodológico de nuestra investigación:

$>$ Objetivo específico 1. Describir y analizar, de una forma clara y nítida, las principales variables o categorías analíticas de nuestra investigación para que, de este modo, podamos dibujar el perfil temático objeto de estudio.

> Objetivo específico 2. Abordar el estudio pragmático del contexto interno en el que operan y se implementan los distintos modelos de acceso/admisión hacia la educación superior en los sistemas analizados.

Objetivo específico 3. Diagnosticar y presentar las semejanzas y diferencias encontradas en el acceso/admisión hacia los estudios de educación superior de 
los sistemas educativos objeto de estudio, atendiendo a sus planteamientos institucionales, curriculares y sociales.

Objetivo específico 4. Explicar, de una forma fundamentada, las semejanzas y diferencias encontradas en la investigación, atendiendo a las variables sociohistóricas, políticas y culturales de cada uno de los sistemas educativos.

Objetivo específico 5. Verificar o refutar las hipótesis planteadas al comienzo del estudio.

\section{5) Recogida de la información}

Todo este entramado metodológico será desarrollado a través de una extensa revisión bibliográfica, tanto de fuentes primarias como secundarias y terciarias. Hemos de reconocer que, a lo largo de nuestro trabajo, nos hemos encontrado con situaciones en donde la información era insuficiente o, incluso, inexistente. En otras ocasiones, la información era excesiva, y en otras muchas, inapropiada e incluso un tanto subjetiva. Por todo ello, creemos que es fundamental recurrir a aquellas fuentes que más se adecúen a nuestros intereses, siempre que mantengan unos estándares de fiabilidad y objetividad apropiados.

Por tanto, podemos afirmar que el objetivo que perseguimos en nuestro trabajo no es otro que la indagación acerca del acceso/admisión hacia las instituciones de educación superior en los países ya señalados, a través de fuentes documentales ya existentes (Llorent, 2006). 
1) INTR ODVCCIÓN Y JVSTIFICACI@́N DEL

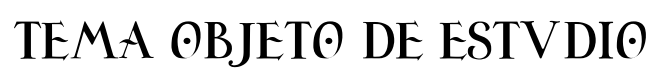

\section{2) CATEG@RÍAS $\odot$ VARIABLES DE ANÁLISIS DEL ACCES๑/ADMISIÓN A LA EDVCACIÓN SVPERIOR}

3) EL ACCESC/ADMISI@́N A LA EDVCACI@́N SVPERIOR EN ESPAÑA, FRANCIA Y

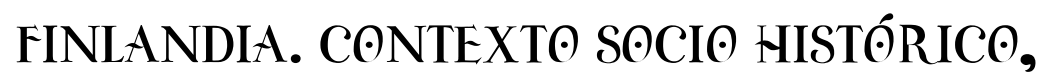
POLÍTICO Y CVLTVRAL

4) ¿CÓMค ACTV́AN LOS MODELOS DE ACCESৎ/ADMISIÓN HACIA LA EDVCACIÓN SVPERIOR?

5) LA COMPARACI@́N CONTEXTVAL DEL ACCESO/ADMISIÓN A LA EDVCACIÓN SVPERIOR. EL CARÁCTER FVNCIONAL DE LAS TRANSICIONES

6)CONCLVSI@NES 



\section{2) CATEGORIAS @ VARIABLES DE ANÁLISIS QVE CONCVRREN EN

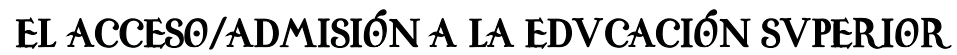

El objetivo que se persigue a lo largo de este capítulo es el de presentar una serie de variables o categorías analíticas que tengan especial relevancia y, a su vez, puedan interferir en el proceso de transición hacia la educación superior en los sistemas educativos objeto de estudio. Las variables que analizaremos a continuación hacen referencia a aspectos, no solo de carácter académico, como es lógico, sino también de carácter político, social, cultural y administrativo. Y es que son muchos los aspectos ajenos al ámbito pedagógico, los que inciden en este proceso de transición. Estamos, por tanto, ante los ejes vertebradores sobre los que se sustenta nuestro trabajo.

Para analizar estas variables, vamos a partir de los que, a nuestro parecer, son los actores y agentes educativos que gozan de un mayor protagonismo en este complejo proceso de transición educativa. El término «actor educativo» está adquiriendo una gran relevancia a lo largo de los últimos años. Se trata de un concepto muy amplio, que defiende que el principio de educatividad no reside solamente en las personas, sino que también lo hace en el entorno, en los objetos y en los recursos. 
Históricamente, se ha hecho alusión a dos grandes actores educativos, como son la familia y la escuela. Sin embargo, con el paso del tiempo, se están incorporando otros nuevos, que están adquiriendo un papel de gran relevancia, como son: los medios de comunicación, las nuevas tecnologías de la información y la comunicación, las ciudades, etc. (García Ruíz y García, 2011).

Nosotros, en nuestro estudio, trabajaremos con cinco actores educativos, habiendo seleccionado aquellos que, a nuestro juicio, tienen una mayor trascendencia en este proceso de transición. No cabe duda de que podríamos haber seleccionado alguno más, pero creemos que es más oportuno poner nuestro foco de atención sobre los más relevantes, a fin de ser lo más exhaustivo posibles en aquellas variables que, a nuestro parecer, son más determinantes. El primer actor que hemos seleccionado es el alumno, y de él analizaremos sus características académicas, el rendimiento competencial en las pruebas de acceso y su origen social. En segundo lugar, nos centraremos en los procesos de organización y gestión, donde prestaremos atención a las competencias organizativas del acceso, al papel desempeñado por los centros de educación secundaria y, finalmente, los requisitos de acceso/admisión. Posteriormente, haremos alusión a la regulación educativa, donde analizaremos los diferentes modelos de acceso/admisión que están vigentes en los sistemas educativos analizados y que, sin duda alguna, guardan una gran trascendencia para nuestra investigación. El cuarto agente educativo es la sociedad, del que destacaremos algunos indicadores sociales y culturales que puedan facilitarnos una mayor y mejor comprensión de este proceso de transición. Por último, analizaremos el sistema escolar, donde incidiremos sobre dos variables que están estrechamente relacionadas con el asesoramiento pedagógico, como son el papel desempeñado por los sistemas de orientación en los centros de educación secundaria y la acción tutorial ejercida por sus docentes. 
Por tanto, estamos ante un capítulo con una gran relevancia en el devenir de nuestra investigación, ya que vamos a tratar de definir, de una forma clara y concisa, aquellas variables sobre las que se cimentará nuestro trabajo, algo que se presenta como fundamental para poder analizarlas posteriormente de una manera individual, en cada uno de los sistemas educativos con los que estamos trabajando.

\section{1) El alumno}

No cabe duda de que el alumno es el principal actor educativo en el tema que a nosotros nos concierne analizar en este trabajo, el acceso hacia los estudios de educación superior. Lógicamente, existen otros muchos factores, ajenos al estudiante, que pueden incidir sobre este fenómeno educativo, pero es él, sin duda alguna, nuestro principal protagonista, sobre el que tendremos que depositar una mayor atención. En este sentido, podríamos hacer alusión a una gran cantidad de variables que pudieran tener una cierta incidencia respecto al estudiante y su transición hacia el contexto universitario, si bien, nosotros vamos a centraremos en tres de ellas. Por un lado, las características académicas de los alumnos que están en disposición de acceder a la universidad; fundamentalmente, nos estamos refiriendo a estudiantes de educación secundaria superior (tanto de la vertiente académica como profesional), si bien, como podremos apreciar más adelante, existen algunas excepciones. Por otro lado, analizaremos el rendimiento competencial del alumno en las diferentes pruebas de acceso. Ya anticipamos que estas pruebas serán diferentes según el sistema educativo en el que se enmarquen, pudiendo existir pruebas de carácter nacional, que todos los alumnos han de superar, o pruebas específicas (en este caso deberíamos hablar de pruebas de admisión), que son fijadas de forma autónoma por las propias instituciones de educación superior. Por último, también analizaremos el origen social del alumno que, como podremos apreciar, es una de las variables que más puede llegar a condicionar el acceso universitario, tanto en el propio proceso de transición, como de forma previa, durante su desarrollo en la educación secundaria. 


\subsection{1) Características académicas del alumno}

No cabe duda de que esta, es una de las variables con mayor influencia en el desarrollo de nuestro trabajo. A lo largo de los últimos años, multiplicidad de estudios han mostrado como el rendimiento académico del alumno, que se hace tangible a través de su expediente académico durante la educación secundaria superior, determinan en gran medida el proceso de transición hacia los estudios de educación superior. Latiesa (1989), muestra en su estudio como existen múltiples factores que condicionan la elección de estudios universitarios por parte de los alumnos, entre los que se encuentran sus calificaciones en la educación secundaria superior. En una línea semejante de trabajo, encontramos la investigación llevada a cabo por Martínez et al. (2016), donde los autores ponen de manifiesto la gran influencia que el expediente académico de los alumnos tiene en la elección de estudios universitarios, junto a otras dos variables, como son: el género y la rama de conocimiento por la que el alumno ha optado durante su periplo formativo. Y es que, son muchos los autores que afirman que estas variables estarían interconectadas, ya que el sexo tiene una fuerte incidencia a la hora de elegir la modalidad cursada, lo que, a la postre, será determinante, no solo en la elección, sino también en el acceso universitario de los estudiantes (Santana, Feliciano y Jiménez, 2012). Pero hay autores que van más allá, afirmando que el acceso universitario no solamente se ve influenciado por los años previos al desarrollo de esta transición, sino que será todo el proceso educativo del alumno el que condicione su llegada al contexto universitario (Vincent-Lancrin, 2008).

De este modo, estamos en disposición de afirmar que estamos ante una de las variables con mayor trascendencia en el acceso universitario. A lo largo de los últimos años, numerosos estudios han evidenciado como las características académicas de los alumnos, que se ven reflejadas a través de su expediente académico, son un claro determinante, no solo en el acceso universitario, sino también en la elección previa que los alumnos realizan. 


\subsection{2) Rendimiento competencial en pruebas de acceso}

A lo largo de los últimos años, la Unión Europea (U.E) ha apostado por llevar a cabo una serie de acciones pedagógicas que fomenten la cooperación entre sus estados miembros. Entre sus muchas acciones, destaca el proceso de Bolonia (1999) ${ }^{9}$ que dio lugar al actual Espacio Europeo de Educación Superior (EEES), o el programa de Aprendizaje Permanente (2007-2013). Pero sin duda alguna, una de las actuaciones de mayor relevancia fue la definición de competencias a través de la Estrategia de Educación y Formación, en el año 2010 (Valle y Manso, 2013).

Este nuevo paradigma al que aludimos solo puede ser entendido en un nuevo contexto como es en el que nos encontramos, un contexto de cambio, donde destacan fenómenos como la globalización, el multiculturalismo, las nuevas tecnologías de la información y de la comunicación, etc. (Cheetham y Chivers, 2005; Illeris, 2009). Frente a esta sociedad tan compleja, la educación debe estar capacitada para dar una respuesta. $\mathrm{Y}$ es en este sentido, donde el aprendizaje por competencias ${ }^{10}$ gana enteros, haciendo frente, no solo a las necesidades en el ámbito laboral, sino también en el educativo (Valle y Manso, 2013). A partir de esta propuesta desarrollada por la U. E, se conceptualizaron ocho competencias clave, que serán el elemento central acerca de todo aquello que los educandos deben adquirir en sus procesos de educación y formación: comunicación en lengua materna, comunicación en lengua extranjera, competencia matemática, científica y técnica, competencia digital, aprender a

${ }^{9}$ El Espacio Europeo de Educación Superior. Declaración conjunta de los ministros europeos de educación, reunidos en Bolonia el 19 de junio de 1999.

${ }^{10}$ The Key Competences for Lifelong Learning - A European Framework. Se trata de un anexo de un documento publicado por el Parlamento Europeo en el Consejo de 18 de diciembre de 2006, sobre las competencias clave para el aprendizaje permanente, publicada en el Diario Oficial de la Unión Europea de 30 de diciembre de 2006. 
aprender, competencia cívica y moral, sentido emprendedor e iniciativa y sentido y expresión cultural.

Sin embargo, no es fácil abordar el concepto de competencia, dado que la terminología utilizada es un tanto ambigua, o contiene algunas dificultades semánticas (Freire, Teijeiro y Pais, 2013). Así, son varias las definiciones propuestas. Bunk (1994), las define como el conjunto de conocimientos, destrezas y actitudes necesarias para desempeñar una profesión. En cambio, si ponemos el foco sobre nuestro propio país, Echeverría (2002) las define como aquellas capacidades que permiten poner en práctica aquellos conocimientos, procedimientos, actitudes y capacidades que una determinada persona posee y que, a su vez, necesita para hacer frente de una forma efectiva las funciones y tareas que demanda la profesión.

En este sentido, debemos destacar que valorar estas competencias mediante una serie de pruebas externas, ha sido uno de los grandes requerimientos de las instituciones de educación superior a la hora de regular su acceso. Estas pruebas, que nacieron hace relativamente poco, pretendían eliminar el favoritismo, el clientelismo, el nepotismo o cualquier otra forma de privilegio. Uno de sus grandes objetivos es el de servir como instrumento para garantizar la igualdad de oportunidades en el acceso universitario (Moreno, 1992). Por ello, a lo largo de nuestro trabajo, dedicaremos un pequeño apartado a estas pruebas de acceso que, por lo general, son instauradas desde la administración educativa. $\mathrm{Si}$ bien, también haremos alusión, directa o indirectamente, a las pruebas de admisión que, en este caso, son fijadas desde las propias instituciones de educación superior, y que poseen un carácter más específico. Estas pruebas, no solo complementan el acceso del estudiante, sino que, con el paso del tiempo, están adquiriendo una gran relevancia en los procesos de transición universitaria. 
2.1.2.1) ¿Garantizan estas pruebas la adquisición de una serie de competencias?

Un porcentaje significativo de los países del contexto internacional emplean pruebas de acceso a la universidad que, combinadas junto al expediente académico de los alumnos, sirven como instrumento de acceso hacia la universidad. De este modo, estas pruebas aparecen como un método que permite valorar si el proceso educativo al que se ha enfrentado el alumno ha dado los resultados esperados en términos de aptitudes y competencias (Valle, 2008). Pero, en realidad ¿miden estas pruebas las aptitudes y competencias que el alumno debe poseer para comenzar su periplo universitario? Debemos recordar que el desarrollo de estas pruebas se centra, sobre todo, en la valoración de contenidos. De este modo, el principal problema que nos encontramos es que la adquisición de estos conocimientos, por si mismos, no te garantizan estar en posesión de unas determinadas competencias o aptitudes. Es por ello por lo que algunos autores (véase Vega y Hernández, 2015), catalogan estas pruebas como culturales, donde el fin último no es otro que el de valorar y evaluar una serie de conocimientos que poco o nada tienen que ver con las competencias o aptitudes que el alumno debe poseer para hacer frente a unos determinados estudios universitarios.

Por tanto, estas pruebas no garantizan por sí mismas la adquisición de unas determinadas competencias por parte del alumno, si bien, se trata de un instrumento más al servicio de los sistemas educativos. De hecho, tal y como veremos durante el desarrollo de nuestro trabajo, en algunas ocasiones, estas pruebas son utilizadas por los centros de educación superior como instrumentos de admisión, ya que les permite clasificar y ordenar a los alumnos cuando la demanda de estudiantes supera a la oferta académica. 
2.1.2.2) ¿Qué relación existe entre el rendimiento competencial de los alumnos y su posterior elección universitaria?

Para finalizar, planteamos brevemente una cuestión que, a nuestro parecer, puede ser de gran interés teniendo en cuenta la variable que estamos analizando, y es si condicionan estas pruebas de acceso la posterior elección de los alumnos hacía unos determinados estudios. Son muchas las investigaciones que han sido desarrolladas a lo largo de los últimos años y que se han preocupado por esta cuestión que nosotros planteamos. Nosotros vamos a destacar una por encima del resto, que fue desarrollada por Martínez, Castro, Zurita y Lucena (2015). Estos autores han evidenciado la existencia de una fuerte interrelación entre la elección universitaria de los alumnos y el rendimiento de estos en estas pruebas de acceso. Pero, además, añaden que, a su vez, el rendimiento de los alumnos en estas pruebas está condicionado por la modalidad de estudios cursados previamente.

De este modo, estamos en disposición de afirmar que existe una fuerte correlación entre estas pruebas competenciales que muchos de los países vienen utilizando como instrumento de acceso universitario y el propio acceso de los estudiantes.

\subsection{3) Origen social de los alumnos que acceden a la educación superior}

La procedencia social de los alumnos que están en disposición de acceder a los estudios de educación superior tiene una gran relevancia en nuestro trabajo, ya que puede determinar, no solamente la elección del estudiante, sino también su posterior acceso. Es por ello por lo que, a continuación, analizaremos brevemente la influencia que el origen social puede tener sobre cualquier fenómeno educativo y, de una forma más específica, sobre el acceso hacia los estudios de educación superior, que es el eje principal de nuestro trabajo. 


\subsubsection{1) Origen social y educación}

El informe PISA (2015) ${ }^{11}$, pone su foco de atención sobre las escuelas exitosas, catalogándolas como aquellas que disponen de unas mejores condiciones internas: mejores profesores, mayor autonomía, mayor innovación, etc. Atendiendo a los resultados de este informe, estas escuelas serían las que corresponden, mayoritariamente, con los centros de titularidad pública. Sin embargo, además de estos condicionantes internos, también debemos tener en consideración otros, que podemos catalogar como externos y que gozan de una gran influencia sobre el rendimiento académico del estudiante. De este modo, podemos observar cómo estos factores externos, posibilitan que los alumnos adscritos a centros de titularidad privada obtengan un mayor rendimiento académico que los centros de titularidad pública (OECD, 2016).

Los resultados obtenidos en este último informe muestran cómo los alumnos de 32 sistemas educativos matriculados en centros de titularidad pública obtienen peores puntuaciones que aquellos matriculados en centros de titularidad privada. Sin embargo, si no tuviéramos en consideración la situación socioeconómica -analizada a través del indicador denominado ESCS $^{12}$-, observamos cómo en 22 de los sistemas educativos, los estudiantes matriculados en escuelas públicas obtendrían un mayor rendimiento que aquellos matriculados en centros privados. En la tabla número 1 podemos observar un pequeño análisis acerca de la situación de los tres sistemas educativos analizados en nuestro trabajo, atendiendo al indicador socioeconómico y cultural del estudiante.

${ }^{11}$ OECD (2016), PISA 2015 Results (Volume II): Policies and Practices for Successful Schools, PISA, OECD Publishing, Paris.

${ }^{12}$ ESCS se refiere a un indicador utilizado por PISA para aludir al estatus económico, social y cultural del estudiante. 


\section{Tabla 1. Rendimiento en competencia científica (PISA 2015) de los alumnos adscritos a centros de titularidad pública de los sistemas educativos de España, Francia y Finlandia, según el índice ESCS.}

\begin{tabular}{|c|c|c|}
\hline & ANTES ESCS & DESPUÉS ESCS \\
\hline ESPAÑA & & \\
\hline FRANCIA & & \\
\hline FINLANDIA & & \\
\hline OECD & & \\
\hline
\end{tabular}

Fuente: Elaboración propia a partir de OECD (2016:125)

Asociación Positiva

Asociación Negativa

Sin Asociación Significativa

Como podemos observar, los tres sistemas educativos analizados presentan una asociación negativa en la prueba antes de tomar en consideración el estatus socioeconómico del alumno (ESCS). En cambio, cuando tenemos presente este indicador observamos cómo la tendencia varía sensiblemente. Mientras que Francia mejora sustancialmente sus resultados, España y Finlandia no presentan diferencias especialmente significativas. Estos resultados, son consecuentes con la de los anteriores informes, donde la tendencia era muy similar (OECD, 2010; OECD, 2013). Por tanto, estamos en disposición de afirmar, que los factores externos -entre los que se encuentra el origen social- condicionan el rendimiento académico del alumno, y por tanto, debe ser una variable a tener en cuenta a la hora de analizar los procesos de transición hacia los estudios de educación superior; dado que, en buena medida, el rendimiento educativo y, en el fondo, la clase social, están en la base de la elección de estudios superiores.

Históricamente, este fenómeno ha sido analizado desde distintos sectores, no solo dentro de nuestras fronteras, sino también fuera de ellas. En los años 70, se comenzaron a formular distintas teorías que hacían hincapié en la relación entre estas dos variables, como la teoría de la reproducción (Baudelot y Establet, 1979; Bowles y Gintis, 1976), que ponía de manifiesto el carácter discriminante de la escuela como 
reproductora de desigualdades. En una línea semejante de trabajo, encontramos también el planteamiento neoweberiano de Collins, que examina el papel de la escuela en la desigualdad del estatus (Barañano y Finkel, 2014). La lógica del «credencialismo» de Collins se asienta sobre la creencia en la justicia y eficiencia económica de los resultados académicos, mostrando una clara influencia de las desigualdades sociales sobre las desigualdades educativas (Dubet, Duru-Bellat y Vérétout, 2010).

Íntimamente relacionado con el estrato u origen social de las familias, estarían también los niveles de renta de las mismas. Existen multiplicidad de estudios que analizan la relación entre origen social de una familia y su inversión en educación (Bernardi y Cebolla, 2014; Fernández Enguita, 2008; Lynch y Moran, 2006; Matsuoka, 2018; Rogero-García y Andrés-Candelas, 2014; Smyth, 2009; Villar y Hernández, 2014, 2015). Si analizamos los datos de gasto privado en educación en relación a los diferentes grupos sociales, podemos apreciar como existe un comportamiento desigual, que puede llegar a generar grandes desigualdades educativas (Villar y Hernández, 2015). Esta hipótesis también es defendida por Alexander, Entwisle y Olson (2014), quienes a través de su estudio, pusieron de manifiesto como los estudiantes de familias humildes y los estudiantes de familias más acomodadas mantenían un nivel educativo similar, y que sería fuera del centro escolar, cuando la brecha educativa se iría ensanchando en favor de las familias mejor posicionadas económicamente.

Otro planteamiento ampliamente conocido, y que apoya esta hipótesis, es la teoría del capital humano. Existen autores que defienden que la educación se trata de un bien de inversión (Castro, Fernández y Martín, 2015; Marcenaro y Navarro, 2005). "La definición de capital humano está relacionada con las habilidades, capacidades, actitudes, destrezas y conocimientos que los trabajadores poseen y que afectan directamente a su proceso productivo" (Castro, Fernández y Martín, 2015: 97-98). En 
base a esta definición, se desarrolló la teoría del capital humano, que tiene sus inicios en los trabajos realizados, entre otros, por Becker $(1964,1975)$, Mincer $(1958,1974)$ y Schult $(1960,1963)$. Según esta teoría "las personas llevan a cabo un proceso de inversión en capital humano, lo que se traducirá en un aumento de su capacidad productiva y, a medio o largo plazo, en un incremento de sus rentas de trabajo" (Marcenaro y Navarro, 2005: 69-70).

Pero también, existen otras corrientes, que son totalmente contrarias a lo que venimos relatando. En este sentido, encontramos la teoría de la modernización, que defiende la inexistencia de relación entre origen social de los alumnos y nivel educativo. "Las mismas desigualdades educativas desaparecían paulatinamente gracias a la expansión educativa. La influencia del origen social perdería importancia al diluirse los atributos adscritos a medida que los individuos pasan más años en el sistema educativo" (Marqués y Gil, 2015: 92). La universidad es, por tanto, una herramienta eficaz para la movilidad social de todas aquellas personas que se embarcan en ella, negando así, la posibilidad de que exista cualquier tipo de influencia social en los niveles educativos de los alumnos (Carabaña, 2004).

\subsubsection{2) Origen social y acceso}

Una vez analizadas diferentes teorías y autores que abordan la influencia del origen social en la educación, vamos a ir un paso más allá en lo que al nivel de concreción se refiere, analizando la influencia del origen social en los procesos de transición hacia la educación superior. El extraordinario crecimiento al que estamos asistiendo en los últimos años, en lo que a la matriculación universitaria se refiere, está generando mucho interés, tanto en el ámbito nacional como en el internacional, por la temática que aquí presentamos. Es por ello por lo que son muchos los autores que, a lo largo de la última década, han mostrado interés en el acceso universitarios $\mathrm{y}$, de una forma más concreta, en la influencia que el origen social puede ejercer sobre 
él: Ariño y Llopis (2011); Barañano y Finkel (2014); De Pablos y Gil (2007); Dupriez, Monseur, Van Campenhoudt y Lafontaine (2010); Enciso (2013).

Por último, queremos poner sobre la mesa la gran importancia que ha adquirido la dimensión social en el contexto universitario a lo largo de los últimos años, ya que ha sido un elemento primordial durante el reciente desarrollo en el proceso de Bolonia, en donde se pretende reflejar la diversidad de poblaciones europeas dentro de las instituciones de educación superior, mediante la participación de todos los grupos sociales (Mühleck, 2013).

\section{2) Los procesos de organización y gestión}

En lo que se refiere a los procesos de organización y gestión, creemos que es necesario analizar y comprender este proceso transitivo, atendiendo al papel que desempeñan los centros de educación secundaria ya que, al fin y al cabo, son los encargados de formar a los estudiantes que están en disposición de acceder a los estudios de educación superior. Y, por otro lado, también es fundamental conocer los requisitos establecidos, tanto por la administración educativa (requisitos de acceso) como por las propias universidades (requisitos de admisión), que tal y como veremos, juegan un papel crucial en este proceso educativo.

\subsection{1) Competencias organizativas del acceso, ¿a quién corresponden?}

La transición desde la educación secundaria hasta la universidad se trata de un proceso de gran complejidad en el que intervienen diferentes agentes e instituciones, pero, en realidad ¿a quién corresponde su regulación? Por lo general, son las propias universidades las encargadas de organizar y gestionar este proceso educativo. Sin embargo, el papel que estas desempeñan no es el mismo en todos los sistemas educativos ya que, a día de hoy, no existe un itinerario global y homogéneo de acceso hacia las instituciones de educación superior. 
Por tanto, gran parte del peso organizativo en este proceso de transición recae sobre las instituciones universitarias, si bien no debemos obviar el papel que desempeña la administración educativa, que también se encarga de gestionar este proceso a través de diferentes agencias, departamentos, etc. En el caso de España, es el Ministerio de Educación y Formación Profesional (MEFP) el encargado de regular todo lo que concierne al ámbito educativo. En Finlandia es el Consejo Nacional de Educación (FNAE). Mientras que en Francia la regulación educativa es compartida. Por un lado el Ministère de Éducation Nationale et de la Jeunesse, que se encarga del sistema no universitario, y por otro lado, el Ministère de l'Enseignement Supérieur et de la Recherche (MESR), que se encarga de todo lo que concierne al ámbito de la educación superior.

De este modo podemos apreciar como el peso organizativo de este proceso de transición recae sobre las propias universidades y sobre la administración educativa, pero no de una forma homogénea. Unas y otras desempeñan diferentes funciones, existiendo matices diferenciales en función del sistema educativo que estemos analizando.

\subsection{2) ¿Qué papel desempeñan los centros de secundaria en el proceso de transición?}

Sin duda alguna, los centros de educación secundaria tienen un fuerte impacto en este proceso de transición universitaria. Son muchos los estudios, tanto a nivel nacional como internacional, que así lo evidencian. Por ello, a lo largo de nuestro trabajo, haremos una pequeña reseña al respecto, resaltando la incidencia que estos puedan tener.

A grandes rasgos, podríamos afirmar que los centros de educación secundaria se encargan de la certificación y/o acreditación competencial del alumno. Esta, se llevará a cabo a través de una evaluación que los propios centros educativos realizan 
a sus alumnos, en estrecha colaboración con la administración educativa, que es la encargada de marcar las pautas de este proceso evaluativo a través del curriculum nacional. En este sentido, son muchos los autores que, a lo largo de los últimos años, han indagado sobre la incidencia que los centros de educación secundaria tienen sobre el acceso a los estudios de educación superior (Moreno, Sánchez y Jiménez, 2014; Pavia y Vila, 2010; Sirin, 2005), poniendo en entredicho que este proceso se dé en unas condiciones de igualdad, bajo la premisa de que algunos centros alteran las notas de sus estudiantes. Sin embargo, hemos de reconocer que no existen evidencias contrastables al respecto. Además, no nos compete a nosotros reflexionar sobre este tema, ya que guarda una gran complejidad y podría desviarnos de nuestro foco de atención.

Por tanto, estamos en disposición de afirmar que, por lo general, los centros de educación secundaria tienen una función meramente acreditativa, mediante la evaluación de conocimientos y competencias de sus alumnos, unos conocimientos y competencias que se presentan como imprescindibles para el correcto desarrollo del alumno durante su estancia universitaria. Si bien, esta certificación no se desarrolla de una forma individual y autónoma, sino que se lleva a cabo en estrecha colaboración con las administraciones educativas, que son las encargadas de establecer el currículum educativo y, a su vez, de expedir el título académico correspondiente.

\subsection{3) Requisitos necesarios para el acceso/admisión a estudios de educación superior}

Ya hemos comentado al comienzo de este trabajo, como la educación superior está sufriendo una enorme eclosión a lo largo de los últimos años. Pese a ello, no todo el mundo tiene cabida en este complejo sistema ya que, comúnmente, el acceso está supeditado a una serie de condicionantes o requisitos que el alumno debe evidenciar 
antes de comenzar su periplo universitario. Estos son fijados, tanto desde la administración educativa (requisitos de acceso) como desde las propias universidades (requisitos de admisión). Como ya hemos comentado, no existe un proceso de transición homogéneo a nivel internacional, ya que cada sistema educativo fija aquellos criterios que cree más oportunos. Por ello, son muchos y muy diversos los requisitos establecidos para la entrada a las instituciones de educación superior: superación de pruebas de acceso, valoración del expediente académico del alumno, entrevistas personales, pruebas competenciales, etc. Además, junto a estos requisitos académicos, encontramos otros de carácter social, laboral, etc. que pueden ser igual de determinantes en el acceso universitario. Nos estamos refiriendo a la acreditación de experiencia profesional (muy valorada en muchos sistemas del contexto internacional), realización de voluntariado, etc.

Por tanto, podemos afirmar que existe una gran variabilidad de requisitos para el acceso universitario que, en algunos casos, no solamente aluden a aspectos estrictamente académicos, sino también de carácter social o laboral. Estos, como es lógico, dependerán del sistema educativo que estemos analizando, ya que, insistimos, hasta la fecha, no existen unos requisitos globales de acceso.

\section{3) La regulación. Sistema educativo y modelos de organización.}

El tercer agente educativo que analizaremos será el de la regulación educativa, entendiendo esta como la ordenación académica que se realiza través de distintas leyes, decretos, cartas, etc. y valorando la influencia que esta ejerce sobre los modelos de acceso a la educación superior. Para ello, analizaremos estos modelos y, además, trataremos de esclarecer las posibles consecuencias que de ellos pueden derivar. 


\subsection{1) Tipología de los modelos de acceso/admisión}

Con las declaraciones de La Sorbona (1998) ${ }^{13}$ y Bolonia (1999) (ver anexo 1 y 2) se puso en marcha el, ya conocido por todos, Proceso de Bolonia, que culminaría en el EEES en el año 2010. Se constituye como determinación política, en aras de la empleabilidad en Europa y su principal objetivo era el de crear un área educativa común de Enseñanza Superior, que abarcara toda la Comunidad Europea. Estamos ante el primer gran compromiso educativo a nivel europeo, ya que, hasta ese momento, la materia educativa ocupaba un lugar residual en la agenda política de la U.E (González Faraco, Luzón y Torres, 2009).

En este sentido, si analizamos este proceso que ha conformado el EEES, podemos apreciar cómo los diferentes estados miembros han adoptado múltiples medidas que les han permitido alcanzar los objetivos marcados: establecimiento de un sistema de títulos fácilmente comprensibles y comparables, conformación de una estructura basada en tres niveles (Grado, Máster y Doctorado), puesta en marcha de un sistema de créditos ECTS (European Credits Transfer System), eliminación de todo tipo de obstáculos para favorecer la movilidad y el derecho a la libre circulación, etc. (González Faraco et al, 2009; Luzón et al., 2009). En cambio, frente a todas estas propuestas, resulta paradójico que no se haya tenido en consideración un aspecto de vital importancia, como son los sistemas de acceso/admisión hacia los estudios de educación superior, que se han dejado en manos de los propios sistemas educativos, los cuales han actuado con total libertad, generándose, de este modo, diferentes escenarios educativos (Revesado, 2018), que, en ocasiones, pueden llegar a verse ejemplificados en el seno de un mismo país (Egido, 2020).

\footnotetext{
${ }^{13}$ Declaración de La Sorbona. Declaración conjunta para la armonización del diseño del sistema de educación Superior Europeo, a cargo de los cuatro ministros representantes de Francia, Alemania, Italia y el Reino Unido. La Sorbona, Paris, 25 de mayo de 1998.
} 
2.3.1.1) Binomio derecho a la educación - igualdad de oportunidades

Antes de definir y analizar los diferentes modelos de acceso/admisión, creemos conveniente realizar una pequeña reflexión en torno al binomio «derecho a la educación» - «igualdad de oportunidades», que tanta controversia genera cuando hablamos de acceso universitario. Hemos de tener en cuenta que el acceso debe respetar minuciosamente el principio de igualdad de oportunidades. Desde esta perspectiva podemos afirmar que hablar de acceso a la educación (sea en el nivel que sea) es hablar de derecho a la educación y para que este se produzca en condiciones legítimas, debe producirse en igualdad de oportunidades. El derecho a la educación supone que todos los ciudadanos tengan la posibilidad de acceder a los distintos niveles educativos, sin limitación alguna, más allá de sus propias capacidades intelectuales (Valle, 2001). Pero, la cuestión no termina ahí, ya que se surge otra dimensión, que podemos denominar como socioeconómica, que privaría a muchos estudiantes de cursar estudios universitarios, pese a estar capacitados intelectualmente para así hacerlo (Valle, 2008). Esto se debe en gran medida a la expansión educativa que se ha producido en los últimos años en los sistemas educativos de casi todos los países de nuestro planeta. Un aumento que, no solo se limita a los niveles básicos y obligatorios de enseñanza, sino que se ha prolongado en las últimas décadas hasta la educación secundaria, lo que, a la postre, se ha traducido en un aumento de la demanda universitaria fruto, no solo de la expansión educativa a la que hacemos referencia, sino también de las nuevas exigencias sociales.

En este sentido, una de las amenazas que podemos encontrar, y que debemos tener en consideración, es que los sistemas de acceso a la educación superior no partan de la misma filosofía de selección y que, por ello, no sean armonizables entre sí. Y es que, este problema, impide que podamos hablar de un «Pasaporte Universitario Europeo» (Valle, 2008). Estos sistemas selectivos de acceso son defendidos desde varias posturas: necesidad de controlar posibles desigualdades, la excesiva demanda 
académica que se ha producido durante los últimos años, el ajuste entre número de titulados y la necesidad del sistema económico-productivo, etc. (Valle, 2001). Sin embargo, el gran problema con el que nos topamos radica en la multiplicidad de sistemas de acceso a la universidad, que puede esconder tras de sí distintas formas de entender la posición de acceso en el binomio «derecho a la educación»- «igualdad de oportunidades» (Valle, 2008).

\subsubsection{2) Distintos modelos de acceso/admisión a la educación superior}

Ya hemos comentado que la entrada al sistema universitario, pese a la reciente creación del EEES, no es homogénea en todos los países que conforman el mismo. El acceso a la educación superior tiene unas características diferenciales en cada uno de los sistemas educativos, que responden a los factores académicos, sociales, culturales, históricos, etc. Por ello, cuando hablamos de modelos de acceso hacia las instituciones de educación superior, debemos hacer alusión, al menos, a tres de ellos: abierto, cerrado y entreabierto.

El primero de ellos, el modelo abierto, es aquel que permite que todos los alumnos que estén capacitados para seguir con su formación universitaria lo hagan. El segundo de los modelos, el cerrado, se caracteriza fundamentalmente porque en él, no todos los alumnos que estén capacitados para seguir su formación universitaria podrán hacerlo, ya que se produce una selección muy rigurosa con el fin de determinar que el número de aspirantes a unos determinados estudios sea similar a la demanda que precisa el mercado laboral. Por último, en lo que respecta al modelo entreabierto podemos definirlo como aquel en el que se limita el acceso universitario, pero no de una forma tan rigurosa como para hacerlo pensando, solo y únicamente, en las necesidades del sistema económico productivo (Valle, 2001).

De este modo, atendiendo a esta categorización que acabamos de realizar, podemos hablar de dos modelos totalmente opuestos, y uno que podemos catalogar 
como intermedio. El primero de ellos, un modelo totalmente accesible, sin restricción alguna; en el extremo contrario, nos encontramos con un modelo muy restrictivo, que selecciona rigurosamente a los estudiantes; y finalmente, un modelo intermedio, donde el acceso universitario será un tanto restringido, pero se mantendrá vigente una cierta accesibilidad. Pero ¿de qué depende la puesta en marcha de uno u otro modelo? Fundamentalmente, del carácter que haya adquirido la educación superior en el país de origen. Así, podemos encontrarnos sistemas con un modelo cerrado o restrictivo, con una clara vocación profesionalizante; o, por el contrario, sistemas con un modelo más abierto, en donde las instituciones de educación superior no están tan enfocadas hacia el mercado laboral, sino que mantienen un carácter más germánico y humanista, en donde los aspectos sociales y culturales prevalecen sobre los mercantiles.

\subsection{2) Importancia de los modelos de acceso/admisión en la elección de los estudios superiores}

Estos modelos de acceso/admisión pueden condicionar y determinar la elección realizada por los estudiantes. Cada uno de ellos, tiene unas características específicas, que trae consigo unas consecuencias totalmente distintas. Por todo ello, nos gustaría detenernos en analizar las ventajas y desventajas de estos modelos, así como los efectos que provocan sobre el sistema económico productivo (tabla 2).

Tabla 2. Modelos de acceso/admisión hacia la educación superior

\begin{tabular}{|c|c|c|c|c|}
\hline Modelo & Entrada & Efecto & Ventajas & Desventajas \\
\hline Abierto & $\begin{array}{c}\text { Entrada } \\
\text { libre }\end{array}$ & $\begin{array}{c}\text { Posible gran } \\
\text { desajuste }\end{array}$ & Derecho a la educación & Exceso de titulados \\
\hline Eerrado & $\begin{array}{c}\text { Entrada } \\
\text { limitada }\end{array}$ & $\begin{array}{c}\text { Mínimo } \\
\text { desajuste }\end{array}$ & $\begin{array}{c}\text { Ajuste sobre el sistema } \\
\text { económico productivo }\end{array}$ & $\begin{array}{c}\text { Limitación del } \\
\text { derecho a la } \\
\text { educación }\end{array}$ \\
\hline Entreabierto & $\begin{array}{c}\text { Posible } \\
\text { cierto } \\
\text { abierta }\end{array}$ & $\begin{array}{c}\text { Derecho a la educación y } \\
\text { ajuste en el sistema } \\
\text { económico productivo }\end{array}$ & $\begin{array}{c}\text { Posible exceso de } \\
\text { titulados } \\
\text { Pequeña limitación } \\
\text { del derecho a la } \\
\text { educación }\end{array}$ \\
\hline
\end{tabular}

Fuente: VALLE (2001: 212) 
Como se puede apreciar en la tabla, en el primero de los modelos, el sistema sería respetuoso con el derecho a la educación, ya que solo dejaría fuera a aquellos alumnos que no tengan las capacidades suficientes para afrontar dichos estudios; además, se trata de un modelo que respeta la libertad individual, puesto que deja que cada alumno pueda elegir los estudios que considere oportunos. El principal problema que trae consigo este modelo es el gran desajuste que provoca entre número de egresados y las necesidades del sistema económico productivo, puesto que gran parte de la fuerza laboral que se está generando, acabara estando sobrecualificada (Valle, 2001). Además, supone una inversión muy elevada para el Estado, una inversión que no será rentabilizada debido a este gran desajuste que estamos mencionando. Por no hablar del fraude que supone ofertar títulos aun sabiendo que un porcentaje significativo de los estudiantes no tendrán cabida en el mercado laboral, una vez hayan finalizado su etapa formativa.

A diferencia del modelo abierto, la gran ventaja del modelo cerrado es que no existiría desajuste alguno en el mercado laboral, ya que el número de titulados se ajustaría a las necesidades del sistema económico productivo; además, gracias a este modelo, el Estado puede tener un ahorro económico importante, ya que la fuerza laboral que se está produciendo, acabará siendo rentable en un futuro inmediato. Por el contrario, el gran problema que ofrece este modelo es que, en cierta medida, vulnera el derecho a la educación ya que el acceso estará altamente restringido, privando a muchos estudiantes de su incorporación al sistema universitario (Valle, 2001).

Finalmente, en el modelo entreabierto, se limita el acceso universitario, pero no de una forma tan rigurosa como para hacerlo pensando únicamente en las necesidades del mercado laboral. Esta limitación se hace especialmente en aquellos desarrollos institucionales en donde la demanda es muy elevada o, por el contrario, la oferta es muy limitada. Podríamos decir, que este modelo sería el más adecuado, ya que pretende aunar los beneficios de los dos sistemas anteriores: derecho a la 
educación y ajuste entre la oferta y la demanda de egresados en el mercado laboral (Valle, 2001).

\section{4) Sociedad y educación.}

El cuarto de los agentes al que haremos referencia, y que además juega un papel fundamental en el estudio que estamos realizando, es la propia sociedad en la que se enmarca este proceso de transición. Es por ello que en nuestro trabajo, hemos querido incorporar una variable que consideramos de gran interés, como es el análisis de algunos indicadores culturales, que puedan tener una cierta transcendencia en el proceso de transición que aquí analizamos.

\subsection{1) Indicadores culturales y acceso a la educación superior}

Durante el análisis del primer agente educativo, el alumno, hemos realizado una pequeña alusión acerca del origen social del estudiante, presentando esta variable como determinante en este complejo proceso de transición. En este caso, queremos ser un poco más más globales, poniendo nuestro foco de atención en algunos indicadores culturales de la sociedad en la que estos sistemas se enmarcan, que nos ofrecen una mejor perspectiva acerca del fenómeno educativo que estamos analizando. Para ello, vamos a analizar algunos indicadores que nos han suscitado interés y que, lógicamente, puedan tener una cierta incidencia en el plano académico, como son: el hábito de lectura, el gasto público cultural, el nivel de estudios alcanzado por una determinada población -haciendo especial hincapié en aquellos que no disponen de unos estudios mínimos y en los que han alcanzado el nivel de estudios terciarios-, etc. Todo ello nos ofrecerá una panorámica social y cultural más completa, que nos permitirá analizar la incidencia de estos factores sobre el sistema educativo, y de una forma más específica, sobre los procesos de transición hacia la educación superior. 


\section{5) El sistema escolar}

Por último, como no podía ser de otra manera, vamos a analizar el marco escolar donde se desarrolla el alumno. Para ello, vamos a centrarnos en alguna de las variables que puedan interferir en él, y más concretamente, en el proceso de transición en el que se verá envuelto. Nos estamos refiriendo a los sistemas de orientación educativa -con especial ahínco en la etapa de educación secundaria- y acción tutorial ejercida, directa o indirectamente, por los docentes. Y es que, dentro de la complejidad del sistema educativo, estos servicios se presentan como indispensables para favorecer unas pautas que mejoren el acceso de los estudiantes.

\subsection{1) Sistemas de orientación en los centros de educación secundaria y su relación con el acceso/admisión hacia la educación superior}

A lo largo del s. XX los procesos de orientación han experimentado profundos cambios, pasando de ser un proceso restrictivo, reducido a momentos puntuales para dar respuesta a una situación problemática, hasta ser un procedimiento que se desarrolla a lo largo de toda la vida. En lo que se refiere al ámbito educativo, la orientación académica se trata de una intervención dirigida a todos los alumnos, a lo largo de todas sus etapas educativas, con el fin de preparar a estos para la vida en general y, de una forma más específica, para su vida profesional (Álvarez González y Bisquerra, 2012). Las complejas transformaciones a las que se está viendo sometida nuestra sociedad en los últimos años, así como las diferentes exigencias que impone el sistema educativo en todos y cada uno de sus niveles, hace necesario que los centros educativos cuenten con recursos especializados de asesoramiento educativo, y estos son, principalmente, los servicios de orientación (Stone y Dahir, 2006). Entendemos la orientación como una necesidad de la persona a lo largo de toda su vida, pero que adquiere especial relevancia en los procesos de escolarización del alumnado durante 
las etapas no universitarias, dado que estas suponen las bases que el individuo seguirá durante su vida adulta (Watts y Fretwell, 2004).

La orientación educativa está reconocida por el Consejo de la Unión Europea como un derecho para todos los alumnos que permite mejorar la calidad de la enseñanza en el seno de las instituciones educativas:

La facilitación de la orientación educativa en el marco de los sistemas de educación y formación, especialmente en los centros escolares o a nivel escolar, tiene una función esencial que desempeñar para garantizar que las decisiones individuales relacionadas con la educación y la carrera dispongan de una base sólida, y para ayudarles a desarrollar una autogestión eficaz de sus trayectorias de aprendizaje y de carrera. Es también un instrumento clave para permitir a las instituciones de educación y formación mejorar la calidad y oferta de la enseñanza. (Proyecto de Resolución del Consejo y de los Representantes de los Gobiernos de los Estados miembros reunidos en el seno del Consejo, de 18 de mayo de 2004, sobre el fortalecimiento de las políticas, sistemas y prácticas en materia de orientación permanente en Europa).

\subsubsection{1) Objetivos y funciones que persigue la orientación}

Aparentemente, existe una falta de consenso respecto a cuál es el fin último que persigue la orientación. Esta falta de acuerdo no responde tanto a un problema interpretativo de los autores, sino más bien a un problema terminológico, dado que cada uno de ellos establece cuál es ese objetivo último de la orientación con sus propias palabras. Nosotros vamos a hacer referencia a autores de gran relevancia, como es el caso de Álvarez, González y Bisquerra (2012), que definen que el objetivo primordial que persigue la orientación es el bienestar de cada individuo. Estos autores, atestiguan que la orientación debe hacer posible que cada individuo construya su propio bienestar, tanto de carácter personal como social.

Respecto a las funciones que desempeñan los equipos de orientación, son muchas y muy diversas en cada uno de los centros educativos. En primer lugar, la organización y planificación de la orientación. Por otro lado, la elaboración de 
diagnósticos psicopedagógicos del centro, mediante la cooperación con el cuerpo docente. Otra de las funciones que deben llevar a cabo es la de realizar programas de intervención en el proceso de enseñanza-aprendizaje, desarrollando diferentes tareas como: orientación curricular, tratamiento de dificultades de aprendizaje y comportamientos disruptivos, coordinación de la atención a la diversidad, etc. Además, también deben realizar una intervención para la prevención y el desarrollo humano. En este sentido es importante que desde los servicios de orientación se conciencien a los alumnos sobre la importancia del consumo de drogas, se atienda el desarrollo emocional del alumnado, se desarrollen programas de educación para la salud, etc. Por último, en el tema que a nosotros nos atañe, una de las funciones primordiales que desempeñan los equipos de orientación es la consulta o asesoramiento, que será llevada a cabo, no solo con alumnos, sino también con profesores y familias (Álvarez González y Bisquerra, 2012), que también forman parte del proceso educativo del estudiante.

\subsubsection{2) Orientación en las transiciones}

Dada la línea de trabajo que vamos a llevar a cabo en nuestra investigación, no podemos obviar el proceso de orientación durante las «transiciones». Estos procesos, tal y como hemos mostrado al comienzo de nuestro trabajo, han recibido un importante impulso en las últimas décadas, favoreciendo la aparición de un importante marco teórico (Figuera, 2006). Son muchas las aportaciones que diversos autores han realizado durante los últimos años, estudiando y analizando los diferentes modelos de transición (Bandura, 1990; Gimeno, 1996; Lazarus y Folkman, 1986; Lent, Hackett y Brown, 1994; Schlossberg, 1984, 1989). Uno de los indicadores más relevantes para alcanzar el éxito académico es el de conseguir una adaptación rápida al nuevo entorno en el que se va a integrar el alumno. A lo largo de su formación académica, el estudiante debe recorrer cuatro grandes momentos o etapas. En algunos casos, el proceso se realizará dentro de una misma institución -Educación Infantil y Primaria o 
Educación Secundaria Obligatoria y Educación Secundaria Postobligatoria-, pero en otros, este proceso se realiza entre distintas instituciones -Centros de Educación Primaria e Institutos de Educación Secundaria, o entre éstos con la Universidad-. En este último caso, la relación entre niveles educativos es prácticamente inexistente, lo que genera dificultades para establecer una cierta coordinación, afectando de una forma negativa al proceso de transición (Grau et al., 2013).

La U.E recomienda orientar a los jóvenes y adultos en los periodos de transición, especialmente cuando esta se produce durante la vida activa. En este complejo proceso de transiciones, la orientación académica jugara un papel indispensable, ofreciendo una respuesta frente a todas las problemáticas existentes, así como realizando propuestas de intervención que faciliten una adecuada madurez personal, educativa y vocacional del alumno (Álvarez González y Bisquerra, 2012).

\subsection{2) Acción tutorial en los alumnos de educación secundaria y su relación con el acceso/admisión hacia la educación superior}

Como ya hemos comentado con anterioridad, nos encontramos frente a un nuevo escenario educativo, un escenario en el que la calidad desciende y en el que la confianza sobre el sistema educativo decrece. Ante este panorama tan desalentador, debe existir una respuesta desde el campo de la orientación y la acción tutorial, donde se le otorgue un rol significativo sobre el logro de posibles efectos positivos (Rodríguez Espinar, 2006).

Pese a que todos los profesores deben estar implicados en la acción tutorial, hay uno que es el encargado de coordinar dicha acción, el denominado «tutor». Este, además, debe supervisar el desarrollo integral del alumno; para ello, es fundamental que ejerza una cierta función de liderazgo democrático y, por tanto, tenga la capacidad de trabajar en equipo. Por otro lado, dentro de las funciones que debe ejercer el tutor, encontramos la tutoría, que es un aspecto concreto de la acción tutorial. En este 
sentido, debemos distinguir entre tutoría individual y tutoría grupal (Bisquerra, 2006). La tutoría individual es la que se realiza mediante la entrevista personal con un alumno concreto o, en algunos casos, con un grupo reducido de estudiantes. Mientras que la tutoría grupal, es aquella que está constituida por todas aquellas actividades que se realizan con el grupo o clase, principalmente mediante la sesión semanal asignada.

\subsubsection{1) ¿Qué entendemos por acción tutorial?}

Algunos autores definen la acción tutorial como la orientación llevada a cabo por los profesores y, de una forma más específica, por los tutores: “acción formativa de orientación y ayuda que el profesor-tutor y el resto del equipo docente realizan con sus alumnos a nivel individual y grupal en los ámbitos personal, escolar y profesional al mismo tiempo que ejercen su función docente" (Álvarez González, 2006: 29). Pero, la acción tutorial, no es algo que deba dejarse al azar, sino que, con anterioridad, debe desarrollarse un análisis previo, en donde se planifique y programe las diferentes acciones que los docentes deberán llevar a cabo. Para ello, la administración educativa debe facilitar las condiciones necesarias para que esta acción tutorial se desarrolle de una manera eficaz. Si bien, hemos de destacar que el correcto desarrollo de esta acción educativa dependerá de múltiples factores, como son la formación de los profesionales educativos, la concienciación sobre la importancia de la acción tutorial, estar en disposición de unas infraestructuras de calidad, el apoyo real por parte de los agentes educativos, la existencia de una ayuda y coordinación desde la propia institución educativa, etc. (Álvarez González, 2006).

\subsubsection{2) Objetivos y principios de la acción tutorial}

Podríamos hablar largo y tendido acerca de los diferentes objetivos que se plantea la acción tutorial de cara a su intervención con el alumno, pero vamos a detenernos tan solo en uno, el que podríamos definir como fin último, que no es otro que el de conseguir el desarrollo integral y armónico del alumno que le prepare para 
la vida activa. La acción tutorial tiene como finalidad preparar al alumno para afrontar cualquier situación, ya sea personal, social, educativa o profesional (Álvarez González, 2004).

Respecto a los principios, tres son fundamentales los principios por los que se rige la acción tutorial: prevención, desarrollo e intervención social. La prevención implica una anticipación frente a una situación conflictiva. Se debe preparar al sujeto para que afronte todos sus problemas, y a su vez, para que pueda superarlos. Desarrollo, ya que el sujeto va estructurando su propia personalidad a través de su interacción con el medio. Y finalmente, intervención social, puesto que la acción tutorial no debe obviar nunca el contexto social en el que el sujeto se desarrolla. El profesor debe localizar aquello que pueda obstaculizar al alumno dentro de su contexto social, pero también, todo aquello que lo estimule (Álvarez González, 2004).

\subsubsection{3) Destinatarios de la acción tutorial}

La acción tutorial enfocada hacia el desarrollo humano debe contemplar tres actores: los alumnos, los profesores y las familias. Sin duda alguna, el alumno es el destinatario último de la acción tutorial, pero para que la intervención que se realice sobre él sea efectiva, no debemos obviar los otros dos actores implicados. En este sentido, el profesorado es fundamental ya que necesita actualizarse constantemente, dado que, en la acción tutorial, la formación permanente es especialmente importante. Finalmente, hablamos de las familias, que también desempeñan un papel esencial en el desarrollo personal del alumno. Si podemos organizar la acción tutorial con el apoyo de las familias, se producirá con mayor facilidad el efecto de sinergia. Profesorado y familia deben trabajar conjuntamente para la educación de los alumnos (Bisquerra, 2006). 
Itinerarios de acceso/admisión a la educación superior. Un análisis comparado en los sistemas educativos de España, Francia y Finlandia

Por otro lado, y ya para finalizar, nos gustaría incidir en la importancia de que las familias participen en la planificación del Plan de Acción Tutorial (PAT), dentro de lo que vamos a denominar «espacio familiar»:

Utilizamos la expresión espacio familiar para referirnos a un conjunto de actividades (...) dirigidas a la familia, con objeto de desarrollar actitudes y competencias para que puedan contribuir de forma significativa en el desarrollo humano de sus hijos e hijas (Bisquerra, 2006: 86). 



\section{1) INTR ODVCCIÓN Y JVSTIFICACIÓN DEL TEMA

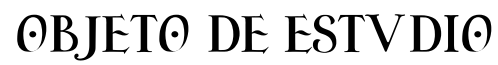

2) CATEGORÍAS $\odot$ VARIABLES DE ANÁLISIS DEL ACCESO/ADMISIÓN A LA EDVCACIÓN SVPERIOR

3) EL ACCESค/ADMISIÓN A LA EDVCACIÓN SVPERIOR EN ESPAN̂A, FRANCIA Y

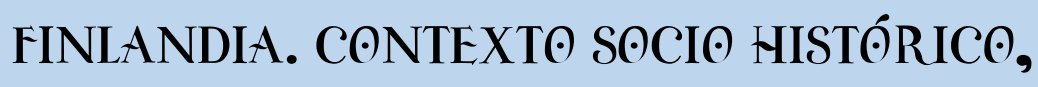
PคLÍTICO Y CVLTVRAL

4) ¿CÓM@ ACTV́AN LOS MODELOS DE ACCES๑/ADMISIÓN HACIA LA EDVCACIÓN SVPERIOR?

5) LA COMPARACIÓN CONTEXTVAL DEL ACCES@/ADMISIÓN A LA EDVCACIÓN SVPERIOR. EL CARÁCTER FVNCIONAL DE LAS TRANSICIONES

6) CONCLVSI@NES 



\section{3) EL ACCESఠ/ADMISI@́N A LA EDVCACIÓN SVPERIOR EN

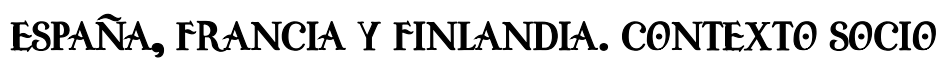

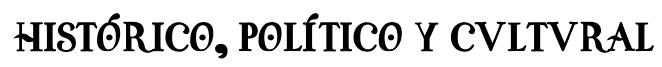

Ya hemos comentado en el apartado introductorio de nuestro trabajo como, desde el punto de vista metodológico, íbamos a seguir las pautas marcadas por el método clásico de comparación. Una de las etapas a las que aludíamos cuando describíamos este método comparativo era la interpretativa o contextual, que pretendía mostrar las numerosas interrelaciones que existen entre los distintos componentes educativos y la sociedad en la que estos se enmarcan. Es por ello por lo que, a lo largo de este capítulo, analizaremos diferentes elementos contextuales que puedan tener una cierta incidencia sobre los procesos de transición y, más concretamente, sobre la transición desde la educación secundaria superior hacia la educación superior. Estos elementos que aquí se estudian tienen la finalidad de enmarcar las categorías o variables de análisis que hemos descrito en el capítulo anterior. En este sentido, pretendemos analizar tanto el contexto interno como externo de las transiciones. El primero de ellos viene expresado, fundamentalmente, por diferentes componentes del sistema educativo en el que estas se desarrollan (estructura del sistema educativo, cultura escolar, mentalidad y acción política, etc.). 
Mientras que el contexto externo haría referencia al marco social (aspectos históricos, culturales, políticos, económicos, etc.). En este sentido, hemos tomado la decisión de trabajar sobre cinco componentes, que nos van a esclarecer el contexto en el que toma forma este proceso de transición. En primer lugar, analizaremos la cultura histórica del sistema educativo, donde podremos examinar la evolución que el entramado educativo ha llevado a cabo a lo largo de los últimos años, décadas e incluso siglos en cada uno de los países objeto de análisis. En segundo lugar, estudiaremos la cultura escolar, que nos permitirá tener una visión panorámica de los códigos pedagógicos y prácticas escolares que, día a día, se desarrollan en los centros educativos. Por otro lado, prestaremos atención a los modelos y formas de regulación, que hacen referencia al conjunto de normas establecidas desde el sector público para garantizar unos niveles mínimos de calidad en la formación (Charo, 2016). También analizaremos el funcionamiento del propio sistema educativo, teniendo en consideración aspectos como: su estructura, política educativa, escolarización, abandono escolar temprano, etc. Por último, tomando como referencia uno de los organismos de mayor relevancia internacional, como es OCDE, estudiaremos la eficacia de estos sistemas educativos, mediante el análisis de las pruebas PISA, unas pruebas que están adquiriendo un gran impacto sobre los sistemas educativo a lo largo de los últimos años.

\section{1) Contexto socio histórico, político y cultural en España}

\subsection{1) Cultura histórica del sistema educativo español}

El proceso de institucionalización del sistema educativo en España se inicia con la crisis del Antiguo Régimen y guarda una estrecha relación con el desarrollo de la sociedad liberal. En este sentido, hemos de reconocer que la Constitución de Cádiz (1812) será el punto de inflexión en el desarrollo de los primeros proyectos educativos de nuestro país (Escolano, 2002). 


\subsubsection{1) Construcción del sistema educativo en España (1812-1874)}

La Constitución de Cádiz, en su título IX, decretaba el derecho de todos los españoles a recibir instrucción educativa. El Informe Quintana (1813), junto al Dictamen y Proyecto de Decreto para el arreglo general de la Instrucción Pública (1814) y el Reglamento General de Instrucción Pública (1821), constituyen el primer corpus legislativo sobre el que se estructura el sistema nacional de educación en España. No obstante, estos proyectos educativos, quedarían en el aire tras la vuelta de Fernando VII, en el año 1814. Finalizado este periodo absolutista, los ideales liberales volverían a la palestra de la mano del trienio liberal (1820-1823), que recuperaría el espíritu del Informe Quintana (Escolano, 2002).

Años más tarde, en 1833, se iniciará un nuevo ciclo que supondrá una ruptura con los viejos esquemas del Antiguo Régimen, gracias al despegue definitivo de la revolución liberal. A lo largo de esta etapa, se producirá una normalización de la vida política, con alternancias en el gobierno entre progresistas y moderados. En el plano educativo, debemos resaltar la aparición del Plan General de Instrucción Pública (1836), inspirado en el Informe Quintana. Poco después, en 1838, las Cortes aprobaron el Plan de Instrucción Primaria, una norma que ordenaría este nivel educativo hasta 1857. Este Plan, destacaba por la política secularizadora que llevaba a cabo, que ponía en riesgo la influencia de la Iglesia en toda cuestión educativa (Escolano, 2002).

Tras el bienio progresista (1854-1856), se aprueba una de las leyes con mayor relevancia en la historia de nuestro país, y con vigencia durante más de un siglo. Estamos hablando de la Ley de Instrucción Pública (1857), también conocida popularmente como Ley Moyano. Esta ley, consensuada por progresistas y moderados, fue el punto de partida de una gran estabilidad educativa en nuestro país, sobre todo, en lo que concierne al plano administrativo y legislativo (Bernal, Cano y 
Lorenzo, 2014). En ella, se recogían los principios de obligatoriedad y gratuidad de la enseñanza elemental, así como la centralización administrativa, uniformidad y secularización. La inspección educativa, quedaría en manos de la iglesia, gracias a la firma del Concordato de 1851 entre moderados y eclesiásticos, que pretendía poner fin a los problemas de índole político y religioso que habían surgido años atrás. En lo que respecta a la segunda enseñanza la situación no variaría ostensiblemente, tal vez porque se asumía como válido el plan que venía aplicándose para este nivel educativo desde el año 1845 (Vega, 1995).

\subsubsection{2) La educación en la restauración (1874-1931)}

El tiempo que transcurre entre 1874-1931, ha sido tratado por los historiadores bajo el nombre de Restauración. Dado que estamos hablando un periodo temporal muy extenso, algunos estudiosos han dividido este periodo en dos etapas. Por un lado, la alta restauración y por otro, la baja restauración, ambas separadas por un cambio de coyuntura que desembocó en la crisis de 1917. Este periodo se cerrará con la Dictadura de Primo de Rivera (1923-1930), que dará paso a la II República. Sin duda, será durante esta segunda etapa cuando se producirá una consolidación del sistema educativo, gracias, entre otras cosas, a una mayor implicación por parte del Estado. Como consecuencia de ello, se creará el Ministerio de Instrucción Pública y Bellas Artes (1900), que dará un gran impulso a la institucionalización educativa en España (Escolano, 2002).

El espíritu conciliador de la Restauración pronto puso de manifiesto serias contradicciones, sobre todo, en materia de educación. La circular de Orovio (1875), que defendía la confesionalidad católica del Estado, supuso una ruptura con la libertad de cátedra establecida por los liberales, generando uno de los mayores conflictos que se recuerdan en la historia contemporánea de nuestro país (Escolano, 2002). Como consecuencia de todos estos acontecimientos, se produjo en España uno de los 
movimientos intelectuales más importantes de nuestra historia, como fue la creación de la Institución Libre de Enseñanza (ILE) en el año 1876. La ILE, fundada por Giner de los Ríos, fue concebida como una institución ajena a cualquier interés de ámbito religioso, político o filosófico. Su actuación será decisiva en varios aspectos del apartado educativo, como por ejemplo: la asunción por parte del Estado del sueldo de los maestros, la creación de la cátedra de Pedagogía en 1904, la ampliación de la escolaridad obligatoria, etc.

La ILE, que será el soporte ideológico utilizado por los dirigentes republicanos del primer bienio, desaparecerá, finalmente, en el año 1932 (Molero, 1985). El final de esta etapa viene caracterizado por la fuerte crisis social generada en nuestro país, fruto de la alternancia de gobiernos que terminaría desembocando en un golpe militar que llevaría al poder al general Primo de Rivera. Este periodo dictatorial (1923-1930), se caracterizó por sus grandes restricciones. Si bien, también es cierto que, durante esta época, se consiguen grandes logros en materia de educación, como la construcción de dos mil nuevas escuelas y la modernización de otros tantas, que supuso un considerable esfuerzo para mejorar las infraestructuras del sistema educativo primario de nuestro país (Escolano, 2002).

\subsubsection{3) La educación en la segunda república española (1931-1939)}

La fuerte crisis social sufrida durante la Restauración terminó desembocando en una nueva situación política, con la proclamación de la II República, tras las elecciones del 14 de abril de 1931. Entre la dimisión de Primo de Rivera, y la llegada de la II República, pasan quince meses en el que el republicanismo va cogiendo forma, gracias al apoyo de numerosos ciudadanos que, conforme la dictadura llegaba a su fin, veían con buenos ojos la llegada del régimen republicano (Domínguez, 2008).

Sin duda alguna, la educación sería una cuestión de Estado en esta nueva etapa, donde el regeneracionismo del país y el asentamiento del nuevo régimen se 
plantean como objetivos fundamentales. Desde la República, se confiaba plenamente en la escuela como la única vía útil para superar la lacra del analfabetismo. Nuevamente, la regulación de la enseñanza religiosa pasará a ser uno de los temas candentes. El decreto del 6 de mayo de 1931 establecía que la instrucción religiosa no sería obligatoria en las escuelas, si bien los alumnos cuyos padres expresaran el deseo de recibirla, podrían hacerlo. De este modo, se sentaban las bases del laicismo, que iban a consagrarse en la Constitución republicana de 1931 (Escolano, 2002).

El corto periodo en el que se desarrolló la II República, tuvo tres etapas claramente definidas, marcadas por el carácter ideológico del gobierno de turno. La orientación izquierdista del primer bienio, que se marcó como objetivo prioritario hacer de la educación el motor del cambio social en España. Posteriormente, la crisis del gobierno (1933), que se saldaría con la derrota electoral del gobierno progresista, y la consiguiente llegada al poder de las fuerzas conservadoras, donde se pone freno a las iniciativas propuestas hasta la fecha; y por último, el regreso de estas ideas a partir de 1936, tras la llegada al poder de la izquierda mediante la reagrupación en el Frente Popular (Domínguez, 2008).

\subsubsection{4) La educación durante el franquismo (1939-1975)}

Algo más de un tercio de siglo es el periodo que transcurre entre la guerra civil y la restauración democrática, un periodo histórico que fue ocupado por el franquismo. Sin embargo, existe mucha controversia en torno a la periodicidad de esta etapa, en cuanto a las diferentes interpretaciones habidas respecto a su comienzo, y lo que es lo mismo, el punto y final de la etapa anterior, la República. Hay quien entiende que el núcleo fundamental de la República, tan solo se desarrolló durante el primer bienio (1931-1933) ya que, en esos años, es cuando se llevaron a cabo las reformas educativas más importantes. Por contra, hay otro grupo que defiende que la Republica va más allá, y que se extiende hasta marzo de 1938, tras la derrota en la Guerra Civil, 
ya que este régimen político sigue existiendo durante los tres años de la contienda. Sea como fuere, queda patente que el periodo que abarca el final de la Republica y la transición hacia el periodo dictatorial es un tanto ambiguo (Viñao, 2008).

Este periodo que estamos analizando, posee rasgos muy definidos en lo que se refiere al ámbito educativo: enseñanza confesional católica, enseñanza obligatoria de la religión, derecho de la Iglesia a inspeccionar la educación, etc. (Bernal et al., 2014). En síntesis, el modelo ideológico-cultural de este periodo se formula en torno al nacionalcatolicismo, que venía a expresar el nacionalismo del Estado y la jerarquía eclesiástica, especialmente en el ámbito educativo (Escolano, 2002).

La política educativa del nuevo régimen comienza a desarrollarse en pleno conflicto bélico. Uno de los propósitos fundamentales y conseguidos por el régimen dictatorial, fue el de borrar cualquier rastro republicano del colectivo de los españoles (Viñao, 2008). Por otro lado, el Ministerio de Educación Nacional, tomó otra serie de medidas de gran relevancia, como fue la supresión del bilingüismo, la coeducación y el laicismo. De este modo, la Iglesia recuperaba los poderes políticos y pedagógicos. Además, a partir de 1936, se lleva a cabo en la llamada zona nacional, una política de depuración del profesorado, particularmente en los maestros de educación primaria. Este proceso de purificación se extendería hasta después de la guerra con una persecución hacia todos aquellos que presentasen una ideología liberal o marxista. (Escolano, 2002).

En lo que respecta a la ordenación de la enseñanza, la educación primaria es abordada por el franquismo en 1945, colocándola bajo el control de la Iglesia y del Movimiento Nacional, introduciendo dentro del currículum la religión y la formación del espíritu nacional. En lo que respecta a las enseñanzas medias, en 1953, se llevará a cabo una nueva reforma, que pondría fin a lo establecido años atrás. Por último, en lo que concierne al plano universitario, el acceso estará supeditado a la superación del 
Examen de Estado, si bien, además de esta prueba, las universidades iban a disponer de autonomía para fijar otros requisitos adicionales de acceso, denominados exámenes de ingreso. Estos exámenes serán regulados a través de varios decretos que permiten seleccionar a los estudiantes atendiendo a criterios de extrema necesidad, para favorecer un acceso equilibrado, que respete las necesidades del país. Años más tarde, tras la reforma del Bachillerato, se instaurará un curso preuniversitario, que será complementado con una Prueba de Madurez (que sustituiría al antiguo Examen Nacional); en un principio, esta prueba estaba considerada como una evaluación final del curso preuniversitario, si bien, con el paso del tiempo, fue convirtiéndose en una prueba de acceso hacia los estudios universitarios (Muñoz Vitoria, 1993).

En 1962, se hace cargo del Ministerio de Educación y Ciencia, Lora Tamayo, que buscará implantar definitivamente el modelo tecnocrático, coincidiendo estos años con los planes de desarrollo económico y social del país, que trataban de modernizar las estructuras productivas del régimen franquista. Ante esta nueva coyuntura, en 1970, se va a iniciar una de las reformas educativas más importantes de la historia de España: la Ley General de Educación (LGE), un proyecto ambicioso que solo contaba con un precedente similar, la ley Moyano, promulgada un siglo atrás. Desde el punto de vista organizativo, esta ley abogaba por una reforma completa de todos los niveles educativos, desde preescolar hasta la educación superior (Escolano, 2002). Sin duda, en esta etapa será fundamental la conformación de un nuevo modelo de acceso universitario, escudado en la Selectividad, un examen nacional de acceso que se pondría en marcha, por primera vez, durante el curso académico 1974-1975. La importancia de esta prueba a nivel histórico es tal, que se mantiene vigente en nuestros días, con pequeñas modificaciones que afectan tanto a su denominación como a su estructura. 


\subsubsection{5) La restauración democrática y la educación}

Tras la caída del franquismo, España ha vivió un proceso de democratización política basado en el consenso y la participación. En pocos años pasamos de un régimen dictatorial a una incipiente democracia, donde la educación desempeñó un papel crucial en el desarrollo de nuevos valores democráticos (Bernal et al., 2014).

A nivel educativo, España no modificó sustancialmente la reforma llevada a cabo en 1970, salvo puntos muy básicos como el derecho a la educación y el ordenamiento de las universidades. A finales de la década de los 80, la administración educativa planteó la necesidad de elaborar una nueva ley. Los grupos políticos coincidieron en reconocer el derecho a la educación como un elemento fundamental. Además, se declaró la educación básica como obligatoria y reconocieron el papel de la administración en materia de inspección y homologación de títulos (Escolano, 2002). La llegada del Partido Socialista Obrero Español (PSOE) al poder en 1982 traería de la mano un nuevo planteamiento educativo, mediante la Ley Orgánica de Derecho a la Educación ${ }^{14}$ (LODE), aprobada definitivamente en 1985, que pretendía trasladar los nuevos principios constitucionales al marco educativo (Bernal et al., 2014).

El Libro Blanco para la reforma del Sistema Educativo (1989), venía a desarrollar una serie de ideas y propuestas, que acabarían dando lugar, un año más tarde, a la Ley de Ordenación General del Sistema Educativo (LOGSE) ${ }^{15}$, permeado por la experimentación educativa implementada a lo largo de los años ochenta. Esta

\footnotetext{
${ }^{14}$ Ley Orgánica 8/1985, de 3 de julio, reguladora del Derecho a la Educación, Boletín Oficial del Estado, 4 de julio de 1985, Núm. 159, p. 21015-21022.

${ }^{15}$ Ley Orgánica 1/1990, de 3 de octubre, de Ordenación General del Sistema Educativo. Boletín Oficial del Estado, 4 de octubre de 1990, Núm. 238, p. 28927-28942.
} 
reforma llevaría a cabo una reestructuración exhaustiva del sistema educativo, tanto en lo que a principios como a su organización se refiere (Escolano, 2002). Esta reestructuración afectaría también al acceso universitario, donde la selectividad, legitimada por los socialdemócratas durante la década de los 80 , sufrirá una reordenación interna que, sin embargo, no traería consigo grandes modificaciones (Revesado, 2018). Y es que esta prueba consiguió atravesar de una forma inmaculada el proceso de transformación política y social que trajo consigo la transición democrática (Moreno, 1992). No obstante, donde sí se han llevado a cabo cambios, es en la finalidad de la prueba, que ha dejado de seleccionar alumnos, para distribuirlos y ordenarlos. De este modo, se comienza a reconocer que todos los alumnos están capacitados para iniciar estudios universitarios, siendo el objetivo de la prueba el de distribuirlos armónicamente (Muñoz Vitoria, 1993), para así garantizar un ajuste entre la oferta y la demanda académica.

A grandes rasgos, podemos afirmar que la LOGSE se ha mantenido viva en nuestra sociedad durante más de dos décadas. Si bien es cierto que existieron intentos de acabar con ella, no obstante, sin mucho éxito. Un ejemplo de ellos lo encontramos al comienzo de siglo (2002), cuando el Partido Popular (PP) trató de poner en marcha una nueva propuesta educativa, la Ley Orgánica de Calidad de la Educación ${ }^{16}$ (LOCE). Sin embargo, la llegada al poder de los socialistas tras las elecciones de 2004, lo impidió, manteniendo de este modo una línea continuista, mediante la promulgación de la Ley Orgánica de Educación ${ }^{17}$ (LOE), aprobada en el año 2006, con la que se buscaba consenso necesario para terminar con las continuas

\footnotetext{
${ }^{16}$ Ley Orgánica 10/2002, de 23 de diciembre, de Calidad de la Educación. Boletín Oficial del Estado, 24 de diciembre de 2002, Núm. 307, p. 45188-45220.

${ }^{17}$ Ley Orgánica 2/2006, de 3 de mayo, de Educación. Boletín Oficial del Estado, de 4 de mayo de 2006, Núm. 106, p. 17158-17207.
} 
reorientaciones de las políticas educativas (Tiana, 2007). Si bien, esta reforma no tuvo excesiva continuidad, ya que en el año 2013 se promulgaría la Ley Orgánica para la Mejora de la Calidad Educativa ${ }^{18}$ (LOMCE), que se ha convertido en una de las leyes más controvertidas de las últimas décadas, con la puesta en marcha de algunas medidas que no contaban con el apoyo de distintos sectores de la sociedad. La LOMCE, entre sus muchas propuestas, pretendía llevar a cabo una recentralización del sistema educativo a través de las evaluaciones externas y del incremento de las materias troncales; también apuesta por la libertad de elección de centro, donde los progenitores podrán matricular a sus hijos en aquellos centros educativos que se adecúen a sus convicciones, gustos y preferencias. Aunque, sin duda alguna, la más polémica de todas, ha sido el cambio de fórmula para el acceso universitario, donde se apuesta por eliminar la prueba de acceso a la universidad tras más de cuarenta años (Pérez Gómez, 2014; Viñao, 2016). Si bien, hemos de reconocer que muchas de estas medidas que acabamos de describir no terminaron de afianzarse ya que tras la moción de censura celebrada en junio de 2018, lo populares perdieron el poder en favor de los socialistas que, rápidamente, se apresuraron a preparar un proyecto de ley para enmendar la LOMCE, aunque, hasta el momento, sin mucho éxito, al no contar con la mayoría necesaria en la Cámara. Y es que, la reciente irrupción de distintas fuerzas parlamentarias ha creado un nuevo escenario político en nuestro país, que ha acabado con el bipartidismo y ha generado serias dificultades a la hora de formar gobierno. Frente a este escenario, la puesta en marcha reformas educativas se está convirtiendo en una tarea, cuanto menos, compleja, debido a la falta de acuerdos entre las distintas formaciones políticas.

\footnotetext{
${ }^{18}$ Ley Orgánica 8/2013, de 9 de diciembre, para la Mejora de la Calidad Educativa. Boletín Oficial del Estado, de 10 de diciembre de 2013, Núm. 295, p. 97858-97921.
} 


\subsection{2) Cultura escolar en el sistema educativo español}

\subsubsection{1) Fundamentación teórica y contenido}

Otras de las variables que analizaremos en este capítulo y que guarda una estrecha relación con el contexto en el que se desarrollan los diferentes sistemas educativos analizados en nuestro trabajo, es la cultura escolar. Este concepto, nace de la mano del historiador francés Dominique Julia que, en la última década del s. XX, acunó este término en uno de sus trabajos ${ }^{19}$. Este autor definía la cultura escolar como "un conjunto de normas que definen los saberes a enseñar y los comportamientos a inculcar, y un conjunto de prácticas que permiten la transmisión y asimilación de dichos saberes y la incorporación de estos comportamientos" (Julia, 1995: 354). Otro de los autores que ha abordado este término, es Viñao (2002), que coincidía con la propuesta de Julia, considerando la cultura escolar como un conjunto de teorías, normas y prácticas que se materializaban en los modos de pensar y actuar, proporcionando una serie de estrategias que permitiesen organizar la clase, interactuar con los compañeros e integrarse en día a día del centro. De este modo, podemos afirmar que la cultura escolar estaría constituida por un conjunto de teorías, ideas, normas, pautas, etc. asentadas en forma de tradiciones y compartidas por sus actores en las instituciones educativas.

Por otro lado, es interesante hacer un pequeño apunte terminológico, diferenciando los términos cultura escolar y culturas escolares. Así, puede existir una única cultura escolar, sin embargo, desde el punto de vista histórico, parece más fructífero hablar de este término en plural. Cada centro tiene más o menos acentuada su propia cultura, con unas características determinadas. De este modo, podemos

\footnotetext{
19 JULIA, D. (1995). La culture scolaire comme objet historique. Paedagogica Historica. International journal of the history of education, 31 (Sup. 1), pp. 353-382.
} 
encontrar culturas específicas para cada centro docente, para cada nivel educativo e incluso, para cada uno de los actores que participan en estas instituciones educativas (Viñao, 2002).

Dicho esto, podemos aludir a tres tipos de culturas escolares: una que estaría constituida por la cultura empírico-práctica que han construido los propios docentes mediante su ejercicio profesional; otra que se organizaría en torno a los saberes que genera la investigación educativa (cultura pedagógica); y, finalmente, una última asociada al discurso y las prácticas de orden político-institucional (cultura política) (Escolano, 2001).

La cultura empírica se constituye por el conjunto de prácticas creadas por los docentes para regular la enseñanza y el aprendizaje, construyendo, de este modo, el habitus de su oficio. Esta cultura se refleja, no solo en las conductas de los sujetos, sino también en la llamada cultura material de la escuela (Escolano, 2008). Se comenzó a fraguar a lo largo del s. XIX, gracias a que los enseñantes de esta época la mayoría de ellos sin una formación pedagógica-, tuvieron que configurar sus propios métodos de trabajo y formas organizativas. Es por ello, que podemos afirmar que la cultura empírica, tiene sus orígenes en la intervención de los propios maestros, debido a los nulos antecedentes que existían en ese momento, más allá de los viejos usos establecidos durante el Antiguo Régimen (Escolano, 2002). En España, la cultura empírica se ha ido configurado de forma paralela al despegue del sistema nacional de educación. En un primer momento, se configuraría en torno a la propia práctica escolar de los docentes. En este sentido, uno de los documentos más relevantes para la configuración de esta cultura escolar fue el Reglamento General de Escuelas de Primeras Letras (1825), a partir del cual comienza a determinarse un ritmo en la gestión de los tiempos escolares; más tarde, con el Reglamento Provisional de las Escuelas Públicas de Instrucción Primaria Elemental (1838), se configura el ordenamiento práctico de la enseñanza. Esta normativa, uniformizaba la distribución 
de tareas, señalando pormenorizadamente todos los tiempos y movimientos de la actividad docente. Pero, sin duda, una de las etapas fundamentales en la conformación de esta cultura escolar fue la Restauración gracias, sobre todo, a la creación del Ministerio de Instrucción Pública, que sentaría las bases para el diseño de una escuela moderna, higiénica y racional. Se llevaría a cabo una modificación en la gestión de los tiempos dentro del aula, siempre acorde a la propia experiencia del docente; otro hecho de gran relevancia es la declaración de las vacaciones de verano como obligatorias a partir de 1887. También es interesante resaltar que, durante esta época, se comenzarían a distribuir a los alumnos atendiendo a criterios de graduación que imponían las normas, tanto pedagógicas como administrativas (Escolano, 2002).

En segundo lugar, hablaremos de la cultura pedagógica, que está ligada al desarrollo del conocimiento y se plasma a partir de los textos científicos que produce la comunidad intelectual. Se constituye a lo largo del s. XIX, como una disciplina académica para satisfacer las demandas metodológicas de los primeros centros de formación de maestros, con dos objetivos claros: fundamentar las orientaciones que debía trasmitir la enseñanza y sistematizar la acción educativa de la práctica docente (Escolano, 2008). Curiosamente, en nuestro país, la mayor parte de estos modelos teóricos se buscaron en el exterior, a través de la traducción de libros o de la propia producción nacional, que transcribía contenidos de los manuales, sobre todo de los británicos, franceses y alemanes (Escolano, 2001). La etapa tecnocrática, desarrollada durante la segunda fase del franquismo, traerá consigo una serie de innovaciones en el plano pedagógico, asociadas a las nuevas dinámicas económicas y sociales, ya que el tradicionalismo pedagógico del sistema educativo español era incompatible con la dinámica de industrialización que estaba experimentando nuestro país. Será en este ciclo, cuando se renueve la tecnoestructura de la escuela (nuevos espacios y escenarios, nuevos manuales, etc.), poniendo fin a esa imagen arcaica de la escuela (Escolano, 2002). 
Por último, aludiremos al tercer tipo de cultura escolar, la política, que está estrechamente relacionada al lenguaje y a las prácticas que generan las burocracias que administran los sistemas educativos. Esta cultura, se materializa en los textos y las acciones que promueven los planificadores y gestores de la educación, así como los agentes sociales que intervienen en ella (Escolano, 2008). En nuestro país, la creación del Ministerio de Instrucción Pública y Bellas Artes, en el año 1900 fue, sin duda, el hecho más determinante para la renovación de la cultura política y la definición de la escuela como una institución social. No obstante, uno de los principales escollos con el que se encontraban estas propuestas burocráticas es que, en muchas ocasiones, estaban lejos de los planteamientos empíricos de la práctica escolar. Las reformas impulsadas en España a lo largo de los últimos años han traído consigo unos aires renovadores que no han tenido en cuenta los hábitos profesionales de los docentes que, al fin y al cabo, son los encargados de aplicar dichas reformas (Escolano, 2002).

\subsection{3) Modelo de regulación}

3.1.3.1) Conceptualización de modelo de regulación y formas de
descentralización

Antes de comenzar a analizar y describir el modelo de regulación español, nos gustaría realizar algunas consideraciones previas que creemos son de suma relevancia y que, además, nos facilitarán la comprensión, no solo del modelo de regulación español, sino también del francés y el finlandés, que serán abordados a lo largo de nuestro trabajo.

De una forma muy genérica, podemos mencionar dos modelos básicos: el centralizado y el descentralizado. Los sistemas centralizados son aquellos en los que las responsabilidades y el poder de la toma de decisiones reside en la autoridad superior, determinando desde arriba hacia abajo, lo que puede (o no) hacerse. 
Mientras que los sistemas descentralizados, son aquellos que transfieren las responsabilidades y poderes hacia agentes intermedios (Gimeno, 2005). Estos sistemas parten de estructuras administrativas inicialmente centralizadas pero que, con el paso del tiempo, se han ido descentralizando en mayor o menor medida (García Garrido, 2005).

Pero, además de estos, podemos hablar de otros grados de organización educativa. Atendiendo a los criterios «¿Quién tiene el poder?» y «¿Sobre qué materias?», diversos autores han desarrollado sus propios enfoques. Green, Leney y Wolf (2001), han establecido cuatro grados de organización educativa: en primer lugar, aquellos sistemas centralizados con elementos de cesión de poder; por otro lado, sistemas regionales, donde las responsabilidades y los poderes descansan en niveles intermedios; en tercer lugar, sistemas de control local dentro de una pequeña estructura de regulación central; y, por último, sistemas de cuasi mercado en educación. Otros autores, como Puelles (1992), han apostado por un enfoque más completo, estableciendo hasta siete grados de organización educativa: el primer de ellos, sería el de los sistemas educativos centralizados; en segundo lugar, estarían los sistemas centralizados que han manifestado una tendencia hacia la descentralización; en tercer lugar, nos encontraríamos con aquellos países que tienen un estado regional $\mathrm{y}$, por tanto, los entes territoriales son constituidos por las regiones; en cuarto lugar, un sistema descentralizado como el que acabamos de mencionar, pero con un menor grado de exigencia; el quinto grado lo desempeñan los sistemas educativos federales; en sexto lugar, aquellos países en los que la descentralización alcanza las corporaciones locales; y finalmente, un séptimo grado, que alcanza los propios centros docentes e incluso las propias aulas.

Para finalizar, debemos tener muy presente que, frente a estos modelos de regulación, también existen unas determinadas formas de descentralización, que veremos ejemplificadas en cada uno de los sistemas analizados. Por un lado, 
encontraríamos la regionalización, que hace referencia a una descentralización política territorial. Como ya indicamos, la descentralización se refiere a aquellas tendencias que parten de una situación previa de centralización, mientras que la regionalización, hace referencia a aquellos sistemas construidos sobre el respeto a la autonomía de los poderes regionales o locales. En segundo lugar, nos encontramos con la desconcentración. Si mediante la descentralización las funciones pasan a ser asumidas por otros órganos de gobierno, en la desconcentración, estas responsabilidades tan solo se promocionan y/o ejecutan, manteniéndose los poderes en los órganos centrales. Por otro lado, debemos aludir a una forma de descentralización con mucha presencia en los países nórdicos, como es la localización, donde las funciones serán asumidas por las entidades locales en un intento de que los servicios educativos sean más innovadores, con un mayor grado de sensibilidad frente a las necesidades locales (García Garrido, 2005). Pero, además, si tenemos en cuenta que la organización educativa alcanza las propias aulas, tal y como manifiesta autores de la talla de Puelles (1992), debemos hacer alusión a una nueva forma de descentralización que está tomando fuerza como es el actor social. Durante los últimos veinte años ha sido evidente, en todos los estados miembros de la UE, la dispersión de algunos poderes y responsabilidades educativas hacia diferentes grupos de interés. La mayoría de los gobiernos han tratado de hacer partícipes a diferentes colectivos sociales: padres, empresarios y otros accionistas interesados en la política educativa. De este modo, se pretende ampliar la representación en la toma de decisiones educativas, haciendo que la educación sea más sensible para los intereses sociales. Por último, no debemos obviar una última forma de descentralización, como es la autonomía escolar, que es la que ha suscitado un mayor apoyo a lo largo de los últimos años. Los ambientes escolares donde los profesores y líderes de la escuela gozan de una mayor autonomía, son los más favorables para el aprendizaje. Son muchos los autores que defienden la autonomía escolar como la solución frente al 
control escolar burocratizado que ahoga la iniciativa y reduce los incentivos (Green et al., 2001).

\subsubsection{2) El sistema educativo español descentralizado /regionalizado}

Si atendemos a la clasificación mencionada, unas líneas más arriba, España se encontraría en el cuarto grado de organización, un sistema descentralizado, donde "las competencias que la Constitución, los Estatutos de Autonomía y las leyes orgánicas de educación asignan al Estado como conjunto de instituciones centrales o generales son importantes desde el punto de vista del poder de decisión" (Puelles, 2002: 163). Si bien, tal y como aludimos en el epígrafe de este subapartado, el modo de regulación descentralizado se acompaña de la forma de regionalización, ya que son las CC. AA las que disponen de amplias competencias en materia de educación, bajo la supervisión y control por parte de los aparatos del Estado.

La evolución histórica del sistema educativo español ha estado marcada por la inhibición del Estado en materia de educación. El punto de partida de la descentralización educativa se encuentra en la Constitución de 1978, donde se define la nueva organización territorial del Estado, algo que sería de gran relevancia para el reparto de competencias en materia de educación (Bonal, Rambla, Calderón y Pros, 2005). Entrada la democracia (en 1980, para ser más exactos), se aprobará la Ley Orgánica por la que se regulan los Estatutos de los Centros Escolares (LOECE), que asignaba al Estado la orientación general del sistema educativo, otorgando a las CC. AA competencias de desarrollo legislativo y administrativo en materia de educación (Puelles, 2002). Dos años más tarde, con la llegada del PSOE al poder, se pretenden acometer grandes reformas en el plano educativo al objeto de adaptar el sistema a las exigencias constitucionales. En este sentido, dos reformas de sumo interés: las plasmadas en la LODE y en la LOGSE. La LODE (1985) pretendía incrementar las competencias de las CC. AA, mientras que la LOGSE (1990), planteó una reforma 
ambiciosa del sistema educativo en su totalidad. Además, en materia de regulación, esta ley ampliaría las competencias de las CC. AA, correspondiéndoles, desde ese mismo momento, la aplicación efectiva de la reforma educativa (Puelles, 2002).

Para entender cómo se ha ido desarrollando el proceso de descentralización/regionalización en España, debemos tener en cuenta tres ideas preliminares. En primer lugar, que este proceso se ha producido de manera paralela a la democratización. En segundo lugar, que las competencias educativas no fueron delegadas por el poder central, sino en virtud de la CE. Y finalmente, que el proceso de descentralización/regionalización que comenzó con el mandato constitucional no culminó hasta el año 2000, ya que las CC. AA fueron asumiendo competencias a velocidades distintas. En este sentido, podemos distinguir tres etapas en el proceso de transferencia.

\section{Tabla 3. Etapas en el proceso de transferencia de competencias educativas en}

\section{España}

\begin{tabular}{|c|c|c|}
\hline $\begin{array}{c}\text { Primera } \\
\text { etapa } \\
\mathbf{1 9 7 9 - 1 9 8 0 )}\end{array}$ & $\begin{array}{c}\text { Primeros } \\
\text { traspasos }\end{array}$ & Cataluña y País Vasco \\
\hline $\begin{array}{c}\text { Segunda } \\
\text { etapa } \\
\mathbf{( 1 9 8 1 - 1 9 9 2 )}\end{array}$ & $\begin{array}{c}\text { Comunidades de } \\
\text { vía rápida }\end{array}$ & Andalucía, Canarias, Comunidad Valenciana, Galicia y \\
Navarra
\end{tabular}

Fuente: BONAL et al., (2005)

En primer lugar, en 1980, momento en el que País Vasco y Cataluña reciben plenas competencias, fruto de los proyectos de autonomía que habían refrendado en el pasado. Posteriormente, una segunda etapa, tras la firma de los pactos autonómicos de 1981, donde Galicia y Andalucía (1982), Canarias y Comunidad Valenciana (1983) 
y, finalmente, Navarra (1990), recibirán plenas competencias. Y, por último, una última etapa, que fue la vía más lenta, es en la que el resto de CC. AA, a excepción de Ceuta y Melilla, acceden a las competencias educativas, ya entrada la última década del pasado siglo (Bonal et al., 2005).

En lo que a nosotros nos atañe, este sistema descentralizado también se ve reflejado en los procesos de transición que aquí analizamos, ya que la competencia de acceso recae tanto en la administración central como en la administración autonómica que, a través de sus propios órganos, pueden dictar, dentro de sus competencias, las indicaciones para la aplicación de la normativa establecida para todo el Estado (Muñoz-Repiso et al., 1997). No obstante, veremos cómo esta situación no es la más común, ya que en el resto de los sistemas educativos que analizamos en nuestro trabajo, la competencia de acceso está mucho más definida.

\subsection{4) Organización y funcionamiento del sistema educativo}

Otro de los factores que nos gustaría analizar en el apartado contextual es la propia organización del sistema educativo. En este sentido, creemos que es importante comenzar analizando la legislación vigente que regula nuestro sistema educativo, que es, sin duda, una de las más comprometidas y que ha suscitado mayor polémica en la era moderna. Por otro lado, también haremos alusión a la estructura del sistema educativo. Además, también valoraremos otros aspectos de interés, como el periodo de escolarización, las tasas de abandono escolar temprano, la titularidad de los centros educativos, etc. De este modo, queremos hacer alusión a todos aquellos aspectos que creemos puedan ser relevantes en la configuración de los sistemas educativos analizados. 


\subsubsection{1) Política educativa}

En nuestro país, toda propuesta educativa debe desarrollarse a partir de dos escenarios: a nivel europeo, siguiendo las directrices y estrategias fijadas desde la U.E; y a nivel nacional, mediante los Programas Nacionales de Reformas, que establecen, anualmente, una serie de objetivos que deben alcanzarse a corto o medio plazo.

En España, la educación ha experimentado una gran evolución a lo largo de las últimas décadas, coincidiendo con la llegada de la democracia (Gimeno, 2014). Sin embargo, aún quedan varios retos pendientes, que debemos mejorar en las próximas fechas. Uno de ellos, es el de lograr el éxito académico de todos los alumnos en la etapa obligatoria (Díez, 2014). En este sentido, debemos reconocer que este es uno de los grandes objetivos que se marca la LOMCE:

Los principales objetivos que persigue la reforma son reducir la tasa de abandono temprano de la educación, mejorar los resultados educativos de acuerdo con criterios internacionales (...), mejorar la empleabilidad, y estimular el espíritu emprendedor de los estudiantes. Los principios sobre los cuales pivota la reforma son, fundamentalmente, el aumento de la autonomía de centros, el refuerzo de la capacidad de gestión de la dirección de los centros, las evaluaciones externas de fin de etapa, la racionalización de la oferta educativa y la flexibilización de las trayectorias (Ley Orgánica 8/2013, de 9 de diciembre, para la Mejora de la Calidad Educativa, p. 97862).

Para lograr estos objetivos, la nueva propuesta educativa ha puesto en marcha numerosas medidas que, si bien es cierto, no han contado con el consenso de ciertos sectores de la sociedad. En primer lugar, pretende llevar a cabo una recentralización del sistema educativo, principalmente, a través de las evaluaciones externas y del incremento de las materias troncales en el currículum. Estas evaluaciones -dos de ámbito nacional y otra de ámbito autonómico- tienen como objetivo mejorar la calidad del sistema educativo, así como posicionar a España en los puestos nobles de las evaluaciones internacionales (Viñao, 2016). Quienes apuestan por estas pruebas 
defienden que son un instrumento manejable y económico que, además, permite conocer las fortalezas y debilidades del sistema educativo de una forma sencilla (Pérez Gómez, 2014). La libertad de elección de centro por parte de los padres es otras de las medidas que ha generado cierta controversia en nuestra sociedad. Se pretende atender la demanda social de los padres, dejando que sean ellos mismos los que elijan el tipo de educación que quieren para sus hijos, atendiendo a sus convicciones, creencias y preferencias (Viñao, 2016). Aunque, sin duda, la nueva propuesta de acceso hacia los estudios universitarios ha sido la gran protagonista de este último texto legislativo. No podemos obviar que en ella se encuentran muchas de las motivaciones que nos han llevado a la investigación que aquí mostramos, ya que tras casi medio siglo, el sistema educativo español apuesta por dar un giro en sus políticas de acceso hacia el sistema universitario. Cierto es que, tal y como venimos comentando, muchos sectores de nuestra sociedad se han posicionado en contra de esta ley, alegando que vulnera dos principios básicos, como son el derecho a la educación y la igualdad de oportunidades. Pero igual de cierto es que, a lo largo de los últimos años, numerosos países del ámbito internacional ya han puesto en marcha medidas similares, cosechando grandes éxitos. La nueva normativa para el acceso pretende llevar a cabo tres reformas de suma importancia. En primer lugar, propone eliminar la Prueba de Acceso a la Universidad (PAU). Por otro lado, pretende restablecer la reválida, que se trata de una prueba que se realizará en los propios centros de educación secundaria y que deberá ser superada por todos los alumnos como requisito indispensable para obtener el título de bachiller. Por último, la ley pretende dotar con una mayor autonomía a las universidades, permitiendo que sean ellas mismas las encargadas de seleccionar a sus alumnos mediante una serie exámenes de ingreso, que les permitan comprobar que los candidatos están en disposición de las competencias necesarias para cursar, de forma exitosa, los estudios elegidos (Revesado, 2018).

Si bien, debemos tener presente que la LOMCE, pese a que debía haber sido instaurada a partir el curso académico 2017-2018, nunca llego a consolidarse de forma 
plena, ya que muchas de sus medidas fueron suspendiéndose de forma momentánea, entre ellas, la nueva propuesta de acceso a la que aquí hacemos alusión. Y es que debemos tener presente que, en la actualidad, estamos inmersos en un momento de gran inestabilidad política en nuestro país que afecta, en gran medida, a la puesta en marcha de reformas educativas estables. Después de que los populares perdieran el poder en el año 2018, se han llevado a cabo varias modificaciones en materia de educación. La última, a comienzos del año 2020, bajo el nombre de LOMLOE (Ley Orgánica por la que se Modifica la Ley Orgánica de Educación). Esta propuesta, será llevada al Congreso de los Diputados por parte del gobierno socialista, y será sometida a votación. Si recibe el apoyo parlamentario (recordemos que la irrupción de distintas fuerzas políticas a lo largo de los últimos años ha creado un nuevo escenario de gran ambigüedad política), pondrá fin a la LOMCE. Entre las propuestas socialistas se encuentran: eliminar las distintas vías en la educación secundaria obligatoria, garantizar una calificación única para el final de la ESO, aumentar la flexibilidad, especialmente, en la etapa de educación secundaria superior, restaurar la participación de toda la comunidad educativa en la planificación y gestión de las instituciones educativas, puesta en marcha de evaluaciones de diagnóstico para la mejora de la calidad y cohesión del sistema educativo, etc. Por tanto, nos encontramos ante un momento de gran inestabilidad política, lo cual frena muchas de las aspiraciones educativas planteadas por el gobierno de turno, debido a la falta de acuerdos parlamentarios.

En definitiva, estamos ante una de las reformas más polémicas que se recuerdan en la era democrática, donde sus opositores critican, fundamentalmente, su férrea apuesta por la privatización de la educación, el fomento de la competitividad y el mercantilismo en el seno de las instituciones educativas (Díez, 2014; Gimeno, 2014; Pérez Gómez, 2014; Viñao, 2016). 


\subsubsection{2) Escolarización}

El artículo 27 de la CE establece, dentro de los derechos fundamentales y libertades públicas, el derecho a la educación. Si bien, para garantizar este derecho en toda su extensión, es necesaria una adecuada oferta de puestos escolares gratuitos en todas las etapas educativas básicas, así como en el segundo ciclo de educación infantil -si bien es cierto que esta etapa carece de obligatoriedad- (Álvarez Guisasola, 2006). De este modo, estamos en disposición de afirmar que la escolarización en nuestro país se rige a través de dos principios básicos, como son la obligatoriedad y la consiguiente gratuidad. Y es que la educación es considerada un bien tan preciado, que su ordenamiento se establece como obligatorio (Redondo, 2006), siendo, no solamente un derecho, sino también un deber que tienen todos y cada uno de los ciudadanos cuyas edades se encuentren comprendidas entre los 6 y los 16 años.

A raíz de lo expuesto, es fundamental que la oferta educativa sea capaz de cubrir la totalidad de la demanda. En aquellos casos en los que la demanda desborde a la oferta, debe establecerse una selección de los candidatos, que respeten los derechos establecidos por la CE. Así pues, debemos añadir un tercer principio, que se une a los anteriormente citados (obligatoriedad y gratuidad), como es la igualdad. En este sentido, le compete al legislador formular aquellos criterios objetivos que permitan ordenar esta demanda educativa, de una forma justa, racional e igualitaria (Fernández-Miranda, 2006). Ahora bien, las administraciones educativas deben realizar el mayor esfuerzo posible por atender a la gran mayoría de peticiones, dado que no se estaría garantizando el derecho a la educación si solo un porcentaje mínimo de familias obtuviese plaza escolar en el centro elegido como opción preferencial (Álvarez Guiasola, 2006; Redondo, 2006).

Los últimos datos facilitados por el Ministerio de Educación y Formación Profesional (2019) muestran cómo, durante el curso académico 2018/2019, un total 
de 8.217.330 alumnos estaban matriculados dentro del sistema educativo no universitario español. Si desglosamos estos datos por etapas, observamos como la de educación primaria es la que cuenta con un mayor número de alumnos (2.938.425), seguida de la de educación secundaria obligatoria (1.975.358), educación infantil (1.747.374), estudios de Formación Profesional (838.764) y, por último, bachillerato (667.426).

Por tanto, a grandes rasgos, podemos afirmar que el sistema educativo español, afín a la tendencia europea, instaura la escolarización obligatoria durante un periodo de diez años (desde los 6 hasta los 16 años), de manera totalmente gratuita, siendo los poderes públicos los encargados de proporcionarla y supervisarla. Del mismo modo, esta escolarización, además de gratuita, debe atender al principio de igualdad.

\subsubsection{3) Abandono escolar temprano}

Otra de las variables que pretendemos analizar en relación al sistema educativo y que guarda una estrecha relación con la escolarización educativa, es el abandono escolar temprano. Eurostat lo define como el porcentaje de jóvenes, con edades comprendidas entre los 18 y los 24 años, que han alcanzado como nivel máximo de estudios la primera etapa de educación secundaria y que, en la actualidad, no están recibiendo ningún tipo de formación.

En España, el abandono prematuro no es cuestión baladí, ya que es una de las principales preocupaciones de la política educativa nacional, constituyendo una de las prioridades de la Estrategia 2020 (Romero y Hernández, 2019). Y es que, nuestro país, históricamente, ha presentado unos datos alarmantes, que lo sitúan a la cola en la U.E. Desde comienzos de siglo hasta el año 2008, España presentó unos datos muy preocupantes -llegando a superar el 32\%-. Sin embargo, el año 2009 sirvió como punto de inflexión, ya que sería a partir de ese momento cuando se comenzaría a 
producir una reducción sistemática en la tasa de abandono (Bayón-Calvo, 2019), hasta situarse en el 17,9\% actual (ver gráfico 2).

\section{Gráfico 2. Evolución (\%) de la tasa de abandono escolar temprano en España durante el s. XXI}

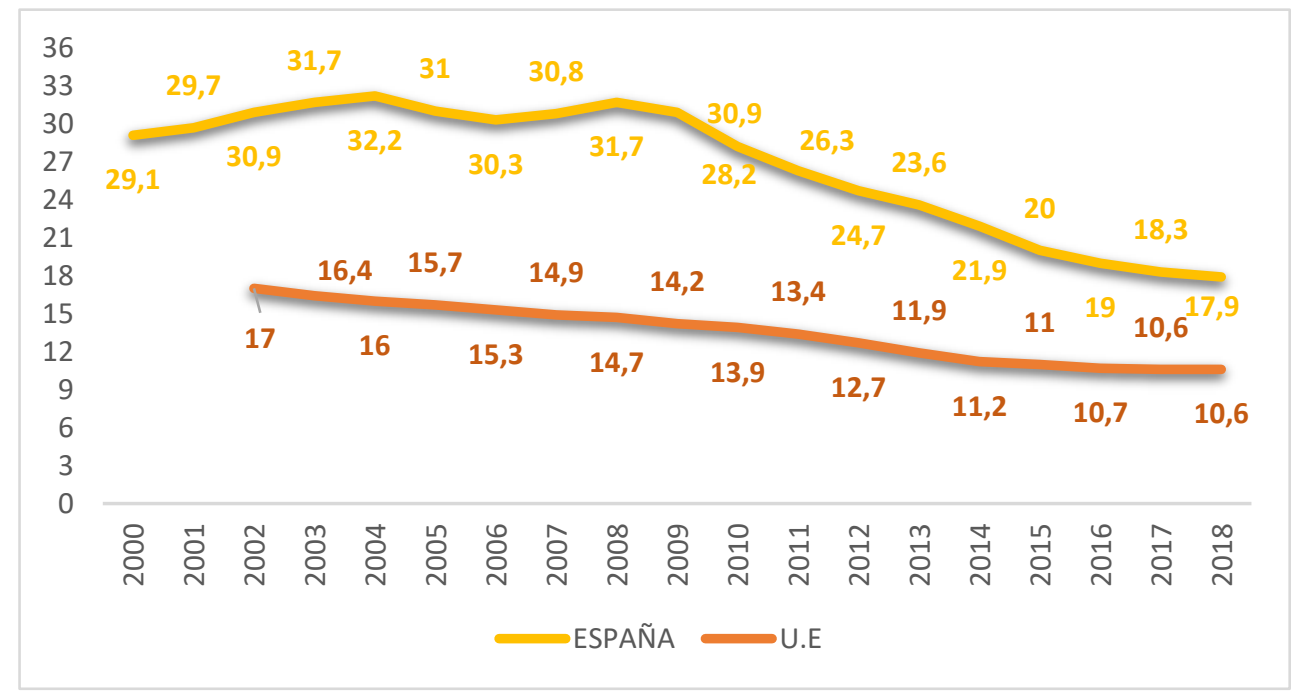

Fuente: Elaboración propia a partir de los datos de Eurostat

Sin embargo, nuestro sistema educativo aún tiene mucho trabajo por delante, ya que estos datos están lejos de alcanzar el objetivo mínimo establecido por la U. E, que es el de reducir la tasa de abandono escolar temprano hasta el 10\%, para el año 2020. Si analizamos este fenómeno desde el punto de vista demográfico, podemos observar cómo la evolución de hombres y mujeres ha sido similar en España. Si bien, diversos estudios ponen de manifiesto cómo el abandono educativo es un problema que afecta con una mayor intensidad a los hombres que a las mujeres (Marks y Fleming, 1999; Casquero y Navarro, 2010; Fernández-Macías, Antón, Braña y Muñoz de Bustillo, 2013).

Por otro lado, si analizamos este fenómeno atendiendo a la edad de los sujetos, podemos afirmar que, a medida que aumenta la edad, también lo hace la tasa de 
abandono. Esta tendencia guarda una cierta lógica, ya que a partir de los 18 años finaliza la educación secundaria postobligatoria (tanto bachillerato como formación profesional de grado medio) y, por consiguiente, hay una mayor fuga de alumnos del sistema educativo formal en busca de nuevas oportunidades laborales (Bayón-Calvo, 2019).

\subsubsection{4) Estructura del sistema educativo}

Respecto a la estructura del sistema educativo español, debemos reconocer que ésta se ha mantenido de forma prácticamente inamovible, durante más de dos décadas, desde la aprobación de la LOGSE, momento en el que se llevó a cabo una reestructuración del sistema educativo, tanto en lo que concierne a sus principios como a su propia estructura (Gráfico 3).

\section{Gráfico 3. Estructura del sistema educativo español}
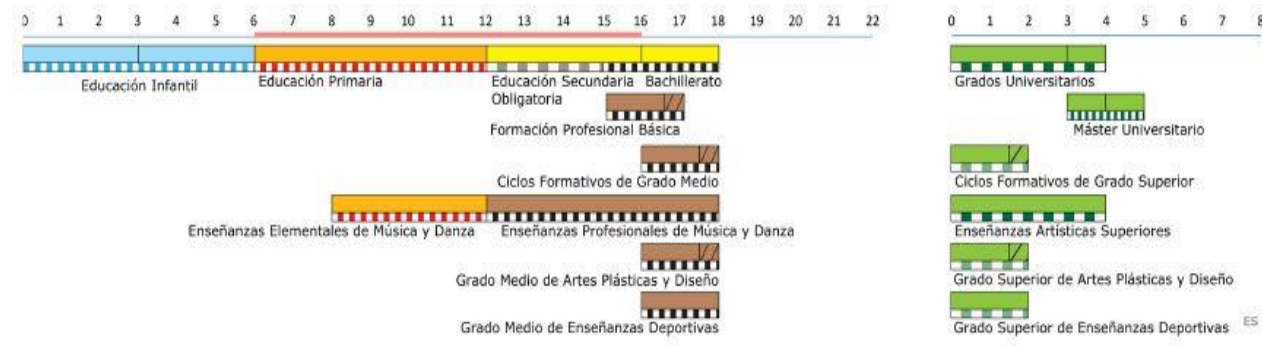

Fuente: Eurydice

De este modo, la composición actual de nuestro sistema educativo estaría conformado por las siguientes etapas: educación infantil, educación primaria, educación secundaria obligatoria, bachillerato, formación profesional, enseñanza de idiomas, enseñanzas artísticas, enseñanzas deportivas, educación de personas adultas y enseñanza universitaria. 
La educación infantil, constituye la etapa educativa que se preocupa de los niños desde su nacimiento hasta el inicio de la escolarización obligatoria (0-6 años). Se configura en torno a dos ciclos, de tres años cada uno de ellos; el segundo de estos ciclos, pese a no tener carácter obligatorio, es financiado con fondos públicos. Esta etapa educativa tiene carácter voluntario, y su finalidad no es otra, que la de contribuir al desarrollo físico, afectivo, social e intelectual de los niños (Bernal, et al., 2014). Las prioridades que ha fijado la administración Educativa en esta etapa escolar de cara al futuro más inmediato se centran en aumento del número de plazas en escuelas públicas para niños menores de 3 años y el establecimiento de un número suficiente de plazas sostenidas con fondos públicos que garanticen un segundo ciclo totalmente gratuito.

La educación primaria, constituye junto a la educación secundaria obligatoria, la enseñanza básica, que comprenderá diez años de escolaridad (6-16 años). Este tipo de educación será de carácter obligatorio y gratuito y se extenderá durante seis cursos académicos, desde los seis hasta los doce años, divididos, a su vez, en tres ciclos, de dos años cada uno de ellos. Su finalidad no es otra que proporcionar a todos los alumnos una educación común que haga posible la adquisición de elementos básicos culturales.

La obligatoriedad educativa continúa con la educación secundaria obligatoria, una etapa cuyo objetivo es, además de la adquisición de una serie de conocimientos básicos a nivel cultural, la preparación de los alumnos para estudios posteriores, así como para su inserción en el mercado laboral (Bernal, et al., 2014). Esta etapa abarca cuatro años, desde los doce hasta los dieciséis. Los primeros tres cursos son comprensivos, mientras que el último es más específico, con dos itinerarios muy diferenciados: por un lado, un itinerario académico, más enfocado hacia los estudios de bachillerato y, por otro lado, un itinerario más vocacional, para iniciar los estudios de formación profesional. 
Mientras que la etapa de bachillerato estará compuesta por dos cursos académicos, que podrán cursarse a través de tres modalidades distintas: ciencias, humanidades y ciencias sociales y finalmente, artes. La evaluación, al igual que durante toda la educación secundaria, será continua y diferenciada según las materias cursadas. Para promocionar de primero a segundo, los alumnos deberán tener, como máximo, dos asignaturas con evaluación negativa, y que estás no sean Lengua Castellana y Literatura y Matemáticas, de forma simultánea. Los alumnos tan solo podrán repetir una vez, cada uno de los cursos de este nivel educativo, si bien, excepcionalmente, podrán repetir en una segunda ocasión, siempre y cuando el equipo docente lo considera oportuno. Para superar esta etapa y, por tanto, obtener el título de bachiller, los alumnos deberán aprobar todas las materias cursadas durante este segundo año académico.

El título de bachillerato habilitará a los alumnos para el acceso hacia la formación terciaria, en donde se encuentran los estudios de formación profesional de grado superior (Bernal, et al., 2014), que conforman, junto a la Formación Profesional Básica y la Formación Profesional Media, el itinerario vocacional de nuestro sistema educativo, con una organización modular, de duración variable. La Formación Profesional Básica, contribuirán a que el alumnado adquiera una serie de competencias relativas al aprendizaje permanente. La formación profesional de grado medio se inserta a continuación de la Enseñanza Secundaria Obligatoria (ESO), que con la nueva propuesta educativa se producirá con un año de antelación, siendo una alternativa a Bachillerato que comprende un conjunto de ciclos formativos de los diversos campos profesionales. Estos ciclos contribuirán, además, a la ampliación de las competencias de la enseñanza básica adaptándolas a un campo o sector profesional, que permita al alumno el aprendizaje a lo largo de la vida. Mientras que los ciclos formativos de grado superior se insertan a continuación del Bachillerato, con el fin de facilitar la incorporación de los jóvenes a la vida activa, así como para 
atender a las demandas de cualificación y formación permanente. En este sentido, debemos de destacar que el título de técnico superior permite que el alumno acceda directamente a la universidad en aquellos estudios relacionados con su formación profesional. (Bernal, et al., 2014).

Por último, encontramos los denominados estudios universitarios, que constituyen junto a las enseñanzas artísticas superiores, la Formación Profesional de grado superior y las enseñanzas deportivas superiores, la denominada educación superior $^{20}$, se regulará a partir de una normativa específica.

\subsubsection{5) Titularidad de los centros educativos}

La escolarización tiene lugar, principalmente, en las instituciones públicas, si bien es cierto que existen países con una consolidada tradición de educación privada. Los defensores de la escuela privada defienden que esta es más rentable y que, además, aumenta la competencia, la responsabilidad y la diversidad pedagógica (Chapman y Salokangas, 2012; Jiménez y Paqueo, 1996). Quienes la critican, ponen de manifiesto los grandes efectos perjudiciales que esta tiene, como, por ejemplo, la segregación y la amenaza a la cohesión social (Elacqua, 2012; Levin, Cornelisz y Hanisch-Cerda, 2013; Renzulli y Evans, 2005; Saporito, 2003). Pero también hay quien defiende una postura intermedia, apostando por una combinación de gestión privada y financiación pública, bajo la premisa de que esta fórmula es la que produce mejores resultados académicos (Angrist, Pathak y Walters, 2013).

A nivel internacional las escuelas públicas son aquellas que están administradas por una autoridad de educación oficial, agencia gubernamental, o junta gobernante designada por un gobierno, cuyo acceso es libre. Todo ello al margen de

\footnotetext{
${ }^{20}$ Las enseñanzas de idiomas tendrán consideración de enseñanzas de régimen especial
} 
la titularidad. Mientras que las escuelas privadas, son aquellas administradas, de forma directa o indirecta, por una organización no gubernamental, como puede ser la Iglesia, los sindicatos, empresas o cualquier otro grupo corporativo o gestor; al margen también de la titularidad. Dependiendo de si reciben o no financiación del gobierno, las escuelas privadas pueden ser consideradas como escuelas independientes del gobierno -cuando al menos el 50\% de su financiación proviene de fuentes privadas- o dependientes del gobierno -cuando al menos el 50\% de su financiación proviene del gobierno- (OECD, 2016). Cuando hablamos de privatización, podemos hacerlo, fundamentalmente, aludiendo a dos formas concretas: privatización exógena y privatización endógena. La primera de ellas, -que también es conocida como privatización visible-, es aquella que se centra, esencialmente, en la financiación de escuelas privadas, la externalización de servicios escolares y la subcontratación de colegios. Mediante este modelo de privatización se produce una apertura de los servicios públicos hacia agentes privados (Puelles, 2005). Mientras que la privatización endógena -también conocida como privatización encubierta-, se centraría en la incorporación de todo tipo de diseños, métodos y prácticas provenientes del sector "empresarial” al ámbito educativo (Ball y Youndel, 2009; Bernal, et al., 2014).

Tal y como podemos apreciar en el gráfico 4, en los países de la OCDE, el $84 \%$ de los estudiantes de 15 años están matriculados en centros de titularidad pública. En cambio, solamente el 16\% asisten a escuelas de titularidad privada, de las cuales un $12 \%$ son dependientes del gobierno y un $4 \%$ independientes del gobierno. $\mathrm{Si}$ analizamos específicamente la situación de nuestro sistema educativo, podemos apreciar cómo el número de alumnos matriculados en centros de titularidad pública es menor que el que presenta la media de la OCDE. Para ser más exactos, España cuenta con un $70 \%$ de alumnos matriculados en centros públicos, unos datos que están lejos de la media de la OCDE. 


\section{Gráfico 4. Porcentaje de alumnos matriculados en centros de titularidad pública (PISA, 2015)}

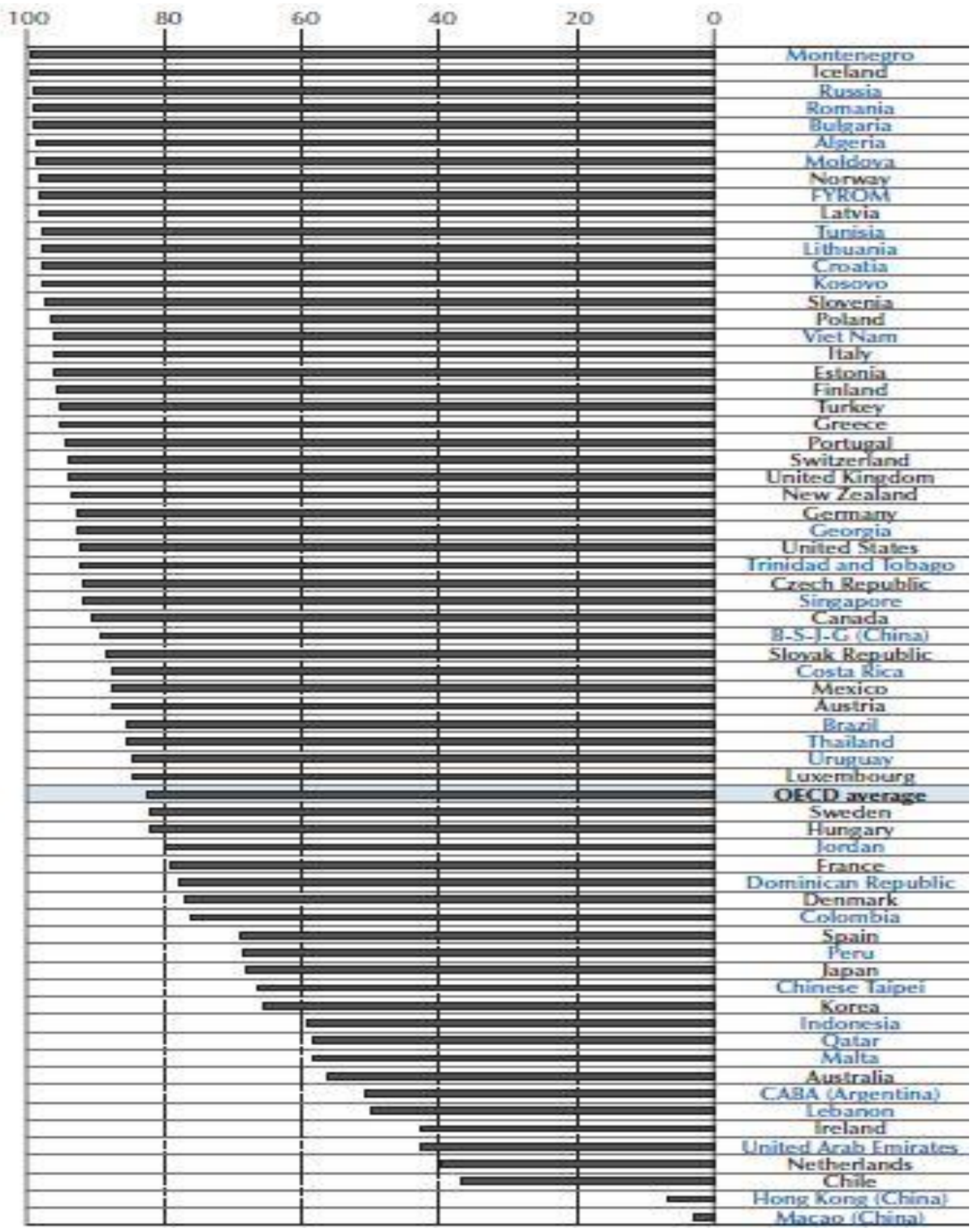

Fuente: OECD (2016: 125) 
Si desglosamos estos datos por regiones, podemos observar cómo la Comunidad Autónoma con mayor porcentaje de alumnos matriculados en centros de titularidad pública es Castilla la Mancha, con un $81 \%$, mientras que en el extremo opuesto encontramos al País Vasco, con tan solo un 53\% de alumnos (MECD, 2016b). En este sentido, varios son los motivos que pueden explicar esta baja tasa de escolarización pública, si bien, nosotros vamos a hacer alusión, principalmente, en uno de ellos, como es la siempre controvertida política de elección de centro docente $^{21}$ (Fernández Soria, 2007), a partir de la cual las familias tienen total libertad para elegir el centro educativo que se adecúe a sus preferencias, gustos o convicciones.

\subsection{5) Eficacia del sistema educativo}

Por último, vamos a analizar la eficacia de los sistemas educativos, entendiendo que esta es determinante a la hora de comprender el correcto funcionamiento del mismo. Consideramos que un sistema educativo es eficaz cuando permite que el mayor número posible de estudiantes sea capaz de asimilar los conocimientos impartidos en los tiempos correspondientes, consiguiendo, a su vez, elevar el nivel de todos sus alumnos y reduciendo al mínimo las diferencias (Urteaga, 2010b).

Para valorar la eficacia de un sistema educativo, podríamos valernos de distintas herramientas, si bien, para nuestro estudio, hemos considerado oportuno examinar las pruebas competenciales de PISA, que han sido llevadas a cabo por la OCDE desde comienzos de siglo, y que, sin duda alguna, se han convertido en uno de los puntos de referencia del contexto educativo a lo largo de los últimos años. Y es

\footnotetext{
${ }^{21}$ Real Decreto 1635/2009, de 30 de octubre. Boletín Oficial del Estado, de 3 de noviembre de 2009, Núm. 265, pp. 91697-91702.
} 
que, en la actualidad, la OCDE se ha convertido en uno de los organismos internacionales más activos, posicionándose como uno de los actores educativos más influyentes (Calero y Choi, 2012; Jakobi y Martens, 2007; King, 2007; Lingard y Rawolle, 2010; Luzón y Torres, 2013).

De este modo, podemos considerar el informe PISA como una herramienta de gran alcance, que la OCDE utiliza para tener un cierto impacto, de forma directa o indirecta, sobre los sistemas educativos de los diferentes países participantes (Bonal y Tarabini, 2013). De hecho, son muchas las investigaciones que se han venido realizando en los últimos años (Dobbins y Martens, 2012; European Commission, 2017C; Fernández - González, 2015; Pedró, 2012; Pongratz, 2013; Tröhler, 2009; Saura y Luengo, 2015), que han puesto de manifiesto la influencia que estas pruebas pueden llegar a ejercer sobre la formulación de políticas educativas, sirviendo, en muchos casos, como evidencia para su justificación:

Estos OI generan en materia educativa lo que se denomina soft policies o políticas blandas que animan, alientan, recomiendan, proponen, sugieren e invitan a reformas a los estados miembros, pero nunca obligan. Sin embargo, la autoridad que ejercen sobre ellos es evidente (Alonso-Sainz y Thoilliez, 2020: 175).

España es, sin duda alguna, uno de los países participantes en donde el informe PISA ha tenido una mayor repercusión social, debido, básicamente, a su organización territorial (Luzón y Torres, 2011). La participación de las CC. AA en PISA se ha ido dando de manera progresiva. Tres fueron las autonomías que participaron en la edición de 2003 (Cataluña, País Vasco y Castilla y León); a ellas, se le sumaron Asturias, Aragón, Galicia, Cantabria, La Rioja, Navarra y Andalucía en el año 2009; y en la actualidad, la participación se ha expandido a todas las CC. AA del territorio español (tan solo España y Canadá pueden presumir de incorporar todas sus regiones en el informe) (Vega, Hernández y García 2016). Esta participación se orienta desde la pretendida legitimación política de los 17 sistemas educativos en los 
que se ha descompuesto el sistema educativo español que, a través de PISA, está siendo jerarquizado (Vega, 2016). Y es que las puntuaciones obtenidas por los estudiantes de las diferentes CC. AA en esta prueba son muy dispares, poniendo de manifiesto la gran brecha académica existente entre dichas regiones. Por poner un ejemplo, si analizamos los últimos datos publicados en el informe del año 2018, podemos observar cómo existen comunidades muy eficaces, como Navarra y Castilla y León, que obtuvieron grandes calificaciones en las pruebas de Matemáticas (503 y 502 puntos) y Ciencias (492 y 501 puntos), y que superaban, holgadamente, tanto la media nacional como la de la OCDE. En cambio, en el extremo opuesto, localizamos otras comunidades, como Ceuta y Melilla, cuyas puntuaciones en Ciencias (415 y 439 puntos) y Matemáticas (411 y 432 puntos) se alejan ostensiblemente, no solo de la gran mayoría de participantes de la OCDE, sino también de la del resto de las regiones de nuestro país.

A continuación, en la tabla 4, podremos analizar las puntuaciones que, históricamente, ha obtenido España en las diferentes áreas de conocimiento evaluadas por esta prueba.

Tabla 4. Puntuaciones obtenidas por los alumnos españoles en las diferentes áreas de conocimiento evaluadas por PISA

\begin{tabular}{|c|c|c|c|}
\hline & Lectura & Matemáticas & Ciencias \\
\hline $\mathbf{2 0 0 0}$ & 493 & 476 & 491 \\
\hline Media OCDE & 500 & 500 & 500 \\
\hline $\mathbf{2 0 0 3}$ & 481 & 485 & 487 \\
\hline Media OCDE & 494 & 500 & 496 \\
\hline $\mathbf{2 0 0 6}$ & 461 & 480 & 488 \\
\hline Media OCDE & 500 & 500 & 500 \\
\hline
\end{tabular}




\begin{tabular}{|c|c|c|c|}
\hline $\mathbf{2 0 0 9}$ & 481 & 483 & 488 \\
\hline Media OCDE & 493 & 496 & 501 \\
\hline $\mathbf{2 0 1 2}$ & 488 & 484 & 496 \\
\hline Media OCDE & 496 & 494 & 501 \\
\hline $\mathbf{2 0 1 5}$ & 496 & 486 & 493 \\
\hline Media OCDE & 493 & 490 & 493 \\
\hline $\mathbf{2 0 1 8}$ & ---22 & 481 & 483 \\
\hline Media OCDE & 487 & 489 & 489 \\
\hline
\end{tabular}

Fuente: Elaboración propia a partir de los datos publicados de http://www.oecd.org/

Tal y como ya hemos comentado al comienzo de nuestro trabajo, el rendimiento del sistema educativo español puede ser considerado como un rendimiento medio, con unas puntuaciones que oscilan en torno a la media de la OCDE, y que se han mantenido en unos parámetros muy estables en todas y cada una de sus ediciones. En este sentido, debemos destacar que el rendimiento dispar de los alumnos españoles, poco o nada tienen que ver con la política educativa de nuestro país, dado que los datos no se han visto modificados con los cambios de gobierno, tanto a nivel nacional como autonómico (Vega, 2016). De este modo estas diferencias de rendimiento podemos achacarlas a otros factores como: características de los alumnos, influencia social o cultural, situación económica del estudiante, etc. (Vega, Hernández y García, 2016). Como podemos apreciar en el gráfico 5, las puntuaciones obtenidas por los estudiantes de nuestro país se han mantenido estables en las tres

\footnotetext{
${ }^{22}$ Los datos relativos a la prueba de lectura en España no han sido recogidos al haberse detectado anomalías en las respuestas de los alumnos.
} 
áreas de conocimiento evaluadas, sin grandes sobresaltos más allá de algún caso excepcional, como la prueba de lectura del año 2006.

\section{Gráfico 5. Evolución de las puntuaciones obtenidas por los estudiantes españoles, en las diferentes áreas de conocimiento evaluadas por PISA}

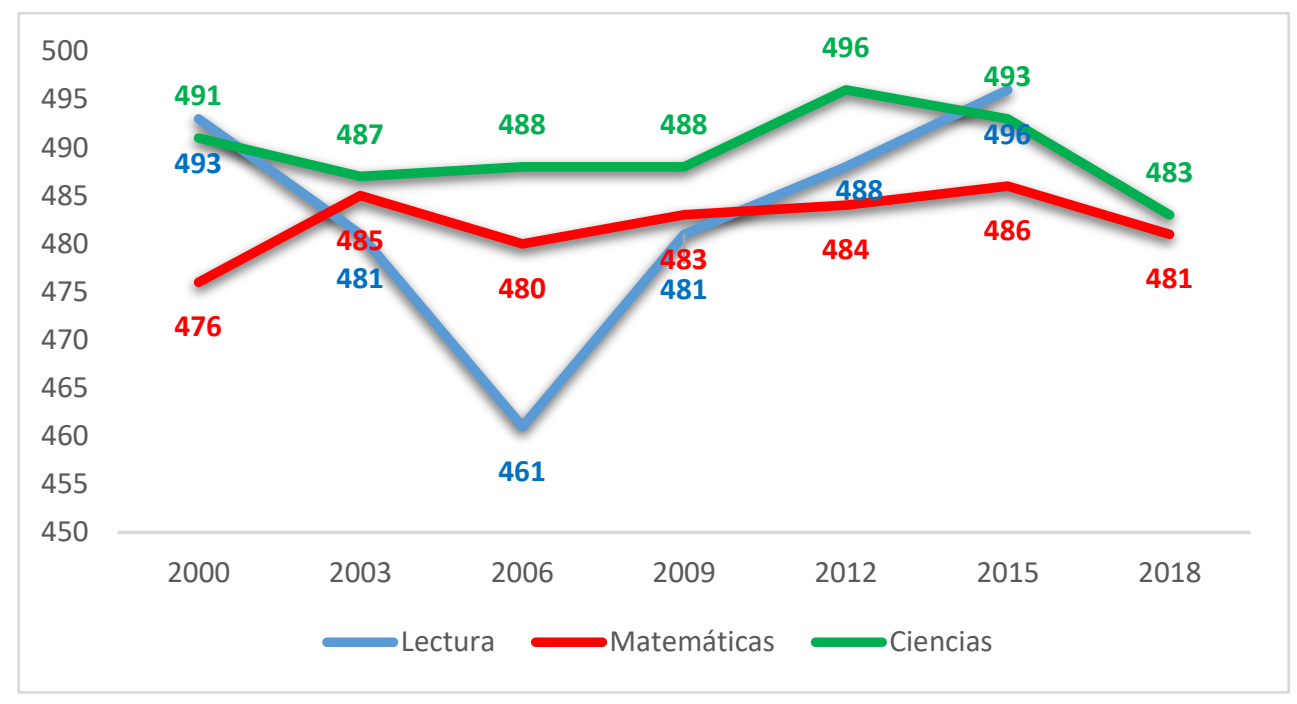

Fuente: Elaboración propia a partir de los datos publicados de http://www.oecd.org/

\section{2) Contexto socio histórico, político y cultural en Francia}

\subsection{1) Cultura histórica del sistema educativo francés}

Para comenzar con el análisis de la cultura histórica del sistema educativo francés, tomaremos como referencia la Revolución francesa de 1789 que, sin duda alguna, supuso un punto de inflexión en la concepción de la educación como un elemento público. A comienzos del siglo XIX, el sistema educativo francés se convertiría en uno de los grandes referentes educativos en el panorama europeo. Un claro ejemplo de esta influencia ejercida por Francia la podemos encontrar en nuestro propio sistema educativo, donde la proximidad geográfica, histórica y cultural, ha generado una gran influencia de la educación francesa en la legislación educativa de 
nuestro país, especialmente, a partir de la Constitución de Cádiz de 1812 (Gavari, 2005a).

3.2.1.1) La Revolución Francesa como punto de partida del sistema educativo público francés

Tras la Revolución francesa, se produce un hecho de gran relevancia en lo que concierne al ámbito educativo como fue la aprobación de la Constitución de 1791, que será determinante para la creación del Ministerio de Instrucción Pública en Francia, durante el primer tercio del siglo XIX (1824). Esta iniciativa, que fue tachada por muchos como revolucionaria, no gozaría del beneplácito de toda la sociedad, que consideraba que una instrucción generalizada era un tanto inútil e incluso podría llegar a ser perjudicial para la sociedad francesa. A partir de ese momento, se produce un cambio de rumbo en la educación gala, donde, por primera vez, se reconoce al Estado la responsabilidad en materia de educación, un principio que ya nunca volvería a ponerse en tela de juicio (Darcos, 2008).

\subsubsection{2) El Imperio Napoleónico: en busca de una educación nacional}

Pese a que, tras la Revolución Francesa, comienza a reconocerse al Estado la responsabilidad que este tiene en materia de educación, no será hasta la llegada del régimen napoleónico cuando se aprobarán las bases definitivas del sistema educativo francés. La llegada al poder del general Napoleón, cuyo gobierno se caracterizó, principalmente, por el predominio absoluto del poder ejecutivo y la centralización estatal, tuvo una fuerte incidencia en el apartado educativo, con unas políticas que serían canalizadas, principalmente, a través de tres leyes, aprobadas en 1802, 1806 y 1808, respectivamente (Gavari, 2005b). Esta etapa será fundamental para el devenir de nuestro trabajo, ya que, bajo el mandato de Napoleón, se crearía el Baccalauréat (1808), también conocido popularmente como Bac, un examen y/o título de enseñanza secundaria, que facultaría para el acceso a los estudios superiores (Gauthier, 2005). 
El Bac, que fue el primer certificado de estudios secundarios en Europa, se ha mantenido con relativa estabilidad a lo largo del s. XIX, tanto en lo que se refiere a su contenido como a su nivel de exigencia (Moreno, 1992).

Tras la derrota de Napoleón en Waterloo, el régimen imperial toco su fin. A partir de este momento, se instaura en Francia una fuerte inestabilidad, tanto en el plano político como institucional. En el periodo comprendido entre los años 1815 y 1870, se sucedieron cinco regímenes distintos: Restauración (1815-1830), Monarquía de Julio (1830-1848), II República (1848-1852), II Imperio (1852-1870) y, finalmente, la III República (1870) (Gavari, 2005b).

\subsubsection{3) Restauración (1814-1830): inicio de la enseñanza primaria}

La Restauración borbónica, vino acompañada de un intento de restauración religiosa y de reconquista de los antiguos privilegios por parte de la Iglesia. A nivel educativo, este periodo destaca, fundamentalmente, por la puesta en marcha de tres medidas de gran relevancia, como fueron: la creación del Ministerio de Instrucción Pública (1824), la voluntad de democratizar la enseñanza a partir de la obligatoriedad educativa y la creación de una escuela primaria en cada comuna. La enseñanza primaria, que fue sacrificada durante el periodo napoleónico en detrimento de los institutos y de la universidad, volverá a tomar fuerza en el país galo con el regreso de la monarquía (Darcos, 2008).

\subsubsection{4) La monarquía de Julio (1830-1848)}

Tras la revolución de 1830, se mantendría una fuerte pugna entre los partidarios de la Iglesia y del Estado. De nuevo, la mayor preocupación de esta época sería la instrucción primaria, debido a la existencia de unos niveles de ignorancia muy agravados en la sociedad francesa. Como consecuencia de ello, se aprobaría la ley 
Guizot $^{23}$ (1833). Esta ley fue redactada de manera que cuidaría minuciosamente los intereses de la Iglesia, asegurando la libertad de instrucción primaria y, por ende, la posibilidad para los católicos de crear escuelas independientes (Cabanel, 2006). Esta época, fue una tregua en la pugna entre Iglesia y Estado, permitiendo que ambos convivieran con una cierta tranquilidad (Weill, 2006).

Esta ley obligaba a todos los municipios de más de 5.000 habitantes a tener, al menos, una escuela elemental, bien fuera por sí mismos, o reuniéndose con uno o varios municipios vecinos; del mismo modo, obligaba a que todas las capitales de provincia y municipios con más de 6.000 habitantes tuvieran una escuela primaria superior. Además, llevaría a cabo una apuesta por la inspección escolar, no solo el estado material de las escuelas, sino también la moralidad del maestro y la calidad pedagógica de los libros y manuales. De este modo, Francia experimentaría una serie de avances de gran consideración (Darcos, 2008) que, si bien es cierto, no traerían consigo una organización educativa (Chapoulie, 2005), ya que el país galo seguiría careciendo de algunos aspectos pedagógicos como correcta agrupación de sus alumnos, distribución eficaz del tiempo escolar, etc.

\subsubsection{5) La II República francesa (1848-1851)}

Tras la revolución de 1848, llegarían al poder los republicanos, que llevarán a cabo distintas reformas encaminadas a la consecución de la secularización y gratuidad de la educación primaria.

Durante los inicios revolucionarios de la II República, se pondrán en marcha diferentes iniciativas educativas. El entonces ministro de Instrucción Pública, Hippolyte Carnot, pone en marcha una serie de medidas que esbozarían las futuras

${ }^{23}$ Loi dite Guizot sur l'instruction primaire. (1833). Loi du 28 juin 1833, dite Guizot sur l'instruction primaire (Publiée dans le Journal Officiel de la République Française du 8 juin 1833). 
leyes promulgadas por el ministro republicano Jules Ferry, tres décadas más tarde: obligatoriedad, gratuidad, y laicidad de la enseñanza. Pero, con la llegada de los conservadores al poder, y el nombramiento de Falloux como nuevo ministro de Instrucción Pública, se produce en Francia una autentica regresión educativa. Falloux, legitimista y clerical, refuerza, en tan solo dos años (1848-1849), la escuela confesional, desarrollando múltiples disposiciones que serían favorables para el clero (Darcos, 2008).

\subsubsection{6) El II Imperio (1852-1870)}

Uno de los aspectos más destacables durante el II Imperio, en clave educativa, fue el cambio de línea pedagógica y política, hasta entonces muy favorable al bando conservador, que comenzará a orientarse hacia el bando republicano, preparando, de este modo, el advenimiento de las leyes Ferry de la década de 80 (Darcos, 2008). Los ministros Fortoul y Duruy, responderían frente a las exigencias de una Francia que, en ese momento, estaba adquiriendo un gran desarrollo en el plano industrial. De este modo Fortoul estableció una enseñanza secundaria superior estructurada en tres ciclos, mientras que Duruy propuso impulsar la enseñanza profesional, estructurándola en cuatro cursos, que se iniciarían a partir de la enseñanza secundaria.

3.2.1.7) III República: las leyes Ferry como punto de partida de la laicidad educativa

En 1870, se produce la derrota del Sedán, y con este acontecimiento, se pone fin al II Imperio. Ese mismo año se proclama la III República Francesa, si bien su creación formal no tendrá lugar hasta 1875 (Gavari, 2005b). Desde que se puso fin al II Imperio, tanto republicanos como demócratas, habían reclamado una instrucción obligatoria y, por consiguiente, gratuita. Además, comenzaba a haber una cierta unanimidad en torno a la laicidad educativa. En lo que atañe a la enseñanza 
secundaria, no se desarrollarían importantes cambios, ya que, en ese momento, no se consideraban prioritarios (Weill, 2006).

Con la llegada del nuevo gobierno, la cartera de Instrucción Pública fue confiada a Jules Ferry, conocido por ser el autor de las leyes educativas más importantes de la historia francesa. Se trata de una figura de reconocido prestigio en el país galo, ya que desempeñó una función política de primer orden, que sería crucial para la consolidación de la III República, ocupando múltiples de cargos políticos, entre los que destacan, el de presidente del Gobierno y candidato a la presidencia de la República (Darcos, 2008).

Sin duda alguna, sería en la enseñanza primaria, donde el gobierno republicano depositaría sus mayores esfuerzos, con el objetivo de poner fin a una de las grandes lacras presentes en la sociedad francesa: el analfabetismo. Pese a las críticas de la Iglesia, Ferry siempre defendió la necesaria gratuidad de la enseñanza primaria, una gratuidad que traería consigo la obligatoriedad educativa (Weill, 2006). Será en este contexto, en el que nacen las leyes Ferry, unas leyes que defienden el marco pedagógico y político de la escuela de la república. La primera de ellas (1881), aboga por la gratuidad de la enseñanza primaria pública; mientras que la segunda (1882), instaura la obligación para niños de entre 6 y 13 años de ir a la escuela y de recibir en ella, una enseñanza laica. De este modo, la escuela dejará de ser confesional e impartir enseñanza religiosa (Darcos, 2008). Además, esta época también viene caracteriza por la puesta en marcha de una serie de reformas en el ámbito de la enseñanza técnica, fruto del importante desarrollo industrial que estaba experimentando Francia en esa época. De este modo, en el año 1880, se crean las escuelas de aprendizaje, que permitieron responder a las necesidades industriales. $\mathrm{La}$ proclamación de la ley Astier (1919) pretende crear, por primera vez, una red de centros en los que se impartiría enseñanza técnica industrial y comercial. Durante tres 
años se podían cursar los estudios y obtener el denominado Certificat d'Aptitude Professionelle (CAP).

En definitiva, podemos afirmar que la política educativa de Jules Ferry trajo consigo uno de los hechos más destacados e influyentes en la historia de la educación en Francia, como fue la organización laica de la escuela, así como la gratuidad y obligatoriedad de la enseñanza. Por el contrario, la parte negativa la encontramos en la lucha constante frente a la Iglesia, y de una forma más específica, contra los jesuitas (Weill, 2006).

\subsubsection{8) Ruptura definitiva entre Iglesia y Estado}

La llegada del nuevo siglo trajo consigo la ruptura definitiva entre Iglesia y Estado. Tras las elecciones de 1902, llegan al poder los radicales, con el apoyo de los socialistas, llevando a cabo una política activa de anticlericalismo. En 1904, rompen las relaciones con la Santa Sede, y poco después, en 1905, se producirá la separación definitiva entre Iglesia y Estado. A lo largo de la siguiente década, se intentará dar un giro radical a esta situación, con la llegada al poder del Bloque Nacional (1919), que buscaba otorgar una mayor influencia de la Iglesia en la enseñanza secundaria. Sin embargo, tanto radicales como socialistas muestran su oposición, impidiendo que estas medidas se pusieran finalmente en marcha (Gavari, 2005b).

\subsubsection{9) Política educativa francesa entre 1943-1958}

Tras la dimisión de De Gaulle como Jefe de Estado, la Asamblea Constituyente aprueba la Constitución de 1946 que guardará grandes similitudes con la aprobada por la III República. La situación educativa francesa presentaba grandes carencias y es por ello por lo que los diferentes gobiernos plantearon numerosas propuestas orientadas a implantar una reforma global del sistema educativo. De entre estas propuestas, vamos a destacar dos de ellas que, sin duda, gozaron de un mayor 
protagonismo. En primer lugar, el Plan Langevin-Walon (1949) que, pese a no llevarse a cabo, fruto de la gran inestabilidad política, fue un punto de referencia en la política educativa francesa; $\mathrm{y}$, en segundo lugar, el proyecto Billères, que destaca por poner en marcha medidas educativas de gran trascendencia, como la ampliación de la escolaridad obligatoria hasta los 16 años o la creación de una escuela media de dos años de carácter comprensivo.

\subsubsection{0) Política educativa francesa entre 1958-1973}

A finales de los años 50, De Gaulle vuelve a Francia, y deposita todos sus esfuerzos en la redacción de una nueva Constitución, que se aprobaría, finalmente, en 1958. De Gaulle, tras convertirse en presidente de la República, lleva a Francia a convertirse en una de las principales potencias industriales de la segunda mitad del s. XX. En lo que concierne al plano educativo, se llevarán a cabo múltiples medidas de interés: ampliación de la obligatoriedad escolar hasta los 16 años (1959) gracias a la reforma Berthoin (Prost, 1995), creación de los Collège, como centros únicos de enseñanza secundaria (1963), redefinición de las ramas de segundo grado y creación de los bachilleratos técnicos (1965), reorganización de los estudios universitarios en 3 ciclos (1966) y reforma de la enseñanza superior (1968) ${ }^{24}$.

Tras las elecciones de 1967 y la confirmación de popularidad del partido golista, se producen múltiples manifestaciones estudiantiles, que traerán consigo una importante crisis social y política en el país galo (Mammarella, 1996). En 1969, De Gaulle somete a referéndum un nuevo texto constitucional. Los resultados de esta consulta no son favorables y, por este motivo, acabará dimitiendo. Su sustituto será Georges Pompidou, que se manifestará como un gran conservador, con una política

\footnotetext{
${ }^{24}$ Loi dite Edgar Faure d'orientation de l'enseignement superieur. (1968). Loi n ${ }^{\circ} 68-978 \mathrm{du} 12$ novembre 1968, dite Edgar Faure d'orientation de l'enseignement superieur. (Publiée dans le Journal Officiel de la République Française du 13 novembre 1968).
} 
educativa que se regirá por el orden, la cultura clásica y la selección (Lelièvre, 2002). Por tanto, la política educativa de Pompidou supuso una importante regresión en la sociedad francesa, que pondrá nuevamente en entredicho la democratización y la unificación educativa.

\subsubsection{1) Política educativa francesa de finales del s. XX}

La política educativa francesa, en este último cuarto del siglo, puede dividirse en dos periodos claramente definidos. El primero de ellos, bajo el mandato del presidente golista, Giscard D'Estaing; y, por otro lado, el que tendría lugar bajo el mandato del dirigente socialista, François Mitterrand.

La Política educativa de Giscard D’Estaing, estuvo marcada por la puesta en marcha de dos reformas. La primera de ellas, la reforma Haby $(1975)^{25}$, que redefinió la estructura del sistema educativo francés. En este sentido, la innovación más importante de esta reforma reside en la educación secundaria, donde se unificarán los Collèges d'Enseignement General (CEG) y de los Collège d'Enseignement Secondaire (CES), bajo la denominación de Collège Unique. Y, en segundo lugar, la ley Guermeur (1977), aprobada por los golistas para dar respuesta al anteproyecto socialista Plan pour l'education ${ }^{26}$, que supondría una confirmación definitiva del reconocimiento del pluralismo escolar en Francia (Gavari, 2005b).

La segunda etapa a la que aludimos comienza en 1981, con la llegada de los socialistas al poder, y a la cabeza, François Mitterrand. El acceso al poder de la

\footnotetext{
${ }^{25}$ Loi relative à l'éducation (Loi Haby). (1975). Loi n ${ }^{\circ} 75-620$ du 11 juillet 1975, relative à l'éducation (Loi Haby). (Publiée dans le Journal Officiel de la République Française du 12 juillet 1975).

${ }^{26}$ El Plan pour l'education (Plan para la educación), redactado por el que, años más tarde sería ministro socialista, Mexandeau, proponía la laicización de la enseñanza y la unificación de del sector público y privado bajo un mismo sistema (Gavari, 2005b).
} 
izquierda parecía una oportunidad inmejorable para impulsar un cambio en la política educativa francesa. Una de las figuras más relevantes durante el mandato de Mitterrand sería el ministro de educación Savary, que durante su corta estancia al frente del gabinete, puso en marcha múltiples disposiciones: reforma administrativa para la transferencia de responsabilidades a los entes locales $(1983)^{27}$, reforma universitaria $(1984)^{28}$, concesión de una mayor autonomía a los collèges y a los lycées, adopción de una política compensatoria que luchara contra el fracaso escolar, etc. En lo que concierne a la educación secundaria, debemos destacar la aparición de los bachilleratos profesionales (1985), que pretenden fomentar la inserción laboral de los jóvenes, y a su vez, favorecer la continuación de los estudios en el ámbito de la educación superior.

\subsubsection{2) La política educativa a principios del siglo XXI}

Con la llegada al poder de Nicolás Sarkozy, se aprobará una de las leyes con mayor relevancia de este inicio de siglo, como es la Loi d'Orientation et de programme pour l'avenir de l'ecole ${ }^{29}$ (2005). Esta ley, que renovó el sistema educativo en función de objetivos formulados en la declaración final del Consejo Europeo de Lisboa (2000), pretende garantizar la igualdad de oportunidades, consiguiendo que todos sus alumnos concluyan exitosamente sus estudios. Para ello,

\footnotetext{
${ }^{27}$ Loi relative à la répartition de compétences entre les communes, les départements, les régions et l'Etat. (1983). Loi n 83-8 du 7 janvier 1983, relative à la répartition de compétences entre les communes, les départements, les régions et l'Etat. (Publiée dans le Journal Officiel de la République Française du 9 janvier 1983).
}

${ }^{28}$ Loi dite Savary sur l'enseignement superieur. (1984). Loi n ${ }^{\circ} 84-52$ du 26 janvier 1984, dite Savary sur l'enseignement superieur. (Publiée dans le Journal Officiel de la République Française du 27 janvier 1984).

${ }^{29}$ Loi d'Orientation et de programme pour l'avenir de l'école. (2005). Loi n 2005-380 du 23 avril 2005, d'Orientation et de programme pour l'avenir de l'école. (Publiée dans le Journal Officiel de la République Française du 24 avril 2005). 
se fija el objetivo de que, al menos el $80 \%$ de los alumnos que se encuentren en edad de cursar estudios de bachillerato y el 50\% de alumnos que estén en edad de conseguir un título de educación superior, lo hagan de forma exitosa (Maillet, 2007).

Más tarde, con la llegada de los socialistas al poder (2013) y François Hollande al frente del gobierno, se aprobará la ley de orientación y programación para la refundación de la escuela de la República ${ }^{30}$, que pretendía reafirmar las cifras marcadas por la ley de 2005, y que, hasta la fecha, no se habían conseguido (Auduc, 2013).

En lo que respecta a la educación superior, en el año 2007 se aprobó la Loi relative aux libertés et responsabilités des universités ${ }^{31}$ (LRU), a partir de la cual, las universidades adquieren nuevas habilidades y responsabilidades, además de reforzar su autonomía presupuestaria. Esta ley, será modificada unos años más tarde, en 2013, por la Loi relative à l'enseignement supérieur et à la recherche ${ }^{32}$, que pretende conseguir el éxito de los graduados universitarios. Entre las múltiples disposiciones llevadas a cabo se encuentra el desarrollo de un plan para la mejora de la articulación entre educación secundaria y educación superior, facilitando, de este modo, la adaptación de los nuevos estudiantes (Auduc, 2013).

\footnotetext{
${ }^{30}$ Loi d'orientation et de programmation pour la refondation de l'école de la République (2013). Loi $\mathrm{n}^{\circ}$ 2013-595 du 8 juillet 2013, d'orientation et de programmation pour la refondation de l'école de la République. (Publiée dans le Journal Officiel de la République Française du 8 juillet 2013).

${ }^{31}$ Loi relative aux libertés et responsabilités des universités (2007). Loi n 2007-1199 du 10 août 2007, relative aux libertés et responsabilités des universités. (Publiée dans le Journal Officiel de la République Française du 10 août 2007.

${ }^{32}$ Loi relative à l'enseignement supérieur et à la recherche (2013). Loi n 2013-660 du 22 juillet 2013 relative à l'enseignement supérieur et à la recherche. Publiée dans le Journal Officiel de la République Française du 22 juillet 2013).
} 
Actualmente, Emmanuel Macron, líder del partido En Marche!, se encuentra al frente de la presidencia de la República Francesa. El que fuera ministro de economía durante el gobierno de François Hollande, accedió al poder en el año 2017. Pese que aún es pronto para valorar el impacto del nuevo gobierno en materia de educación, lo cierto es que ya ha marcado una serie de pautas a seguir a lo largo de los próximos años que guardan un gran interés: dar prioridad a la educación primaria; dotar de una mayor autonomía a los equipos educativos para la contratación de docentes; limitar a 12 el número de alumnos por maestros en 12.000 aulas de zonas prioritarias; incluir la enseñanza de la religión en las escuelas francesas; modernización del baccalauréat con el objetivo de flexibilizar la transición hacia los estudios de educación superior; dotación de una mayor autonomía de las instituciones universitarias, etc.

\subsection{2) Cultura escolar del sistema educativo francés}

Siguiendo la misma línea de trabajo que hemos realizado en el análisis del sistema educativo español, vamos a desgranar la cultura escolar del país galo en las tres variables de análisis referidas anteriormente: empírica, pedagógica y política (administrativa)

Desde el punto de vista empírico, ponemos de manifiesto dos elementos de gran interés pedagógico en nuestro proceso de investigación. En primer lugar, la singularidad de sus ritmos escolares y, en segundo lugar, la autonomía de sus centros educativos. Sin duda alguna, la peculiaridad de los ritmos escolares del sistema educativo francés es una de las características que mejor lo definen. En este sentido, vamos a detenernos en analizar tanto la duración como la estructura de su jornada escolar. De este modo, encontraremos dos formas básicas de disponer el tiempo: la jornada continua, con una organización de las clases durante la primera mitad del día; y, por otro lado, la jornada partida, con horario de mañana y tarde y un pequeño receso 
entre medias para la comida. En el caso del sistema educativo francés, dispondrá su horario en jornada partida, con una distribución semanal un tanto anómala, donde los miércoles son los días de descanso, mientras que los sábados por la mañana son lectivos. El horario habitual para el comienzo de las clases es entre las 8 y las 9 horas, por la mañana y entre las 13 y las 14 horas, por las tardes (Lázaro, 2007). De esta manera, los estudiantes franceses cuentan con la jornada escolar más larga en el contexto europeo, aunque también disponen del año académico más corto, con tan solo 162 días lectivos (exceptuando la educación secundaria superior, que cuenta con 180), y un total de 16 semanas de vacaciones lo largo del curso académico (European Commission, 2017b, 2018b; 2019). Las críticas a este modelo organizativo han sido constantes desde diferentes sectores, manifestando la necesidad de reducir las intensas jornadas escolares a las que se ven sometidos los alumnos, aunque para ello sea necesario incrementar el número de días lectivos de su calendario escolar. A lo largo de los últimos años, son muchos los gobiernos que han accedido a realizar pequeñas modificaciones en los ritmos escolares, si bien, éstas no han llegado a concretarse para evitar que se realizaran alteraciones sobre los periodos vacacionales; y es que, tanto los sindicatos de profesores como la industria del ocio y tiempo libre (hostelería, transporte, etc.), se oponen a una reducción de estos períodos, salvaguardando sus propios intereses (Lázaro, 2007). Y, en segundo lugar, debemos hacer mención a la autonomía escolar de los centros educativos franceses. Históricamente, Francia no ha dispuesto de una amplia autonomía en materia de educación, pero con el paso de los años la ha ido adquiriendo, reforzando las medidas introducidas en los años ochenta del pasado siglo. En este sentido, es curioso apreciar cómo en un país tan sumamente centralizado - algo que analizaremos con un mayor detenimiento a continuación-, los centros educativos gozan de una amplia autonomía, que se ve reflejada en la utilización de fondos públicos, en la búsqueda de financiación privada, en la toma de decisiones, tanto curriculares como institucionales :contratación de personal para el 
centro, establecimiento de horarios lectivos, elección del ritmo escolar, componentes curriculares, etc. (European Commission, 2008a).

Pero, además de estas realidades educativas que acabamos de mostrar, existen grandes proyectos académicos dibujados por muchos de los pensadores franceses, que materializan lo que hemos denominado como cultura pedagógica. No debemos obviar que el país galo ha sido uno de los grandes referentes educativos del contexto internacional, ejerciendo una fuerte influencia sobre distintos sistemas europeos a lo largo de su historia (Puelles, 2011). En este sentido son muchos los participantes, gobernantes, políticos, educadores, etc. que han tenido una cierta incidencia en la historia educativa francesa, como los ilustrados Voltaire, Diderot, Rousseau, D’Alembert, La Chalotais, Condorcet, Le Peletier, Lakanal, etc. Si utilizamos el término iconización acuñado por Frijhoff (2011), son varias las figuras históricas que se han convertido en iconos en la historia educativa de Francia, como San Juan Bautista de la Salle en la educación popular; Rousseau en la educación natural, el abad Grégoire en la educación igualitaria, Robespierre en el rigor cívico, Condorcet en la apuesta por una instrucción del pueblo bien regulada, Guizot en la apuesta por una la libertad de enseñanza, Jules Ferry por la laicidad, etc. Y como ellos, otros muchos pensadores más, que han ayudado a impulsar la educación francesa a lo largo de su historia.

Por último, analizaremos lo que anteriormente hemos denominado como cultura política (la administración). Desde tiempos de la revolución, Francia ha realizado serios esfuerzos educativos. Las reformas iniciadas por Condorcet en sus Mémoires sur l'instruction publique (1791), a las que le siguieron otras muchas (Lakanal, Le Peletier, Daounou, etc.), tenían como objetivo primordial refundar la instrucción pública del país galo. El lamentable estado de la educación primaria fue lo que motivo el enorme esfuerzo legislativo, institucional y didáctico de la Revolución. También fue modernizada la educación secundaria, especialmente, a 
partir de 1795, tras la supresión de todos los colegios, que serían sustituidos por una red sistémica de escuelas centrales que ofrecerían un currículum mucho más moderno. Con la creación de los liceos (1802), se pretendía garantizar un mayor y mejor acceso a la educación superior. Pero sin duda alguna, donde Francia fue un referente para Europa, es en lo que respecta al contexto universitario. La supresión de las antiguas universidades (1793) provocó un saneamiento del sistema universitario francés que, en esa época, era anticuado y poseía una estructura poco adaptada a al mundo moderno (Frijhoff, 2011).

\subsection{3) Modelo de regulación}

Si aludimos, nuevamente, a la clasificación realizada en el apartado anterior «Conceptualización de modelo de regulación y formas de descentralización», podemos afirmar que Francia se encuentra dentro de un modelo de organización centralizado que, si bien es cierto, poco a poco viene manifestando una cierta tendencia hacia la descentralización, mediante un proceso de desconcentración (Green et al., 2001; Puelles, 1992). Este proceso, se viene acometiendo con la voluntad de modernizar el aparato de gestión de los asuntos públicos (Gauthier, 2005). Francia es, sin duda alguna, el modelo más claro de centralización educativa en un país de régimen democrático, teniendo un sistema tan centralizado, que incluso a muchos sorprende que pueda ser compatible con una democracia verdadera (García Garrido, 2005). Si bien, como ya hemos comentado en el apartado anterior, disfruta de una gran autonomía escolar, lo cual es un tanto paradójico, dado el marcado centralismo que predomina en el país galo

Desde tiempos de la Revolución, Francia se halla dividida en departamentos, a cuyo frente se encuentra un Prefecto, delegado del gobierno francés. En lo que se refiere al ámbito educativo, las unidades en las que se divide son las Académies, que serán el primer enlace con la administración central. Actualmente existen un total de 
30, que están dirigidas por un Rector que, previamente, ha sido nombrado por el Consejo de Ministros. Estamos, por tanto, ante un esquema administrativo vertical, en cuya cúspide se encuentra el gobierno central, a través del Ministère de Éducation Nationale et de la Jeunesse, y en donde la base la forman los distintos centros educativos, cada uno ellos, con su propia administración. Al frente de estos centros, se encuentra un director (o principaux si hablamos de los lycées), que están en disposición de una amplia formación pedagógica (Bourdin, 1981; Gauthier, 2005).

El agobiante centralismo y la marcada burocracia francesa, ha generado numerosas críticas a su sistema, que han desembocado en modificaciones, de mayor o menor envergadura, a lo largo de las últimas décadas. Algunas de las más importantes fueron la constitución de unidades administrativas con mayores facultades de decisión en el Ministère de Éducation Nationale et de la Jeunesse, el refuerzo de la autonomía de las Universidades y la concesión de mayores atribuciones a los Rectores de las Académies. De este modo, Francia ha experimentado una fuerte desconcentración funcional y burocrática (García Garrido, 2005). Hablamos de desconcentración, y no de descentralización, ya que las decisiones básicas, tanto de carácter normativo como ejecutivo, continúan en manos de la administración central, si bien, el Estado se encarga de transferir la gestión escolar hacia las colectividades locales, conservando amplias competencias en materia pedagógica y de planificación (Gauthier, 2005; Gavari, 2005a).

Por tanto, podemos afirmar, que la administración educativa francesa sigue siendo una administración básicamente centralizada, en donde se van abriendo, muy lentamente, tendencias descentralizadas, esgrimidas por personas, entidades y áreas de población que, en muchas ocasiones, se sienten discriminadas por el centralismo francés (García Garrido, 2005). 


\subsection{4) Organización y funcionamiento del sistema educativo}

\subsubsection{1) Política educativa}

La política educativa francesa está a cargo del Ministère de Éducation Nationale et de la Jeunesse que, a su vez, está asistido por un Secretario de Estado responsable del área de Educación Superior e Investigación. Los departamentos de la administración central son los encargados de preparar y dar forma a las disposiciones legislativas que el ministerio desea implementar. Una vez se han redactado los planes de reforma, estas deben de ser evaluadas por el Conseil Supérieur de l'Éducation o, en el caso de la educación superior, al Conseil National de l'Enseignement Supérieur et de la Recherche.

En la actualidad, la política educativa francesa ha dado un pequeño giro tras la llegada al poder de Emmanuel Macron, en el año 2017. En tan corto periodo de tiempo, el nuevo presidente francés, no ha podido llevar a cabo modificaciones de gran envergadura en materia de educación. Sin embargo, ya ha puesto en marcha algunas medidas que son sumamente interesantes y que vamos a tratar de analizar. En primer lugar, pondremos nuestro foco de atención en una propuesta que ya hemos referido en nuestro trabajo, como son los ritmos y el calendario escolares; es decir, el tiempo escolar. Nuevamente, el sistema educativo francés ha regresado a la semana de 4 días y medio (con veinticuatro horas de clase por semana y dos horas de ayuda personalizada). Esta reforma tiene como objetivo prioritario aligerar los días para así conseguir una mejor distribución del tiempo y reducir de forma significativa la repetición del alumno. Sin embargo, esta modificación no afectará a la duración del año escolar, que permanecerá estable, en treinta y seis semanas lectivas.

Por otro lado, se pretende ampliar la cobertura escolar para niños menores de 3 años. Tal y como recoge la ley en su anexo, la escolarización temprana de los niños menores de 3 años es una palanca esencial para el éxito académico de los alumnos de 
entornos desfavorecidos. Además, mediante esta propuesta, se pretende iniciar a los niños en la vida común, así como facilitar la conciliación familiar de los padres y madres.

En lo que concierne a la transición desde la educación secundaria hasta la universidad, que es el eje temático de nuestro trabajo, no podemos obviar una de las grandes propuestas del gobierno francés en el presente más inmediato, como es el Baccalauréat 2021: un tremplin pour la réussite (coloquialmente conocida como Bac 2021). Esta reforma, que fue aprobada durante el gobierno de François Hollande, se ha consolidado durante el mandato de Macron. Se trata de una reforma pactada desde el punto de vista social, ya que, además de la administración educativa, en ella también han intervenido diferentes colectivos empresariales, sindicatos, asociaciones de padres, etc. Mediante esta nueva propuesta, se pretende poner fin a la complejidad del Bac, una prueba cada vez más farragosa que, desde hace tiempo, demanda ser simplificada. La nueva propuesta educativa pretende reducir a cuatro el número de pruebas: dos escritas sobre la modalidad cursada por el alumno, una de filosofía y, finalmente, un examen oral. De este modo, Francia se suma a la tendencia europea, en la que numerosos países han pasado a otorgar un mayor peso al proceso educativo de los alumnos durante su estancia en la educación secundaria, a la vez que han reducido la presencia de este tipo de pruebas. Pero, además, también se pretenden llevar a cabo otras modificaciones que favorezcan una mayor interrelación entre educación secundaria y educación superior, como por ejemplo, abrir las especialidades en los Lycées, con el objetivo de que el acceso hacia los centros de educación superior sea más flexible.

Por último, en el ámbito de la educación superior, también se han llevado a cabo algunas propuestas de sumo interés, como el establecimiento de las Écoles Supérieures du Professorat et de l'Éducation (ESPE). Estas instituciones, que desde el curso académico 2019-2020 han sido renombradas como Instituts Nationaux 
Supérieurs du Professorat et de l'Éducation (INSPE), están adscritas a las Universidades y son las encargadas de organizar la formación inicial docente y continua de todos los profesionales de la educación (Alonso-Sainz y Thoillez, 2020).

\subsubsection{2) Escolarización}

La escolarización en el sistema educativo francés guarda muchas similitudes con el panorama que ya hemos analizado en España. No en vano, tanto el sistema educativo español como el francés, siguen la tendencia europea, en donde la escolarización obligatoria da comienzo con la etapa de educación primaria (CINE 1) que, generalmente, se inicia a la edad de 6 años. De este modo, la escolarización en Francia es obligatoria y, por consiguiente, gratuita. Los alumnos tienen, no solo el derecho de escolarizarse dentro del sistema educativo, sino también la obligación. El período de obligatoriedad abarca 10 años de escolarización, entre los 6 y los 16 años y se corresponde con los niveles de educación primaria (CINE 1), educación secundaria inferior (CINE 2) y educación secundaria superior (CINE 3). Se trata de 5 cursos en el école elementaire, 4 en el college y 1 en los lycées (European Commission, 2017a). Al igual que ya ocurría en nuestro sistema educativo también en Francia serán los poderes públicos a quien corresponda garantizar este derecho/deber, cuyo ordenamiento se establece como obligatorio (Redondo, 2006).

Los últimos datos publicados por el Ministère de Éducation Nationale et de la Jeunesse francés a través de su web (relativos al año 2018), muestran cómo un total de 13.055.400 alumnos estaban matriculados en el sistema educativo no universitario francés. Si desglosamos estos datos por etapas, observamos como la educación primaria es la que cuenta con un mayor número de alumnos (4.206.600), seguida de la de educación secundaria obligatoria, llevada a cabo en los collège (3.374.400), educación infantil (2.492.500), estudios de educación secundaria generales y 
tecnológicos (1.621.800) y, finalmente, estudios de educación secundaria profesionales (648.900).

Por tanto, el sistema educativo francés, en consonancia con la tendencia instaurada, de forma mayoritaria, en los países europeos, apuesta por una escolarización obligatoria que abarque diez años, de manera totalmente gratuita, en donde los poderes públicos serán los encargados, no solo de proporcionarla, sino también de supervisarla. Del mismo modo, esta escolarización, además de obligatoria y gratuita, debe desarrollarse atendiendo al principio de igualdad.

\subsubsection{3) Abandono escolar temprano}

Tal y como ocurre en la gran mayoría de sistemas educativos internacionales, Francia se ha comprometido a reducir la tasa de aquellos jóvenes, cuyas edades se encuentran comprendidas entre los 18 y los 24 años, que se encuentran fuera del sistema educativo formal y que, además, no han alcanzado un nivel de estudios superior a la primera etapa de educación secundaria. En la actualidad, el país galo ya ha alcanzado el objetivo establecido por la U.E que, recordemos, era reducir este indicador hasta el 10\% para el año 2020 (el país galo cuenta con un 8,9\% en el año 2018). Y es que, gracias a la contribución de distintos programas educativos, Francia ha conseguido reducir su tasa de abandono escolar, de forma sistemática, durante las últimas dos décadas (ver gráfico 6).

Demográficamente hablando, los jóvenes franceses que tienden a abandonar el sistema educativo son aquellos que presentan mayores dificultades académicas y que, además, provienen de un entorno social humilde. Entre ellos, podemos distinguir tres tipos: jóvenes con un bajo nivel de estudios que han repetido en varias ocasiones; jóvenes con un buen nivel de estudios cuando acceden a la educación secundaria, pero que no han conseguido aprobar el CAP o el Brevet y, finalmente, jóvenes que 
estuvieron matriculados en cursos especializados de secundaria, en la «Sección de Enseñanza General y Profesional Adaptada» (García Hernández 2018).

\section{Gráfico 6. Evolución (\%) de la tasa de abandono escolar temprano en Francia durante el s. XXI}

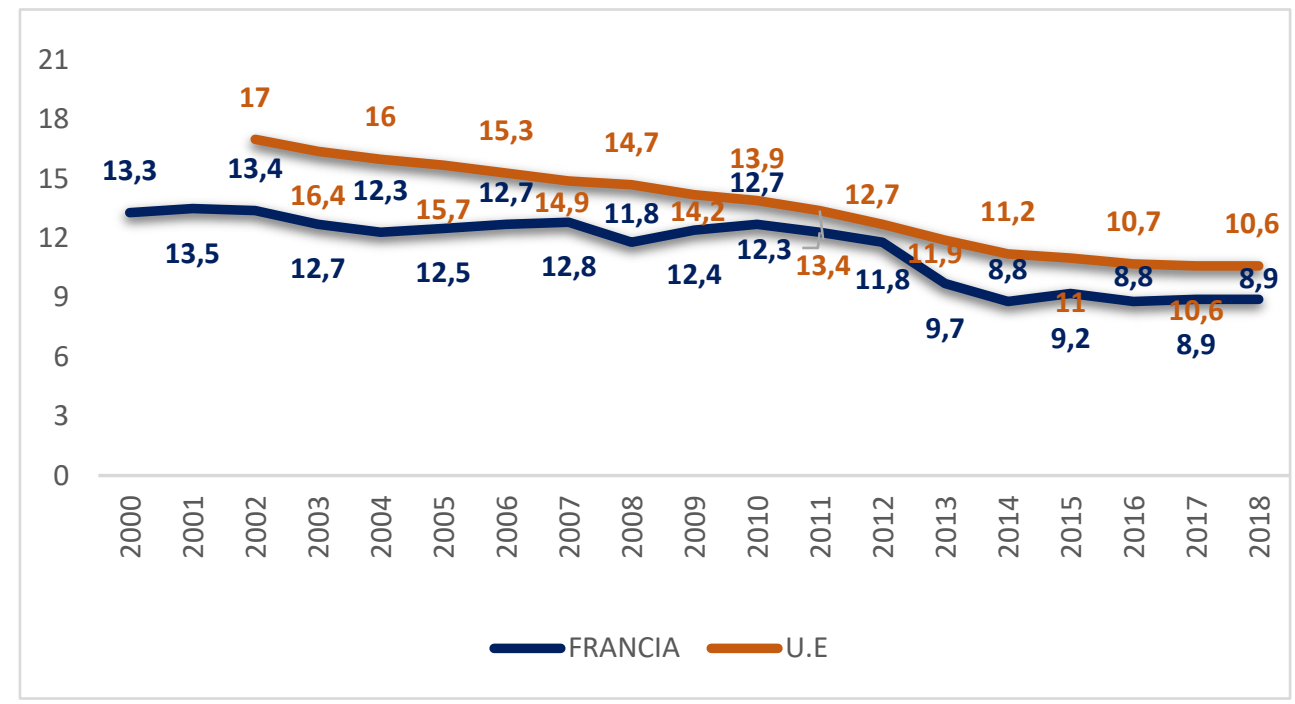

Fuente: Elaboración propia a partir de los datos de Eurostat

3.2.4.4) Estructura del sistema educativo

Como ya hemos comentado, la educación es obligatoria en el sistema educativo francés entre los 6 y los 16 años y estaría conformada por educación infantil o preescolar, educación primaria, educación secundaria inferior. Fuera de la obligatoriedad escolar, encontramos la educación secundaria superior (cuyo primer curso aún es obligatorio) y, finalmente, educación superior.

La educación preescolar, que se imparte en las escuelas maternales (écoles maternelles), hace referencia a la etapa educativa que se encarga de los niños de entre 3 a 6 años (si bien, se permite el acceso un año antes, siempre y cuando exista disponibilidad de plazas). Se trata de una red pública y gratuita, a la que asisten casi 
la totalidad de los niños, pese a tratarse de una etapa opcional. Contribuye a la integración social y cultural de los alumnos, además de desempeñar, para muchas familias, un papel social. Sus programas están supervisados desde la administración central. Si bien, pese a tratarse de una red pública, no cuentan con un presupuesto operativo, siendo los municipios los encargados de proporcionar las propias instalaciones y de sufragar los diferentes gastos ocasionados. Por otro lado, si nos centramos en el análisis del primer ciclo de educación infantil (0-3 años), podemos apreciar como en Francia, no existe una estructura única para estos alumnos, ya que pueden ser recibidos en distintos servicios de atención educativa, ajenos al sistema educativo formal.

Dentro de la educación primaria, encontramos dos ciclos. En primer lugar, la escuela elemental (écoles élémentaires), que escolariza a los alumnos entre los 6 y los 11 años. Marca el comienzo de la escolaridad obligatoria, y se trata de una etapa secular y gratuita. Sus objetivos, contenidos y horarios se definen desde la administración central y son divulgados públicamente. El profesorado de esta etapa se incluye dentro de la categoría de maestros o profesores de las escuelas, perteneciente al cuerpo de funcionarios del Estado. Al finalizar este nivel obligatorio, los alumnos acceden automáticamente al nivel secundario de educación, que se imparte en los collège (11-15 años), y que abarca los cuatro años de la secundaria inferior. Se trata de un nivel educativo que no admite selección, por lo que el acceso está abierto, atendiendo siempre al principio de igualdad. El objetivo que pretende llevar a cabo esta etapa educativa es el de prolongar y completar las adquisiciones básicas. Sus programas vienen determinados por la administración educativa y ponen su foco de atención sobre las disciplinas tradicionales: francés, matemáticas, lenguas vivas, historia, geografía, física y química, ciencias de la vida y de la tierra, artes y educación física (Gauthier, 2005). La superación de este nivel educativo supone la consecución por parte del alumno del Diplôme National du Brevet; sin embargo, la 
admisión al siguiente nivel no está condicionada por este título ya que, al finalizar del college, la escuela hace una serie de recomendaciones, basándose en los informes escolares del alumno y en sus intereses particulares.

La etapa de educación secundaria superior se desarrolla en los lycées, durante un periodo de 3 años, siendo el primero de ellos obligatorio. En este sentido, existen, por un lado, los lycées generales y tecnológicos (que se desarrollan en una misma institución), y por otro, los lycées profesionales. De este modo, la educación secundaria superior ofrece tres trayectorias: general, tecnológica y profesional. La primera de ellas, la general, ofrece tres itinerarios distintos: Literario (L), Económico y Social (ES) y Científico (S). Por otro lado, el Bac tecnológico, ofrece una mayor variabilidad de trayectorias que prepara a los alumnos para los estudios superiores del ámbito tecnológico: Techniques de la Musique et de la Danse (TMD), Sciences et Technologies de l'hôtellerie et de la Restauration (STHR, antiguo Hôtellerie.), Sciences et Technologies du Design et des Arts Appliqués (STD2A), Sciences et Technologies de l'industrie et du Développement Durable (STI2D), Sciences et Technologies de Laboratoire (STL), Sciences et Technologies de la Santé et du Social (ST2S), Sciences et Technologies du Management et de la Gestión (STMG). Por último, encontramos los baccalauréats profesionales, que son unos sesenta en total (los analizaremos más adelante, en el apartado comparativo de nuestro trabajo), y que corresponden a las principales ramas de producción y servicios. El final de la educación secundaria superior es sancionado por el título de baccalauréat, y el acceso a estudios superiores está condicionado a su obtención. Este título, se obtiene tras la superación de un examen, que goza de una enorme repercusión (Gauthier, 2005) en el país. Por otro lado, no nos gustaría dar por finalizado este apartado sin hacer alusión a las clases preparatorias para las Grandes Écoles, que se llevan a cabo durante dos o tres años, una vez finalizada la etapa de educación secundaria, y que tiene como 
objetivo preparar a los alumnos para estos estudios, cuyo acceso estará altamente restringido (Maillet, 2007).

El último eslabón del sistema educativo es la de educación superior, donde encontramos una amplia variedad de estados legales, que se enmarcan dentro del Código de Educación Francés. Pese a la gran heterogeneidad de cursos y desarrollos formativos impartidos en las instituciones de educación superior francesa, la mayoría de ellos están estructurados en tres ciclos: Grado, Máster y Doctorado, a través del sistema de créditos ECTS, tal y como recogen los principios del Espacio Europeo de Educación Superior.

\section{Gráfico 7. Estructura del sistema educativo francés}
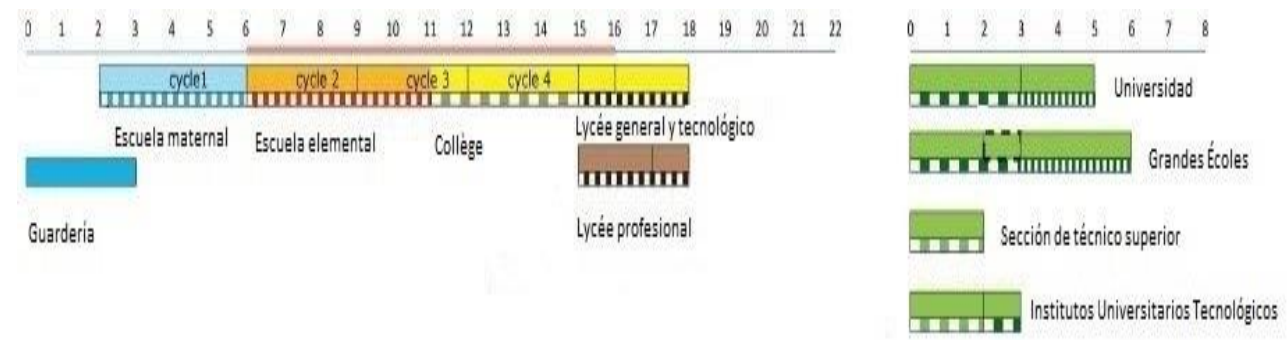

Fuente: Eurydice

\subsubsection{5) Titularidad de los centros educativos}

Si analizamos el contexto francés, en lo que a la titularidad de los centros educativos se refiere, podremos apreciar cómo la situación que presenta guarda ciertas similitudes con la de España, con un porcentaje muy elevado de alumnos adscritos a centros de titularidad pública. Estos datos no son especialmente significativos ya que, tal y como hemos comentado a lo largo de nuestro trabajo, la escolarización obligatoria de los estudiantes en el contexto internacional - también en lo que concierne a la enseñanza secundaria postobligatoria- se da, mayoritariamente, en este tipo de centros. Los datos arrojados por la OECD (2016), así lo demuestran: el 84\% 
de los estudiantes de 15 años están matriculados en centros públicos, mientras que menos de un $12 \%$ asisten a escuelas privadas dependientes del gobierno y tan solo un $4 \%$ asisten a escuelas privadas independientes del gobierno.

En este sentido, Francia, sigue la tónica de la OCDE, con un porcentaje de alumnos matriculados en centros públicos muy superior al de los matriculados en centros privados. Pese a ello, Francia presenta seis puntos menos respecto a la media de la OCDE (Gráfico 4), con un 78\% de alumnos. Si bien, debemos destacar que, pese a que los alumnos del sistema educativo francés están matriculados mayoritariamente en centros de enseñanza pública, lo cierto es que Francia es, junto a España y Bélgica, el país que posee un porcentaje más alto de alumnos matriculados en centros privados dependientes del gobierno. Los motivos que pueden justificar la irrupción de estos centros son muy diversos: proximidad geográfica, disconformidad con el centro público impuesto por el mapa escolar, preferencias sociales, económicas o culturales de los progenitores, etc. (Gauthier, 2005).

\subsection{5) Eficacia del sistema educativo}

En lo que respecta a la eficacia del sistema educativo francés, podemos apreciar coómo Francia obtiene unas puntuaciones que se sitúan ligeramente por encima de la media de la OCDE (ver tabla 5), pero que en ningún caso pueden hacer considerar al sistema francés como un sistema de alto rendimiento. La prueba no goza de una buena prensa en el país galo, dado que existen muchas reticencias, en buena medida, debido a la imagen poco halagüieña del sistema educativo francés y, más concretamente, de sus alumnos. De hecho, en numerosas ocasiones, los responsables del ministerio de educación han manifestado que esta prueba se encuadra dentro de un marco muy restrictivo, donde los criterios evaluados son ajenos a las cualidades del sistema educativo francés, que está organizado sobre la base de la transmisión de 
los conocimientos y en donde la noción de competencia tan solo ha ocupado un espacio mínimo en los estudios de formación profesional (Urteaga, 2010a, 2010b).

\section{Tabla 5. Puntuaciones obtenidas por los alumnos franceses en las diferentes áreas de conocimiento evaluadas por PISA}

\begin{tabular}{|c|c|c|c|}
\hline & Lectura & Matemáticas & Ciencias \\
\hline 2000 & 505 & 517 & 500 \\
\hline Media OCDE & 500 & 500 & 500 \\
\hline $\mathbf{2 0 0 3}$ & 496 & 508 & 511 \\
\hline Media OCDE & 494 & 500 & 496 \\
\hline 2006 & 488 & 496 & 495 \\
\hline Media OCDE & 500 & 500 & 500 \\
\hline $\mathbf{2 0 0 9}$ & 496 & 497 & 498 \\
\hline Media OCDE & 493 & 496 & 501 \\
\hline $\mathbf{2 0 1 2}$ & 505 & 495 & 499 \\
\hline Media OCDE & 496 & 494 & 501 \\
\hline $\mathbf{2 0 1 5}$ & 499 & 493 & 495 \\
\hline Media OCDE & 493 & 490 & 493 \\
\hline $\mathbf{2 0 1 8}$ & 493 & 495 & 493 \\
\hline Media OCDE & 487 & 489 & 489 \\
\hline & & & \\
\hline & & & \\
\hline
\end{tabular}

Fuente: Elaboración propia a partir de los datos obtenidos de http://www.oecd.org/

En líneas generales, podemos apreciar cómo, el sistema educativo francés, se ha estabilizado a lo largo de los últimos años. No obstante, desde que se puso en marcha esta prueba -año 2000-, hasta el año 2006, las puntuaciones obtenidas por el sistema educativo francés habían descendido de forma estrepitosa (ver gráfico 8). 
Fue a partir de ese momento, cuando Francia evolucionó hacia unos parámetros más positivos, que lo situaron de nuevo en una posición de cierto prestigio, entre todos los países participantes en esta prueba. Y es que, a pesar de la postura escéptica que ha tomado la sociedad francesa frente estas evaluaciones internacionales, lo cierto es que, poco a poco, estas pruebas han ido adquiriendo protagonismo. Es más, a lo largo de los últimos años, la administración francesa, en su afán por mejorar su desempeño educativo, ha desarrollado una serie de políticas educativas que han sido justificadas mediante los resultados obtenidos en esta prueba (Dobbins y Martens, 2012). De este modo, volvemos a confirmar la fuerte influencia que OCDE, ejerce sobre los sistemas nacionales de educación.

\section{Gráfico 8. Evolución de las puntuaciones obtenidas por los estudiantes} franceses, en las diferentes áreas de conocimiento evaluadas por PISA

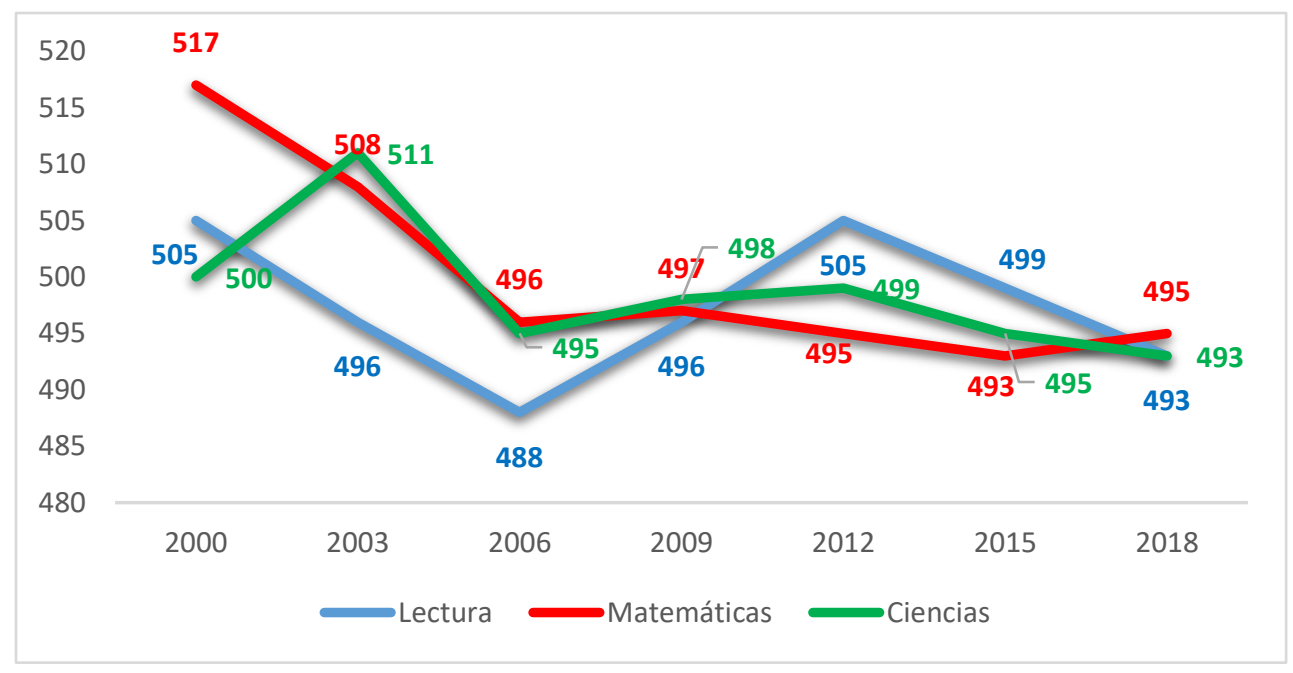

Fuente: Elaboración propia a partir de los datos obtenidos de http://www.oecd.org/

\section{3) Contexto socio histórico, político y cultural en Finlandia}

No cabe duda de que el sistema educativo finlandés ha adquirido un gran protagonismo educativo a lo largo de los últimos años, fruto de sus excelentes 
resultados en las evaluaciones internacionales de PISA. Popularmente, este éxito ha sido asociado a la excelencia de sus profesores y, de una forma más particular, a la gran calidad de sus procesos formativos (Darling-Hammond, 2017; Gripenberg y Lizarte, 2012; Simola, 2005,2013; Simola y Rinne, 2013 y Vega, 2005, etc.). Pero la realidad es otra muy distinta, ya que existen multitud de factores, que van más allá de las propias cuestiones pedagógicas y que favorecen el alto rendimiento del sistema educativo finlandés, como: tradición educativa, consenso político, desarrollo económico, etc. (Lie, Linnakylä, y Roe, 2003; Linnakylä y Yalijärvi, 2006; Simola, 2013). A continuación, y siguiendo el mismo esquema establecido para el estudio del sistema educativo español y francés, realizaremos un pequeño análisis del contexto en el que se enmarca el sistema educativo finlandés, especialmente, desde comienzos del pasado siglo, momento clave en la historia de Finlandia, dado que consigue su independencia como estado democrático.

\subsection{1) Cultura histórica del sistema educativo finlandés}

A la hora de analizar el desarrollo histórico del sistema educativo finlandés, vamos a tomar como punto de partida la Constitución de 1919. Este texto, que fue aprobado poco después de que Finlandia consiguiera la independencia como Estado (1917), tuvo una grandísima transcendencia en la historia reciente del país nórdico y, como es evidente, sobre su sistema educativo.

\subsubsection{1) Independencia de Finlandia. Constitución de 1919}

Finlandia, que desde 1809 se encontraba bajo el poder del Imperio Ruso, no tuvo un camino sencillo hasta lograr su independencia. El primer texto que rusos y finlandeses firmaron de manera conjunta, fue el Tratado de Porvoo, a partir del cual el país nórdico aceptaba a Alejandro I como líder, siempre que éste se comprometiera a respetar las leyes, la religión y los privilegios del país nórdico. No obstante, el conflicto ruso-finlandés no tardaría en llegar dado que, en 1880, los finlandeses 
emitieron un panfleto sobre su posición legal que, rápidamente, seria desmentido por el país soviético, que desestimaba la existencia de Finlandia como Estado. Pese a que, en ese momento, ni finlandeses ni rusos tenían argumentos suficientes para demostrar su posicionamiento, lo cierto es que, poco a poco, la idea de Finlandia como nación comenzó a tomar fuerza (Roiko-Jokela, 2012).

La llegada del s. XX, trajo consigo años de represión para Finlandia, que veía cómo el Zar traicionaba su promesa de autonomía. De este modo, el país nórdico quedaría dividido en dos facciones: la de los Antiguos Finlandeses, que tenían una actitud conciliatoria, y la de los constitucionalistas que se encontraban entre los Jóvenes Finlandeses y los partidarios de los suecos (Roiko-Jokela, 2012). Durante el primer tercio de siglo, Finlandia aprovecharía la encrucijada en la que se encontraban los rusos que, lastrados por la revolución rusa y las consecuencias de la Primera Guerra Mundial, le permitiría declarar su independencia el 6 de diciembre de 1917 (Astola, 2001; Roiko-Jokela, 2012; Simola, 2013). Tras conseguir la liberación, Finlandia aprobaría su primera constitución el 17 de julio de 1919. Se trataba, sin duda alguna, de un texto constitucional especialmente rígido, en un intento por parte de los finlandeses de mantener intacta su independencia (Astola, 2001). Este documento estaba configurado como un «Instrumento de Gobierno», y de este modo quedaba descrito en su preámbulo (Rubio y Daranas, 1997: 195):

Por cuanto Finlandia se ha convertido en un Estado independiente, se ha juzgado necesario desarrollar y consolidar su Constitución por nuevas leyes con carácter de Leyes Constitucionales (...) Por lo tanto, de conformidad con la resolución adoptada por el Parlamento según el procedimiento prescrito en el artículo 60 de la Ley del Parlamento de 20 de julio de 1906, se sanciona por la presente proclamación el siguiente Instrumento de Gobierno.

Por otro lado, debemos destacar una peculiaridad que presentaba el país nórdico y que va a tener una gran relevancia en nuestro trabajo, como fue su industrialización tardía (Heller, 2015), en consonancia con lo que estaba ocurriendo 
en el resto de Europa. Como es evidente, esta regresión repercutiría sobre el plano educativo, siendo Finlandia uno de los últimos países en instaurar la obligatoriedad de la enseñanza en el año 1921 (Halinen y Järvinen, 2008; Simola, 2005; Simola, 2013, Valtonen y Rautiainen, 2012). El artículo 13 de la constitución, abogaba por una enseñanza, que no solo debería ser obligatoria, sino también gratuita (Rubio y Daranas, 1997: 197):

Todos tendrán derecho a recibir gratuitamente una enseñanza general básica. La ley regulará la escolaridad obligatoria. El Estado, conforme a las normas que se establezcan por la ley, asegurará a todos, las mismas posibilidades, incluso a quienes carezcan de recursos, según sus respectivas aptitudes y su vocación específica, de recibir asimismo una educación distinta de la enseñanza básica, así como desarrollar la propia personalidad.

Además, este primer texto constitucional, dedicó un capítulo íntegro al apartado educativo (capítulo VIII), donde se exponían seis artículos. En ellos, entre otras cosas, se establecía que el Estado mantendrá, e incluso si fuera necesario, subvencionará las escuelas de enseñanza secundaria, así como las de enseñanza primaria de segundo grado (artículo 79); se fijarán los principios rectores de la organización de la enseñanza primaria y las obligaciones del Estado y de los municipios de mantener dichas escuelas (artículo 80). Además, se regulará por ley el derecho a establecer escuelas u otras instituciones privadas de educación y a organizar la enseñanza en ellas (artículo 82).

\subsubsection{2) La situación después de la Segunda Guerra Mundial}

La guerra terminó para Finlandia en 1944 cuando, durante una tregua, fue golpeado por la Unión Soviética. Las condiciones de paz impuestas al país nórdico fueron muy estrictas, ya que tuvo que ceder el $12 \%$ de su territorio, además de pagar las reparaciones de guerra, lo que supuso aproximadamente el $7 \%$ de su PIB. Irónicamente, este hecho, aceleró la industrialización del país. Los finlandeses habían 
creído en el poder de la educación durante siglos y este mismo espíritu emergió después de la Segunda Guerra Mundial. Los cambios efectuados sobre la estructura poblacional, que habían afectado a la economía y a la sociedad finlandesa, requerirían de nuevas reformas sobre el sistema educativo (Aho, Pitkänen y Sahlberg, 2006; Valtonen y Rautiainen, 2012).

\subsubsection{1) El sistema comprensivo finlandés}

A mitad del pasado siglo, Finlandia emprendió una reforma, tanto en el seno de la educación primaria como de la educación secundaria, que se ha convertido en un continuo, y que ha supuesto una transformación exitosa en la educación básica a partir de la década de 1970. La unidad de la educación básica, tras abandonar el sistema de escuelas paralelas, ha sido la meta del desarrollo de este sistema (Aho et al., 2006; Gripenberg y Lizarte, 2012; Valtonen y Rautiainen, 2012). El argumento fundamental en torno al que giraba esta reforma era el principio de igualdad. $Y$ es que la escuela comprensiva significó el fin de un sistema que segregaba a los alumnos según su talento (Lukkanen, 2013).

\subsubsection{2) Contexto socio político de la reforma}

Desde el punto de vista político, el nacimiento de la escuela comprensiva se produjo gracias al apoyo de la izquierda finlandesa, que encabezaría el gobierno tras las elecciones parlamentarias de 1966. Y es que, sin duda alguna, sería este gobierno el que comenzaría a reconocer la educación como uno de sus principales activos del país nórdico (Aho et al., 2006).

Además, la reforma educativa también jugó un papel fundamental en la política social finlandesa, donde las viejas estructuras del país nórdico ya no podían satisfacer las demandas de una población cambiante, inmersa en una rápida expansión industrial. En este contexto, se dieron una serie de acontecimientos que, a la postre, 
serían determinantes para el desarrollo del sistema educativo finlandés: transición de una sociedad agrícola hacia una sociedad industrializada, crecimiento del sector servicios, aparición de las nuevas tecnologías de la información y la comunicación, etc. (Routti y Ylä-Antilla, 2006). Frente a tal panorama, la demanda los trabajadores mejor educados comenzaría a incrementarse, lo cual traería consigo un aumento de las provisiones para las escuelas (Aho, et al., 2006).

\subsubsection{3) Las fases de la reforma}

A mediados de la década de 1960, se hizo evidente que Finlandia necesitaba una regeneración de su sistema educativo. El sistema de escuelas primarias de más de cien años de antigüedad había llegado a su fin (Valtonen y Rautiainen, 2012). El nivel general de educación tenía que elevarse para apoyar el crecimiento económico de la nación. Dado que la estructura social finlandesa estaba cambiando con gran rapidez, el sistema educativo debía hacerlo del mismo modo. Para ello, la mejora de la calidad del sistema educativo iba a abordarse desde una triple perspectiva: educación básica, educación secundaria y formación de profesores (Aho et al., 2006).

La reforma sería controlada por el Consejo Nacional de Educación General. El Parlamento aprobó la Ley de Educación de 1968, en un acto de preparación de la reforma de la escuela integral. Dos años más tarde, la formación de profesores se trasladaría hacia las universidades, siendo el Ministerio de Educación el encargado de asumir la responsabilidad sobre ella. Esta reforma tenía como principal finalidad conseguir la profesionalización de los docentes (García Ruíz, 2011). La puesta en marcha se iniciaría en el norte de Finlandia, debido a la baja densidad de población; su impacto fue inmediato, requiriendo una estrecha cooperación en todas las partes implicadas. Los municipios, se convertirían en la clave para la organización y ejecución de la reforma, siendo estos, los encargados de aportar a los alumnos las 
mismas oportunidades para recibir una educación básica pública y de calidad (Aho et al., 2006; Sahlberg, 2006).

\subsubsection{3) Reforma de la educación secundaria superior (1985)}

Tras la consolidación de la reforma de la educación básica, el siguiente paso era expandir estos principios de la escuela integral hacia la educación secundaria postobligatoria. De este modo, entre las décadas de 1980 y 1990, la educación secundaria finlandesa se vería sometida a una profunda transformación (Aho et al., 2006; Sahlberg, 2006; Valtonen y Rautiainen, 2012).

\subsubsection{1) Desarrollo económico de Finlandia}

La extensión de la reforma de educación secundaria superior tiene sus raíces en la cambiante situación económica de Finlandia a mediados de s. XX. El crecimiento económico favoreció la necesidad de los trabajadores por ser educados, particularmente en el sector industrial y en el sector servicios. La educación se expandió para satisfacer la demanda de la sociedad, que iría más allá de las escuelas básicas, incrementando ostensiblemente el acceso hacia estudios de nivel universitario. La proporción de estudiantes matriculados en instituciones de formación profesional incrementaría entre 1960 y 1970, en un 50\%; mientras que en las universidades el incremento ascendió hasta el 60\% (Aho et al., 2006).

\subsubsection{2) Nueva política de educación secundaria}

Pese a que la reforma se implementó bien entrada la década de 1980, lo cierto es que su periodo de planificación e implantación se extendió más allá de dos décadas (Sahlberg, 2006). En 1971 Finlandia estableció un comité para analizar su contexto económico, social y cultural para, de este modo, llevar a cabo las reformas sociales pertinentes que le permitiera implantar un estado democrático de bienestar. El comité 
propuso una educación básica de seis años. Posteriormente, los graduados se formarían durante seis años más en educación secundaria; la propuesta que se iba a llevar a cabo en educación secundaria superior, pretendía dividirla en dos vías; una tradicional, donde los estudiantes podían elegir entre las ramas de humanidades y ciencias y otra de carácter profesional. Finalmente, en 1974, el Consejo de Ministros aprobó una medida que incluía planes para desarrollar un sistema educativo desde preescolar hasta la educación superior. El objetivo era unificar la escuela comprensiva (Aho et al., 2006; Sahlberg, 2006).

La ampliación en dos años de la obligatoriedad escolar pretendía acabar con los viejos problemas del antiguo sistema. No obstante, esta idea no estuvo exenta de polémica entre los partidos más conservadores y, sobre todo, los empleadores, que consideraban que era una amenaza para la calidad de los estudios profesionales, así como su fuerza de trabajo, ya que suponía un retraso en el acceso de los jóvenes al mercado laboral (Aho et al., 2006).

\subsubsection{3) Lanzamiento de la reforma}

En 1975, el Ministerio de Educación puso en marcha un programa masivo para preparar la reforma. En él estarían implicadas más de 1.800 personas entre los que se encontraban maestros, empresarios, sindicatos, etc. Para que la reforma se implantara con éxito, era necesario aumentar la financiación en el sector educativo, algo que se llevaría a cabo, especialmente a partir de la década de 1980. El número de escuelas secundarias superiores aumentó considerablemente, al igual que los centros de formación profesional (Aho et al., 2006). El desarrollo llevado a cabo por el sistema de educación secundaria finlandés es fruto de la mejora en la calidad, el acceso, la eficacia y la flexibilidad de este nivel educativo (Sahlberg, 2006). 


\subsubsection{4) Ley de $1998^{33}$}

A finales del pasado siglo, encontramos la última gran reforma educativa, que se llevó a cabo en 1998. A partir de esta ley, se aprobarían los nuevos modelos curriculares para cada nivel educativo. El objetivo fundamental que planteaba esta reforma era el de modernizar el contexto educativo, reduciendo y simplificando considerablemente el número de documentos legislativos. Por otro lado, los objetivos más específicos establecidos, giraban en torno al desarrollo del proceso de desregulación y la potenciación de la autonomía municipal y escolar (García Ruíz, 2011). Si analizamos el desarrollo legislativo durante estos primeros años del nuevo siglo, podemos apreciar cómo la política educativa se ha articulado en torno a cuatro grandes ejes: mayor flexibilidad, creación de una nueva estructura institucional de educación profesional, diseño de una nueva administración pública y, finalmente, fomento de la internacionalización (Aho et al., 2006).

\subsection{2) Cultura escolar del sistema educativo finlandés}

El sistema educativo finlandés está maravillando al mundo a lo largo de los últimos años, gracias a sus extraordinarios resultados académicos. Estos, no son fruto del azar, ya que existen toda una serie de factores que favorecen la consecución de este éxito. A lo largo de nuestro trabajo ya hemos aludido a algunos de estos elementos, que han permitido el desarrollo de la excelencia educativa en Finlandia, como su enfoque hacia la equidad, la reforma escolar integral de 1970 como base de su sistema educativo, la ausencia de pruebas estandarizadas, la amplia autonomía de la que disponen los centros educativos y sus docentes, el escaso número de horas que

${ }^{33}$ Basic Education Act 628/1998 
los alumnos dedican a realizar tareas escolares fuera del sistema educativo, la inconmensurable calidad de su sistema de formación docente, etc. (Heller, 2015).

Siguiendo una estructura similar a la del sistema educativo español y francés, vamos a hablar de tres tipos de cultura escolar: empírica, pedagógica y política. $\mathrm{Si}$ analizamos la cultura empírica del sistema educativo finlandés, debemos destacar que las prácticas educativas llevadas a cabo por sus docentes se enmarcan dentro de un entorno cercano y familiar, donde existe una gran flexibilidad y donde, además, los docentes gozan de una amplia autonomía, que se extiende hasta las propias instituciones educativas. En este sentido, uno de los hechos más reseñables, y que favorecen la consecución del éxito académico, es la gran homogeneidad entre los alumnos. De hecho, hasta el año 2000, los alumnos con necesidades educativas especiales (NEE) no estaban integrados en lo que podemos denominar como clases «normales». Este hecho, junto al escaso porcentaje de estudiantes inmigrantes, ha suscitado una notable homogeneidad cultural de los estudiantes en las aulas finlandesas, que ha contribuido notablemente al desarrollo de un ambiente óptimo para el desarrollo de los procesos de enseñanza-aprendizaje (García Ruíz, 2011). En este sentido, debemos destacar el importante papel que juegan los maestros especiales, que se encargan de dar clases personalizadas a aquellos alumnos que no comprenden cabalmente una clase. Estos profesionales, por lo general, son las de mayor experiencia y tienen estudios de posgrado. Además, tienen otra peculiaridad en su forma de trabajo y es que suelen hacerlo en aulas contiguas a la clase del alumno. De este modo, imparten clases personalizadas que favorecen que ningún alumno se quede atrás dentro del proceso educativo (Oppenheimer, 2010). Otro aspecto que caracteriza al sistema educativo finlandés es el modelo de evaluación desarrollado por sus docentes. Pese a que existen pequeñas evaluaciones que valoran el nivel adquirido por el alumno, lo cierto es que no existen exámenes obligatorios. Además, estas evaluaciones no tienen un carácter sancionador, si no que pretenden guiar y orientar al alumno en el proceso educativo. La reticencia frente a las evaluaciones es tal que, 
durante los primeros cursos de la educación básica, las calificaciones no son numéricas, sino que son cualitativas, favoreciendo el conocimiento sobre sí mismo del propio alumno (Enkvist, 2010).

Por otro lado, si hacemos referencia a lo que en nuestro trabajo hemos denominado como cultura pedagógica, no podemos obviar la fuerte influencia que los teóricos suecos han ejercido sobre sus vecinos finlandeses, especialmente, a partir de la década de los cincuenta del pasado siglo. En este sentido, podemos referenciar, por encima del resto, la figura del pedagogo Torsten Husén. En la actualidad, esta influencia se ha expandido de una forma exponencial, siendo numerosos los investigadores, tanto a nivel nacional como internacional, los que centran sus estudios en el análisis del sistema educativo finlandés, especialmente, durante los últimos años, a raíz del rotundo éxito en las evaluaciones internacionales. En el apartado nacional, debemos destacar a algunos autores de suma relevancia, como son Pasi Sahlberg (Finnish Lesson: What can the World learn from educational change in Finland?), Risto Rinne, Hannu Simola, etc.

Por último, si analizamos la cultura política (administrativa) del país nórdico. En este sentido debemos reconocer la escasa intervención que existe en materia de educación por parte de las autoridades educativas, debido, fundamentalmente, a dos factores: por un lado, la gran autonomía de la que disponen los centros educativos y, por otro lado, la enorme eficacia del sistema educativo finlandés. De este modo, el modelo comprensivo, vigente en Finlandia desde la década de los setenta del pasado siglo, es incuestionable, y desde el plano político, nadie plantea la necesidad de introducir grandes cambios. Y es que, desde que Finlandia alcanzó su independencia en el año 1917, no se han llevado a cabo modificaciones de gran envergadura, sino que ha mantenido una gran estabilidad educativa que, sin duda alguna, ha sido fundamental en la consecución de unos resultados académicos extraordinarios. Este proceso de reforma ha sido establecido a partir de tres fases: un primer periodo de 
reconstrucción, hasta 1965, orientado hacia la mejora de la igualdad de oportunidades, en un momento de transición desde una sociedad agrícola hacia una sociedad industrial. Un segundo periodo, que abarcará hasta 1985, donde se crea la escuela comprensiva. Y finalmente, desde 1985 a la actualidad, donde se lleva a cabo una mejora de la calidad y expansión de la educación secundaria y educación superior, dentro de una nación altamente internacionalizada (Routti y Ylä-Anttila, 2006; Sahlberg, 2010, 2011b).

\subsection{3) Modelo de regulación}

Si ponemos nuevamente sobre la mesa la clasificación llevada a cabo por el profesor Puelles (1992), podemos afirmar que Finlandia se encontraría en lo que él mismo ha catalogado como sexto grado de descentralización, con un modelo de regulación descentralizado que alcanza a las corporaciones locales. No obstante, este posicionamiento no es unánime, ya que hay autores (García Perales y Martín Sánchez, 2012; Niemi, Toom y Kallioniemi, 2016) que hacen pequeños matices al respecto, aludiendo al modelo nórdico como un modelo de regulación mixto, que presentará tanto aspectos centralizados como descentralizados. Quien defiende este posicionamiento afirma que existe financiación, dirección y control estatal, pero, a su vez, las autoridades locales disponen de grandes competencias pedagógicas, especialmente, en lo que concierne al apartado organizativo:

Además de la administración Central, la unidad básica de la administración local es el municipio (gobierno local). La base de la administración municipal se asienta en un viejo principio de autonomía, cuyo autogobierno ha mejorado en los últimos años. Cada autoridad local es responsable de proporcionar a su población los servicios fundamentales de acuerdo a la legislación vigente (García Perales y Martín Sánchez, 2012: 73).

Por tanto, la política educativa finlandesa, vendrá determinada por los órganos nacionales, si bien estos dejarán cierta libertad para que cada escuela y/o 
municipio tome las decisiones que crea convenientes en torno a distintos aspectos organizativos del ámbito escolar, como: asignaturas, objetivos, pruebas, gestión de la educación especial, etc. (Enkvist, 2010). Esta libertad, también se verá reflejada en el contexto de la educación superior, donde las instituciones universitarias, por delegación de las administraciones educativas, gozan de una gran autonomía para, entre otros muchos aspectos, fijar aquellos criterios de acceso que crean más oportunos, que es el tema que a nosotros nos concierne en nuestro trabajo.

La parte descentralizada -localización- se organiza a partir del Finnish National Agency for Education. Este organismo será el encargado de desempeñar tareas como: organización del currículum, actividades de gestión y evaluación, servicio de apoyos, control y dirección del sistema educativo, etc. Por otro lado, en lo que respecta al apartado económico, debemos tener en cuenta que es el Estado el que se encarga de gestionar la financiación, entregando a los municipios partidas desglosadas para que, posteriormente, éstos decidan sobre su aplicación. El presupuesto vendrá determinado por aspectos como la matrícula o, de una forma más concreta, las necesidades específicas de cada centro educativo (Delannoy y Guzmán, 2009).

En definitiva, podemos afirmar que Finlandia ha desarrollado un modelo de regulación en donde la administración central tiene un peso específico, pero, a su vez, los municipios, e incluso los propios centros educativos, gozan de una amplia autonomía pedagógica.

\subsection{4) Organización y funcionamiento del sistema educativo}

\subsubsection{1) Política educativa}

A grandes rasgos, podemos afirmar que la normativa vigente en Finlandia en materia de educación es la misma que se puso en marcha a finales del pasado siglo, 
mediante la ley de educación básica de 1998. Como ya hemos comentado, esta ley pretendía modernizar y simplificar la legislación educativa. Para ello, pondría en marcha nuevos modelos curriculares en todos y cada uno de los distintos niveles educativos. Además, pretendía potenciar el proceso de desregulación, dotando de una mayor autonomía a las entidades locales (García Ruíz, 2011). No obstante, el sistema educativo finlandés no se ha quedado anclado esta ley, que data del siglo pasado, sino que ha impulsado pequeñas modificaciones legislativas, que tienen objetivo, la constante mejora del sistema educativo. Alguna de las más relevantes, y que han tenido lugar recientemente, son las que afectan a la atención a la infancia y a la obligatoriedad escolar. La primera de ellas se produjo en el año 2013, y hace referencia al traslado de competencias de la atención a la infancia hacia las administraciones educativas. Debemos recordar que, en Finlandia, históricamente, esta etapa educativa había sido competencia directa de los departamentos sociales del gobierno finlandés; sin embargo, desde el año 2013, se apostó porque fuera el Ministerio de Educación y Cultura, y no el de Servicios Sociales y Salud, el encargado de gestionarla. Esta transferencia, no ha sido mero trámite, sino que ha traído consigo numerosas modificaciones de carácter pedagógico, como: la configuración de un nuevo currículum, la puesta en marcha de políticas educativas específicas, la profesionalización de la enseñanza, etc. A este respecto, nos gustaría destacar la influencia que Suecia tuvo sobre Finlandia en esta reforma, ya que, tan solo tres años antes, había acometido esta misma modificación legislativa.

Por otro lado, otra de las reformas educativas impulsadas por Finlandia, y que abordaremos con mayor detenimiento en el siguiente apartado, es la que afecta a la escolarización. En Finlandia, la obligatoriedad escolar se ha desarrollado, históricamente, entre los 7 y los 16 años. Como podemos apreciar, el inicio de esta obligatoriedad se produce de una forma más tardía que en la mayoría de los países europeos. No obstante, a lo largo de los últimos años (a partir del 2015, para ser más 
concretos), Finlandia ha permitido la incorporación de los alumnos a su sistema educativo con un año de antelación, de forma voluntaria, y totalmente gratuita.

Por último, vamos a hacer alusión a un par de reformas que afectarán a la educación secundaria. Una de las más importantes, desde nuestra perspectiva, es la reforma en el examen de matriculación de educación secundaria superior, que pretende flexibilizar estos estudios para reducir el estrés de los estudiantes. Además, este nuevo examen, que entrará en vigor para aquellos alumnos que comiencen los estudios de educación secundaria superior en el año 2020, también podrá realizarse en inglés, con el fin de promover la internacionalidad de este grado educativo. Por otro lado, desde el sistema educativo finlandés también se va a apostar por un impulso en el acceso hacia el mercado laboral. Para ello, se están estudiando distintas medidas durante la etapa de educación secundaria y, de una forma más concreta, durante los estudios de formación profesional.

\subsubsection{2) Escolarización}

Como hemos podido apreciar en nuestro trabajo, la tendencia más común cuando hablamos de escolarización es que esta se desarrolle entre los 6 y los 16 años. Si bien, existen excepciones, como la de Hungría que comienza su escolarización obligatoria antes de los 6 años o Suecia y Estonia que la inician con posterioridad (European Commission, 2017a). Tal y como hemos podido apreciar en el apartado anterior, Finlandia estaría más próxima a esta segunda tendencia, si bien, existen matices que debemos tener en consideración, y que vamos a abordar a continuación. De antemano, ya anticipamos que Finlandia fue uno de los últimos países en incorporar la enseñanza obligatoria en Europa, en el año 1921. Y es que, la expansión de la educación primaria en el país nórdico se produjo de una forma lenta, y sin ser del todo funcional, ya que no conseguía alcanzar la totalidad de la demanda (Simola y Rinne, 2013). 
Históricamente, la escolarización en el sistema educativo fines se ha llevado a cabo durante un periodo de 9 años (desde los 7 hasta los 16), de forma totalmente gratuita. A simple vista, lo primero que nos llama la atención es que algo que ya hemos comentado, como es el comienzo de la escolarización de una forma más tardía que en la mayoría de los países de la U.E (Melgarejo, 2006). No obstante, ya hemos explicado como Finlandia se sumó a la tendencia europea el pasado 2015, permitiendo la incorporación de los alumnos al sistema educativo con un año de antelación, de forma voluntaria, y totalmente gratuita. En este sentido, hemos de reconocer que esta medida ha sido todo un éxito dentro del país nórdico, ya que casi la totalidad los niños de 6 años están matriculados en el sistema educativo formal, pese a carecer de obligatoriedad.

Si bien, a la hora de hablar de escolarización obligatoria en el país nórdico, debemos ser cautos, ya que existen matices que debemos tener en consideración, que hacen del sistema educativo finlandés uno de los más peculiares del panorama internacional. La Comisión Europea, se refiere a la educación obligatoria como un período de asistencia educativa que se requiere de todos los alumnos. Este período, está regulado por ley y se desarrolla en las instituciones formales de educación. Sin embargo, en algunos sistemas educativos, se permite que esta capacitación se desarrolle fuera de las aulas (European Commission, 2017a). Y es en esta tesitura donde se encuentra el sistema educativo finlandés, un sistema donde existe obligatoriedad escolar, pero no obligatoriedad de asistir a la escuela. Sin duda, esto algo un tanto atípico si tenemos presente el panorama internacional, ya que los alumnos no tienen obligación de asistir a los centros escolares. Lo que se les exige, es que estén en disposición de unas determinadas competencias, que bien pueden adquirir en los propios centros educativos o, por el contrario, a través de otros medios (como, por ejemplo, mediante la práctica del homeschooling o educación en casa). La ley recoge la posibilidad de que se den estas situaciones, siempre y cuando las 
autoridades locales se encarguen de supervisar el progreso educativo del niño. No obstante, pese a que esta alternativa liberal entra dentro de la legalidad del país nórdico, son pocas las familias que apuestan por ella, ya que prácticamente la totalidad de alumnos asisten al sistema educativo formal (Vega, 2005). Los últimos datos publicados por la Oficina de Estadística Finlandesa (2018), establecen que más de medio millón de estudiantes (560.503), participan en el sistema educativo formal no universitario.

Por último, nos gustaría poner fin a este apartado señalando cuales son, a grandes rasgos, algunas de las características que presenta la enseñanza obligatoria dentro del sistema educativo finlandés. En primer lugar, se trata de una enseñanza integradora y no selectiva, llevada a cabo dentro de los denominados centros polivalentes y que, además, es totalmente gratuita. Por otro lado, se trata de un sistema comprensivo, donde se pretende poner fin a la segregación escolar, estableciendo el principio de igualdad como eje vertebrador del sistema educativo. Finalmente, debemos destacar que desarrollan un modelo de evaluación muy flexible, donde los alumnos no se ven sometidos a la presión de los de exámenes y donde, además, no existe la posibilidad de repetir curso (Vega, 2005).

\subsubsection{3) Abandono escolar temprano}

Desde el punto de vista europeo, podemos afirmar que Finlandia pertenece al reducido grupo de países donde el índice de abandono escolar prematuro es realmente bajo (8,3\% en el año 2018); el 90\% de los jóvenes finlandeses han obtenido certificados académicos superiores al nivel de la enseñanza obligatoria (Julkunen, 2007). De hecho, Finlandia es el único país de la U.E -junto a la Republica Checaque ya presentaba un porcentaje inferior al 10\% en el año 2020 (objetivo prioritario de la UE en la Estrategia 2020) (ver gráfico 9). Pese a ello, el país nórdico ha seguido trabajando para reducir este porcentaje, llevando a cabo distintas medidas en el plano 
educativo: modernización de la formación profesional, mejora del acceso a las instituciones de educación superior, mejoras en el asesoramiento pedagógico, etc. (Bayón-Calvo, 2019).

\section{Gráfico 9. Evolución (\%) de la tasa de abandono escolar temprano en Finlandia durante el s. XXI}

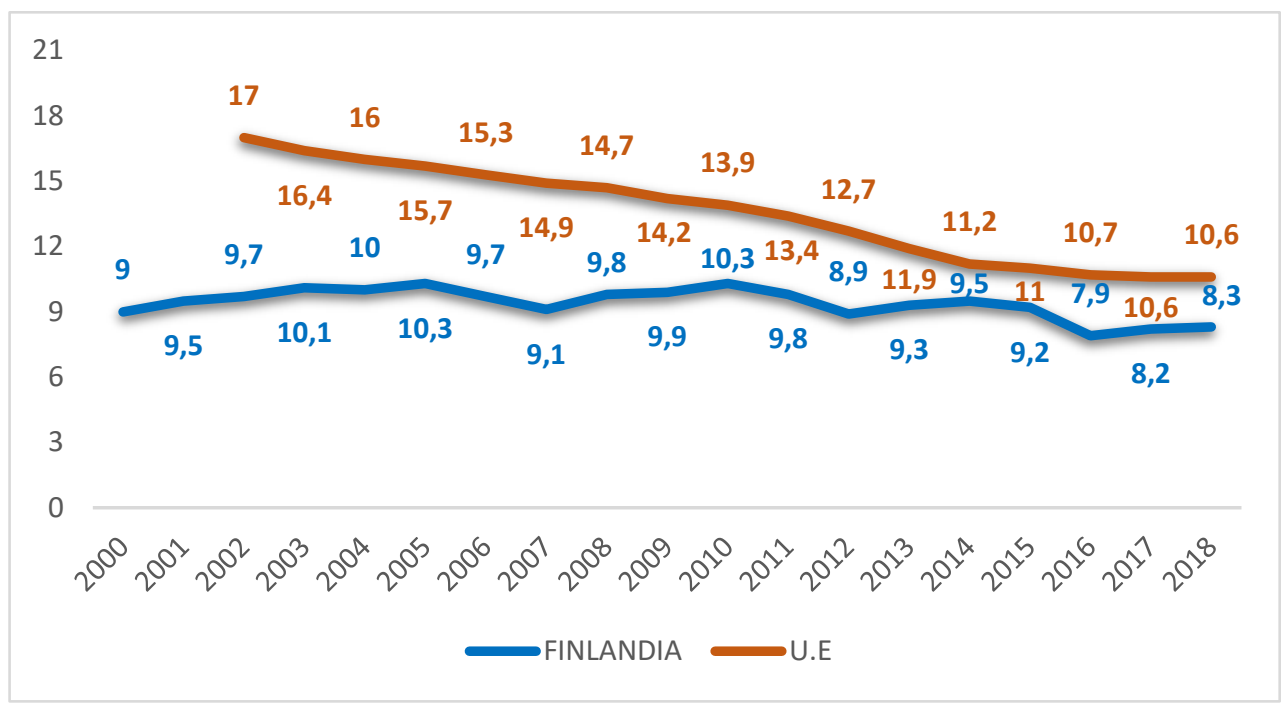

Fuente: Elaboración propia a partir de los datos de Eurostat

Específicamente, debemos destacar que este fenómeno se manifiesta en mayor medida en aquellos jóvenes cuyas familias no han alcanzado niveles educativos superiores. Si atendemos al género, las diferencias se acrecientan a partir de la educación secundaria postobligatoria, donde un mayor porcentaje de mujeres continúan su formación; si bien, los hombres alcanzan posiciones más altas y mejores sueldos (Julkunen, 2007).

\subsubsection{4) Estructura del sistema educativo}

Tal y como hemos explicado, el sistema educativo finlandés guarda una cierta peculiaridad, ya que carece de la obligatoriedad escolar, algo un tanto insólito en la sociedad actual. No obstante, son pocas las familias que apuestan por no matricular a 
sus hijos dentro del sistema educativo. La educación es totalmente gratuita, siendo la administración central, junto a las autoridades locales, la encargada de su provisión. Los municipios, tienen amplias competencias en materia de educación, especialmente desde la década de los 90 del pasado siglo, cuando se redujeron algunas competencias del gobierno central (Jakku-Shivonen y Niemi, 2011; Ruzzi, 2005). La estructura del sistema educativo estaría compuesta por: educación infantil, educación básica, educación secundaria superior y educación superior.

La etapa de educación infantil abarca desde los 0-7 años (aunque ya hemos comentado que cada vez es más común la incorporación de los alumnos con un año de antelación). Se trata de un modelo integrado que, históricamente ha bajo el control de los departamentos de bienestar social, pero que, recientemente, ha sido traspasado a los departamentos educativos. Sin embargo, pese a que su regulación se establece desde la agencia educativa, legalmente, son los municipios a quien les compete proveer estos servicios. Los principales centros en esta etapa educativa son los denominados Paivakoti. Este último año previo a la educación obligatoria tiene una gran relevancia en el país nórdico, ya que trata de preparar a los niños para la educación básica. Desde el año 2001, corresponde a las autoridades locales su provisión, siendo un derecho de las familias finlandesas. Esta etapa, comprende un mínimo de 700 horas y, tal y como ya hemos comentado, pese a no ser obligatoria, posee un porcentaje de asistencia realmente alto, que alcanza casi la totalidad de alumnos (Jakku-Shivonen y Niemi, 2011; Ruzzi, 2005).

La educación básica, se rige por un sistema comprensivo que abarca nueve años de escolarización (desde los 7 hasta los 16 años), de forma totalmente gratuita (enseñanza, material educativo, transporte escolar, etc.). Los seis primeros cursos, hacen referencia a la educación general, mientras que los tres últimos, serían la educación secundaria. Por otro lado, debemos destacar que, recientemente, se ha llevado a cabo una reforma en el currículum básico (2014), que ha sido puesta en 
marcha de manera progresiva: en 2016 se aplicaría sobre el currículum de la educación general (seis primeros cursos de educación básica) y tres años más tarde, se aplicaría en la educación secundaria (tres últimos cursos de educación básica). Por último, también nos gustaría poner de manifiesto el gran número de escuelas de habla sueca que existen en Finlandia, fruto de la gran influencia que han ejercido históricamente sobre la sociedad finesa (Jakku-Shivonen y Niemi, 2011; Ruzzi, 2005).

Tras superar la etapa de educación obligatoria (es necesario el certificado de la educación secundaria básica), los alumnos tienen una amplia gama de posibilidades en la educación postobligatoria. Aproximadamente, la mitad de los alumnos eligen cursar el itinerario general, mientras que la otra mitad, apuesta por la formación profesional. Ambas rutas aseguran el acceso a la educación superior (Jakku-Shivonen y Niemi, 2011; Ruzzi, 2005). La vía general, se cursa en el Gymnasium, y ofrece programas curriculares que tienen asignaturas tanto obligatorias como optativas. Cuando lo finalizan, realizan un examen de carácter nacional, que incluye diferentes pruebas, y cuya aprobación les permite obtener el certificado de educación secundaria superior, que a su vez, les facultará para el acceso universitario. Mientras que la vía profesional, se lleva a cabo en los centros de formación profesional, y su certificado, también capacita para el acceso hacia las instituciones de educación superior. La formación profesional finlandesa, incluye una serie de programas cuyo objetivo es el desarrollo de habilidades en el ámbito laboral. La duración de estos programas varía, aunque lo normal es que abarque un total de tres años, y se expanden por diferentes sectores. En total, existen unas 52 cualificaciones, distribuidas en un total de 113 programas de estudio (Aho et al., 2006). 
Por último, haremos mención a la educación superior, que en Finlandia se rige por un sistema dual, compuesto por universidades y escuelas profesionales superiores (también conocidas como universidades de ciencias aplicadas).

Con el fin de fortalecer el posicionamiento de las universidades finlandesas en el EEES, Finlandia reformó la estructura en este nivel educativo. El nuevo sistema fue aprobado en agosto de 2005. Las leyes que administran estos estudios son la de Universidades y el Decreto de Titulaciones, aprobadas en julio y agosto de 2004, respectivamente. La estructura básica consiste en una titulación académica menor, que sería el grado (3 años/180 ECTS) y una titulación académica mayor, que haría referencia al máster (2 años/120 ECTS). La tercera fase de la educación corresponde a los estudios postgrado, que conducen al título de doctorado (Jakku-Shivonen y Niemi, 2011). El ingreso está altamente restringido, ya que la oferta académica no puede superar a la demanda del sistema económico productivo; por ello, la administración educativa se encarga de consensuar con los centros de educación superior cual será el número de matrículas que puedan ofertar, siempre atendiendo a las necesidades mercantiles que presenta el país (Niemi et al., 2016). De este modo, los centros de educación superior optan por utilizar mecanismos de selección, que consisten, principalmente, en el análisis del expediente académico del alumno durante la educación secundaria superior (con una ponderación sobre la nota final de acceso que varía en función del centro e incluso dentro de un mismo centro, entre los distintos itinerarios formativos), así como la superación de exámenes de ingreso. Para las escuelas profesionales superiores, se permite el acceso de aquellos alumnos que provengan de la educación secundaria profesional o vocacional. En este caso, la selección se basa principalmente en exámenes de ingreso, antecedentes escolares y experiencia laboral. Si bien, nos gustaría incidir en la fuerte autonomía de la que disponen estos centros, tanto a nivel administrativo como en lo que concierne al 
ámbito académico e investigador. Por ello no podemos hablar de un modelo de acceso homogéneo que guarde similitudes entre los diferentes centros de educación superior.

\section{Gráfico 10. Estructura del sistema educativo finlandés}

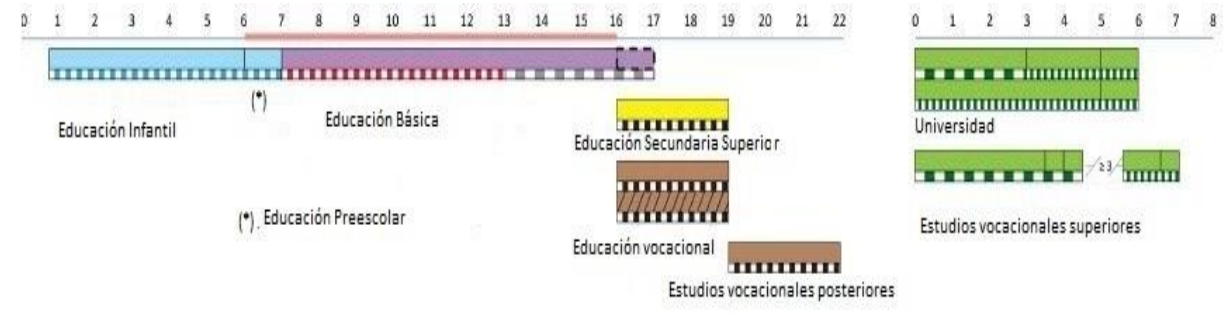

Fuente: Eurydice

\subsubsection{5) Titularidad de los centros educativos}

Volviendo a poner sobre la mesa los datos de OECD (2016), recordamos que la escolarización es un fenómeno que se lleva a cabo, principalmente, dentro de las instituciones públicas (el 84\% de los alumnos de 15 años están matriculados en centros de titularidad pública). La tendencia es idéntica en el país nórdico, de hecho, debemos reconocer a Finlandia como un claro ejemplo de sistema público de educación. La mayor parte de las instituciones educativas finlandesas, tanto de educación primaria como de secundaria, está bajo la protección de los municipios. Pero, además, el escaso número de instituciones privadas del país nórdico, también están bajo supervisión de las autoridades públicas, ya que están obligados a seguir los currículos nacionales, que son establecidos por la FNAE. De hecho, estos centros reciben el mismo nivel de financiación por parte de la administración que las escuelas públicas. Por tanto, la financiación de los centros escolares está dividida entre el Estado y los municipios, cubriendo la administración central un 57\% de los costes, y los entes locales el $43 \%$ restante (FNAE, 2007). 
Si analizamos de una forma más específica el sistema educativo finlandés, podemos apreciar como el número de alumnos matriculados en centros de titularidad pública, es superior a la media de la OCDE (Gráfico 4), abarcando, prácticamente, la totalidad de los mismos (con cerca de un 95\%). Estos datos contrastan con la situación que vive sistema educativo español y francés, donde el porcentaje de alumnos matriculados en centros públicos se situaba por debajo de la media de la OCDE (OECD, 2016).

\subsection{5) Eficacia del sistema educativo}

Si hablamos de eficacia, el sistema educativo finlandés es, sin lugar a dudas, uno de los más eficaces del panorama internacional, ya que ha obtenido puntuaciones ostentosas -y por supuesto, muy superiores a la media de la OCDE - en todas y cada una de las áreas de conocimiento evaluadas por el programa de competencias PISA, tal y como podemos observar en la tabla 6 . Y es que Finlandia, que ha encabezado históricamente este ranking, ha sido uno de los pocos sistemas educativos capaz de hacer frente a las grandes economías asiáticas, como Singapur, Macao, Hong Kong, China Taipéi o Corea, que se ha venido erigiendo como los grandes líderes de esta prueba. Estos resultados causaron una grata

Los primeros resultados obtenidos por Finlandia en las pruebas causaron una grata sorpresa en el contexto internacional, dado que habían alcanzado un lugar privilegiado en todas y cada una de las áreas de conocimiento. Sin embargo, no fue así en el país nórdico que consideraba que el éxito cosechado era tan solo un producto del desarrollo que había experimentado, históricamente, su sistema educativo (Niemi et al., 2016). 
Tabla 6. Puntuaciones obtenidas por los alumnos finlandeses en las diferentes áreas de conocimiento evaluadas por PISA

\begin{tabular}{|c|c|c|c|}
\hline & Lectura & Matemáticas & Ciencias \\
\hline 2000 & 576 & 536 & 538 \\
\hline Media OCDE & 500 & 500 & 500 \\
\hline 2003 & 543 & 539 & 548 \\
\hline Media OCDE & 494 & 500 & 496 \\
\hline 2006 & 547 & 548 & 563 \\
\hline Media OCDE & 500 & 500 & 500 \\
\hline 2009 & 536 & 541 & 554 \\
\hline Media OCDE & 493 & 496 & 501 \\
\hline 2012 & 524 & 519 & 545 \\
\hline Media OCDE & 496 & 494 & 501 \\
\hline 2015 & 526 & 511 & 531 \\
\hline Media OCDE & 493 & 490 & 493 \\
\hline 2018 & 520 & 507 & 522 \\
\hline Media OCDE & 487 & 489 & 489 \\
\hline
\end{tabular}

Fuente: Elaboración propia a partir de los datos obtenidos de http://www.oecd.org/

El área de conocimiento de ciencias ha sido, sin lugar a dudas, el punto fuerte del sistema educativo finlandés; mientras que las puntuaciones obtenidas en el área de compresión lectora y matemáticas también han sido muy destacadas, superando holgadamente la media internacional. Sin embargo, hemos de reconocer que estas han sufrido un pequeño descenso a lo largo de los últimos años (ver gráfico 11) que, por otro lado, trataremos de analizar más adelante. 


\section{Gráfico 11. Evolución de las puntuaciones obtenidas por los estudiantes} finlandeses, en las diferentes áreas de conocimiento evaluadas por PISA

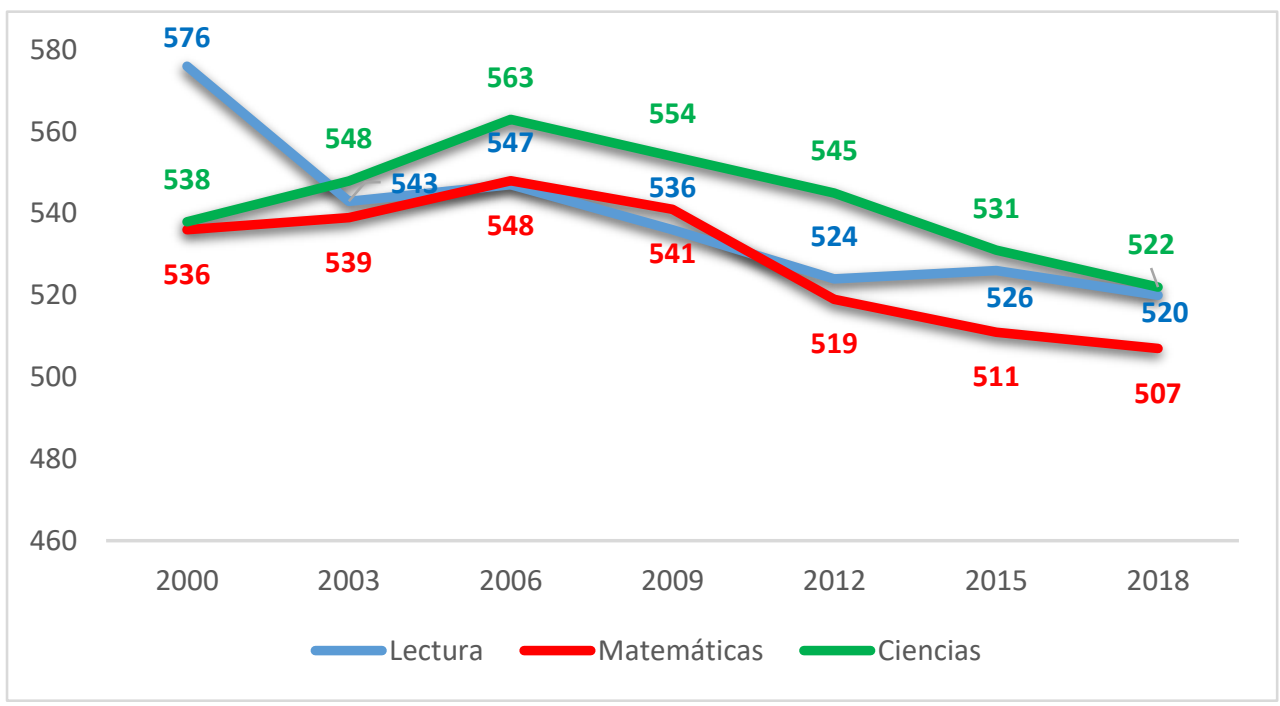

Fuente: Elaboración propia a partir de los datos obtenidos de http://www.oecd.org/

De este modo, podemos afirmar que se ha producido un cambio en el desempeño de los alumnos finlandeses, algo que es realmente llamativo si tenemos en cuenta que, tras la publicación de los primeros resultados, Finlandia incrementó el número de horas lectivas de aquellas materias evaluadas en esta prueba, lo que evidencia un problema en cuanto a la calidad de la instrucción, y no de la cantidad (Niemi, et al., 2016). A continuación, vamos a tratar de analizar algunas de las posibles razones que han traído consigo este descenso en el rendimiento de los alumnos finlandeses. El reconocido investigador finlandés Pasi Sahlberg, exdirector general de CIMO (Center for International Mobility and Cooperation), ha hablado sobre ello en una entrevista publicada el diario Education Week. En ella, afirma que la caída de los resultados no es algo sorprendente para la sociedad finlandesa, dado que diversos estudios llevados a cabo en universidades del país ya anticipaban estos 
resultados. Entre los muchos factores que han podido condicionar este descenso de las puntuaciones, Sahlberg hace hincapié en uno que destaca por encima del resto, y ese no es otro que la poca iniciativa del gobierno finlandés para poner en marcha medidas que permitan mejorar el rendimiento académico de los estudiantes. Por otro lado, algunos expertos aluden a un segundo factor que, si bien no debería tener demasiada incidencia, puede considerarse como determinante, como es la gran cantidad de inmigrantes de habla no finlandesa que están llegando a las aulas del país nórdico a lo largo de los últimos años. Si bien, pese a ser cierto que este tipo de alumnos tienen un rendimiento menor que los nativos, es poco probable que esta sea una explicación real, ya que los niveles de inmigración no han sido lo suficientemente significativos como para justificar semejante descenso de las puntuaciones. Por último, queremos hacer mención a un tercer factor que puede ser más determinante que los anteriores, como es el cambio al que se está viendo sometida la sociedad finlandesa en los últimos tiempos, donde las prácticas escolares estén padeciendo un cambio que puede llegar a condicionar el rendimiento académico de los estudiantes.

Sin embargo, este pequeño declive no resta mérito a los magníficos resultados cosechados por el país nórdico, que sigue siendo uno de los grandes referentes del panorama educativo. Además, la consecución de estos resultados se obtiene a partir de una inversión, tanto económica como temporal, muy similar a la del resto de participantes. Pon poner un ejemplo, el sistema educativo finlandés, realiza una inversión económica muy similar a la de Alemania, obteniendo unas puntuaciones muy superiores a las del país germano. De este modo, se desmonta el mito de que una mayor inversión educativa genera un mayor éxito académico (Schleicher, 2018). Mientras que si analizamos el tiempo dedicado a la educación (siempre atendiendo a los datos de OCDE, en sus informes Education at Glance), podemos observar cómo, de media, los alumnos finlandeses acuden 1000 horas menos al año a clase, que sus 

educativos de España, Francia y Finlandia

homólogos europeos, lo que vuelve a poner de manifiesto que la cantidad de horas lectivas no es determinante en el desarrollo educativo del alumno (Niemi et al., 2016).

Para finalizar este apartado, y haciendo una pequeña alusión a la temática objeto de estudio, nos gustaría destacar como uno de los países más eficaces del panorama internacional es, a su vez, también uno de los más exigentes en materia de acceso. Las universidades finlandesas, por delegación de la administración educativa, poseen potestad para seleccionar a sus alumnos mediante pruebas de ingreso. Esto, adquiere una mayor relevancia si tenemos en cuenta lo sucedido en el sistema educativo español y francés, donde son mucho más flexibles (salvo en algunos desarrollos institucionales muy concretos), pese a tener alumnos que, aparentemente, cuentan con un rendimiento académico menor que en el país nórdico. 

1) INTRODVCCIÓN Y JVSTIFICACIÓN DEL TEMA

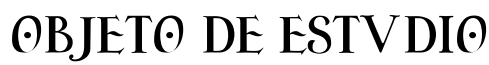

2) CATEG@RÍAS $\odot$ VARIABLES DE ANÁLISIS DEL ACCESO/ADMISIÓN A LA EDVCACIÓN SVPERIOR

3) EL ACCESの/ADMISIÓN A LA EDVCACIÓN SVPERIOR EN ESPAN̂A, FRANCIA Y

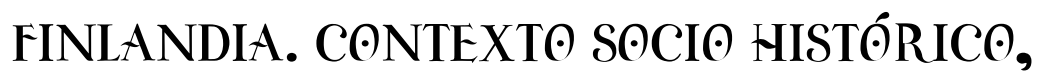
POLÍTICO Y CVLTVRAL

4) ¿CÓM@ ACTVAAN LOS MODELOS DE ACCESค/ADMISIÓN HACIA LA EDVCACIÓN SVPERIOR?

5) LA COMPARACIÓN CONTEXTVAL DEL ACCESO/ADMISIÓN A LA EDVCACIÓN SVPERIOR. EL CARÁCTER FVNCIONAL DE LAS TRANSICIONES

6) CONCLVSI@NES 



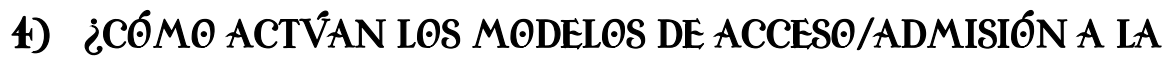 EDVCACI@́N SVPERI@R?}

\section{1) Análisis individualizado del proceso de transición hacia la educación superior en España, Francia y Finlandia}

A continuación, iniciaremos el proceso comparativo de nuestro trabajo que, tal y como ya explicamos en el apartado metodológico, abarcará los dos próximos capítulos. Durante el primero de ellos, en la denominada fase de yuxtaposición, realizaremos un análisis individualizado de todas y cada una de las variables o categorías analíticas descritas al comienzo de nuestro estudio, en cada uno de los sistemas educativos objeto de análisis. El objetivo que perseguimos a lo largo de este capítulo no es otro que el de cotejar estas variables, para así poder encontrar las semejanzas y diferencias que los sistemas educativos manifiestan en los procesos de transición hacia el sistema universitario. Posteriormente, durante el próximo capítulo, en la denominada fase comparativa, trataremos de explicar de una forma coherente y racional estas convergencias y divergencias atendiendo al desarrollo contextual en que se desarrollan estos sistemas educativos. $\mathrm{Y}$ es que, sin lugar a dudas, el contexto va a tener un gran impacto sobre el sistema educativo en general y sobre los distintos modelos de acceso/admisión hacia las instituciones de educación superior en 
particular. Por tanto, el objetivo que pretendemos alcanzar es el de interpretar estas semejanzas y diferencias que presentaremos a lo largo de este capítulo.

Antes de comenzar, nos gustaría recordar que, aunque el análisis de estas variables se realice de una forma totalmente individual, estas forman parte de lo que nosotros hemos denominado como actores (agentes) educativos. Nosotros, en nuestro trabajo, hemos seleccionado aquellos que, a nuestro parecer, tienen una mayor trascendencia en este proceso de transición. El primero de ellos es el alumno, y de él analizaremos sus características académicas, el rendimiento competencial en las pruebas de acceso y su origen social. En segundo lugar, nos centraremos en los procesos de organización y gestión, donde prestaremos atención a quien corresponden la competencia organizativa de acceso, al papel desempeñado por los centros de educación secundaria y, finalmente, los requisitos de acceso/admisión. Posteriormente, haremos alusión a la regulación educativa, donde pondremos nuestro foco de atención sobre los modelos de acceso/admisión vigentes en cada uno de los sistemas educativos analizados. El cuarto agente educativo es la sociedad, de la que analizaremos algunos indicadores sociales y culturales que puedan tener una cierta incidencia en estos procesos de transición que aquí analizamos. Por último, abordaremos el sistema escolar, donde examinaremos dos variables que están estrechamente relacionadas con el asesoramiento pedagógico del alumno, como son el papel desempeñado por los sistemas de orientación en los centros de secundaria y la acción tutorial ejercida por sus docentes.

\subsection{1) Características académicas de los alumnos que están en disposición de acceder a los estudios de educación superior}

\subsubsection{1) Sistema educativo español}

Comenzaremos analizando el perfil académico de los alumnos que están en disposición de acceder a los estudios de educación superior en nuestro país. Para ello, 
vamos a evaluar los datos oficiales que, anualmente, son emitidos desde la administración educativa, a través del Ministerio de Educación y Formación Profesional (estos informes pueden ser revisados en el apartado bibliográfico de nuestro trabajo). En ellos, se presenta una radiografía del sistema educativo español, tanto de los niveles educativos obligatorios como postobligatorios. Dada la evolución y el gran crecimiento que ha experimentado nuestro sistema educativo a lo largo de los últimos años -e incluso décadas-, hemos optado por tomar como referencia el año 2010 para realizar este análisis. De este modo, aseguramos un trabajo académico con datos plenamente actualizados y evitamos que exista disparidad entre los mismos, ya que la tendencia ha sido muy continuista durante este periodo. Más adelante, cuando analicemos los datos relativos al sistema educativo francés y finlandés, seguiremos esta misma fórmula, a fin de que exista la mayor homogeneidad posible en el análisis realizado. Por otro lado, también pondremos nuestro foco de atención en el propio contexto universitario, a partir del análisis de una serie de informes que, nuevamente, han sido emitidos desde la administración educativa española y que se centran, específicamente, en el contexto universitario.

En nuestro país, un porcentaje mayoritario de los alumnos que acceden a la universidad, lo hacen tras cursar estudios de bachillerato, si bien, tal y como veremos más adelante, este no es el único itinerario de acceso válido. Pese a tratarse de la primera etapa de carácter no obligatorio, casi 670.000 alumnos cursan estudios de bachillerato en España, de los cuales, algo más de la mitad son mujeres (en torno al $53 \%$ ). Sin embargo, tal y como podemos apreciar en el gráfico número 12, a lo largo de los últimos años se ha producido un descenso paulatino en la matrícula de este nivel educativo, con especial énfasis, a partir del curso académico 2013-2014.

Por otro lado, si nos centramos en la especialidad cursada, podemos afirmar que la tendencia ha variado ligeramente durante el último curso académico, ya que la modalidad de Ciencia y Tecnología (52,2\%), ha superado en número de alumnos a la 
de Humanidades y Ciencias Sociales (43,3\%), algo que no sucedía a lo largo de la última década; mientras tanto, la especialidad de Artes sigue siendo la menos demandada por los estudiantes, con un porcentaje de matriculación que desciende año tras año (en la actualidad, se sitúa por debajo del 4\%).

\section{Gráfico 12. Evolución del número de alumnos matriculados en bachillerato}

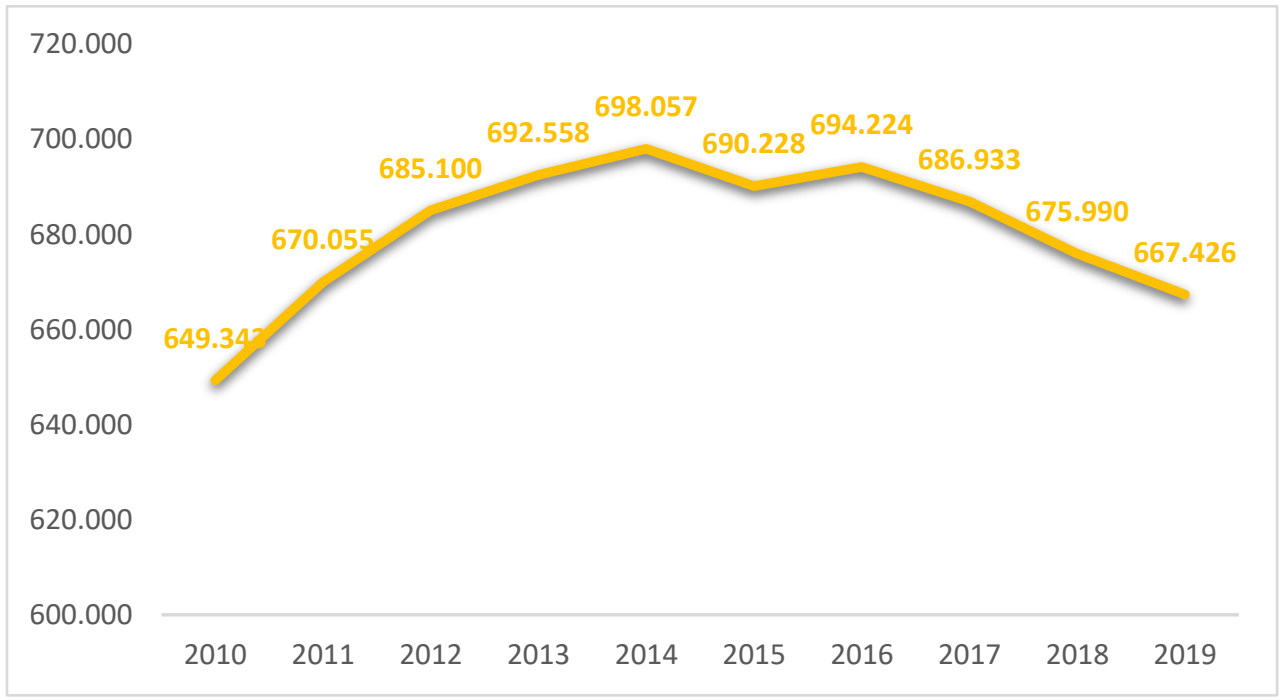

Fuente: Elaboración propia a partir de los datos de los informes «Cifras y Datos»

Si pasamos a analizar el número de alumnos extranjeros en bachillerato, podemos apreciar cómo este ha crecido progresivamente, situándose en torno a los 43.000, lo que supone en torno a un 9\% del total de estudiantes. Geográficamente, las CC. AA con mayor presencia son: Andalucía (21,3\%), Cataluña $(14,1 \%)$ y Comunidad de Madrid (15,7\%). Por otro lado, si analizamos a la titularidad del centro educativo a la que están adscritos estos alumnos, podemos apreciar como la tendencia es idéntica a la del resto de etapas educativas de carácter obligatorio, siendo, mayoritariamente, públicos, con un porcentaje que oscila en torno al $73 \%$ de los 
alumnos (ver gráfico 13) ${ }^{34}$. Mientras que, tan solo un dieciséis y un once por ciento de estos alumnos estarían adscritos a centros de titularidad privada y centros concertados, respectivamente.

\section{Gráfico 13. Evolución (\%) de los alumnos de bachillerato atendiendo a la titularidad del centro al que están adscritos}

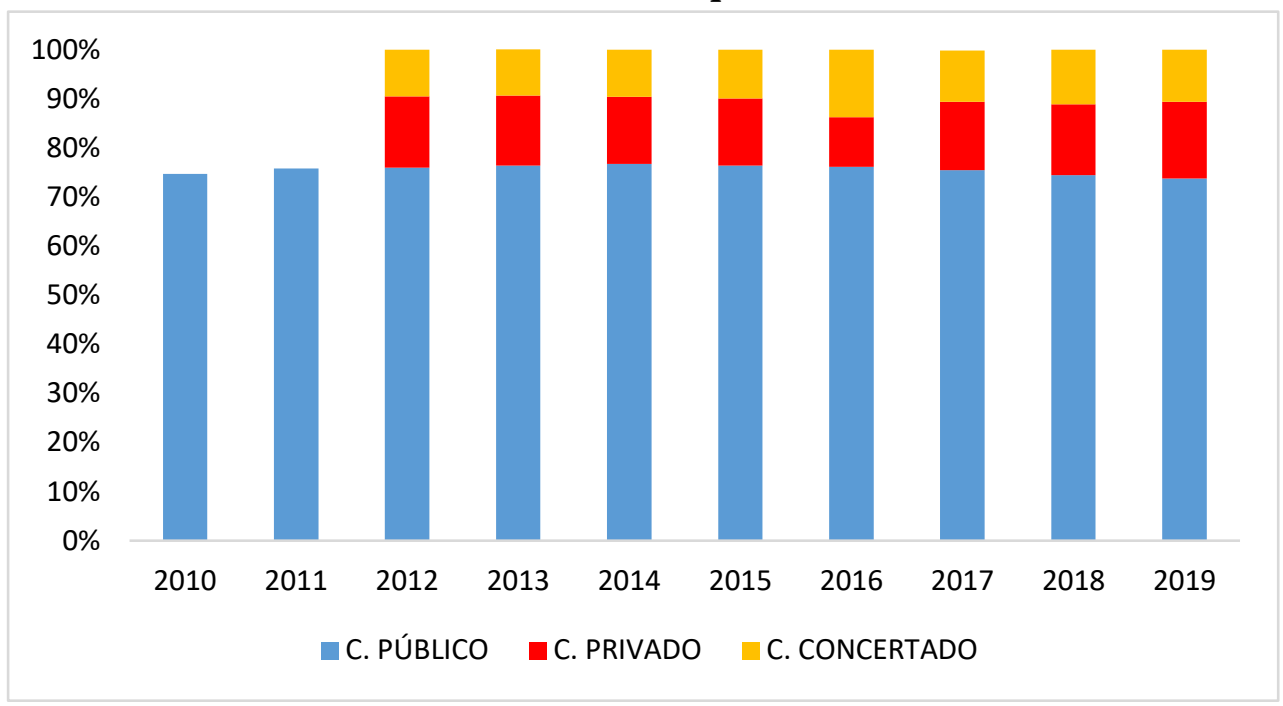

Fuente: Elaboración propia a partir de los datos de los informes «Cifras y Datos»

Para finalizar, también nos gustaría hacer una mención especial a los estudiantes de formación profesional, que se trata de un colectivo que está creciendo de forma exponencial a lo largo de la última década. Y es que, tal y como hemos explicado al comienzo de este apartado, el acceso ordinario a la universidad en España se realiza a través de los estudios de bachillerato, si bien, esta no es la única vía existente. A lo largo de los últimos años, el número de alumnos que llega a las aulas universitarias tras haber cursados estudios de formación profesional de grado superior ha crecido ostensiblemente. De este modo, podemos afirmar que, aproximadamente,

\footnotetext{
${ }^{34}$ Los datos relativos al porcentaje de alumnos adscritos a centros de titularidad privada y concertada durante los cursos 2009-2010 y 2010-2011 no fueron recogidos en los informes analizados.
} 
un $10 \%$ de los alumnos que acceden a los estudios de educación superior, lo hacen tras haber alcanzado el título de técnico superior de formación profesional. Esta, es la segunda forma más común de acceso hacia los estudios de educación superior en nuestro país, superando a otras como: acceso para mayores de 25 años, acceso para mayores de 45 años, acceso desde otros sistemas educativos extranjeros, traspaso de expediente, etc. En la actualidad, la formación vocacional en España se sitúa en torno a los 840.000 alumnos (gráfico 14), entre estudiantes de formación profesional básica, formación profesional de grado medio y formación profesional de grado superior.

\section{Gráfico 14. Evolución del número de alumnos matriculados en estudios de formación profesional (Modalidad presencial)}

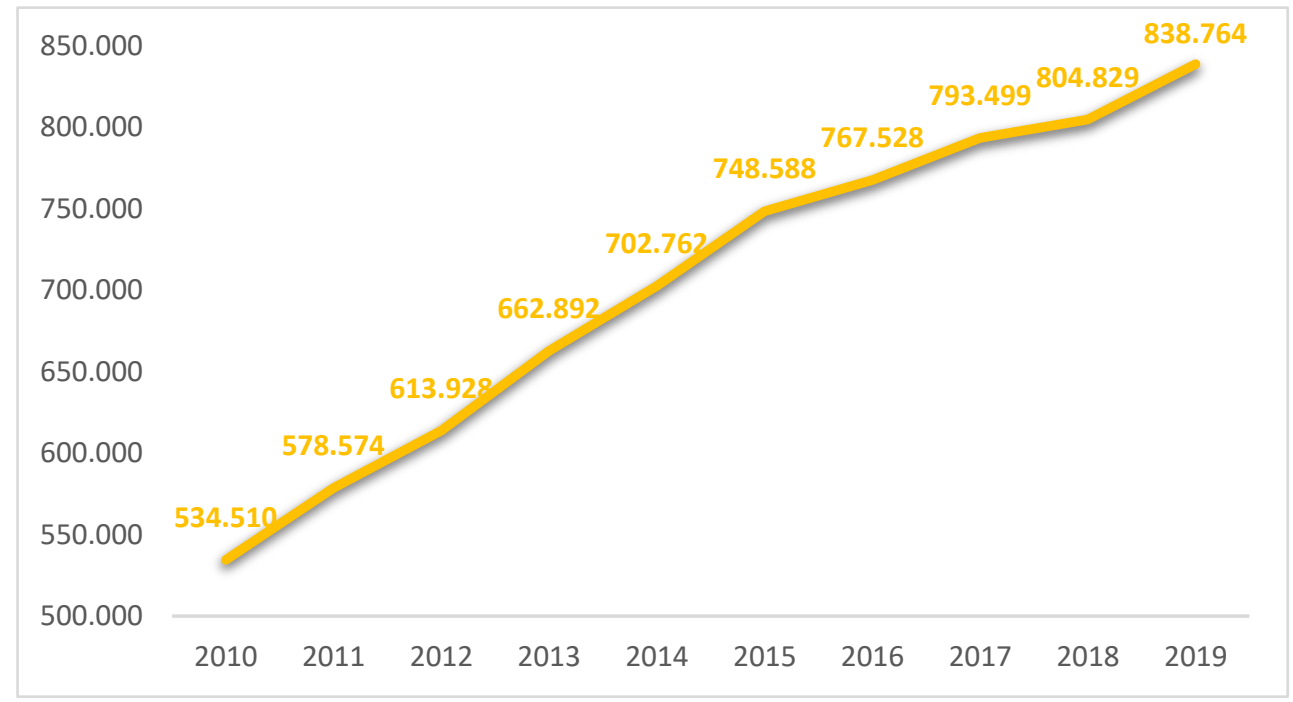

Fuente: Elaboración propia a partir de los datos de los informes «Cifras y Datos»

Si nos centramos en el análisis específico de los estudiantes de ciclos superiores de formación profesional, que es el colectivo que a nosotros nos interesa al ser aquellos alumnos que están en disposición de acceder al sistema universitario, podemos apreciar como el número de matriculaciones ha ascendido hasta situarse en casi 400.000 alumnos (tabla número 7): 
Itinerarios de acceso/admisión a la educación superior. Un análisis comparado en los sistemas educativos de España, Francia y Finlandia

Tabla 7. Número de alumnos matriculados en Ciclos Formativos de Grado Superior, atendiendo a la variable género y familia profesional (2019)

\begin{tabular}{|c|c|c|c|}
\hline Familia profesional & Total $(\mathbf{N})$ & Hombres (\%) & Mujeres (\%) \\
\hline Actividades físicas y deportivas & 22.996 & 79,7 & 20,3 \\
\hline Administración y gestión & 58.555 & 36,8 & 63,2 \\
\hline Agrarias & 6.896 & 80,6 & 19,4 \\
\hline Artes Gráficas & 2.228 & 43,7 & 46,3 \\
\hline Artes y Artesanías & 110 & 54,5 & 45,5 \\
\hline Comercio y Marketing & 25.626 & 51,6 & 48,4 \\
\hline Edificación y Obra Civil & 3.924 & 69,3 & 30,7 \\
\hline Electricidad y Electrónica & 23.650 & 95,2 & 4,8 \\
\hline Energía y Agua & 2.010 & 91,5 & 8,5 \\
\hline Fabricación Mecánica & 9.807 & 90,6 & 9,4 \\
\hline Hostelería y Turismo & 22.173 & 44,0 & 56,0 \\
\hline Imagen Personal & 7.865 & 5,9 & 94,1 \\
\hline Imagen y Sonido & 16.559 & 67,7 & 32,3 \\
\hline Industrias Alimentarias & 2.321 & 53,9 & 46,1 \\
\hline Informática y Comunicaciones & 47.456 & 88,6 & 11,4 \\
\hline Instalación y Mantenimiento & 12.601 & 86,8 & 13,2 \\
\hline Madera, Mueble y Corcho & 895 & 79,8 & 20,9 \\
\hline Marítimo-Pesquera & 1.858 & 90,6 & 9,4 \\
\hline Química & 7.138 & 49,6 & 50,4 \\
\hline Sanidad & 51.282 & 25,0 & 75,0 \\
\hline Seguridad y Medio Ambiente & 1.050 & 65,6 & 34,4 \\
\hline Servicios Socioculturales a la Comunidad & 58.810 & 12,9 & 87,1 \\
\hline Textil, Confección y Piel & 1.621 & 15,0 & 85,0 \\
\hline Transporte y mantenimiento de Vehículos & 11.421 & 96,8 & 3,2 \\
\hline Vidrio y Cerámica & 56 & 69,6 & 30,4 \\
\hline TOTAL & 398.908 & 52,6 & 47,4 \\
\hline
\end{tabular}

Fuente: MEFP (2019)

En este sentido, observamos que el porcentaje de hombres (53\%) es ligeramente superior al de mujeres. Por otro lado, si analizamos la titularidad del centro a la que están adscritos estos alumnos, debemos reconocer que esta es, mayoritariamente, pública (72\%), tal y como también sucedía en el itinerario de Bachillerato. Por último, respecto a las ramas profesionales más demandas, podemos 
observar estas serían las de «Servicios Culturales a la Comunidad», «Administración y Gestión», «Sanidad» y, por último, «Información y Telecomunicaciones».

\subsubsection{2) Sistema educativo francés}

A continuación, analizaremos el perfil académico de los estudiantes que están en disposición de acceder a los estudios de educación superior, en este caso, del sistema educativo francés. Para ello, nos valdremos de los datos oficiales que, anualmente, publica la administración educativa. Como ya pudimos apreciar en el capítulo anterior, el sistema educativo francés ofrece tres trayectorias o itinerarios académicos en la educación secundaria superior: general, tecnológica y profesional. A continuación, vamos a realizar un análisis específico, donde abordaremos de manera conjunta, el itinerario general y tecnológico, que posee una orientación más académica y, el itinerario profesional, más enfocado hacia el ámbito laboral.

El número de alumnos matriculados en educación secundaria superior en el país galo es muy superior al de España, en buena lógica porque se trata de un país que demográficamente posee un mayor índice de población. En este sentido, podemos apreciar (gráficos 15 y 16) cómo la vertiente académica tiene una mayor acogida que la profesional, ya que los lycées generales y tecnológicos disponen de más del doble de alumnos en sus aulas. Además, no solamente los datos muestran una mayor aceptación de esta vertiente, sino que también lo hace la tendencia que éstos están experimentado a lo largo de los últimos años. Mientras que los lycées profesionales están perdiendo alumnos de forma sistemática, los lycées generales y tecnológicos los están recuperando ${ }^{35}$.

\footnotetext{
${ }^{35}$ Los datos relativos al año 2013 no figuran al no estar disponibles en las fuentes oficiales de la administración francesa
} 
Itinerarios de acceso/admisión a la educación superior. Un análisis comparado en los sistemas educativos de España, Francia y Finlandia

\section{Gráfico 15. Evolución del número de alumnos matriculados en educación secundaria superior general y tecnológica}

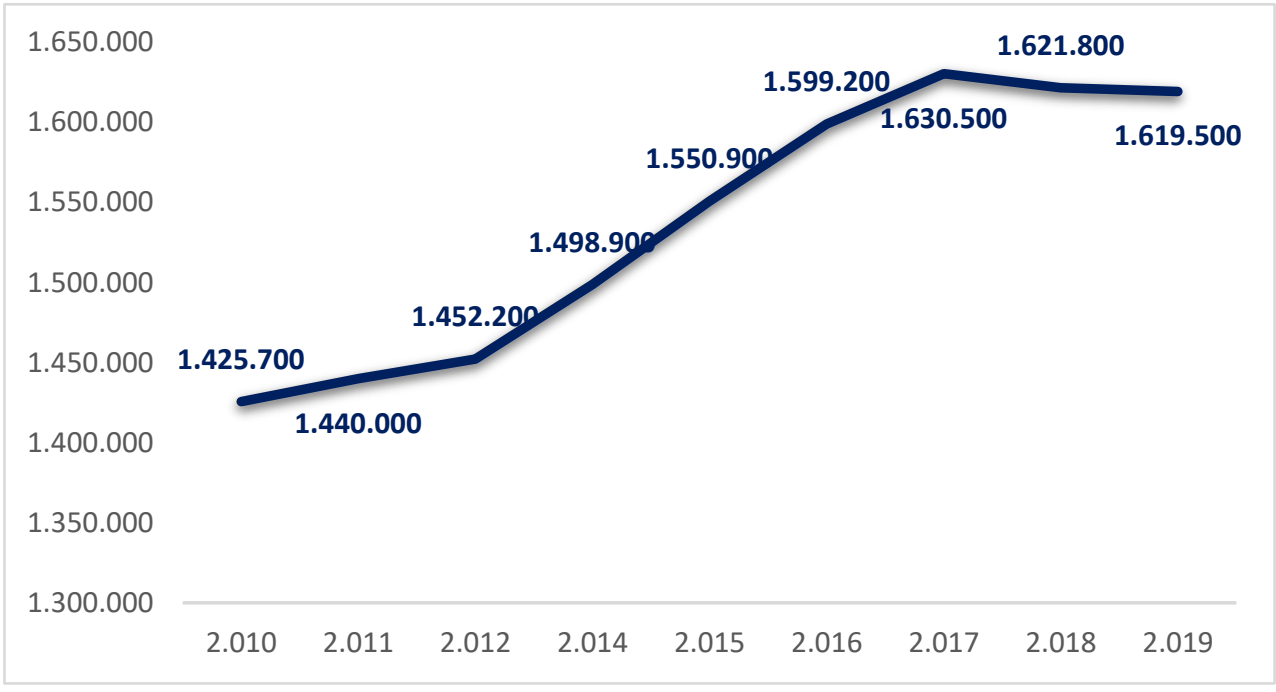

Fuente: Elaboración propia a partir de http://www.education.gouv.fr/

\section{Gráfico 16. Evolución del número de alumnos matriculados en educación secundaria superior profesional}

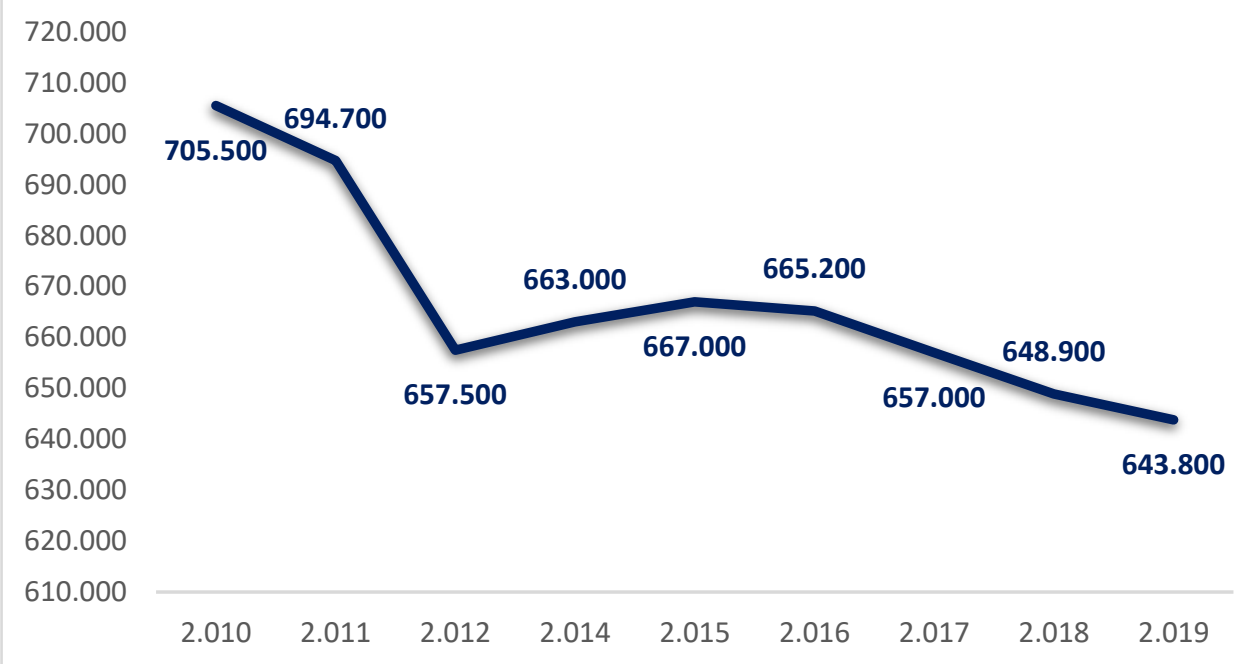

Fuente: Elaboración propia a partir de http://www.education.gouv.fr/ 
A continuación, vamos a analizar estos datos de una forma más específica. En primer lugar, en la tabla 8 , disponemos de un análisis detallado de la matrícula de alumnos de educación secundaria superior general y tecnológica. En él, se muestran los datos de los estudiantes atendiendo a distintas variables de gran interés, como son la variable género, la especialidad cursada por los alumnos y la titularidad del centro educativo al que están adscritos. En este sentido, queremos destacar que estos datos son relativos al curso académico 2018-2019, al no haber publicado el Ministère de Éducation Nationale et de la Jeunesse datos más actualizados.

Tabla 8. Número de alumnos matriculados en educación secundaria superior general y tecnológica, atendiendo a la variable género, titularidad del centro y especialidad cursada (2019)

\begin{tabular}{|c|c|c|c|c|c|c|}
\hline \multirow{2}{*}{ Series } & \multicolumn{3}{|c|}{ Público } & \multicolumn{3}{|c|}{ Privado } \\
\hline & Hombres & Mujeres & Total & Hombres & Mujeres & Total \\
\hline \multicolumn{7}{|c|}{ SECONDES } \\
\hline General/Tecnológico & 201.327 & 235.358 & 436.685 & 55.839 & 62.429 & 118.268 \\
\hline TMD/BT & 943 & 1.180 & 2.123 & 163 & 177 & 340 \\
\hline TOTAL SECONDES & 202.270 & 236.538 & 438.808 & 56.002 & 62.606 & 118.608 \\
\hline \multicolumn{7}{|c|}{ PREMIÈRES } \\
\hline $\mathbf{S}$ & 78.439 & 72.556 & 150.995 & 26.034 & 22.495 & 48.529 \\
\hline ES & 37.303 & 60.135 & 97.438 & 12.224 & 17.671 & 29.895 \\
\hline $\mathbf{L}$ & 9.223 & 35.225 & 44.448 & 2.056 & 7.716 & 9.772 \\
\hline STI2D & 27.309 & 2.411 & 29.720 & 3.949 & 250 & 4.199 \\
\hline STL & 3.373 & 4.530 & 7.903 & 618 & 669 & 1.287 \\
\hline STMG & 29.888 & 32.092 & 61.980 & 5.765 & 5.339 & 11.104 \\
\hline ST2S & 2.130 & 14.649 & 16.779 & 923 & 5.378 & 6.301 \\
\hline STD2A & 581 & 1.993 & 2.574 & 297 & 821 & 1.118 \\
\hline TMD & 134 & 180 & 314 & 3 & 12 & 15 \\
\hline Hôtellerie & 969 & 1.186 & 2.155 & 129 & 174 & 303 \\
\hline Brevet de technicien & 56 & 144 & 200 & 17 & 17 & 34 \\
\hline TOTAL PREMIÈRES & 189.405 & 225.101 & 414.506 & 52.015 & 60.542 & 112.557 \\
\hline \multicolumn{7}{|c|}{ TERMINALES } \\
\hline $\mathbf{S}$ & 80.075 & 72.713 & 152.788 & 24.055 & 21.007 & 45.062 \\
\hline ES & 40.336 & 61.648 & 101.984 & 12.082 & 17.193 & 29.275 \\
\hline $\mathbf{L}$ & 9.377 & 37.449 & 46.826 & 2.106 & 7.863 & 9.969 \\
\hline STI2D & 29.031 & 2.453 & 31.484 & 3.818 & 283 & 4.101 \\
\hline
\end{tabular}


Itinerarios de acceso/admisión a la educación superior. Un análisis comparado en los sistemas educativos de España, Francia y Finlandia

\begin{tabular}{|c|c|c|c|c|c|c|}
\hline STL & 3.313 & 4.537 & 7.850 & 614 & 656 & 1.270 \\
\hline STMG & 31.662 & 33.179 & 64.841 & 5.820 & 5.420 & 11.240 \\
\hline ST2S & 2.218 & 15.150 & 17.368 & 870 & 5.740 & 6.610 \\
\hline STD2A & 556 & 1.893 & 2.449 & 244 & 780 & 1.024 \\
\hline TMD & 121 & 158 & 279 & 4 & 9 & 13 \\
\hline Hôtellerie & 910 & 1.174 & 2.084 & 157 & 170 & 327 \\
\hline Brevet de technicien & 46 & 143 & 189 & 12 & 27 & 39 \\
\hline TOTAL TERMINALES & $\mathbf{1 9 7 . 6 4 5}$ & $\mathbf{2 3 0 . 4 9 7}$ & $\mathbf{4 2 8 . 1 4 2}$ & $\mathbf{4 9 . 7 8 2}$ & $\mathbf{5 9 . 1 4 8}$ & $\mathbf{1 0 8 . 9 3 0}$ \\
\hline TOTAL & $\mathbf{5 8 9 . 3 9 0}$ & $\mathbf{6 9 2 . 2 0 3}$ & $\mathbf{1 . 2 8 1 . 5 9 3}$ & $\mathbf{1 5 7 . 8 4 7}$ & $\mathbf{1 8 2 . 3 1 8}$ & $\mathbf{3 4 0 . 1 6 5}$ \\
\hline
\end{tabular}

Fuente: Elaboración propia a partir de http://www.education.gouv.fr/

Sin ánimo de ser exhaustivos, queremos realizar un pequeño análisis al respecto. Dado que el primer curso de la educación secundaria superior (Seconde) es común para todos los alumnos, vamos a detenernos en los dos últimos (Première y Terminale), que son aquellos cursos con itinerarios específicos de formación. El primer dato que debemos resaltar es cómo dentro del itinerario general, la especialidad más numerosa es la Científica (S) -24,5\% del total de alumnos de educación secundaria superior, frente al 15,9\% y 6,8\% de las especialidades de Ciencias Sociales (ES) y Literatura (L), respectivamente-, tanto en Première como Terminal, y esa misma tendencia se mantiene tanto en los centros públicos como privados. Por otro lado, podemos apreciar cómo los hombres tienen una mayor presencia en la especialidad científica, mientras que las mujeres son mayoritarias en la de Ciencias Sociales y Literatura.

Si nos centramos en el itinerario tecnológico, podemos apreciar como la especialidad STMG, es la más numerosa en términos globales (76.000 alumnos), con una gran presencia tanto de hombres como mujeres, en el ámbito público y privado. Si hacemos un análisis más pormenorizado atendiendo a la variable género, debemos destacar que la mayor proporción de estudiantes masculinos se encuentran en la especialidad STI2D (con un porcentaje que se aproxima al 95\%), mientras que en el femenino en la ST2S (con casi un 90\%). Por último, si atendemos a la titularidad del 
centro educativo, debemos reseñar que no existen diferencias significativas entre los centros públicos y los privados.

Por otro lado, vamos a analizar la vertiente profesional. En este sentido, vamos a realizar una doble distinción, examinando las distintas familias profesionales del sector productivo (tabla 9) y del sector servicios (tabla 10).

Tabla 9. Número de alumnos matriculados en educación secundaria superior profesional (sector producción), atendiendo a la variable género, titularidad del centro y familia profesional (2019)

\begin{tabular}{|c|c|c|c|c|c|c|c|c|}
\hline Especialidad & \multicolumn{3}{|c|}{ CAP } & \multicolumn{3}{c|}{ BAC } \\
\cline { 2 - 8 } & $\mathbf{N}$ & $\%$ & $\begin{array}{c}\text { Privado } \\
(\%)\end{array}$ & $\begin{array}{c}\text { Mujeres } \\
(\%)\end{array}$ & $\mathbf{N}$ & $\%$ & $\begin{array}{c}\text { Privado } \\
(\%)\end{array}$ & $\begin{array}{c}\text { Mujeres } \\
(\%)\end{array}$ \\
\hline $\begin{array}{c}\text { Tecnologías } \\
\text { industriales básicas }\end{array}$ & 282 & 0,2 & 16,7 & 29,1 & 2.367 & 0,4 & 16,3 & 7,2 \\
\hline $\begin{array}{c}\text { Tecnología de control } \\
\text { de transformaciones } \\
\text { industriales }\end{array}$ & 1.189 & 1,0 & 21,1 & 5,8 & 963 & 0,2 & 4,7 & 7,2 \\
\hline $\begin{array}{c}\text { Especialidades } \\
\text { multidisciplinarias de } \\
\text { agronomía y } \\
\text { agricultura }\end{array}$ & 14 & - & 21,4 & 7,1 & - & - & - & - \\
\hline $\begin{array}{c}\text { Producciones } \\
\text { vegetales, cultivos } \\
\text { especializados }\end{array}$ & 444 & 0,4 & 4,1 & 34,2 & 127 & - & - & 46,5 \\
\hline $\begin{array}{c}\text { Producciones animales, } \\
\text { granjas especializadas }\end{array}$ & - & - & - & - & 188 & - & - & 6,4 \\
\hline $\begin{array}{c}\text { Bosques, espacios } \\
\text { verdes, fauna silvestre }\end{array}$ & 24 & - & - & 8,3 & 60 & - & - & 8,3 \\
\hline $\begin{array}{c}\text { Paisajismo, parques, } \\
\text { jardines, espacios } \\
\text { verdes... }\end{array}$ & 644 & 0,6 & 1,9 & 10,9 & 315 & 0,1 & 3,5 & 19,0 \\
\hline $\begin{array}{c}\text { Especialidades } \\
\text { multitecnológicas de } \\
\text { transformaciones }\end{array}$ & 220 & 0,2 & 28,2 & 39,1 & 2.565 & 0,5 & 10,0 & 32,2 \\
\hline $\begin{array}{c}\text { Agroalimentación, } \\
\text { alimentación y cocina }\end{array}$ & 14.684 & 12,8 & 16,6 & 40,8 & 19.266 & 3,7 & 18,1 & 35,4 \\
\hline $\begin{array}{c}\text { Transformaciones } \\
\text { químicas y sus } \\
\text { relaciones }\end{array}$ & 17 & - & - & - & - & - & - & - \\
\hline Metalurgia & 746 & 0,6 & 20,1 & 67,6 & 677 & 0,1 & 13,9 & 51,0 \\
\hline
\end{tabular}


Itinerarios de acceso/admisión a la educación superior. Un análisis comparado en los sistemas educativos de España, Francia y Finlandia

\begin{tabular}{|c|c|c|c|c|c|c|c|c|}
\hline $\begin{array}{c}\text { Materiales de } \\
\text { construcción, vidrio y } \\
\text { cerámica }\end{array}$ & 320 & 0,3 & 3,8 & 52,2 & 718 & 0,1 & 18,9 & 46,5 \\
\hline $\begin{array}{c}\begin{array}{c}\text { Plásticos, materiales } \\
\text { compuestos }\end{array} \\
\end{array}$ & 217 & 0,2 & 4,6 & 6,5 & 1.315 & 0,2 & 2,2 & 7,8 \\
\hline $\begin{array}{c}\text { Energía, ingeniería } \\
\text { climática }\end{array}$ & 1.978 & 1,7 & 10,6 & 0,7 & 8.661 & 1,6 & 9,8 & 0,7 \\
\hline $\begin{array}{c}\text { Especialidades } \\
\text { multitecnológicas de } \\
\text { ingeniería civil, } \\
\text { construcciones y } \\
\text { madera } \\
\end{array}$ & 1.498 & 1,3 & 31,0 & 4,5 & 8.272 & 1,6 & 13,3 & 29,9 \\
\hline $\begin{array}{c}\text { Minas y canteras, } \\
\text { ingeniería civil y } \\
\text { topografía }\end{array}$ & 1.171 & 1,0 & 22,2 & 1,1 & 3.282 & 0,6 & 10,4 & 4,5 \\
\hline $\begin{array}{c}\text { Edificio: construcción } \\
\text { y techo }\end{array}$ & 2.774 & 2,4 & 4,0 & 1,4 & 3.545 & 0,7 & 2,8 & 2,5 \\
\hline Construcción & 6.502 & 5,7 & 4,7 & 6,6 & 4.747 & 0,9 & 6,2 & 19,8 \\
\hline $\begin{array}{c}\text { Carpintería y } \\
\text { mobiliario }\end{array}$ & 6.672 & 5,8 & 9,6 & 10,6 & 12.466 & 2,4 & 12,3 & 11,1 \\
\hline $\begin{array}{c}\text { Especialidades } \\
\text { multitecnológicas de } \\
\text { materiales flexibles }\end{array}$ & 527 & 0,5 & - & 76,3 & 68 & - & - & 91,2 \\
\hline Textil & 67 & 0,1 & - & 92,5 & - & - & - & - \\
\hline Ropa & 2.478 & 2,2 & 9,6 & 87,1 & 9.819 & 1,9 & 10,0 & 90,7 \\
\hline Cuero y pieles & 373 & 0,3 & - & 57,1 & 769 & 0,1 & - & 81,4 \\
\hline $\begin{array}{c}\text { Especialidades } \\
\text { multitecnológicas y } \\
\text { electromecánica } \\
\end{array}$ & - & - & - & - & 23.077 & 4,4 & 12,0 & 2,7 \\
\hline $\begin{array}{c}\text { Mecánica general y } \\
\text { mecanizado de } \\
\text { precisión }\end{array}$ & 464 & 0,4 & 7,8 & 18,3 & 8.588 & 1,6 & 10,8 & 4,2 \\
\hline $\begin{array}{c}\begin{array}{c}\text { Motores y } \\
\text { automecánica }\end{array} \\
\end{array}$ & 5.426 & 4,7 & 12,8 & 2,4 & 24.243 & 4,6 & 10,4 & 3,5 \\
\hline $\begin{array}{c}\text { Mecánica aeronáutica } \\
\text { y espacial } \\
\end{array}$ & 122 & 0,1 & 18,0 & 7,4 & 2.137 & 0,4 & 15,5 & 8,0 \\
\hline Estructuras metálicas & 6.818 & 5,9 & 7,8 & 2,3 & 12.632 & 2,4 & 6,0 & 3,3 \\
\hline $\begin{array}{c}\text { Electricidad y } \\
\text { electrónica }\end{array}$ & 6.861 & 6,0 & 11,6 & 1,1 & 68.836 & 13,1 & 16,5 & 1,9 \\
\hline $\begin{array}{c}\text { TOTAL, } \\
\text { PRODUCCIÓN }\end{array}$ & 62.532 & 54,4 & 11,7 & 18,7 & 219.703 & 41,7 & 12,9 & 12,4 \\
\hline
\end{tabular}

Fuente: Elaboración propia a partir de http://www.education.gouv.fr/ 
Tabla 10. Número de alumnos matriculados en educación secundaria superior profesional (sector servicios), atendiendo a la variable género, titularidad del centro y familia profesional (2019)

\begin{tabular}{|c|c|c|c|c|c|c|c|c|}
\hline \multirow[b]{2}{*}{ Especialidad } & \multicolumn{4}{|c|}{ CAP } & \multicolumn{4}{|c|}{ BAC } \\
\hline & $\mathbf{N}$ & $\%$ & $\begin{array}{c}\text { Privado } \\
(\%)\end{array}$ & $\begin{array}{c}\text { Mujeres } \\
(\%)\end{array}$ & $\mathbf{N}$ & $\%$ & \begin{tabular}{|c|} 
Privado \\
$(\%)$
\end{tabular} & $\begin{array}{c}\text { Mujeres } \\
(\%)\end{array}$ \\
\hline $\begin{array}{c}\text { Especialidad de } \\
\text { servicios polivalentes }\end{array}$ & 183 & 0,2 & 8,2 & 45,9 & 71.382 & 13,6 & 18,2 & 67,9 \\
\hline $\begin{array}{c}\text { Transporte, manejo y } \\
\text { compras }\end{array}$ & 3.416 & 3,0 & 18,6 & 8,8 & 15.034 & 2,9 & 14,3 & 11,2 \\
\hline Comercio y Venta & 18.544 & 16,1 & 20,1 & 50,9 & 112.585 & 21,4 & 24,9 & 52,2 \\
\hline $\begin{array}{c}\text { Técnicas de impresión y } \\
\text { publicación }\end{array}$ & 1.166 & 1,0 & 24,0 & 43,0 & 3.018 & 0,6 & 14,3 & 28,2 \\
\hline $\begin{array}{c}\text { Técnicas de imagen y } \\
\text { sonido, intercambios } \\
\text { relacionados con el } \\
\text { espectáculo }\end{array}$ & 72 & 0,1 & 20,8 & 47,2 & 5.687 & 1,1 & 49,4 & 49,6 \\
\hline $\begin{array}{c}\text { Múltiples } \\
\text { especialidades Sociales } \\
\text { y Sanitarias }\end{array}$ & 40 & - & 5,0 & 72,5 & 65.669 & 12,5 & 33,6 & 90,5 \\
\hline Salud & 83 & 0,1 & - & 39,8 & 2.959 & 0,6 & 30,7 & 56,1 \\
\hline Trabajo Social & 4.847 & 4,2 & 41,9 & 96,3 & - & - & - & - \\
\hline Hostelería y Turismo & 11.366 & 9,9 & 17,5 & 71,9 & 11.421 & 2,2 & 14,1 & 47,1 \\
\hline $\begin{array}{c}\text { Animación Cultural, } \\
\text { Ocio y Deportes }\end{array}$ & 35 & - & 100,0 & - & - & - & - & - \\
\hline $\begin{array}{c}\text { Peluquería, Estética y } \\
\text { otros servicios para las } \\
\text { personas }\end{array}$ & 8.488 & 7,4 & 56,4 & 90,2 & 9.707 & 1,8 & 55,2 & 99,5 \\
\hline $\begin{array}{c}\text { Especialidades } \\
\text { polivalentes de } \\
\text { Servicios Comunitarios }\end{array}$ & 79 & 0,1 & 32,9 & 43,0 & - & - & - & - \\
\hline $\begin{array}{c}\text { Limpieza, Saneamiento } \\
\text { y Protección del Medio } \\
\text { Ambiente }\end{array}$ & 1.233 & 1,1 & 4,1 & 57,1 & 2.598 & 0,5 & 3,5 & 67,2 \\
\hline $\begin{array}{c}\text { Seguridad de propiedad } \\
\text { y personas, Policía y } \\
\text { Vigilancia }\end{array}$ & 2.785 & 2,4 & 45,4 & 26,0 & 6.738 & 1,3 & 34,9 & 29,4 \\
\hline TOTAL, SERVICIOS & 52.337 & 45,6 & 28,4 & 61,9 & 306.798 & 58,3 & 25,7 & 62,7 \\
\hline
\end{tabular}

Fuente: Elaboración propia a partir de http://www.education.gouv.fr/ 
Tal y como podemos observar, el número de alumnos adscritos al sector servicios (359.135), es mayor que al de producción (282.235), si bien, la tendencia es opuesta entre aquellos alumnos matriculados en el CAP (62.532 alumnos en el sector productivo frente a los 57.337 en el sector servicios). Si hacemos un análisis más individualizado de cada una de las especialidades, destacamos que el mayor número de alumnos en el sector productivo se encuentran: Agroalimentación, Alimentación y Cocina, Construcción, Carpintería y Mobiliario, Motores y Automecánica, Estructuras Metálicas y Electricidad y, finalmente, Electrónica. Mientras que en la especialidad de servicios, destacan sobre el resto los cursos de: Comercio y Venta, Hostelería y Turismo y, finalmente, Peluquería, Estética y otros servicios para personas.

Para poner punto y final al análisis académico de los estudiantes franceses, vamos a mostrar el número de alumnos de educación secundaria superior, atendiendo a la titularidad del centro educativo al que están adscritos. En este sentido, podemos afirmar que el sistema educativo francés sigue la tendencia europea, donde la escolarización se desarrolla, mayoritariamente, en centros de titularidad pública, quedando los centros privados relegados a un segundo plano. Esta tendencia se prolonga también hacia los estudios postobligatorios, tanto en los lycées generales y tecnológicos como en los profesionales (gráfico 17 y 18$)^{36}$.

\footnotetext{
${ }^{36}$ Los datos relativos al año 2013 no figuran al no estar disponibles en las fuentes oficiales de la administración francesa
} 
Gráfico 17. Evolución del número de alumnos matriculados en educación secundaria superior general y tecnológica, atendiendo a la titularidad del centro

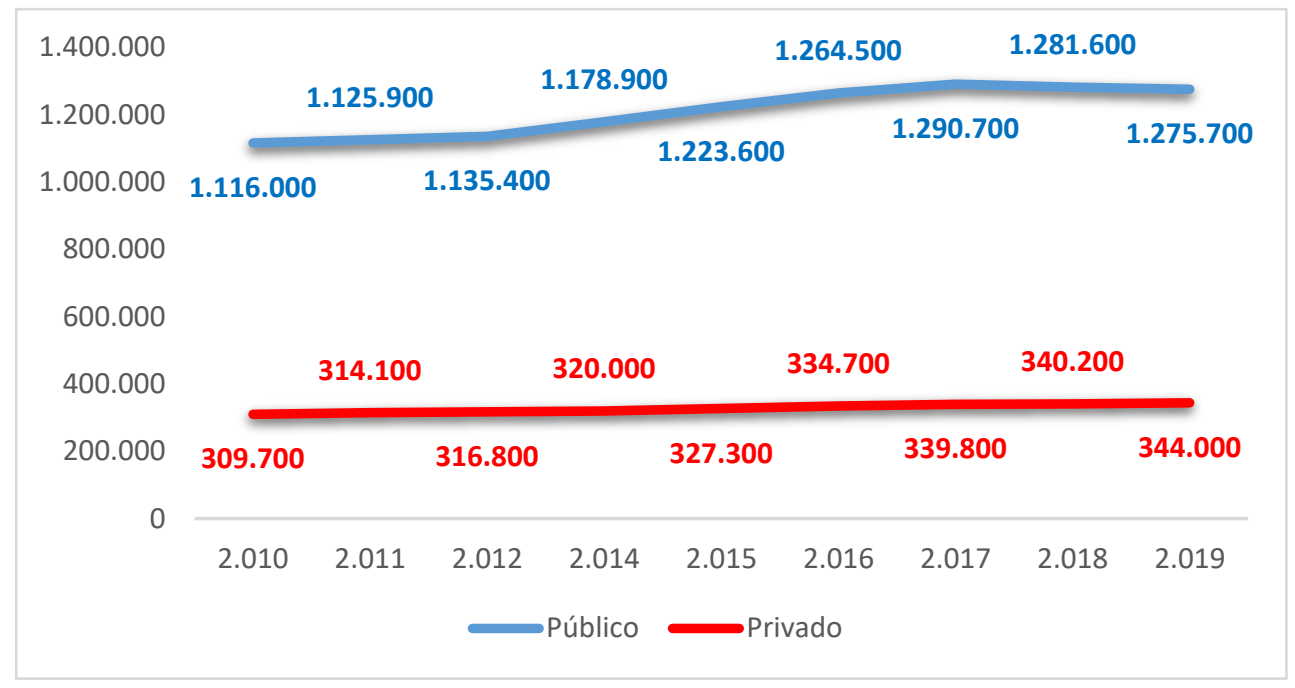

Fuente: Elaboración propia a partir de http://www.education.gouv.fr/

\section{Gráfico 18. Evolución del número de alumnos matriculados en educación secundaria superior profesional, atendiendo a la titularidad del centro}

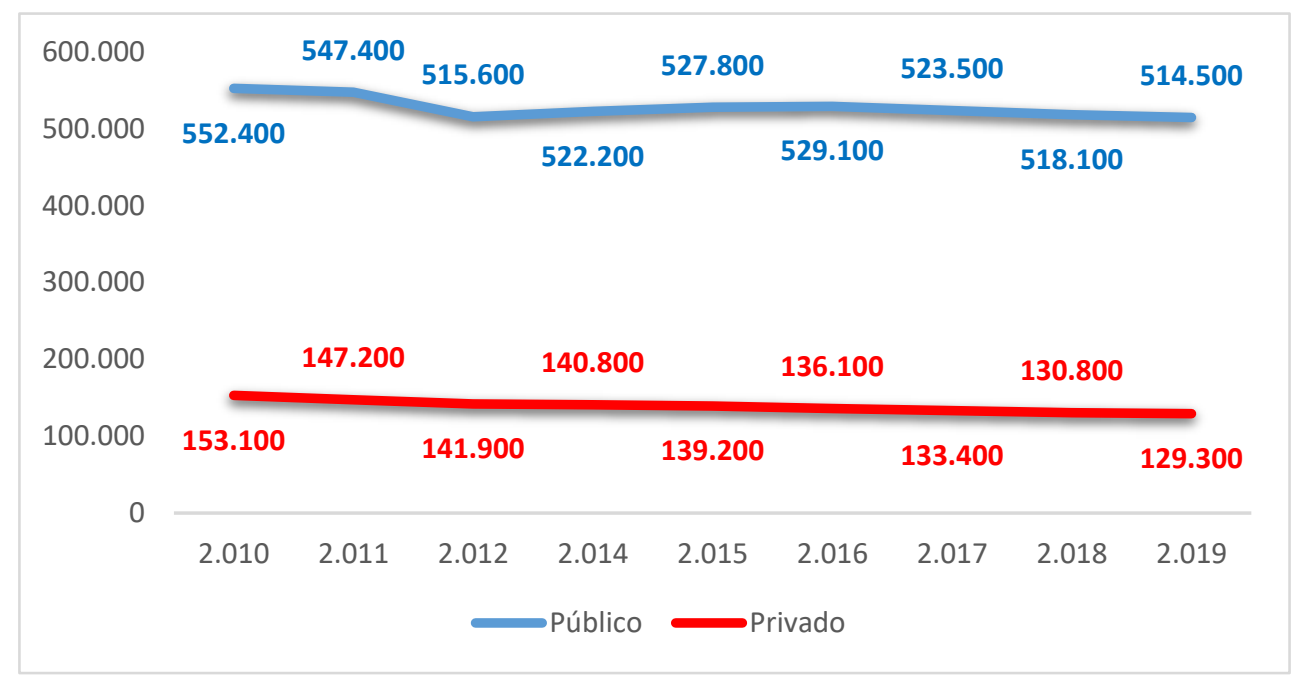

Fuente: Elaboración propia a partir de http://www.education.gouv.fr/ 
Itinerarios de acceso/admisión a la educación superior. Un análisis comparado en los sistemas educativos de España, Francia y Finlandia

\subsubsection{3) Sistema educativo finlandés}

Por último, analizaremos el perfil académico de aquellos alumnos que están en disposición de acceder a los estudios de educación superior en Finlandia. Para ello, nos valdremos de los datos emitidos por la administración finlandesa, a través de su Oficina de Estadística (Statics Finland). En este sentido, vamos a llevar a cabo un análisis muy similar al que venimos realizando hasta el momento, haciendo una distinción entre la educación secundaria superior general y la educación secundaria superior profesional, dado que posee desarrollo institucional y curricular es distinto (ver gráficos 19 y $20^{37}$ ).

\section{Gráfico 19. Evolución del número de alumnos matriculados en educación secundaria superior general}

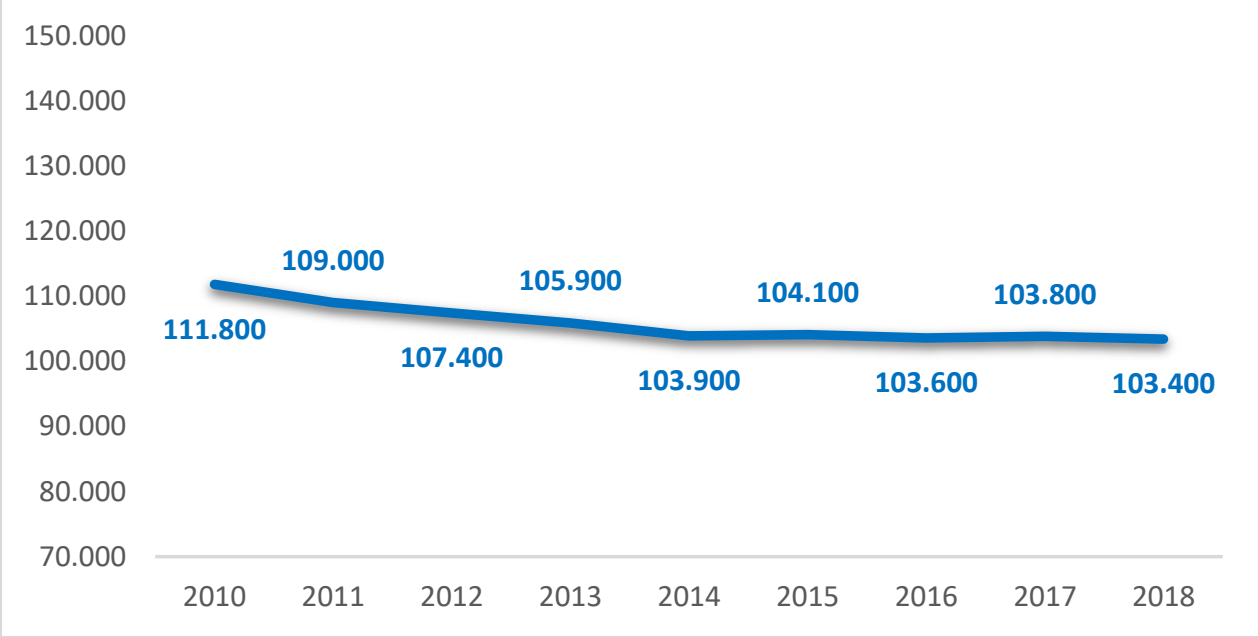

Fuente: Education. Statistics Finland

\footnotetext{
${ }^{37}$ Los datos relativos al número de alumnos matriculados en la educación secundaria superior profesional durante el curso 2010-2011, no estaban recogidos en los informes analizados
} 


\section{Gráfico 20. Evolución del número de alumnos matriculados en educación secundaria superior profesional}

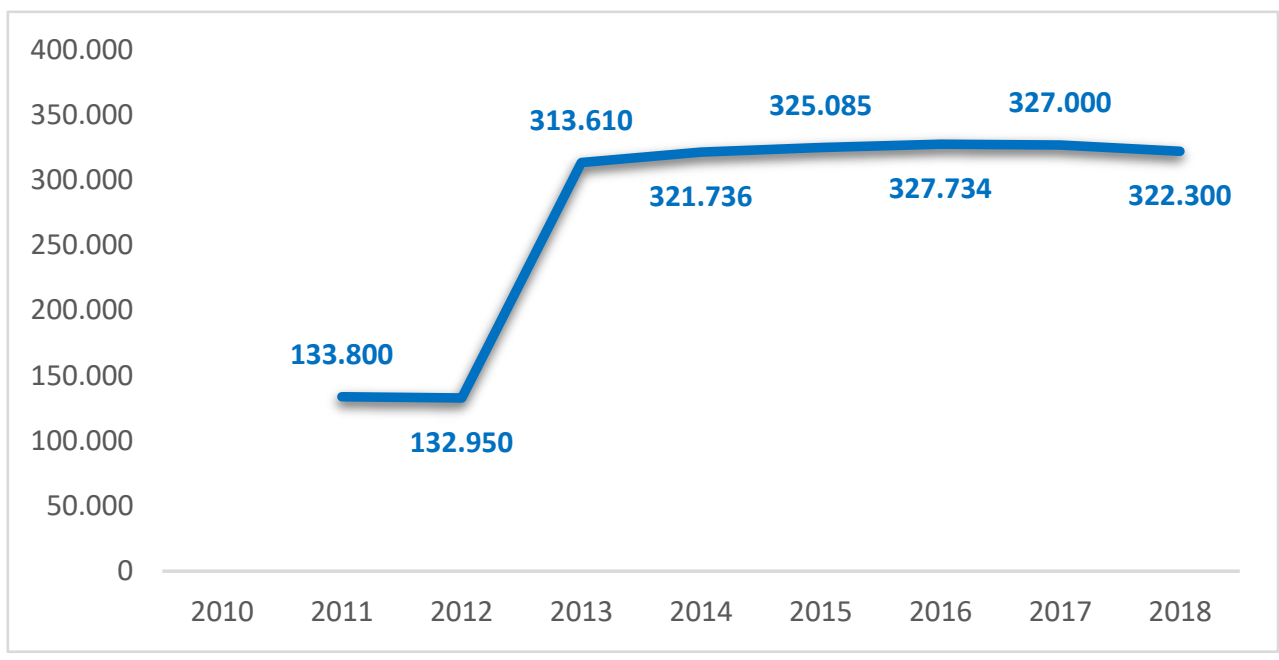

Fuente: Education. Statistics Finland

En este sentido, podemos apreciar como el número de alumnos matriculados en educación secundaria superior profesional es muy superior (casi tres veces más) al número de alumnos de educación secundaria superior general. Este hecho puede ser explicado gracias a la gran flexibilidad que presentan estos programas educativos, que están más enfocados hacia los estudios de educación postsecundaria no superior (CINE 4), que hacia los planes de estudios de educación superior.

Si comenzamos analizando la vertiente profesional, lo primero que nos llama la atención es la gran variación en el número de alumnos matriculados en este itinerario vocacional, especialmente, a partir del curso académico 2012-2013, momento en el que este itinerario experimentó un crecimiento exponencial. Estos datos pueden ser explicados a partir la influencia que ha comenzado a ejercer el sistema económico-productivo sobre los alumnos, generando una gran atracción hacia aquellos perfiles profesionales que guardan relación con las nuevas demandas del 
mercado laboral, que han provocado un mayor auge de esta formación vocacional. Si analizamos estos datos atendiendo a la variable género, apreciamos como el porcentaje de hombres y mujeres es muy similar, si bien, sufre grandes fluctuaciones en función de las ramas profesionales (por ejemplo, el sector tecnológico y las ingenierías son mayoritariamente masculinos, mientras que las de área sanitaria es femenina). Por otro lado, también nos gustaría señalar que, de los más de 300.000 alumnos que durante el curso académico 2018-2019 han cursado estudios vocacionales, aproximadamente 123.000 eran nuevos estudiantes (85.000 de ellos están matriculados en la formación vocacional inicial, 27.300 en la adicional y 10.8000 en la especializada).

En cambio, si analizamos la educación secundaria superior general, podemos observar cómo la tendencia es opuesta, ya que, pese a que la matrícula se ha mantenido muy estable a lo largo de la última década, lo cierto es que se ha producido un descenso durante los últimos años, de entorno a un $8 \%$, según los datos oficiales del gobierno finlandés. Si analizamos el número de mujeres en este itinerario formativo, podemos apreciar como este es ligeramente superior al de hombres con, aproximadamente, un $60 \%$ del total de alumnos, lo que en términos absolutos supone en torno a 60.000 mujeres matriculadas durante el año 2018.

Por otro lado, debemos destacar que Finlandia es un país que apuesta firmemente por la internacionalización, algo que se ve reflejado de una forma clara dentro del contexto educativo. Por ello, junto a este itinerario general, que nosotros vamos a denominar como ordinario, también existen otros, que no son tan comunes (al menos en cuento a número de estudiantes), pero que también cuentan con validez en el sistema educativo nórdico. En primer lugar, debemos tener en cuenta que, en Finlandia, además del finés, la lengua sueca también está reconocida como oficial, y por ello, desde la administración educativa, se ofertan planes de estudio que se desarrollan íntegramente en este idioma. Según los datos oficiales de Statistics 
Finland, en el año 2018, un total de 36 escuelas oficiales impartían estudios de enseñanza secundaria superior en sueco, lo que supone en torno a un $6 \%$ del total de estudiantes. Por otro lado, también debemos señalar que el país nórdico cuenta con una modalidad internacional de bachillerato, donde cada año, casi dos mil estudiantes se forman a partir de este itinerario formativo (en el año 2018, 1.789 alumnos optaron por esta modalidad de estudios). Por último, también debemos hacer alusión al bachillerato europeo, que no goza del mismo protagonismo que el internacional, pero que cada curso congrega un número representativo de estudiantes (los últimos datos, lo cifran en un total de 66).

Para finalizar, haremos un breve comentario acerca de la titularidad de los centros educativos al que están adscritos los alumnos. Como ya hemos comentado, Finlandia es un país que apuesta de una forma vehemente por los servicios públicos, entre los que se encuentra la educación. De hecho, las instituciones educativas de carácter privado tienen un papel residual en Finlandia, donde el porcentaje de centros públicos, no solo en esta etapa educativa, sino en todo su conjunto, es muy elevado, muy próximo al cien por cien. Para ser más exactos, los datos publicados por la OECD (2016) establecían que un 95\% de los estudiantes de educación secundaria estaban adscritos a centros de titularidad pública. Estos datos, nos permiten afirmar de una forma clara y contundente que, prácticamente, la totalidad de alumnos que acceden a los estudios de educación superior en el país nórdico, lo hacen tras haber superados los estudios de educación secundaria superior en centros públicos.

\subsection{2) Rendimiento competencial en las pruebas de acceso}

\subsubsection{1) Sistema educativo español}

España no es un país que cuente con una consolidada tradición de exámenes públicos dentro de su sistema educativo. Esta ausencia, debemos achacarla, en gran medida, al tardío desarrollo de la educación secundaria pública en nuestro país, así 
como al escaso protagonismo que ha desempeñado el Estado hasta hace escaso tiempo (Moreno, 1992). En 1970, con la Ley General de Educación (LGE) ${ }^{38}$, España pasó a formar parte de un reducido número de países que optaba por eliminar cualquier tipo de prueba para el acceso a la universidad; pero, finalmente, en 1975, la fuerte demanda universitaria de nuestro país obligo a instaurar, por primera vez, las Pruebas de Aptitud para el Acceso a la Universidad (PAAU), conocida popularmente como Selectividad. La superación de esta prueba es un requisito indispensable para el acceso universitario en nuestro país. Si bien, además de esta, son muchas las funciones que, diversos autores, han atribuido a este examen a lo largo de los últimos años: homologar y certificar los conocimientos que los alumnos han adquiridos durante la educación secundaria, evaluar su madurez, ubicarlos adecuadamente en unos determinados estudios, etc. (Lorenzo et al., 2014).

En la actualidad, la situación que vive el sistema educativo español es un tanto ambigua. La inestabilidad y polarización política que preside nuestro país ha impedido que la última gran propuesta educativa en materia de acceso se haya implantado de una forma definitiva, tal y como recogía su calendario de aplicación. De este modo, se ha apostado por aprobar diferentes órdenes ministeriales y regionales que, año a año, se encargan de regular el acceso universitario de forma momentánea, hasta que se consolide una propuesta definitiva. Por lo tanto, a día de hoy, el acceso universitario sigue ejerciéndose a través de la histórica prueba de acceso a la universidad, una prueba que, pese a que está adquiriendo un mayor carácter competencial, se mantiene, principalmente, como un examen de carácter cultural (Vega y Hernández, 2015).

\footnotetext{
${ }^{38}$ Ley 14/ 1970, de 4 de agosto, general de Educación y Financiamiento de la Reforma educativa. Boletín Oficial del Estado, 6 de agosto de 1970, Núm. 187, p. 12525-12546.
} 
Por otro lado, debemos reconocer que estas modificaciones que ha sufrido la prueba a lo largo de los últimos años, no han traído cambios en torno a su estructura, que se mantiene, prácticamente, intacta desde hace varios años (RD 1892/2008 de 14 de noviembre), con dos partes claramente definidas: una general, que deben superar todos los alumnos, previo acceso a la universidad, y una específica, de carácter voluntario, a partir de la cual los estudiantes podrán mejorar sus calificaciones. La fase general estará compuesta por cuatro exámenes, tres de ellos correspondientes a las materias comunes del último curso de bachillerato (Lengua Castellana y Literatura, Historia de España o Historia de la Filosofía, y Lengua Extranjera), y el cuarto, sobre una materia de modalidad cursada por el alumno en este último curso. Mientras que, en la fase específica, el alumno podrá examinarse hasta de un máximo de cuatro materias de la modalidad elegida (exceptuando aquella que haya sido elegida en la fase general), de las cuales tan solo se tendrán en consideración las dos mejores calificaciones obtenidas por el alumno. Estos exámenes serán ponderados por la administración con 0,1, mientras que las universidades pueden elevarlo hasta el 0,2. Cada uno de los ejercicios será calificado de 0 a 10 puntos, con dos cifras decimales. La calificación de la fase general se obtendrá a partir de la media aritmética de las calificaciones de todos los ejercicios realizados; será necesario obtener una calificación final igual o superior a 4 puntos para superar esta prueba y, de este modo, poder acceder a los estudios universitarios. Esto es así desde la década de los ochenta del pasado siglo, cuando nuestro país llevó a cabo una apuesta puramente social, reduciendo la nota necesaria para la superación de esta prueba que, hasta ese momento, estaba fijada en 5 puntos. Mientras que, en la fase específica, las materias también serán calificados de 0 a 10 puntos; en este caso, se darán por superadas cuando se obtenga una calificación igual o superior a 5 puntos; si no obtuviesen esa calificación mínima, las materias no serían ponderadas sobre la nota final de acceso del alumno. 
$\mathrm{Si}$ analizamos los datos de la prueba, podemos afirmar que estos son realmente buenos, con un índice de aprobados muy elevado. A continuación, vamos a realizar un análisis específico, desglosando estos datos por CC. AA, atendiendo al último informe publicado por la administración educativa al respecto (MCIU, 2018). Tal y como muestra la tabla 11, el porcentaje de aprobados en esta prueba es sumamente elevado situándose por encima del $92 \%$ en la convocatoria ordinaria; si bien, los datos empeoran ostensiblemente en su convocatoria extraordinaria, reduciéndose en más de 15 puntos. Las CC. AA con mayores porcentajes de aprobado son: País Vasco, La Rioja, Canarias, Aragón y Cantabria; mientras que, en el extremo opuesto, encontramos a Andalucía y a la Comunidad de Madrid.

Tabla 11. Número de alumnos matriculados, presentados y aprobados en la prueba de acceso a la universidad, por comunidades autónomas (2017)

\begin{tabular}{|c|c|c|c|c|}
\hline & Matriculados & Presentados & Aprobados & $\begin{array}{c}\text { Aprobados/Presentados } \\
(\%)\end{array}$ \\
\hline Andalucía & 49.868 & 48.942 & 42.646 & 90,2 \\
\hline Aragón & 6.474 & 6.422 & 6.109 & 96,3 \\
\hline Asturias & 4.594 & 4.531 & 4.084 & 91,9 \\
\hline Islas Baleares & 4.492 & 4.442 & 3.794 & 91,1 \\
\hline Canarias & 11.108 & 10.935 & 10.459 & 96,8 \\
\hline Cantabria & 2.579 & 2.566 & 2.422 & 96,3 \\
\hline $\begin{array}{c}\text { Castilla - La } \\
\text { Mancha }\end{array}$ & 8.998 & 8.906 & 8.083 & 94,0 \\
\hline $\begin{array}{c}\text { Castilla y } \\
\text { León }\end{array}$ & 11.232 & 11.159 & 10.056 & 92,9 \\
\hline Cataluña & 37.492 & 36.407 & 32.231 & 91,9 \\
\hline $\begin{array}{c}\text { Comunidad } \\
\text { Valenciana }\end{array}$ & 23.814 & 23.653 & 22.143 & 95,2 \\
\hline Extremadura & 5.843 & 5.799 & 5.212 & 92,9 \\
\hline Galicia & 12.668 & 12.542 & 10.987 & 91,3 \\
\hline Madrid & 36.350 & 36.017 & 31.622 & 90,3 \\
\hline Murcia & 8.386 & 8.298 & 7.526 & 92,6 \\
\hline
\end{tabular}

${ }^{39}$ Los datos remitidos hacen alusión solamente a la convocatoria ordinaria de la prueba 


\begin{tabular}{|c|c|c|c|c|}
\hline Navarra & 3.371 & 3.351 & 3.139 & 95,5 \\
\hline País Vasco & 12.641 & 12.416 & 12.000 & 97,9 \\
\hline La Rioja & 1.419 & 1.414 & 1.350 & 97,6 \\
\hline UNED $^{40}$ & 5.737 & 5.481 & 4.516 & 84,5 \\
\hline TOTAL & 247.067 & 243.281 & 218.379 & 92,4 \\
\hline
\end{tabular}

Fuente: MCIU (2018)

Si analizamos la evolución de la prueba a lo largo de los últimos años (gráfico 21), podemos apreciar como el número de alumnos presentados ha ido aumentando progresivamente, hasta situarse por encima de los 300.000 durante el curso académico 2016-2017.

\section{Gráfico 21. Evolución del número de alumnos presentados a la prueba de acceso a la universidad (convocatoria ordinaria y extraordinaria)}

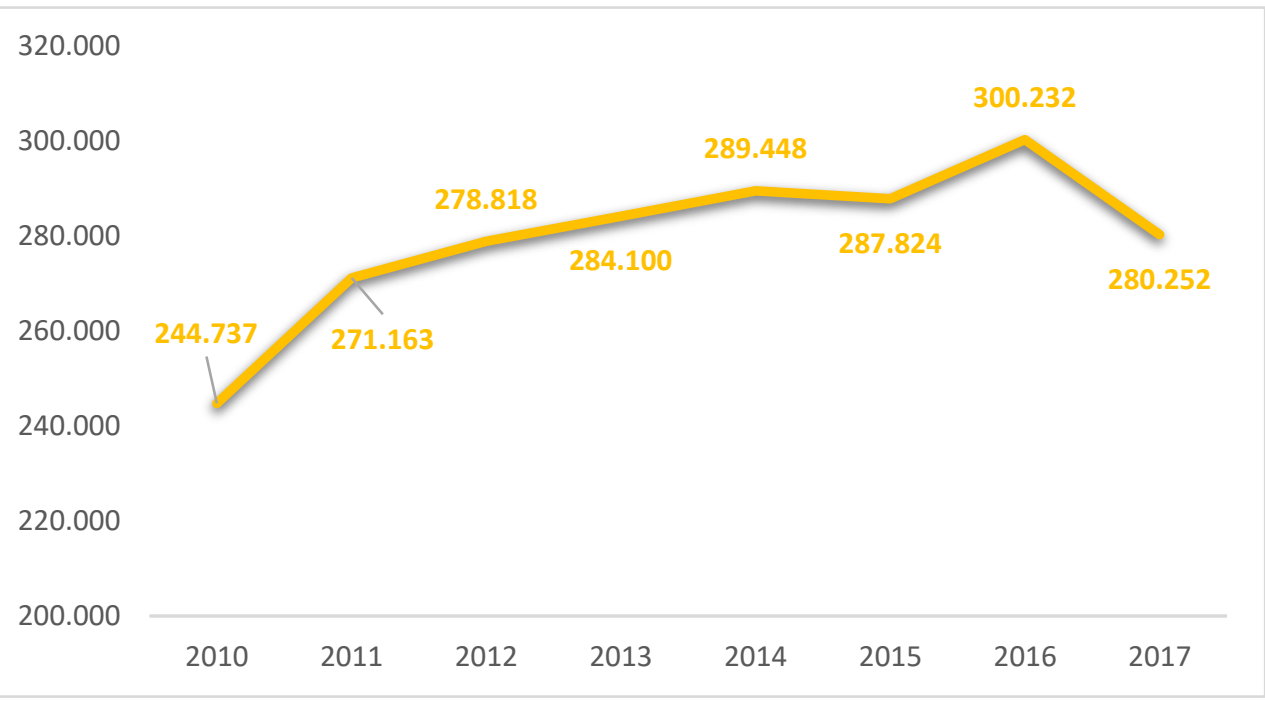

Fuente: Elaboración propia a partir de los datos de los informes «Cifras y Datos del Sistema Universitario Español»

${ }^{40}$ Universidad Nacional de Educación a Distancia 
Por otro lado, si analizamos los datos relativos a la fase específica de la prueba ordinaria de acceso a la universidad, también podemos observar cómo el número de alumnos matriculados ha ido creciendo progresivamente, hasta situarse en 230.000 , lo cual supone más de un $80 \%$ del total de alumnos (gráfico 22$)^{41}$. Estos datos son muy significativos, si tenemos en cuenta que esta fase de la prueba tiene carácter voluntario y que su realización no es imprescindible para el acceso hacia los estudios universitarios.

\section{Gráfico 22. Evolución del número de alumnos presentados a la fase específica de la prueba de acceso a la universidad}

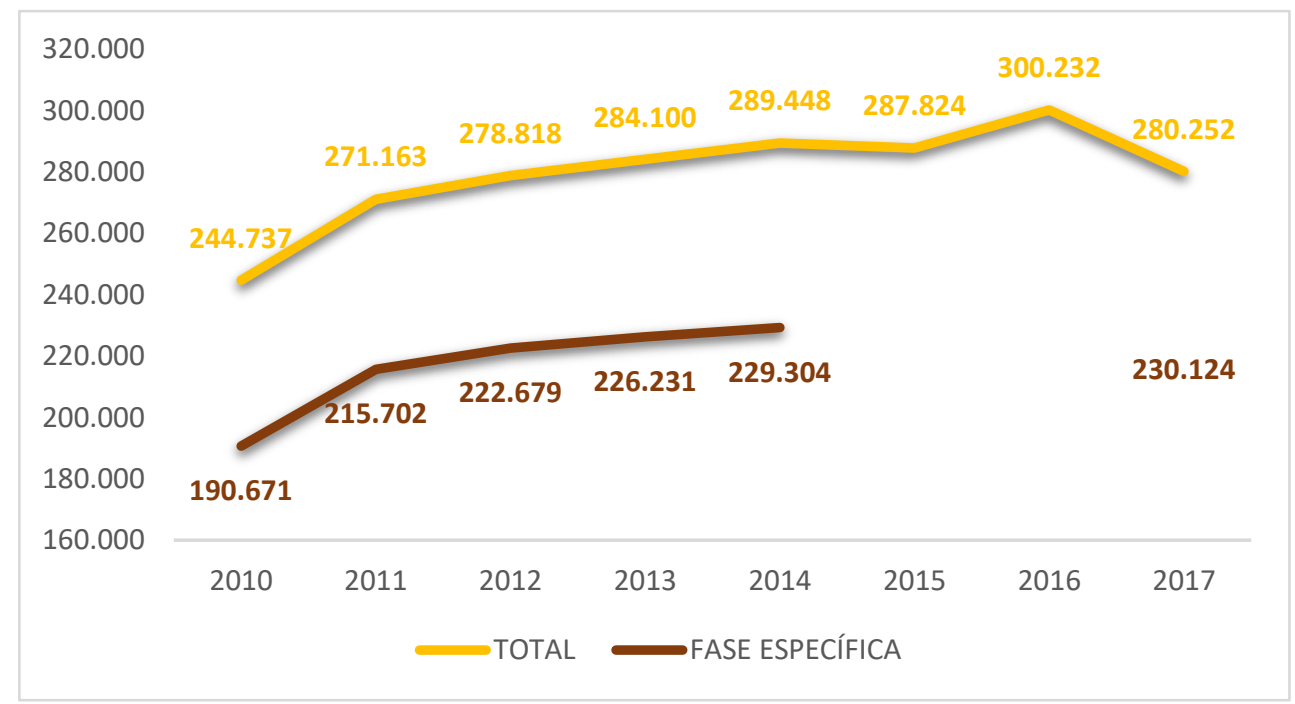

Fuente: Elaboración propia a partir de los datos de los informes «Cifras y Datos del Sistema Universitario Español»

Finalmente, para poner punto y final a este apartado, debemos tener en cuenta que este procedimiento de acceso que acabamos de analizar es el más común, pero no el único que goza de validez en nuestro país. Esto es algo característico de nuestro

${ }^{41}$ Los datos relativos a la fase específica de los cursos académicos 2015-2016 y 2016-2017 no figuran en nuestro estudio, al no existir documentos oficiales de la administración educativa que los recojan. 
sistema educativo, pero un tanto inusual fuera de nuestras fronteras, donde hay países que tan solo cuentan con una única vía de acceso hacia los estudios de educación superior o, por el contrario, disponen de varias vías, pero sin un control oficial (European Commission, 2014). En nuestro caso, existen otras pruebas de acceso que no son tan comunes, pero que están igualmente regladas, como son las pruebas de acceso para mayores de 25 años y las pruebas de acceso para mayores de 45 años. En este sentido, podemos afirmar que cada curso, cerca 30.000 alumnos se presentan a las pruebas para mayores de 25 años y unos 5.000 alumnos a las pruebas para mayores de 45 (ver gráfico 23$)^{42}$.

\section{Gráfico 23. Evolución del número de alumnos presentados a las distintas Pruebas de Acceso a la Universidad}

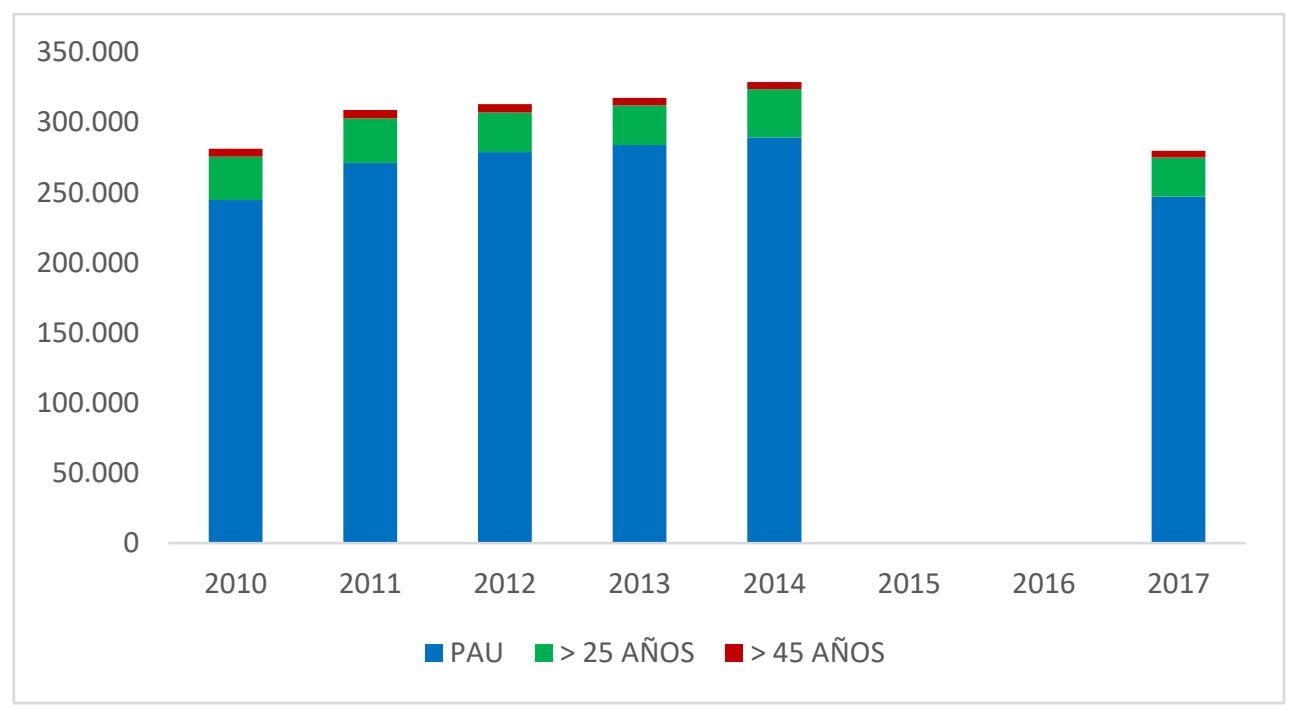

Fuente: Elaboración propia a partir de los datos de los informes «Cifras y Datos del Sistema Universitario Español»

\footnotetext{
${ }^{42}$ Los datos relativos a los cursos académicos 2015-2016 y 2016-2017 no figuran en nuestro estudio, al no existir documentos oficiales de la administración educativa que los recojan.
} 
A las primeras, pueden presentarse aquellas personas que cumplan o hayan cumplido 25 años durante el año de celebración de la prueba, y que no posean ninguna titulación académica que posibilite el acceso a la universidad; la prueba constará de dos partes, una general, con tres exámenes (Comentario de texto o desarrollo de un tema general de actualidad, Lengua Castellana y Lengua Extranjera), y una específica que se estructurará en cinco opciones, vinculadas a las cinco ramas de conocimiento. Mientras que, a las segundas, podrán presentarse aquellas personas que cumplan o hayan cumplido los 45 años durante el año de celebración de la prueba, y que no posean ninguna titulación académica que de acceso a la universidad; en este caso, tan solo será necesario la superación de dos exámenes (Comentario de texto o desarrollo de un tema general de actualidad y Lengua Castellana). En ambos casos, la calificación final se obtendrá a partir por la media aritmética de las calificaciones de los ejercicios anteriormente señalados, calificados de 0 a 10 puntos. Si nos centramos en el análisis específico de los datos, podemos afirmar que cada año, casi 30.000 alumnos se presentan a las pruebas para mayores de 25 años y unos 5.000 a la prueba para mayores de 45 años

\subsubsection{2) Sistema educativo francés}

Francia es, sin duda alguna, el gran «ideólogo» de los exámenes públicos en Europa. Los primeros exámenes públicos para acceder a las Gran Écoles a finales del s. XVIII, así como los exámenes llevados a cabo para la selección de funcionarios públicos, reflejan de una forma muy notoria los ideales ilustrados de Francia (Moreno, 1992). En este caso, la gran prueba para el acceso universitario en Francia es el Baccalauréat, también conocido como Bac, que se puso en marcha a comienzos del s. XIX (1808) de la mano de Napoleón y que es considerado como el primer certificado de estudios de educación secundaria en toda Europa. Este diploma nacional de bachillerato permite a los alumnos acceder directamente a los estudios universitarios, sin exigencias adicionales de acceso, salvo en algunos itinerarios 
formativos muy concretos, en donde la demanda es realmente elevada (Vega y Hernández, 2015). En lo que al apartado administrativo y curricular se refiere, el Bac ha sufrido importantes cambios a lo largo de los años. El gobierno central sigue desempeñando un importante papel en las correcciones y en lo referente al marco legislativo. En cambio, el examen ha pasado a ser competencia de las autoridades educativas regionales-Académies-. Pero no solo es el gobierno el que delega responsabilidades, sino que las propias Académies lo hacen en una serie de comisiones que, a su vez, lo hacen en tribunales, cuya composición estará hecha por correctores individuales (Moreno, 1992).

En función del análisis realizado en el apartado anterior, hemos creído oportuno prestar una mayor atención al Bac general y tecnológico, ya que es el itinerario más común de acceso hacia la educación superior y, además, posee una estructura común. Mientras que el Bac profesional tiene una orientación más específica hacia algunos itinerarios formativos del ámbito profesional (CINE $4 \mathrm{y}$ CINE 5) y, por ello, presenta pequeñas diferencias respecto a las otras dos modalidades. En este caso, el examen de este itinerario vocacional constará de 7 pruebas obligatorias y un máximo de dos opcionales, donde se valorarán, no solo los conocimientos de alumno, sino también sus habilidades. Los alumnos que puedan acreditar una experiencia previa un sector profesional concreto también podrán convalidar este título, sin la necesidad de superar esta prueba.

Si nos centramos en el análisis del Bac general y tecnológico, la estructura de la prueba está compuesta por dos fases claramente diferenciadas: en primer lugar, a través de las denominadas «pruebas anticipadas», que tienen lugar un año antes de finalizar la educación secundaria superior y, posteriormente, una segunda fase, al finalizar el lycée, donde se llevarán a cabo el resto de las pruebas, que versarán sobre las distintas materias cursadas por el alumno en el último curso de educación secundaria (tanto comunes como de especialidad). Las pruebas anticipadas, que 
deberán realizar todos los alumnos de las distintas series del lycée general y tecnológico, constan de una serie de ejercicios, tanto orales como escritos, (de hasta 4 horas de duración) sobre lengua francesa. Además, los alumnos de las series de Literatura (L) y Ciencias Sociales (ES), también deberán superar una prueba escrita de ciencias. Mientras que los alumnos del liceo tecnológico, según el itinerario formativo cursado, deberán superar pruebas adicionales en esta primera fase o etapa: pruebas de Geografía e Historia (STD2A, STI2D, STL), Actividades Interdisciplinares (ST2S) o Pruebas de Gestión (STMG). Las calificaciones conseguidas por los alumnos en esta primera fase serán provisionales durante un año, hasta que el jurado se reúna en la sesión final de evaluación.

La segunda parte de la prueba consistirá en una serie de exámenes acerca de las distintas materias cursadas por el alumno durante el último año de educación secundaria superior. En este sentido, nos encontramos, por un lado, con las materias comunes, que todos los alumnos deberán superar con independencia de la serie a la que estén adscritos. En el caso de los alumnos del lycée general, serían: filosofía, geografía e historia, dos pruebas de idiomas y una prueba de educación física; mientras que las materias comunes de los alumnos adscritos al lycée tecnológico serían: matemáticas, filosofía, una prueba de idiomas y una prueba de educación física. Pero, además, los alumnos también deberán examinarse de materias específicas que, en este caso, dependerán del itinerario cursado durante su trayectoria académica. En este sentido, debemos tener muy presente que la ponderación de estas pruebas (tanto comunes como específicas) sobre la nota final, no será homogénea, ya que la administración fija, libremente, los criterios de evaluación que consideren oportunos.

Una vez realizadas todas estas pruebas, los alumnos que hayan obtenido al menos 10 puntos (sobre un total de 20) reciben un diploma que certifica la superación de la prueba y que, por ende, les faculta para el acceso universitario. Aquellos que 
hayan obtenido una puntuación que se encuentre entre 8-10 puntos, pasan a las pruebas de segundo grupo, coloquialmente conocidas como «orales de repesca». En ellas, los alumnos se examinan sobre dos materias de las que previamente se les ha evaluado (tanto de las pruebas anticipadas como del resto de pruebas comunes y de especialidad), tomando en consideración tan solo la calificación más alta; en caso de no conseguir acercar su puntuación a los 10 puntos, los alumnos recibirán un certificado de Fin de Estudios Secundarios (denominado CFEPS para el itinerario profesional, CFES para el general y CFETS para el tecnológico).

Si analizamos los datos de la prueba atendiendo a los informes remitidos por la administración educativa en su página web, podemos apreciar cómo la cifra de estudiantes ha ido ascendiendo progresivamente a lo largo de las últimas décadas, hasta situarse muy próxima a los 680.000, en el año 2018 (ver gráfico 24).

\section{Gráfico 24. Evolución del número de alumnos presentados a la prueba del Bac}

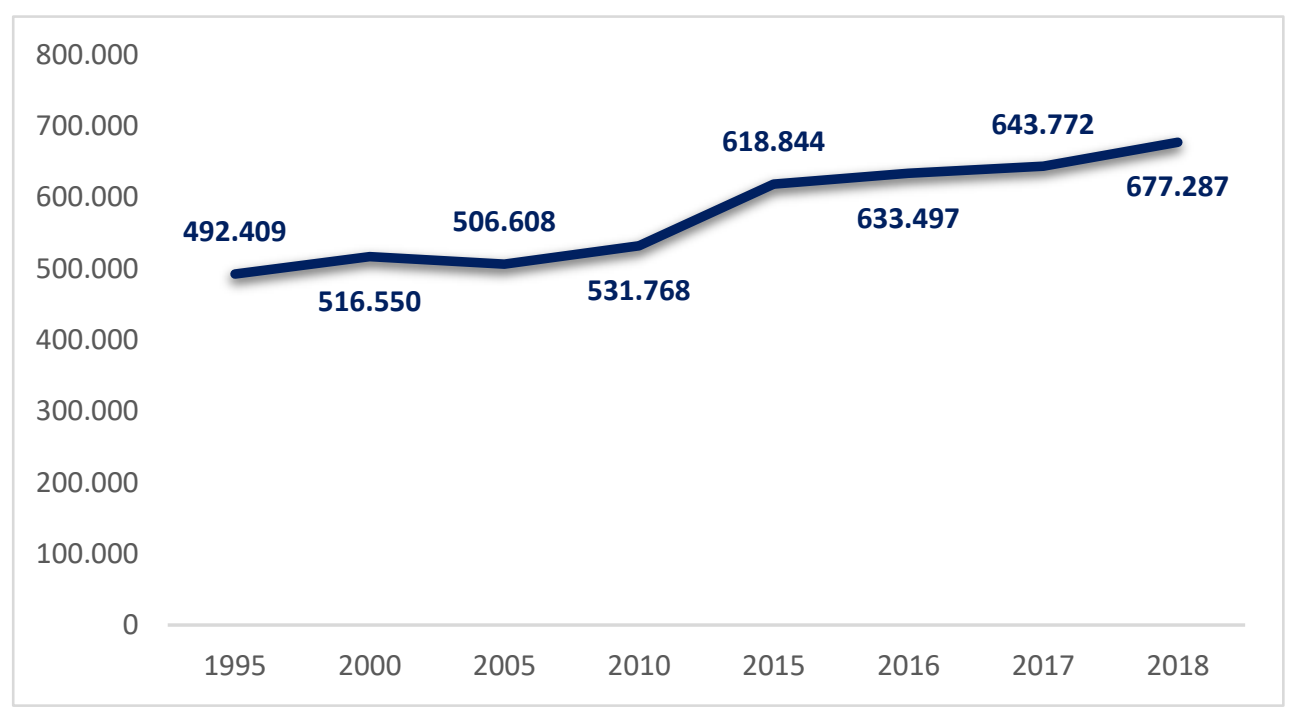

Fuente: Elaboración propia a partir de http://www.education.gouv.fr/ 
Por otro lado, si analizamos estos datos atendiendo a la especialidad cursada (ver gráfico 25), podemos apreciar como la tendencia se ha mantenido estable desde el año 2015, con un mayor número de estudiantes en el itinerario general (359.455), seguidos del profesional (179.262) y, finalmente, del itinerario tecnológico (138.570). Respecto al porcentaje de aprobados, podemos afirmar que este es realmente alto en las tres especialidades formativas, con un $91 \%$ en el $\mathrm{Bac}$ general, un $89 \%$ en el $\mathrm{Bac}$ tecnológico y un $83 \%$ en el Bac profesional.

Por último, si analizamos los datos atendiendo a la variable género, podemos apreciar como las mujeres tienen un mayor éxito que los hombres, con un $91 \%$ de aprobados, frente al $86 \%$ de estos últimos.

\section{Gráfico 25. Evolución del número de alumnos matriculados en educación secundaria superior, atendiendo a la especialidad cursada}

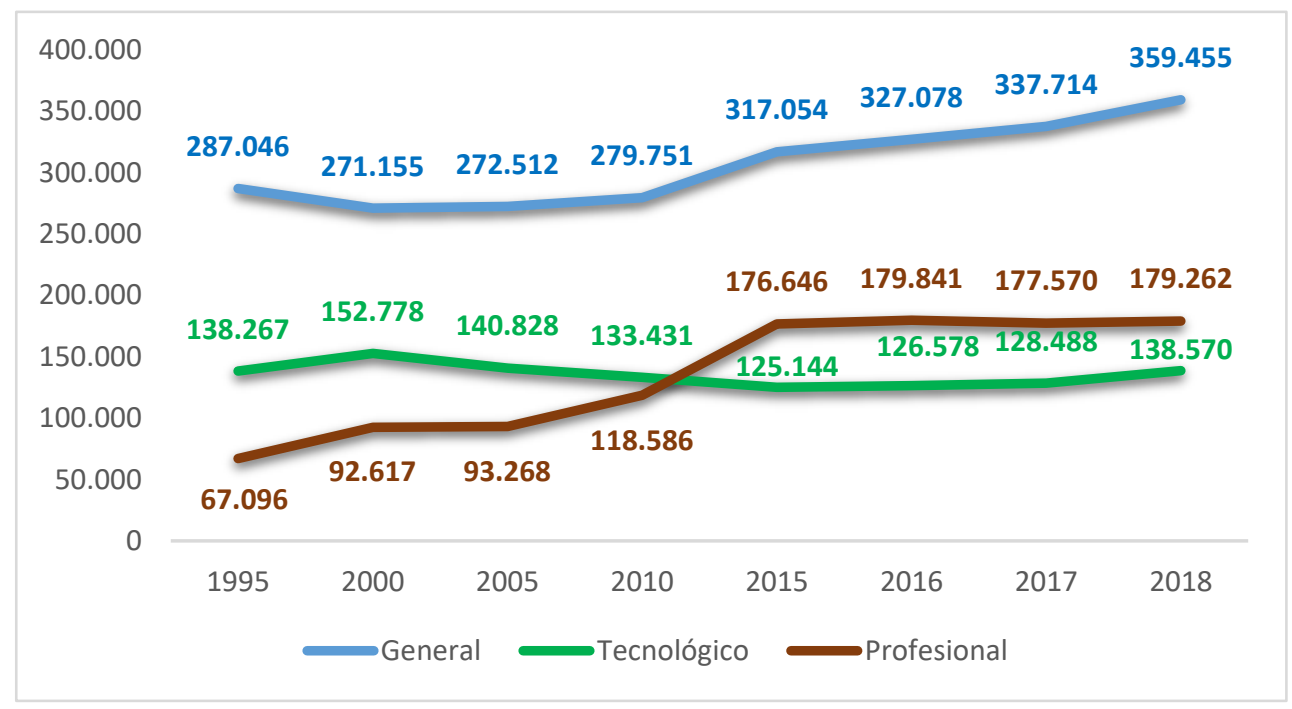

Fuente: Elaboración propia a partir de http://www.education.gouv.fr/ 


\subsubsection{3) Sistema educativo finlandés}

Finlandia, a diferencia de sus homólogos en este estudio, no cuenta con una consolidada tradición de exámenes nacionales. Por este motivo, no podemos hacer referencia a la existencia de pruebas nacionales de acceso en el país nórdico. Si bien es cierto que, pese a que no existe una prueba que sea fijada desde la administración educativa, que se encargue de regular específicamente el acceso a la educación superior, sí que existe un examen de carácter nacional, que todos los alumnos de educación secundaria superior deben superar, previo acceso a la universidad, que es el Finnish Matriculation Examination. No obstante, esta prueba, en ningún caso puede ser considerada como una prueba de admisión, sino más bien, como una prueba acreditativa, que permite al alumno la obtención del título de educación secundaria superior, tras haber superado todas las materias o programas cursados. Se realiza dos veces al año (primavera y otoño), y se pone en marcha en todos los centros de educación secundaria de forma simultánea. Comprende al menos cuatro partes, de las cuales una es obligatoria (lengua materna); el resto de las materias son elegidas por los propios estudiantes: una segunda lengua nacional, una lengua extranjera, matemáticas o un examen acerca de una asignatura de humanidades y ciencias naturales. Además, el examen también puede incluir asignaturas opcionales, atendiendo al itinerario formativo seguido por el alumno.

Si nos centramos en el análisis específico de los datos de esta prueba (gráfico 26), podemos observar cómo, pese a que se ha producido un pequeño descenso a lo largo de la última década, se mantiene una cierta estabilidad en cuanto a la tasa de finalización de este nivel educativo, que se sitúa por encima de los 30.000 alumnos cada año. 


\section{Gráfico 26. Evolución de la tasa de finalización de estudios en educación secundaria superior general}

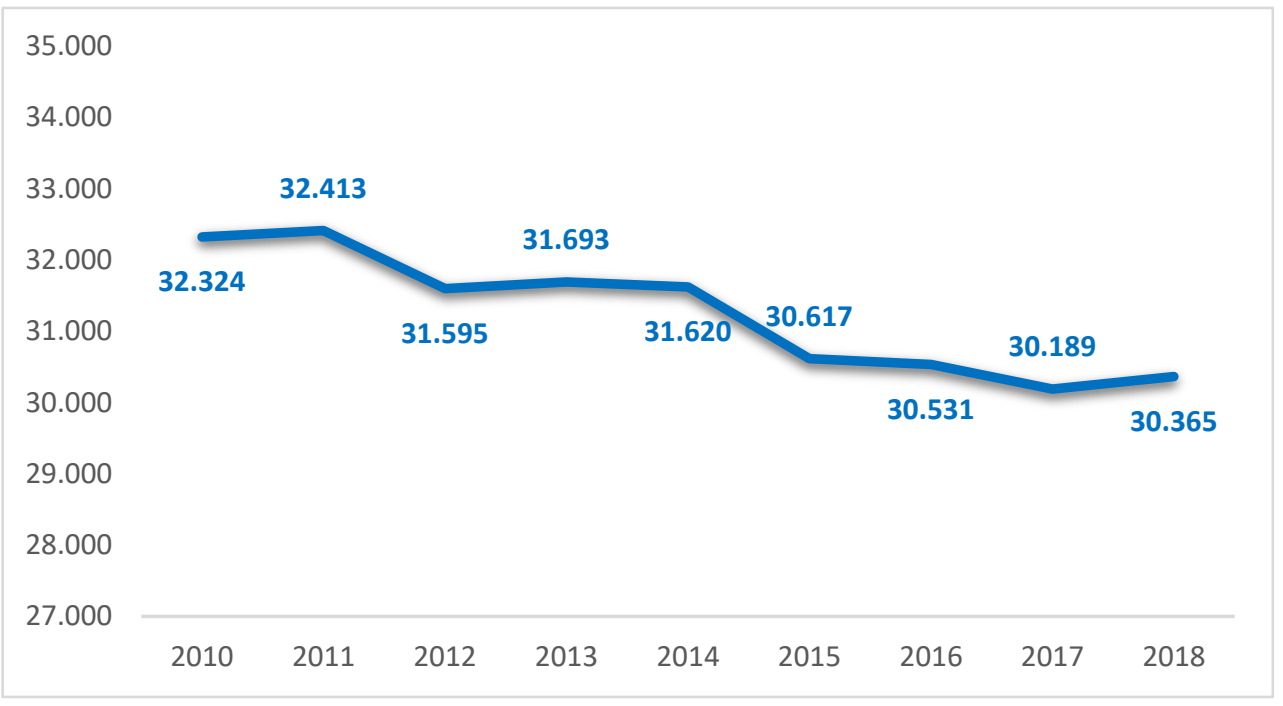

Fuente: Education. Statistics Finland

Por otro lado, también existen otro tipo de pruebas con un mayor grado de especificidad que, por lo general, son de carácter competencial y se utilizan para complementar el proceso de admisión (en este apartado no nos detendremos en analizarlas, puesto que lo haremos con una mayor profundidad cuando hagamos alusión a los requisitos de acceso). No obstante, estas pruebas no gozan de validez a nivel nacional, ya que son las propias instituciones de educación superior las que, individualmente, se encargan de fijarlas y gestionarlas, atendiendo a los criterios que crean convenientes, y siempre tomando como referencia la demanda del sistema económico productivo.

Por último, nos gustaría hacer un pequeño inciso acerca de unas pruebas que son específicas del sistema educativo finlandés y que se desarrollan solamente en algunos desarrollos institucionales, como por ejemplo el VAKAVA en los estudios de formación inicial docente. Estas, a diferencias del $F M E$ o de las pruebas de aptitud, 
si podrían ser consideradas como pruebas de acceso, si bien, estarían restringidas solamente a aquellos candidatos que pretendan cursar estudios de carácter pedagógico, es decir, no pueden ser catalogadas como pruebas generales de acceso. Y es que, ya hemos hecho alusión a lo largo de nuestro trabajo a la gran importancia que el sistema educativo fines otorga a la selección de sus futuros docentes, siendo esta una de las claves sobre las que se ha fraguado su éxito educativo. En este sentido, todos los aspirantes que pretendan acceder al ámbito educativo, en cualquiera de sus modalidades, deberán superarla. Posteriormente, en función de los resultados obtenidos, los estudiantes podrán -o no- continuar con el proceso selectivo que ponen en marcha las propias universidades (Pérez Granados, 2014).

De este modo, no podemos afirmar que en el país nórdico existan pruebas nacionales que regulen el acceso universitario, tal y como nosotros los hemos interpretado en nuestro trabajo. Si bien, lo que sí existe es una serie de pruebas específicas de admisión, que son fijadas individualmente por las propias instituciones de educación superior y que, por tanto, carecen de validez a nivel nacional. Su función no es otra que la de complementar el proceso de transición de los estudiantes, que partirán de un requisito básico de acceso, como es el FME.

\subsection{3) Origen social de los alumnos que están en disposición de acceder a los estudios de educación superior}

\subsubsection{1) Sistema educativo español}

Otra de las variables elegidas para el análisis de nuestro trabajo es el origen social de los alumnos. Y es que, este factor, cuenta con una gran trascendencia en los procesos de transición hacia los estudios de educación superior. Como tal, son muchos los estudios que, a lo largo de los últimos años, han puesto énfasis en la temática que aquí presentamos (Murillo, Martínez-Garrido y Belavi, 2017; Murillo y Martínez- 
Garrido, 2018; OECD, 2011, 2012; etc.), mostrando las diferentes consecuencias que pueden derivarse de él en todo lo que respecta al plano académico.

Para el análisis de esta variable, nos valdremos de los datos publicados por Eurostudent, a través de su informe Social and Economic Conditions of Student Life in Europe. En este sentido, vamos a utilizar los tres últimos informes publicados: Eurostudent IV (Orr et al., 2011), que abarca los años 2008-2011; Eurostudent V (Hauschildt, Gwosc, Netz y Mishra, 2015) que aborda de 2012-2015; y, finalmente, Eurostudent VI (Hauschildt, Yögtle y Gwosc, 2018), que presenta los datos entre los años 2016-2018 -en la actualidad, se está trabajando en una séptima edición, cuyos resultados verán la luz en mayo de 2021-. El motivo por el que hemos desestimado incluir los primeros informes en nuestro trabajo, es debido a que la tendencia en los países objeto de estudio es muy similar a la de estos últimos años y, por tanto, los datos no eran especialmente significativos. De este modo, hemos creído más oportuno centrar nuestro análisis en los datos más actualizados. El informe, pretende mostrar las condiciones sociales y económicas de los estudiantes de gran parte de los países que conforman el EEES (su última edición recoge las respuestas de más de 320.000 alumnos). Desde el punto de vista organizativo, la red está conformada por diferentes colectivos: investigadores, recolectores de datos, representantes de los ministerios nacionales de los países participantes, etc. Y es que Eurostudent, combina un enfoque de coordinación central, que es dirigido desde Hannover (Alemania) por el German Centre for Higher Education Research and Science Studies (DZHW), con una sólida red de socios nacionales de todos los países participantes, que favorece el análisis adecuado de un contexto específico. En su función como coordinador central, el DZHW lidera el consorcio Eurostudent, que consta de seis socios más: Institute for Advanced Studies (IHS, Austria), ResearchNed (Paises Bajos), Research and Higher Education Monitoring and Analysis Centre (Lituania), Praxis Centre for Policy Studies (Praxis, Estonia), the 
Maltese National Commission for Further and Higher Education (NCFHE, Malta) y, finalmente, the Swiss Federal Statistical Office (FSO, Suiza) (Hauschildt et al., 2018).

Si comenzamos a analizar los datos de estos informes, uno de los factores en los que se presta una mayor atención, es el logro educativo de los progenitores. Y es que este componente, a nivel internacional, es considerado como un indicador de impacto sobre los factores sociales y culturales del estudiante. Además, el análisis de este elemento es totalmente pertinente para nuestro estudio, ya que, en muchas ocasiones, las experiencias y aspiraciones educativas de los progenitores son trasmitidas a sus propios hijos. En este sentido, podemos destacar que un porcentaje significativo de los alumnos españoles -en torno al 50\%- no cuentan con antecedentes de educación superior en su familia, y entre ellos, aproximadamente la mitad -en torno al 25\% del total -, ni siquiera han alcanzado un nivel superior a la educación secundaria obligatoria (CINE 0-2). Por el contrario, si nos centramos en el extremo opuesto (progenitores que han alcanzado un nivel de estudios superiores), podemos observar cómo os padres han alcanzado un mayor nivel educativo que las madres (41\% de los hombres, frente al $36 \%$ de las mujeres). Este factor, tiene una gran influencia en el tema que a nosotros nos concierne, ya que los datos del informe ponen de manifiesto que, cuando el nivel educativo de los progenitores es bajo (CINE 0-2), se produce una ralentización en el acceso a la educación superior o, dicho de otro modo, los alumnos con antecedentes de educación superior, acceden más jóvenes a la universidad, que aquellos que no cuentan con estos antecedentes (Orr et al., 2011).

Por otro lado, también nos gustaría hacer referencia a un término que viene utilizando OCDE a lo largo de los últimos años, y que guarda una estrecha relación con el tema que abordamos en este momento, como es el de «resiliencia». Los alumnos resilientes son aquellos que provienen de entornos socioeconómicos desfavorables y que, pese a ello, han alcanzado altas puntuaciones en los estándares internacionales. En este sentido, los alumnos españoles se encuentran entre los que 
obtienen un mayor desempeño a nivel internacional, con más de un $30 \%$ de estudiantes resilientes (OECD, 2011; Schleicher, 2018).

Atendiendo al origen social de los alumnos, también podemos hablar de países inclusivos y exclusivos. Los países inclusivos son aquellos que cuentan con un mínimo de representación de alumnos con antecedentes académicos altos y una subrepresentación de alumnos con antecedentes académicos bajos. Por el contrario, los países exclusivos son aquellos que no cuentan con ese mínimo de representación en ninguna de las dos variables. En este sentido, también podemos hablar de países de transición, entre los que se encuentran los estudiantes españoles, que obtienen un buen nivel representativo en, al menos, una de las dos medidas - en el caso de España, cuenta con una sobrerrepresentación de estudiantes con un origen social alto- (Orr et al., 2011).

Por último, nos gustaría hacer referencia a un factor transcendental, y que está estrechamente relacionado con el origen social de los alumnos, como es la financiación de sus estudios. Y es que los informes analizados también ponen énfasis en aquellos mecanismos de financiación utilizados por los alumnos para hacer frente a los gastos derivados de su formación académica. Fundamentalmente, se centra en tres agentes de financiación: las propias familias, la administración pública y los ingresos de los propios alumnos a través de su trabajo. En el caso de los estudiantes españoles, gran parte de su financiación proviene de las propias familias. Más de la mitad de los estudiantes -el porcentaje desciende ligeramente cuando hablamos de alumnos de máster- tienen como fuente principal de financiación a sus padres. No obstante, un porcentaje significativo de alumnos-en torno al 25\%-recibe fondos públicos (principalmente de la administración central). Si analizamos los datos de una manera más individualizada, podemos apreciar cómo, generalmente, las mujeres obtienen menos ingresos que los hombres, si bien, las diferencias a nivel europeo son mínimas, sin llegar a ser significativas. (Orr et al., 2011). De este modo, podemos 
afirmar que son pocos los estudiantes españoles que financian sus estudios gracias a su implicación laboral, lo cual, por otra parte, es ventajoso para ellos, ya que estos informes ponen de manifiesto que aquellos alumnos que estudian y trabajan a la vez, dedican un menor número de horas a su formación, lo cual les perjudica seriamente frente a sus homólogos que no trabajan.

\subsubsection{2) Sistema educativo francés}

A continuación, analizaremos el origen social de los alumnos que están en disposición de acceder a los estudios de educación superior en el sistema educativo francés. En primer lugar, haremos alusión al logro educativo de los progenitores. En este sentido, podemos destacar que más de la mitad de los alumnos franceses (en torno al 60\%) cuentan con antecedentes de educación superior en su familia (padre o madre). De hecho, este perfil de alumno estaría sobrerrepresentado en el país galo, siendo uno de los pocos países que participan en el estudio que se encuentran por encima de la media europea. Por contra, tan solo uno de cada diez alumnos no cuenta con antecedentes superiores a la educación secundaria obligatoria (Hauschildt et al., 2015; Hauschildt et al., 2018; Orr et al., 2011). Francia cuenta con el menor índice de ralentización de entrada a la educación superior (en torno al 2\%) de todos los países que participan en el proyecto Eurostudent. Generalmente, estos alumnos no tienen antecedentes de educación superior (Hauschildt et al., 2015). Como ya hemos indicamos, este factor tiene una gran transcendencia en el tema que a nosotros nos concierne, ya que cuando el nivel educativo de los progenitores es más bajo (CINE 02), se produce una ralentización en el acceso/admisión a la educación superior (Orr et al., 2011).

Otro de los factores que analiza el informe es el origen migratorio del estudiante, clasificándolos en inmigrantes de primera generación (al menos uno de los progenitores y el estudiante han nacido en el extranjero) e inmigrantes de segunda 
generación (al menos uno de los progenitores el alumno ha nacido en el extranjero). En este sentido, Francia es uno de los países con mayor proporción de estudiantes inmigrantes de segunda generación del contexto europeo. Además, el país galo también destaca debido al amplio porcentaje (en torno al 12\%) de estudiantes internacionales, que han accedido a los estudios de educación superior mediante un certificado de estudios extranjero (Hauschildt et al., 2018).

Finalmente, vamos a hacer referencia a la financiación académica de los estudiantes. Aproximadamente, el 53\% de los alumnos franceses presentan algún tipo de dificultad económica; este porcentaje, se encuentra en torno a la media europea, que es del $60 \%$. En este sentido, volvemos a hacer alusión, nuevamente, a tres agentes de financiación que describe el informe: las propias familias, la administración pública (en Francia, dada su fuerte centralización, hablaríamos de la intervención estatal) y, finalmente, los ingresos de los propios estudiantes a través de su actividad laboral. En el caso de los estudiantes franceses, gran parte de su financiación proviene de los organismos públicos, siendo uno de los países que se encuentra por encima de la media europea (Hauschildt et al., 2015; Hauschildt et al., 2018). Sin embargo, pese a la fuerte influencia de la administración pública, un porcentaje significativo de alumnos (cercano al 50\%) reciben apoyo financiero de sus familias, siendo esta la principal combinación de ingresos del alumnado francés. Si analizamos los datos de una manera más individualizada, podemos apreciar cómo Francia es el único país (junto a Noruega) en donde las mujeres obtienen mayores ingresos que los hombres. Por último, si analizamos la actividad laboral de los estudiantes franceses, podemos apreciar cómo esta es mínima, en donde tan solo un porcentaje insignificantico de alumnos trabajan para hacer frente a los gastos ocasionados por su formación académica (Orr et al., 2011). Por tanto, el alumnado francés, pese a recibir un fuerte apoyo económico de los organismos públicos (del Estado, principalmente), tiene un 
modelo mixto en donde la implicación de la familia también es sumamente importante.

\subsubsection{3) Sistema educativo finlandés}

Por último, vamos a detenernos en el análisis del origen social de los estudiantes finlandeses. De nuevo, comenzaremos aludiendo al origen académico de los progenitores. En este sentido, podemos destacar que Finlandia es, junto a Dinamarca, el país que cuenta con un mayor porcentaje de alumnos con antecedentes de educación superior de todos los que participan en el informe (alrededor del 65\%). Este perfil de alumno estaría sobrerrepresentado en el país nórdico, siendo uno de los países que se encuentra por encima de la media europea. Por contra, tan solo uno de cada diez alumnos no cuenta con antecedentes superiores a la educación secundaria inferior (CINE 2). Sin embargo, es curioso que, pese a que Finlandia cuenta con un bajo porcentaje de alumnos con antecedentes inferiores a la educación obligatoria, el país nórdico presenta unas cotas muy elevadas de alumnos que acceden al sistema universitario de forma retardada (aproximadamente, el 30\%). En este sentido, cuando hablamos de ralentización en el acceso/admisión a los estudios superiores, este puede responder a dos cuestiones, principalmente. En primer lugar, debido a cuestiones de carácter académico (repetición). Y, en segundo lugar, si tenemos en cuenta los tiempos y ritmos escolares; en esta tesitura es donde se encuentra el país nórdico, donde este retraso en la entrada hacia las instituciones de educación superior se ve altamente influenciado por la lógica organizativa y curricular de su sistema educativo. Esto es lo que algunos autores (véase Prats y Raventós, 2005) han denominado "el tren de la educación" de los países nórdico, que desarrollan una lógica organizativa (especialmente en la educación secundaria superior) diferente, trabajando con programas con una duración temporal variable, que hacen que los tiempos escolares ocupen un papel secundario. Si bien, este hecho también puede ser achacado al gran porcentaje de alumnos que se incorporan al mercado laboral antes de comenzar su 
periplo universitario -tal y como veremos a continuación, cuando hagamos referencia a las formas de financiación de los estudiantes-. Además, también existen casos en donde la ralentización, en vez de producirse en el acceso/admisión, se produciría en la graduación, y es que también existe un porcentaje significativo de estudiantes (en torno al 15\%) que interrumpe sus estudios para desarrollarse profesionalmente. Todos estos datos explicarían porque Finlandia es uno de los países que cuenta con los estudiantes más longevos del panorama europeo, con una media de edad de 28 años, y en donde al menos, uno de cada cuatro estudiantes, supera la treintena (Hauschildt et al., 2015; Hauschildt et al., 2018).

Por otro lado, y atendiendo a los datos que hemos recogido hasta el momento, podemos catalogar a Finlandia como un país inclusivo, ya que cuenta con un mínimo de representación de alumnos con antecedentes académicos de educación superior y, a su vez, con una subrepresentación de alumnos con antecedentes académicos bajos (Orr et al., 2011).

Otro de los factores que hemos analizado con anterioridad, es el origen migratorio de los estudiantes. En este sentido, es, cuanto menos paradójico, apreciar como Finlandia cuenta con un mayor porcentaje de inmigrantes de primera generación (en torno al 20\%) que de segunda generación (Hauschildt et al., 2015). Además, el país nórdico cuenta con uno de los porcentajes más alto del contexto europeo (cercano al 15\%) de estudiantes internacionales, que han accedido a los estudios de educación superior mediante un certificado de estudios extranjero (Hauschildt et al., 2018). No hay duda de que este hecho viene motivado por el gran atractivo que ha despertado el país nórdico a lo largo de los últimos años en materia de educación.

Por último, haremos una pequeña alusión acerca de los ingresos que tienen los propios estudiantes de forma paralela al desarrollo de su formación académica. En este sentido, debemos reconocer que Finlandia, a diferencia de otros países, se 
encuentra dentro de un reducido grupo en el que, mayoritariamente, son sus alumnos los que se encargan de sufragar sus propios gastos, a través de su actividad laboral (en torno a la mitad de sus alumnos se encontrarían dentro de esta tesitura). Por otro lado, un porcentaje menor estudiantes -en torno al 25\%- recibe apoyo financiero de sus familias. Estos datos contrastan con la tendencia existente a nivel europeo, en donde los estudiantes de ocho de cada diez países cuentan, principalmente, con el apoyo financiero de sus familias. También existe una tercera fuente de financiación en el país nórdico, que es la administración pública y que, por lo general, presta ayuda a aquellos alumnos con un nivel socioeconómico más bajo. En este sentido, debemos destacar que existen grandes diferencias entre los ingresos percibidos por los alumnos de grado y los de máster, que llegan a alcanzar diferencias de hasta un $30 \%$ en favor de los primeros. Sin embargo, este perfil de alumnos -con un nivel socioeconómico más modesto- no es muy común en el país nórdico. De hecho, Finlandia es uno de los siete países en donde los ingresos mensuales de los estudiantes se encuentran por encima de la media europea (Hauschildt et al., 2015; Hauschildt et al., 2018; Orr et al., 2011).

\subsection{4) Competencia organizativa del acceso, ¿a quién corresponde?}

\subsubsection{1) Sistema educativo español}

A continuación, vamos a prestar atención a la competencia organizativa del acceso. De este modo, analizaremos qué organismos, instituciones, etc. se encargan de llevar a cabo este complejo proceso de transición educativa. Sin duda alguna, ésta no será una tarea sencilla, ya que, tal y como hemos señalado en el capítulo anterior, en este proceso de transición intervienen distintos actores y agentes educativos. En el sistema educativo español, vamos a focalizar nuestra atención en dos de ellos: la administración educativa y las propias universidades. En este sentido, las CC. AA -a través de su departamento educativo-, que han asumido capacidad competencial gracias a la fuerte descentralización instaurada en nuestro país, son las encargadas de 
gestionar este proceso de transición, mediante unas pruebas de acceso a la universidad, que ya hemos analizado previamente. Si bien, éstas cuentan con el apoyo y la intervención de las instituciones de educación superior. Para entender mejor este complejo sistema organizativo, vamos a tratar de explicarlo a través un ejemplo concreto, como es el de las pruebas de acceso a la universidad en Castilla y León, recientemente denominadas bajo las siglas de EBAU (Evaluación de Bachillerato para el Acceso a la Universidad). En este sentido, la normativa vigente aconseja crear una comisión organizadora para esta prueba, en la que participen tanto la Consejería de Educación de la Junta de Castilla y León como las universidades públicas de dicha comunidad (Salamanca, Valladolid, León y Burgos). Esta comisión estará compuesta por distintos participantes (artículo 4, orden EDU/18/2019 de 17 de enero ${ }^{43}$ ):

- Director General de Universidades e Investigación

- Director General de Política Educativa Escolar

- Rector o Vicerrector con competencias en pruebas de acceso de cada una de las universidades públicas de Castilla y León.

- Un profesor responsable técnico de la organización y desarrollo de la evaluación en cada universidad.

- Dos miembros de la Dirección General de Universidades e Investigación.

- Dos miembros de la Dirección General de Política Educativa Escolar.

- Cuatro funcionarios pertenecientes al cuerpo de inspectores de educación, o, en su caso, inspectores accidentales, profesores de educación secundaria, uno por cada distrito universitario.

- Dos directores de centros públicos y uno de centros concertados.

${ }^{43}$ ORDEN EDU/18/2019, de 17 de enero, por la que se crea la comisión organizadora de la evaluación de bachillerato para el acceso a la Universidad de Castilla y León, y se establecen determinados aspectos de la evaluación, para el curso académico 2018-2019. 
Pero, además, junto a esta comisión, se crearán los denominaos grupos técnicos de materia, constituidos por un profesor universitario y un funcionario que pertenecerá al cuerpo de catedráticos o de profesores de enseñanza secundaria, de la especialidad correspondiente. De este modo, se formarán tantos grupos, como materias existan.

Son varios los actores educativos que intervienen en la implementación de este proceso de transición, si bien, a grandes rasgos, podemos «encasillarlos» en dos grandes grupos: por un lado, la administración autonómica, a través de sus departamentos de educación y, por otro lado, las propias universidades públicas de dicha comunidad autónoma.

\subsubsection{2) Sistema educativo francés}

El acceso a los estudios de educación superior en el sistema educativo francés está regulado de forma exclusiva por la administración central, quien, a través del $B a c$, se encarga del desarrollo de este proceso de transición. No obstante, debemos tener en cuenta que, a lo largo de los últimos años, se están produciendo una serie de cambios, tanto en lo que concierne al apartado administrativo como al curricular. Y es que, pese a que el gobierno central sigue al frente del marco regulatorio de esta prueba, lo cierto es que el $B a c$ ha pasado a ser ejecutado por las autoridades educativas regionales, -Académies-, que actúan por delegación del gobierno mediante un proceso de desconcentración. Como consecuencia de ello, el Bac está dejando de ser ese examen homogéneo de principios del s. XIX (Moreno, 1992).

Por tanto, es la administración central la encargada de regular el acceso hacia los estudios de educación superior en el sistema educativo francés. Si bien, a lo largo de los últimos años, han comenzado a aparecer pequeños brotes de descentralización, a través de la intervención de las Académies, que hacen que la prueba comience a 
desarrollar pequeños rasgos distintivos, que rompen con la homogeneidad que tanto la caracterizaban.

No obstante, si aludimos a los procesos de admisión, tendríamos que añadir la participación de un segundo agente educativo, como son las propias instituciones de educación superior. Y es que, pese a no ser lo más común, existen algunos desarrollos institucionales que poseen una fuerte demanda académica, y que, como tal, se ven en la obligación de seleccionar a los estudiantes, de acuerdo a los criterios que crean más oportunos. Por ello, no debemos obviar la participación de los centros universitarios que, si bien, no se encargan de regular el acceso, sino más bien, la admisión.

\subsubsection{3) Sistema educativo finlandés}

En último lugar, analizaremos la competencia organizativa en Finlandia, que corresponde a la agencia educativa del país nórdico, la Finnish National Agency for Education, que se encarga de regular este proceso de transición a través del examen de graduación de estudios secundarios -Finnish Matriculation Examination-. No obstante, al igual que ocurría en Francia, en Finlandia también intervienen las instituciones de educación superior, no para regular el acceso, sino la admisión. Esta regulación se lleva a cabo a través distintas pruebas que las universidades fijan libremente. De este modo, podemos afirmar que tanto la administración central como los centros de educación superior intervienen en este proceso de transición. La agencia educativa finlandesa se encarga de regular el acceso a través del $F M E$, mientras que las universidades complementan esta transición universitaria a través de distintos procedimientos de admisión, pudiéndonos encontrar situaciones en las que, para acceder a unos mismos estudios, puedan existir diferentes procedimientos y criterios de admisión, dependiendo de la universidad que se encargue de regular este proceso. 


\subsection{5) ¿Qué papel desempeñan los centros de secundaria en el proceso de transición?}

\subsubsection{1) Sistema educativo español}

Otra de las variables sobre las que pondremos nuestra atención es la referida a los centros escolares; en nuestro caso los denominados Institutos de Enseñanza Secundaria (IES). A continuación, vamos a tratar de analizar el papel que estos centros desempeñan en el proceso de transición universitaria.

Tal y como hemos señalado en el apartado descriptivo de nuestro trabajo, los centros de educación secundaria se encargan, fundamentalmente, de la acreditación o certificación competencial del alumno. De este modo, y en colaboración con la administración educativa, los IES, a través de sus docentes, se encargan de evaluar a sus alumnos, con el fin de que éstos demuestren que están en posesión de una serie de conocimientos que desde la estructura política se consideran necesarios para la superación de la educación secundaria superior. Además, esta evaluación tiene un peso específico en el proceso de transición universitaria, ya que, aunque el requisito indispensable para el acceso es la superación de una prueba de carácter nacional, debemos tener en cuenta que el expediente académico del alumno puede condicionar el acceso del estudiante, ya que ostenta un peso significativo en las calificaciones necesarias para la obtención de la certificación y tránsito hacia la educación superior.

Por lo tanto, más allá de la influencia que pueda tener en el apartado burocrático, a través de la certificación o acreditación competencial, los centros de educación secundaria tienen una fuerte incidencia académica dentro del proceso de transición hacia los estudios de educación superior. En primer lugar, mediante el expediente académico del alumno, que como ya hemos explicado, goza de una fuerte presencia en la nota final de acceso. Y, por otro, también a través de su participación en las pruebas de acceso que, pese a que están coordinadas desde las universidades, 
también cuentan con la intervención de los docentes de educación secundaria dentro de sus comisiones organizativas para la coordinación, realización y valoración.

\subsubsection{2) Sistema educativo francés}

Los centros escolares de CINE 3 tienen una fuerte responsabilidad en la organización y valoración de las pruebas nacionales de Bac. De este modo, los lycées, a través de sus docentes, preparan a los alumnos para la superación del Bac. Y es que debemos recordar que todos los alumnos deben superar esta prueba para obtener el certificado de estudios de educación secundaria superior que, a la postre, les habilitará para el acceso a las instituciones de educación superior.

Por lo tanto, los centros de educación secundaria franceses poseen una gran incidencia en el proceso de transición, ya que se encargan de la preparación del alumno para la superación del Bac. Si bien, la evaluación competencial llevada a cabo por los docentes posee un menor impacto que, por ejemplo, en nuestro país, ya que, tanto el acceso universitario, como el certificado de estudios de educación secundaria, se obtiene a través del Bac que está organizado completamente por la administración educativa (la Académie).

\subsubsection{3) Sistema educativo finlandés}

En Finlandia, a diferencia de lo que ocurre en otros sistemas educativos internacionales, los centros de secundaria desempeñan una labor más pedagógica -en buena lógica este debería ser su objetivo prioritario- que acreditativa. Los centros educativos se encargan de preparar a sus alumnos para la superación del Finnish Matriculation Examination. Sin embargo, esta prueba, que tiene un enfoque muy competencial está regulada desde la agencia educativa (FNAE), que será, en última instancia, la encargada de establecer las directrices, criterios y competencias de dicha prueba. Pero la implementación corresponde a los centros de educación secundaria 
superior que son lo que imparten los programas temáticos (según perfiles) correspondientes.

\subsection{6) Requisitos necesarios para el acceso/admisión a los estudios de educación superior}

\subsubsection{1) Sistema educativo español}

A grandes rasgos, podríamos afirmar que el sistema educativo español tan solo fija un requisito para el acceso a las universidades, y ese no es otro que la superación de una prueba. Prueba, y certificación correspondiente, que ejerce los dos papeles funcionales de la transición: el acceso y la admisión. No obstante, nada impide formalmente que cualquier establecimiento de educación superior fije sus propios criterios de admisión. A esta prueba solamente se podrá concurrir previa la superación de la educación secundaria superior que, tal y como veremos a continuación, también tiene un peso específico en el proceso de transición. De este modo, la nota final para acceder a la universidad quedará fijada a partir de la siguiente fórmula:

Nota de acceso universidad $=0,6 * \mathrm{NMB}+0,4 * \mathrm{CFG}+\mathrm{a} * \mathrm{M} 1+\mathrm{b} * \mathrm{M} 2$

La nota media de bachillerato (NMB), supondrá un $60 \%$ de la nota final de acceso, mientras que la calificación de la fase general (CFG), un 40\%. A esta nota, habrá que sumarle la ponderación correspondiente (a b) de las dos mejores calificaciones de las pruebas de la fase específica (M1 y M2).

No obstante, frente a este modelo general de acceso, existen algunas excepciones que debemos tener en consideración a la hora de realizar nuestro análisis. En primer lugar, debemos tener muy presente que determinadas titulaciones fijan requisitos adicionales de admisión (pruebas específicas de contenido, entrevistas personales, pruebas competenciales, etc.), que complementan el proceso de admisión del alumno. Esto es algo poco común entre nuestras fronteras, donde tan solo algunos 
desarrollos institucionales muy concretos han apostado por desarrollar estos mecanismos selectivos.

Por otro lado, también existen pruebas alternativas a la Selectividad (que hemos analizado con anterioridad) y que permiten el acceso a las facultades universitarias. Si bien es cierto que estas no gozan de un índice de participación excesivamente alto. Los datos de la administración educativa que hemos analizado en el apartado anterior muestran cómo el itinerario más común de acceso es éste al que estamos haciendo alusión: cursar estudios de bachillerato y, posteriormente, superar la prueba de acceso a la universidad (por poner un ejemplo, hasta un $87 \%$ de los alumnos siguieron este itinerario durante el curso académico 2013-2014). Pero, además de esta prueba, también existen otras que gozan de validez administrativa y que facilitan el acceso de colectivos muy concretos, como son los alumnos mayores de 25 y 45 años. De este modo, el requisito seguirá siendo el mismo, la superación de un examen que, en este caso, tendrá pequeños matices diferenciales respecto de la prueba ordinaria.

Por último, también existen otras formas de acceso/admisión, que estarían exentas de la superación de una prueba o examen. De este modo, aquellas personas mayores de 40 años, que dispongan de una experiencia profesional o laboral acreditada en relación con una enseñanza, también podrán acceder a los estudios universitarios. $\mathrm{O}$, aquellos alumnos que estén en posesión del título de técnico superior de formación profesional. Como hemos visto a lo largo de este capítulo, cada vez son más los estudiantes que acceden a los estudios universitarios tras haber cursado satisfactoriamente estudios de formación profesional, siendo esta la segunda vía de acceso más común en nuestro país.

Por tanto, pese a que el modelo más común de acceso/admisión al sistema universitario español tan solo está condicionado a la superación de una prueba, debemos tener en cuenta que existen otras vías que también gozan de validez 
administrativa. Además, debemos tener presente que a través de estos itinerarios que acabamos de describir podremos acceder al contexto universitario, pero en ningún caso tendremos garantizada la admisión a los estudios deseados ya que, en función de la oferta y la demanda, las universidades establecen unos numerus clausus, que servirán como referencia para el acceso hacía cada una de las titulaciones ofertadas. De este modo, los estudiantes realizarán una solicitud con diversas opciones académicas, que serán clasificadas en función de sus preferencias; una vez admitido en el programa de estudios preferencial, el resto de las opciones marcadas por el estudiante quedarán deshabilitadas. Por el contrario, si la propuesta de admisión no es satisfactoria, el estudiante podrá esperar a las siguientes fases de admisión en las que puede mejorar su posición. Todo ello, ha generado que sean muchos los investigadores que, a lo largo de los últimos años, han puesto en entredicho esta prueba y con ella, su popular denominación (Selectividad), ya que su fin último no es la selección de los estudiantes, sino más bien su ordenación y distribución.

\subsubsection{2) Sistema educativo francés}

Si analizamos los requisitos de acceso/admisión hacia el sistema universitario francés podríamos afirmar que, a grandes rasgos, este tan solo está supeditado a la superación de una prueba de carácter nacional, que todos los alumnos deben superar al finalizar sus estudios de educación secundaria superior, el Bac. Esta prueba, de la que ya hemos hablado largo y tendido durante nuestro trabajo, permite, por sí misma, el acceso a las instituciones universitarias. Si bien es cierto que no podemos afirmar categóricamente que el Bac sea el único requisito indispensable para el acceso a la universidad, pues, tal y como ya hemos comentado, existen algunos desarrollos institucionales muy concretos, como por ejemplo, las Grandes Écoles o los IUTs, que añaden requisitos adicionales de admisión, en forma de pruebas escritas, entrevistas personales, etc., que les permita seleccionar a los candidatos más adecuados. Estos procesos selectivos son muy comunes en aquellos itinerarios formativos en los que la 
oferta es muy limitada o, por el contrario, la demanda muy extensa y tienen componentes profesionales directos; estos elementos complementarios (partiendo del Bac), conforman la admisión.

Sin embargo, tal y como ocurría en el sistema educativo español, el $B a c$ tampoco va a garantizar la admisión de los estudiantes hacia los estudios deseados, ya que atendiendo a la oferta y la demanda, los centros de educación superior establecerán una serie de criterios que regulen este proceso. Si una determinada titulación no cubre el total de plazas, se garantizará la admisión de todos los estudiantes que cumplan los requisitos mínimos de acceso (en este caso, estar en disposición del Bac). Sin embargo, cuando no sea así, se establecerá una clasificación de los estudiantes que, previamente, habrán formulado una solicitud que recogerá distintas opciones académicas; una vez admitido el alumno en el programa de estudios deseado, el resto de las opciones quedarán deshabilitadas. Si la propuesta de admisión no es satisfactoria, el estudiante podrá esperar a las siguientes fases de admisión, en donde tendrá la posibilidad de mejorar su posición, si bien, solamente un $10 \%$ de los estudiantes consiguen avanzar en esas listas. En este sentido, cobra especial interés la plataforma Admission Postbac, que se trata de un portal online que simplifica el proceso de admisión de los estudiantes en el país galo.

Por tanto, pese a que el modelo más común de acceso/admisión tan solo está supeditado a la superación de una prueba nacional, debemos tener en cuenta que existen pequeñas excepciones, que añaden requisitos adicionales que complementan el proceso de admisión y que son igualmente válidas. No obstante, insistimos, esto es algo poco común dentro del país galo que, históricamente, se ha caracterizado ser sumamente flexible en sus procesos de transición hacia la universidad, que no hacia otros marcos institucionales de la educación superior. 


\subsubsection{3) Sistema educativo finlandés}

Sin duda alguna, el caso nórdico es el que goza de una mayor diversidad entre todos los que aquí analizamos. A grandes rasgos, podríamos afirmar que el requisito básico de acceso/admisión hacia los estudios de educación superior es la obtención del certificado de fin de estudios de educación secundaria. Sin embargo, la fuerte autonomía que la administración educativa concede a las universidades nórdicas hace que, a diferencia de lo que ocurre en otros sistemas educativos, no exista homogeneidad en cuanto a los requisitos de admisión, puesto que son las propias instituciones de educación superior las que fijan, de una forma autónoma, los criterios que crean más oportunos. El acceso sería común pero la admisión es diversa. En algunos casos, tan solo se solicita que el alumno este en disposición del FME; pero comúnmente, junto a este certificado, se exige otra serie de requisitos adicionales, como por ejemplo, la superación de pruebas específicas de admisión, la acreditación de experiencia profesional en el mercado laboral, conocimientos previos en un área de estudios determinada (por ejemplo, para acceder a los Institutos Politécnicos suele solicitarse que los alumnos hayan cursado previamente estudios vocacionales de educación secundaria superior), etc.

De este modo, no podemos hablar de unos requisitos comunes y homogéneos de admisión, si no que existen toda una serie de requisitos específicos, que son establecidos por la universidad de origen a la que se pretende acceder el alumno. Además, las instituciones de educación superior no solamente tienen autonomía para fijar aquellas pruebas que crean más convenientes, sino que también pueden otorgar a estas la ponderación que crean más oportuna. De esta manera, podemos encontrarnos situaciones donde el acceso es sumamente flexible, o por el contrario, instituciones altamente selectivas, donde la admisión es ampliamente restrictiva. 


\subsection{7) Sistema educativo y modelos de acceso/admisión}

\subsubsection{1) Sistema educativo español}

Antes de comenzar el análisis de esta variable, nos gustaría hacer una pequeña aclaración con el único fin de favorecer una mayor y mejor comprensión de los modelos de acceso/admisión. Y es que, a la hora de analizar esta variable, debemos ser cautos, ya que encorsetar un sistema educativo dentro de un modelo concreto puede ser un error bastante grotesco. En este sentido, no debemos remitirnos tan solo a la normativa vigente que se encarga de regular los procesos de transición, sino que debemos analizarla atendiendo a la realidad en la que se enmarca. De este modo, frente a lo que dictan los textos normativos, debemos analizar también la realidad de los distintos desarrollos institucionales, que pueden traer consigo pequeños matices que modifiquen por completo los distintos modelos de acceso. En el segundo capítulo de nuestra investigación, cuando describíamos las variables o categorías analíticas de nuestro estudio, aludíamos a tres modelos de acceso/admisión hacia los estudios de educación superior: abierto (flexible), cerrado (rígido) y entreabierto (mixto). Si bien, a continuación, vamos a eludir enmarcar estos sistemas educativos de una forma categórica, ya que, como veremos, existen pequeños matices que harán que la interpretación no sea del todo esclarecedora. Es decir, a veces los modelos no operan realmente de forma pura sino combinada.

Lo primero que debemos tener en cuenta a la hora de analizar el modelo de acceso a la universidad en nuestro país, es la gran ambigüedad que existe desde la promulgación de la LOMCE. Pese a que la nueva ley educativa fue aprobada hace más de un lustro y su aplicación se debería haber llevado a cabo definitivamente a partir del curso académico 2017-2018, lo cierto es que la nueva propuesta de acceso no ha terminado de consolidarse, ya que la administraciones autonómicas se han visto obligada ( a petición de varias de ellas) a aprobar, año a año, diferentes órdenes 
ministeriales y regionales que regulen el acceso hacia las instituciones de educación superior, hasta que una nueva propuesta se consolide de una forma definitiva. Por tanto, pese al cambio de coyuntura que se pretendía llevar a cabo en nuestro país, lo cierto es que la regulación hacia estudios universitarios sigue ejerciéndose a través de una prueba de acceso que, en la actualidad, cuenta ya con más de 40 años de antigüedad. De este modo, los distintos cambios que ha experimentado la puesta en marcha durante la época tecnocrática del franquismo, no se han visto manifestados en la esencia de la prueba, que se mantiene como un examen meramente cultural, que respeta escrupulosamente los principios básicos de derecho a la educación e igualdad de oportunidades.

Estamos, por tanto, ante un modelo abierto, sin restricciones en la admisión, más allá que las propias capacidades de los estudiantes. Si bien es cierto que, frente a este modelo abierto, existen pequeños matices a los que ya hemos aludido, que deben ser tenidos en consideración, donde determinados desarrollos institucionales apuestan por incorporar ciertos mecanismos de selección que le permita valorar la idoneidad del estudiante. Un ejemplo de ello, podemos localizarlo en titulaciones como Traducción e Interpretación, donde los estudiantes, además de cumplir las condiciones generales que establece la normativa estatal, deberán superar una Prueba de Evaluación de Aptitud Personal, que evalúa la competencia lingüística en la primera Lengua Extranjera (lengua B) y en la Lengua Española (lengua A). O en el grado de Ciencias de la Actividad Física y del Deporte, donde los alumnos tendrán que hacer frente a una serie de pruebas físicas que complementen la normativa básica de acceso; es decir, estos desarrollos institucionales han establecido mecanismos propios de admisión. En este sentido, nos gustaría resaltar que estas pruebas no tienen un carácter mercantil, tal y como sí las tienen en otros sistemas educativos que apuestan por ponerlas en marcha. Tratan de valorar la idoneidad del alumno y su 
capacidad para hacer frente a unos determinados estudios, pero no tienen en cuenta la situación del sistema económico productivo.

Por tanto, no podemos afirmar categóricamente que el modelo de acceso/admisión a la universidad en el sistema educativo español sea abierto, sin ningún tipo de restricción, ya que, pese a que la tendencia más normalizada es esa, existen pequeñas excepciones que no siguen este mismo modelo. En todo caso, es un modelo que no se parece a los de los países analizados.

\subsubsection{2) Sistema educativo francés}

En lo que respecta al modelo de acceso/admisión a la educación superior en el sistema educativo francés, debemos destacar que éste se encuentra en una situación que, en algunos elementos, se parece al español en cuanto a la flexibilidad de acceso a las universidades. Se trata, por tanto, de un modelo abierto, sin restricciones de ningún tipo, más allá de la superación del Bac, certificado de estudios secundarios. Tal y como hemos comentado, esta prueba guarda una gran complejidad, sin embargo, no puede ser catalogada como una prueba de carácter selectivo ya que, en ella, se evalúan los contenidos cursados por el alumno durante su estancia en el Lycée. No obstante, la prueba nacional de Bac es mucho más competencial que la Selectividad española.

Sin embargo, cuando nos referimos a otros desarrollos institucionales de la educación superior el modelo es mucho más complejo y exigente. En las Grandes Écoles y los IUTs, se ponen en marcha una serie de mecanismos selectivos de admisión. Esta selección se produce debido a la fuerte demanda de estudiantes hacia estos itinerarios formativos, que hacen que la transición deba ser altamente restrictiva. Así, a diferencia de lo que ocurre en nuestro país, en este caso, además de valorar la idoneidad del estudiante, también se pretende llevar a cabo un equilibrio sobre el 
sistema económico productivo, evitando formar más trabajadores de los que se necesitan.

Por tanto, nuevamente, no podemos afirmar que el modelo de acceso/admisión a las instituciones de educación superior en Francia sea totalmente abierto, con unos procesos de transición sumamente flexibles ya que aunque esa sea la tendencia más normalizada, lo cierto es que también existen itinerarios formativos con un alto grado de restricción y, por tanto, más cerrados.

\subsubsection{3) Sistema educativo finlandés}

Como ya hemos comentado en reiteradas ocasiones, el acceso/admisión a las instituciones de educación superior en Finlandia está en manos, solo y exclusivamente, de las propias universidades. Esto hace que no exista modelo de acceso/admisión homogénea dentro del país nórdico, sino más bien, todo lo contrario, ya que podríamos afirmar que existe un modelo para cada una de las universidades finlandesas. Y es que la autonomía de la que estas disponen hace que cada centro pueda establecer unos criterios distintos. No tanto, es una cuestión de cada centro de educación superior, sino más bien, de sectores académicos agrupados institucionalmente.

Por tanto, si a la hora de analizar el modelo de acceso/admisión a la universidad en España y Francia, no hemos querido etiquetarlo de una forma concreta debido a las especificidades que presentaban, menos aún podremos hacerlo para el caso finlandés, donde la fuerte autonomía de las instituciones de educación superior hace que no exista homogeneidad alguna en los criterios de acceso/admisión y, por tanto, no se pueda establecer un modelo de acceso concreto. 


\subsection{8) Indicadores culturales}

\subsubsection{1) Sistema educativo español}

A continuación, vamos a realizar un breve análisis acerca de algunos indicadores culturales de la sociedad española. Esta variable guarda un gran interés para nuestro estudio, ya que el nivel cultural de nuestra sociedad puede ser un indicador de impacto a la hora de entender los procesos de transición universitaria. En este sentido, hemos optado por indagar acerca de tres factores, que nos puedan facilitar una mayor y mejor comprensión de nuestro estudio, como son: el tiempo medio que los españoles dedican a la lectura, el gasto público del país en actividades culturales y el porcentaje de población con estudios de nivel terciario. La elección de estos indicadores no ha sido aleatoria, ya que hemos tenido que realizar un gran esfuerzo para localizar una serie de variables tangibles, sobre las que previamente se hubieran llevado a cabo un análisis y que, a su vez, nos pudieran aportar información relevante en relación a los procesos de transición universitaria.

En primer lugar, nos detendremos en el análisis del tiempo dedicado a la lectura. Varios estudios, tanto de ámbito nacional como internacional, se han interesado a lo largo de los últimos años por la temática que aquí presentamos. Sin duda alguna uno de los más relevantes, y sobre el que vamos a fundamentar nuestro estudio, es el publicado por European Commission, a través de su informe Culture Statistics (2016). Este documento se apoya en los datos de Eurostat, a través de la encuesta Adult Education Survey (AES), llevada a cabo los años 2007 y 2011. La población que participa en este estudio tiene una edad comprendida entre los 25 y los 64 años. El documento está estructurado en diferentes módulos, de los cuales, uno hace referencia a la participación cultural de los diferentes países participantes, y en él, se ponen sobre la mesa diferentes aspectos que nosotros estamos analizando, como el hábito de lectura en determinados rangos de población, la participación en 
actividades culturales, etc. El informe, hace hincapié en el papel fundamental que desempeña la lectura, no solo en el proceso educativo de los ciudadanos, sino también en su enriquecimiento cultural. En este sentido, analiza el porcentaje de la población que, al menos, ha leído un libro a lo largo de los últimos doce meses. España cuenta con un 58\% de personas, siendo el porcentaje de mujeres superior al de hombres (en más de 15 puntos). Estos datos no son nada halagüeños, ya que se sitúan muy lejos de los países que encabezan el ranking. Por otro lado, si realizamos un análisis atendiendo a la edad de los sujetos, podemos apreciar cómo las diferencias no son muy significativas, siendo aquellas personas cuyas edades se encuentran comprendidas entre los 25 y los 34 años, las que poseen un mayor hábito de lectura.

En segundo lugar, nos detendremos en el análisis de otro indicador de gran interés, como es el gasto público cultural realizado por el Estado español. En este sentido, definimos el gasto cultural público como:

Prestación de servicios culturales; administración de asuntos culturales; supervisión y regulación de instalaciones culturales; Gestión o apoyo de instalaciones para actividades culturales (..); producción, gestión o apoyo de actos culturales (...); Donaciones, préstamos o subsidios en apoyo a artistas, escritores, diseñadores, compositores y otros particulares que se dedican a las artes, o a organizaciones que participan en la promoción de actividades culturales (Almeda y Tataret, 2016:7).

Sin duda, el análisis de esta variable no ha sido una tarea sencilla, ya que hemos tenido serias dificultades para encontrar estudios recientes que aborden la temática expuesta. En este sentido, podemos destacar alguno de ellos, como el publicado por el Consejo de Europa, Compendium - Cultural policies and trends in Europe (2011), que recogía datos acerca de recursos públicos destinados a fines culturales en diferentes países del contexto europeo; o el realizado por la reconocida consultora «Ernest and Young», Creating Growth. Measuring cultural and creative markets in the $E U$ (2014), que centraba su atención en cómo la desinversión y la austeridad presupuestaria están comprometiendo el crecimiento cultural de nuestra 
sociedad. Pero, sin duda alguna, el de mayor relevancia, y al que nosotros prestaremos una mayor atención, es el publicado recientemente por la Fundació Catalunya Europa, «Estudio del gasto cultural en Europa y de los Estados miembros durante la crisis 2007-2014» (Almeda y Tataret, 2016). En él se pone de manifiesto el impacto que la crisis económica ha generado sobre los presupuestos públicos de diferentes países de la U.E., siendo nuestro país, uno de los que más se ha visto afectado por estos tiempos de recesión, especialmente, sobre el Estado del bienestar y, de una forma más específica, sobre el sistema cultural, que se ha visto reducido en casi un $35 \%$ desde el año 2007, lo que en términos absolutos supone 2.271 millones de euros. Si analizamos estos datos per cápita, observamos que la tendencia es la misma, siendo el país que ha experimentado un mayor descenso del gasto público por habitante, con una reducción del 36\%. Por último, si analizamos la inversión desde el punto de vista administrativo, España ha seguido la tendencia europea, reduciendo su inversión cultural en un 3\%. Sin embargo, hemos de reconocer que este descenso se ha sido paliado con un incremento presupuestario por parte de las corporaciones locales, de casi un 7\% (Almeda y Tataret, 2016).

Para finalizar, vamos a poner nuestro foco de atención sobre otro indicador de gran interés, como es el nivel educativo de la población española. Sin duda alguna, esta variable nos reportará información sumamente valiosa, tanto desde el punto de vista académico como cultural. Ya hemos hecho una pequeña alusión al respecto, cuando analizamos el origen social del alumno, poniendo nuestro foco de atención, específicamente, en los progenitores. A continuación, vamos a centrarnos, de una forma más general, en los datos de toda la población. Para ello, nos valdremos del último informe publicado por OECD, Education at a Glance (2019), en el que se lleva a cabo una extensa recopilación informativa acerca de los diferentes sistemas educativos de los Estados que conforman esta organización. Nosotros, en primer lugar, analizaremos el porcentaje de la población con estudios mínimos -primera etapa de educación secundaria-, y posteriormente, nos centraremos en el extremo opuesto, 
es decir, el porcentaje de la población que ha finalizado estudios de nivel terciario CINE 5 y 6-. En este sentido, el porcentaje de adultos que posee estudios de primera etapa de educación secundaria, como nivel educativo máximo alcanzado, ha decrecido a lo largo de los últimos años, situándose en un 40\%, en el año 2018. Este porcentaje se encuentra muy por encima de la media de la OCDE (21\%) y de la U.E (18\%). En cambio, el porcentaje de población con estudios de educación terciaria está de acuerdo con los parámetros europeos, situándose en un $37 \%$ de la población española, cuyas edades están comprendidas entre los 25 y los 64 años. Este porcentaje es similar a la media de la OCDE (38\%) y se encuentra ligeramente por encima de los parámetros de la U.E (35\%).

\subsubsection{2) Sistema educativo francés}

Siguiendo la misma línea de trabajo que hemos realizado en el sistema educativo español, vamos a centrar nuestra atención en los tres indicadores a los que acabamos de aludir en el apartado anterior: tiempo medio dedicado a la lectura, gasto público en actividades culturales y nivel educativo de la sociedad francesa.

A la hora de analizar el primer indicador cultural -hábito de lectura- en el sistema educativo español, hemos utilizado el estudio anteriormente citado de European Commission, Culture Statistics (2016). Sin embargo, este informe no recogía los datos del país galo. Por ello, hemos optado por buscar otras investigaciones que nos pudieran aportar datos al respecto. El estudio que nos ha suscitado un mayor interés es el que realizó el Centre National du Livre (CNL) francés y el instituto IPSOS, Les Français et la lecture (2017), donde se ponen de manifiesto algunos datos relevantes sobre los hábitos de lectura de la población francesa, cuyas edades se encuentran comprendidas entre los 15 y los 65 años. A grandes rasgos, podemos concluir que Francia es un país lector, donde aproximadamente un $84 \%$ de la población manifiesta hacerlo frecuentemente (siendo el porcentaje de mujeres 
superior al de hombres, en más de 10 puntos). Si analizamos este fenómeno por grupos de edades, podemos apreciar cómo, en este caso, sí existen diferencias significativas, ya que la población con edades comprendidas entre los 50 y los 64 años es, sin duda alguna, la que posee un mayor hábito de lectura (30\%).

En segundo lugar, vamos a analizar el gasto cultural del país galo. En este sentido, Francia no se vio tan penalizado por la crisis económica, siendo uno de los países centroeuropeos que, no solamente no vio reducida su inversión cultural, si no que consiguió incrementarla en un $13 \%$, lo que en términos absolutos supone un aumento de 1.738 millones de euros. Si analizamos estos datos per cápita, observamos cómo la tendencia es similar, con un aumento un poco menor, en torno a un $10 \%$, lo que en términos absolutos supone un crecimiento de 19 euros por persona. Por último, si analizamos la inversión cultural, atendiendo los diferentes niveles administrativos, podemos apreciar cómo Francia mantiene la misma tendencia que la mayoría de los países europeos, donde se ha reducido la inversión estatal en un 7\%, pero por el contrario, se ha aumentado la de los entes locales, con un incremento de más del 6\% (Almeda y Tataret 2016).

Para finalizar, analizaremos el nivel educativo de la población francesa. Recordemos que para el análisis de esta variable, vamos a utilizar los últimos datos publicados en el informe Education at a Glance. Siguiendo las mismas directrices que hemos realizado en el anterior análisis, vamos a centrarnos en el porcentaje de la población que tan solo ha alcanzado la primera etapa de educación secundaria como nivel máximo de estudios, y en el extremo opuesto, el porcentaje de la población que ha finalizado estudios de nivel terciario. En este sentido, el porcentaje de población adulta que tan solo ha cursado el primer nivel de educación secundaria se sitúa en torno a los parámetros de la OCDE (21\%) y de la U.E (18\%), con un $21 \%$, en el año 2018. Mientras que el porcentaje de población con estudios de nivel terciario está de acuerdo con los objetivos internacionales, lo que se traduce en un 36\% de la población 
adulta. Este porcentaje se encuentra por debajo de la media de la OCDE (38\%), si bien, supera ligeramente los parámetros europeos (35\%).

\subsubsection{3) Sistema educativo finlandés}

Por último, vamos a detenernos a analizar algunos indicadores que puedan ayudarnos a entender cuál es el nivel cultural de la sociedad finlandesa. Como es lógico, vamos a continuar con el mismo esquema que hemos realizado hasta el momento para el análisis de esta variable. En primer lugar, pondremos nuestra atención sobre el hábito de lectura de la población finlandesa. En este sentido, y atendiendo a los datos publicados por el informe Culture Statistics (2016), podemos afirmar que Finlandia es un país referente, en donde más del 70 de la población afirma haber leído un libro a lo largo de los últimos doce meses. De hecho, cada finlandés lee una media de 48 libros al año, unas magnitudes muy superiores a las de España (10). Aunque, sin lugar a dudas, donde el país nórdico destaca sobremanera, es en la lectura de periódicos, donde más de un $80 \%$ de las personas afirma leer el periódico diariamente. Y es que "la lectura de periódicos también se considera una forma de participación cultural, ya que la prensa es una fuente privilegiada de información" (European Commission, 2016: 121). Si analizamos estos datos atendiendo a la edad de los sujetos, podemos observar cómo, nuevamente, son los más jóvenes (25-34 años), los que poseen un mayor hábito de lectura.

En segundo lugar, analizaremos el gasto cultural del país nórdico. Finlandia fue uno de los países que mantuvo una cierta estabilidad en lo que respecta a su gasto cultural, llegando a aumentar su inversión un 6,5\% durante los años de recesión económica, lo que en términos absolutos supone un aumento de 54 millones de euros. Si analizamos estos datos per cápita, también observamos un ligero aumento, en torno a un $3 \%$. En cuanto a la inversión cultural realizada por los diferentes niveles administrativos, el país nórdico es uno de los pocos países analizados en los que la 
tendencia es opuesta; es decir, incrementado su inversión cultural desde la administración central (en un 6\%), pero, en cambio, ha disminuido la de las corporaciones locales en un porcentaje similar (Almeda y Tataret, 2016). Sin duda alguna, este es uno de los grandes factores sobre los que radica el éxito educativo finlandés, la fuerte inversión que el gobierno ha llevado a cabo, incluso en los momentos más delicados, cuando Finlandia se vio gravemente afectada por la crisis económica. En este sentido, también nos gustaría resaltar la gran inversión realizada en cuestiones educativas e investigación. Sin duda alguna, esta fue una de las medidas que mayor éxito ha generado en la sociedad finlandesa, ya que a medida que aumentaba su inversión, las empresas finlandesas podían contratar más profesionales, lo que hacía crecer el número de estudiantes que se veían atraídos por este factor. De este modo, Finlandia ha logrado alcanzar un círculo virtuoso, en el que el Estado patrocinaba la investigación de las empresas, que conseguían crecer gracias a este apoyo estatal y que, a su vez, le devolvían la inversión realizada en forma de impuestos (Oppenheimer, 2010).

Para finalizar, analizaremos el nivel educativo de la población finlandesa, nuevamente, aludiendo al informe Education at a Glance (2019). Mantendremos las mismas directrices que los análisis anteriormente realizados. En este sentido, la proporción de población adulta que tan solo ha cursado la primera etapa de educación secundaria es mínima en el país nórdico, con un porcentaje en torno al $11 \%$ en el año 2018. Estos datos sitúan a Finlandia como uno de los países destacados de la OCDE (cuyo promedio es muy superior, con un $21 \%$ ) y de la U.E (18\%). Mientras tanto, el porcentaje de población con estudios de nivel terciario está en sintonía con los estándares europeos, superando la media de OCDE (38\%) y de la U.E (35\%), con un $44 \%$ de la población. 
4.1.9) Sistemas de orientación en los centros de educación secundaria y su relación con el acceso/admisión a los estudios de educación superior

\subsubsection{1) Sistema educativo español}

Son muchos los estudios que a lo largo de los últimos años han puesto énfasis en cómo los estudiantes de educación secundaria no están lo suficientemente preparados para afrontar la transición hacia los estudios de educación superior, derivándose de esta situación, serios problemas en el contexto universitario: desorientación, cambios de titulación, prolongación de estudios, abandono prematuro, etc. (Cabrera, Bethencourt, Álvarez y González, 2006; Martín, González, Rodríguez, Pérez y Álvarez, 2010; Rodríguez et al.,2004; Torrado et al., 2010; Sánchez, 2001). Esto se debe, fundamentalmente, a las múltiples necesidades que el alumno presenta y que le generan dificultades en el acceso: desconocimiento de la universidad como institución, falta de información, desconocimiento de sus propias aptitudes y de las posibles salidas profesionales de una determinada titulación, etc. (Salmerón, Ortiz y Rodríguez, 2005). En el año 2019 vio la luz un estudio publicado por el instituto IPSOS, en colaboración con la agencia de orientación profesional JobTeaser ${ }^{44}$, que pone de manifiesto el descontento generalizado de los alumnos europeos en la forma en la que los sistemas educativos preparan a sus alumnos para la transición desde la educación secundaria a la educación superior.

Frente a este escenario, se han comenzado a potenciar diferentes modelos y programas de orientación, que permitan lograr una mejor adaptación del alumno durante este proceso de transición (Álvarez González, Figuera y Torrado, 2011; Rodríguez Moreno y Gallego, 1999; Santana y Álvarez, 2002). Hoy día, se concibe la

\footnotetext{
${ }^{44}$ Preparing the new generation for the future of work. A survey of European youth, employers and universities.
} 
orientación como una acción plenamente integrada en la programación general del centro, siendo asumida por toda la comunidad educativa. No obstante, de una forma más específica, serán los Departamentos de Orientación los encargados de llevarla a cabo. En este sentido, una de las funciones que debe desarrollar el Departamento de Orientación es el asesoramiento del alumnado en relación a las diferentes opciones que le ofrece el sistema educativo, inculcando al alumno la importancia de proseguir sus estudios para su proyección, no solo profesional, sino también personal (Domínguez, Álvarez y López, 2013). Los servicios de orientación educativa deben asesorar a los estudiantes en las etapas preuniversitarias, así como mejorar los canales de información para que los estudiantes sepan realmente qué formación se les ofrece y, sobre todo, qué se les va a requerir para superarla (Iñiguez, Elboj y Valero, 2016). Para ello, existe un Plan de Orientación Académica y Profesional que incluye las acciones específicas que deben llevarse a cabo mediante distintas iniciativas (sesiones informativas, mesas redondas, sesiones de dialogo con profesionales de distintos sectores, visitas a empresas, etc.) que permitan orientar a los estudiantes en la elección de su futura titulación académica y/o profesional, además de facilitarles la transición hacia la vida adulta (European Commission, 2008b).

La forma que cada institución educativa tiene de diseñar y realizar la orientación del alumno se refleja en el Plan de Orientación, que se enmarca en el Plan de Actuación de Centro. Dentro del sistema educativo español, los centros de educación secundaria tienen autonomía para emprender actuaciones que se ajusten a las necesidades de su alumnado y, así, establecer aquellas estrategias que mejor se adapten a su realidad (Tortosa et al., 2015). De este modo, alguna de las acciones llevadas a cabo desde los servicios de orientación, que están trayendo consigo grandes mejoras para favorecer los procesos de transición universitaria, son: jornadas de puertas abiertas, acciones para la adecuación del nivel formativo de los estudiantes (asignaturas propedéuticas, cursos cero, etc.), mejora de sus perfiles formativos, etc. 
(Cabrera et al., 2006; Domínguez et al., 2013). Si bien, pese a la amplia autonomía de la que disponen los centros educativos en materia de orientación, hemos de reconocer que son las CC. AA las que tienen la responsabilidad, dentro de su ámbito de autoridad, de asegurar que se ofrezca esta orientación, encargándose de promover los mecanismos esenciales para que ésta se desarrolle de una manera plena y satisfactoria. Y junto a ella, el gobierno central, que debe proporcionar la garantía de calidad de los servicios de orientación e información (European Commission, 2008b).

En nuestro país, se viene realizando un esfuerzo institucional, a lo largo de las últimas décadas, para mejorar la coordinación de los servicios de orientación entre centros de educación primaria y educación secundaria. Del mismo modo, también se pone mucho énfasis en la transición entre la educación secundaria inferior y la educación secundaria superior ya que será en cuarto de la ESO, por primera vez, donde el alumno tendrá que elegir el itinerario académico que desea seguir, tanto si es por la rama general, que posteriormente le conducirá a la universidad, como si es por la profesional. De este modo, una vez finalizado el primer ciclo de la ESO, los alumnos deben decidir qué optativas se acercan más a sus intereses académicos para, así, empezar a confeccionar su itinerario formativo. Esta elección va a ser fundamental para que el estudiante comience a construir su propio trayecto, eligiendo el itinerario que más se adecue a sus expectativas, aptitudes, habilidades y actitudes. La desorientación, la falta de información, la toma de decisiones precipitadas o inadecuadas y el miedo a la deserción ponen de manifiesto la necesidad de adaptar y mejorar el proceso orientación. Es por ello que, para evitar este tipo de problemas, la orientación educativa debería de iniciarse al principio y no al final de la educación secundaria obligatoria. Además, también debemos tener muy presente que, al finalizar este nivel educativo, el alumno podrá abandonar el sistema para afrontar su primera experiencia en el mercado laboral. Por este motivo, no solo debe aplicarse una orientación de carácter académico, sino también profesional. Sin embargo, es más complicado encontrar procesos de orientación, cuando la transición se produce desde 
la educación secundaria hacia la universidad. Esto es debido, en muchas ocasiones, a que los centros de educación superior y los centros de secundaria tienen sus límites organizativos y su propia planificación académica. Por todo ello, consideramos que es fundamental que encuentren puntos de unión y espacios de encuentro que faciliten el intercambio de ideas que puedan limar todos esos posibles desajustes a los que aquí hemos hecho alusión (Domínguez et al., 2013; Michavila y Esteve, 2011).

Por último, nos gustaría realizar una breve alusión a los profesionales que trabajan en los departamentos de orientación, ya que son parte importante de nuestra investigación. Como norma general, los orientadores que trabajen en centros de educación secundaria españoles (IES) deben poseer un título de educación superior, ya bien sea en psicología o educación, además de un máster de capacitación pedagógica. También deben tener conocimientos específicos sobre distintos aspectos del ámbito académico, como: programas de formación profesional y académica, conocimiento sobre distintas profesiones y ocupaciones, técnicas de recopilación y análisis de la información, asesoramiento individual o grupal, etc. (European Commission, 2008b).

\subsubsection{2) Sistema educativo francés}

El sistema educativo francés otorga un papel primordial a los servicios de orientación educativa debido, fundamentalmente, a la gran complejidad de vías y opciones académicas de la que los estudiantes disponen durante su periplo formativo. Desde el punto de vista institucional, podemos afirmar que Francia ha realizado un gran esfuerzo por introducir los servicios de orientación como uno de los pilares de su sistema educativo a lo largo de los últimos años. De este modo, con la Ley de Educación de 1989, aparece el derecho a la orientación y a la información educativa y laboral, como parte del derecho a la educación. Por otro lado, a partir de la Ley de Orientación y Programación para el Futuro de la Enseñanza (2005), se especifica que 
los alumnos deben elaborar su propio proyecto de orientación educativa y académicoprofesional, mediante la ayuda de los padres, profesores, orientadores y otros profesionales competentes (European Commission, 2008b). Además, con la nueva reforma de bachillerato que finalizará su implantación en el año 2021, se va a apostar por otorgar un mayor apoyo y orientación a los estudiantes, con el único fin de reducir el fracaso durante el tránsito hacia la universidad y la vida activa. Para ello, se van a acometer una serie de reformas de este nivel educativo, entre las que tenemos que destacar la incorporación de una serie de sesiones dedicadas a la orientación, donde el alumno se preparará para la toma de decisiones sobre su futuro académico y/o profesional. Además, la plataforma Admission Postbac, a la que ya hemos hecho alusión, entre sus muchas funciones, permite al alumno solicitar asesoramiento una vez finalizada su etapa de educación secundaria, con el fin de favorecer el éxito académico (y también profesional) del estudiante.

En este sentido, podríamos definir el modelo de orientación francés como un modelo mixto, que combina servicios tanto dentro como fuera de las instituciones académicas. Los servicios prestados dentro de los propios centros se enfocan hacia aspectos de carácter académico, mientras que los servicios externos tienen un enfoque mucho más amplio. Entre ellos destacan, por encima del resto, los Centres d'information et d'orientation (CIO). Estos centros son los encargados de actuar en el ámbito escolar, especialmente, con aquellos alumnos cuyas edades se encuentran comprendidas entre los 11-18 años (educación secundaria). Entre las múltiples funciones que llevan a cabo, destacan: observación de los alumnos, realización de entrevistas, participación en la toma de decisiones del alumno, facilitación y el tratamiento de la información acerca de diferentes aspectos formativos y profesionales, etc. (Maillet, 2007; Marín, 2004; Sanchiz, 2009). Por lo tanto, son estos centros los que, a través de sus profesionales, se encargan de orientar y asesorar al alumno en la toma de decisiones académicas, favoreciendo que elijan el itinerario 
formativo y/o profesional más adecuado a sus intereses, habilidades y motivaciones. Desde el punto de vista organizativo, debemos tener muy presente que estos servicios externos dependen de la administración central, lo que favorece una mayor homogeneidad tanto en la estructura como en las funciones a desarrollar. Los ministerios responsables son los de educación y empleo (Grañeras y Parras, 2009). El apartado educativo es competencia del Ministerio de Educación y también del de Enseñanza Superior e Investigación, que son los encargados de prestar orientación y asesoramiento a todos aquellos jóvenes de educación secundaria y educación superior. Si bien, junto a la administración central, un gran número de organismos públicos, semipúblicos y privados (delegaciones locales, centros de información para los jóvenes, etc.) participan en esta orientación académico-profesional. Desde el punto de vista interno, cada CIO está dirigido por un director o directora que, a su vez, es supervisado por un inspector nacional de educación. Y junto a ellos, estarían los denominados COP (Conseillers d'Orientation-Psychologues), que son los encargados de llevar a cabo estos procesos de orientación y asesoramiento a los que venimos aludiendo. Estos profesionales acceden a su puesto por concurso, tras graduarse en Psicología (o una titulación similar aceptada por la legislación vigente) y tras recibir una formación de dos años (European Commission, 2008b; Maillet, 2007; Marín, 2004). Además, junto a los COP, también debemos hacer alusión a los CPE (Conseiller Principal en Éducation). Estos profesionales, formados en los INSPE, ejercen una labor educativa fuera de las aulas, como mediadores y asesores. Son los educadores de los centros escolares que no actúan en las aulas sino fuera de ellas. Además, están presentes en todos los órganos de participación y administración de los establecimientos escolares.

\subsubsection{3) Sistema educativo finlandés}

En Finlandia, la orientación juega un papel prioritario a la hora de promover la igualdad educativa, así como el bienestar de los y las estudiantes y la prevención 
de la exclusión social. Uno de los aspectos en los que más está incidiendo el país nórdico a lo largo de los últimos años, y que sin duda está logrando, es la mejora de la eficiencia de su sistema educativo, reduciendo ostensiblemente los porcentajes de abandono escolar (European Commission, 2008b). Aunque, sin duda alguna, uno de los aspectos en los que los departamentos de orientación tienen un mayor peso, es en los procesos de transición ya que, desde que se instauró la comprensividad en la década de los 70 del pasado siglo, el sistema educativo finlandés han llevado a cabo distintas medidas que han favorecido la denominada transición vertical, especialmente cuando ésta se ha producido entre la educación básica y la educación secundaria superior (Sahlberg, 2006). La orientación ejerce un papel curricular de carácter transversal tanto en la educación básica como en los programas de educación secundaria superior, con especial interés en esta última etapa, ya que es cuando se inicia el proyecto de vida, académico o vocacional, profesional y laboral. De este modo, se orienta al alumno para cualquier decisión de carácter académico, vocacional o profesional (García Pedraza, 2015).

En términos normativos, la ley que sigue vigente hoy día es la ley de educación básica, que se puso en marcha a finales del pasado siglo (1998). En esta normativa se estipula que todos los alumnos tienen derecho a recibir una orientación y un asesoramiento adecuado (Halinen y Järvinen, 2008), garantizando, entre otras cosas, la recepción de una información útil sobre su trayectoria académica y profesional tanto antes como durante el desarrollo de su formación. A nivel organizativo, la administración educativa es la encargada de los servicios de información y orientación académico-profesional, en donde intervienen tanto la administración central como las corporaciones locales. El gobierno, a través del FNBE, se encarga de determinar el tiempo que se dedica a la orientación. No obstante, cada municipio es libre de decidir las opciones que ofrece, así como su inclusión en el currículum, siempre que se respete el marco legislativo. 
Respecto a los profesionales que trabajan dentro del ámbito de la orientación educativa, debemos destacar que éstos deben ser profesores cualificados con un máster (300 créditos ECTS) que, además, complementen su formación con aspectos específicos relacionados con la orientación y asesoramiento. La formación que estos profesionales reciben durante su periplo universitario varía en función de cada institución por dos motivos: en primer lugar, debido a que no existe una normativa que regule esta orientación académico-profesional y, en segundo lugar, debido a la autonomía de la que disponen las instituciones de educación superior (European Commission, 2008b), que les permite desarrollar, libremente, el plan de estudios que crean más oportuno. Por tanto, estas labores de asesoramiento y orientación recaen en los docentes, con el reconocimiento correspondiente.

Por último, nos gustaría finalizar este pequeño apartado haciendo alusión a una etapa educativa del sistema nórdico, como es el $10^{\circ}$ curso, que es específico del sistema educativo finlandés y que tiene una gran trascendencia para el tema que estamos abordando. En este curso, que tiene un carácter voluntario, pueden matricularse todos aquellos alumnos que lo deseen, una vez han finalizado la etapa de educación secundaria inferior (la matrícula en esta etapa educativa se sitúa en torno al 3\%). Su principal objetivo es el de reforzar las competencias del alumno, especialmente cuando éste se sienta indeciso (García Ruiz, 2010; Sahlberg, 2006). Por lo tanto, este curso se presenta como un itinerario de gran relevancia en el ámbito de la orientación, ya que pretende ayudar al alumno, en una etapa trascendental para su desarrollo académico y profesional. Se trata de reforzar las habilidades y capacidades del alumno para un mejor rendimiento en los programas de educación secundaria superior. 


\subsubsection{0) Acción tutorial en los alumnos de educación secundaria y su relación con el acceso/admisión hacia los estudios de educación superior}

\subsubsection{1) Sistema educativo español}

A finales del pasado siglo, con la promulgación de la LOGSE, la orientación educativa paso a ser uno de los factores de calidad por los que el sistema educativo español apostaba de una forma más vehemente. En este sentido, uno de los principales actores que intervenían en estos procesos de orientación educativa eran los propios docentes. De este modo, la acción tutorial se conforma como el primer eslabón del sistema de orientación, hacia el cual se dirigen gran parte de los esfuerzos de los Departamentos de Orientación y de los Equipos de Zona (Domínguez et al., 2013).

El objetivo principal que pretende llevar a cabo la acción tutorial no es otro que el de facilitar los procesos didácticos y de aprendizaje de los estudiantes, así como contribuir a su desarrollo personal, profesional y social. Para ello, llevarán a cabo distintas acciones, como promover el conocimiento propio de los estudiantes, otorgarle una atención personalizada, proporcionarles información sobre los distintos itinerarios académicos que ofrece el sistema educativo, etc. (European Commission, 2008b). Esta última acción es una de las más trascendentales para la acción tutorial, y como tal, así lo recoge el Libro Blanco para la Reforma del Sistema Educativo en su capítulo XV:

Capacitar a los individuos para su propia autoorientación y crear en ellos de manera progresiva una capacidad y una actitud activa hacia la toma de decisiones fundamentadas y responsables sobre su propio futuro, primero, en la escuela, ante las distintas opciones educativas, y luego, ante las distintas alternativas de vida social y profesional (MEC, 1989: 226)

Por otro lado, no debemos obviar que para que todos estos procesos llevados a cabo por el profesor tutor se desarrollen de una manera satisfactoria, estos deben formar parte de una serie de documentos curriculares del propio centro educativo, 
como son: Proyecto Educativo de Centro (PEC), Proyecto Curricular de Etapa (PCE), Reglamento de Organización y Funcionamiento (ROF), Plan Anual de Centro (PAC) y, en última instancia, Plan de Acción Tutorial (PAT) (Marín, 2004).

Por otro lado, debemos destacar que para que este proceso de transición se desarrolle de una forma eficaz, es muy importante que los tutores comiencen a orientar a los alumnos con suficiente antelación. El último curso de la ESO es una etapa de gran trascendencia para el alumno, ya que será a partir de este momento cuando tendrá que comenzar a conformar el itinerario académico que desea seguir o, por el contrario, buscar alternativas en el mercado laboral. El doble carácter de esta etapa, propedéutico y finalista, es un gran desafío para el profesorado, que tendrá que proporcionar a los estudiantes los conocimientos necesarios para afrontar de una forma exitosa su futuro académico y/o profesional. Por este motivo, más allá de las actividades individualizadas que el tutor llevaba a cabo con los alumnos, la tutoría ha conformado una pequeña parte de los planes de estudios que, sin embargo, no ha sido suficiente, lo cual ha limitado el desarrollo de las actividades planificadas y el alcance de los objetivos previstos (Santana, Feliciano y Cruz, 2010).

Por lo tanto, debemos poner de manifiesto el fuerte impacto que la tutoría ejerce sobre los procesos de transición. Sin embargo, para que esta se desarrolle de una manera satisfactoria, es imprescindible que esta se lleve a cabo antes, durante y tras el proceso de transición.

\subsubsection{2) Sistema educativo francés}

Al igual que ocurría con los procesos de orientación, la acción tutorial goza de un reconocido prestigio en el sistema educativo francés, formando una parte importante del currículum, dentro de la escolaridad obligatoria. De este modo, podemos afirmar que todos los centros educativos franceses tienen institucionalizada la tutoría. Los profesores deben guiar y asesorar al alumno, manteniendo una estrecha 
colaboración con los orientadores del centro (Del Valle, 2004) y con el Consejero Principal de Educación. Esta figura educativa -que desde el año 2013 paso a formar parte de las ESPE-, es propia del sistema francés y se encarga de llevar a cabo diversas acciones pedagógicas dentro del centro.

Además, no podemos obviar un elemento de gran transcendencia en el apartado orientativo del sistema educativo francés, como es el ciclo de orientación. Esta etapa, que se puso en marcha en el año 2004, se corresponde con el tercer curso del collège, y pretende ayudar a los a los alumnos a la hora de tomar decisiones durante su trayectoria académico-profesional. A lo largo de este ciclo, los profesores se encargan de realizar pequeñas entrevistas personalizadas a los estudiantes, en colaboración con los orientadores del centro e incluso, en muchas ocasiones, con la participación de las propias familias. A partir de ellas, se pretende ayudar al alumno en la toma de decisiones, reducir el abandono escolar, orientar su futuro más inmediato, etc. Para ello, es importante que estas actuaciones se lleven a cabo lo antes posible, una vez se inicie el curso escolar, para así poder asesorar a los estudiantes con la mayor inmediatez posible (European Commission, 2008b).

\subsubsection{3) Sistema educativo finlandés}

Los procesos de acción tutorial en el sistema educativo finlandés tienen un gran protagonismo, especialmente, a lo largo de la educación básica, en donde todos los alumnos tienen derecho, como mínimo, a dos sesiones semanales de orientación y asesoramiento. Estas sesiones tienen una duración variable en función de los centros educativos, aunque, en la práctica, no se aprecian diferencias significativas (Gripenberg y Lizarte, 2012; Sahlberg, 2006). Y si estos procesos son importantes en la educación básica, lo son más aún en la educación postobligatoria. En el apartado que a nosotros nos concierne, los procesos de transición, estos mecanismos tienen una gran relevancia ya que, gracias a ellos, se reduce el riesgo de que los estudiantes tomen 
decisiones precipitadas con respecto a su futuro académico o laboral más inmediato (Numminen y Kasurinen, 2003; Sahlberg, 2011a).

Los profesores tienen la tarea de aconsejar y asesorar a los alumnos sobre diversos aspectos de su vida académica. Y es que es fundamental que los alumnos, junto a sus padres, reciban la mayor información posible sobre diferentes aspectos de la vida académica del estudiante: tareas escolares y conocimientos adquiridos, posibles elecciones académicas y/o profesionales, así como sus implicaciones para el futuro, etc. Sin embargo, el principal problema con el que nos encontramos, de nuevo, es el escaso protagonismo que estos procesos de acción tutorial tienen sobre el currículum nacional, ya que tan solo ocupan un porcentaje minúsculo de las horas lectivas del alumno.

\section{2) El proceso de transición hacia la educación superior en España, Francia y Finlandia: convergencias y divergencias}

Una vez presentadas las diferentes variables que influyen en el acceso/admisión hacia los estudios de educación superior, vamos a mostrar, de una forma analítica, cuáles son las principales semejanzas y diferencias que hemos encontrado. Este análisis nos servirá como preámbulo para llevar a cabo la fase comparativa de nuestro trabajo, que desarrollaremos en el próximo capítulo, en donde interpretaremos estas convergencias y divergencias, tomando en consideración todos aquellos factores que puedan determinarlas y que hemos explicado en el capítulo contextual.

Para ello, hemos realizado unas pequeñas tablas comparativas, que sintetizan toda la información analítica recabada. Para ser lo más pragmáticos posible, vamos a sintetizar toda la información en cuatro tablas. La primera de ellas se centrará en el alumno, haciendo especial hincapié en su origen social. En segundo lugar, analizaremos el acceso hacia los estudios de educación superior, prestando atención 
al modelo de acceso/admisión, el papel desempeñado por los centros de educación secundaria, etc. En tercer lugar, aludiremos a los procesos de admisión, donde mostraremos las semejanzas y diferencias encontradas en los requisitos de acceso/admisión. Por último, analizaremos los procesos de orientación educativa, diferenciando estos procesos de la acción tutorial llevada a cabo por los docentes.

Comenzaremos analizando el origen social de los estudiantes (tabla 12). A simple vista podemos apreciar las primeras diferencias de nuestro estudio. En primer lugar, en cuanto a los antecedentes académicos de los alumnos, donde Finlandia destaca sobre sus homólogos en el estudio; y es que, casi un 70\% de los estudiantes (recordemos, se trata del porcentaje más alto de la U.E) poseen antecedentes académicos de educación superior, frente al $50 \%$ y $60 \%$ de los estudiantes españoles $\mathrm{y}$ franceses, respectivamente.

Por otro lado, también observamos diferencias en cuanto a las fuentes de financiación. Mientras que en España destaca la presencia de las familias como principal sustento del estudiante, en Francia hay una mayor presencia de la administración pública, a través de la concesión de ayudas para el estudio. Finalmente, Finlandia destaca por ser un país en el que son sus propios alumnos, los que a través de su empleo hacen frente a sus gatos, compatibilizando su actividad laboral y académica.

Por último, también hemos querido hacer alusión a un aspecto que guarda gran interés en la temática que nosotros presentamos, como es la ralentización en el acceso/admisión a los estudios de educación superior; de este modo, podemos apreciar cómo, paradójicamente, Finlandia, con un sistema educativo de referencia a nivel internacional, presenta un mayor porcentaje de alumnos que acceden a la educación superior de forma más lenta temporalmente que España y Francia, unos países cuyos estudiantes presentan un rendimiento académico que dista mucho del cosechado por los alumnos nórdicos. 
Tabla 12. Origen social de los alumnos que están en disposición de acceder a los estudios de educación superior en España, Francia y Finlandia

\begin{tabular}{|c|c|c|c|c|}
\hline & $\begin{array}{l}\text { Antecedentes } \\
\text { académicos }\end{array}$ & $\begin{array}{c}\text { Fuentes de } \\
\text { financiación }\end{array}$ & $\begin{array}{c}\text { Tipología del } \\
\text { sistema } \\
\text { educativo }\end{array}$ & $\begin{array}{c}\text { Ralentización } \\
\text { (Tiempo de } \\
\text { entrada) }\end{array}$ \\
\hline España & $\begin{array}{c}25 \% \text { de los } \\
\text { progenitores han } \\
\text { alcanzado un nivel } \\
\text { máximo de CINE } 2 \text {. } \\
50 \% \text { progenitores } \\
\text { han alcanzado un } \\
\text { nivel CINE 5-6. }\end{array}$ & $\begin{array}{l}\text { Familia }(<50 \% \text { de } \\
\text { los estudiantes se } \\
\text { encuentran en esta } \\
\text { tesitura). } \\
\text { Fondos públicos (en } \\
\text { torno al } 25 \% \text { de } \\
\text { alumnos) }\end{array}$ & Transición & Moderada \\
\hline Francia & $\begin{array}{c}10 \% \text { de los } \\
\text { progenitores han } \\
\text { alcanzado un nivel } \\
\text { máximo de CINE } 2 . \\
60 \% \text { de los } \\
\text { progenitores han } \\
\text { alcanzado un nivel } \\
\text { CINE 5-6. }\end{array}$ & $\begin{array}{l}\text { La mayor parte de } \\
\text { los estudiantes } \\
\text { franceses reciben } \\
\text { fondos de los } \\
\text { organismos públicos } \\
\text { para hacer frente a } \\
\text { los gastos derivados } \\
\text { de sus estudios. }\end{array}$ & Exclusivo & $\begin{array}{c}\text { Muy baja } \\
\text { (menos del } \\
2 \%)\end{array}$ \\
\hline Finlandia & $\begin{array}{l}\text { País con mayor } \\
\text { porcentaje de } \\
\text { estudiantes con } \\
\text { antecedentes de } \\
\text { educación superior } \\
\quad(65 \%) .\end{array}$ & $\begin{array}{c}\text { Gran parte de los } \\
\text { estudiantes } \\
\text { finlandeses sufragan } \\
\text { los gastos derivados } \\
\text { de sus estudios a } \\
\text { través de su propio } \\
\text { empleo (en torno al } \\
50 \% \text { de los } \\
\text { estudiantes se } \\
\text { encuentran en esta } \\
\text { tesitura). }\end{array}$ & Inclusivo & $\begin{array}{c}\text { Alta (en torno } \\
\text { al } \\
30 \%)\end{array}$ \\
\hline
\end{tabular}

Fuente: Elaboración propia

En segundo lugar, vamos a referirnos en el acceso propiamente dicho (tabla 13). En este sentido, podemos observar cómo el itinerario más común seguido por los estudiantes es similar en los tres sistemas educativos analizados, accediendo a la universidad tras cursar, de una forma satisfactoria, los estudios de educación secundaria superior. Si bien es cierto que, posteriormente, existen diferencias muy acentuadas entre los tres casos analizados. En los casos de Francia y Finlandia, tanto 
las pruebas de Bac como el FME pueden considerarse como pruebas de acceso. En el caso de España, la Selectividad ejerce dos papeles: acceso y admisión. Otra de las grandes diferencias que hemos encontrado cuando hablamos de acceso, tiene que ver con el modelo de admisión. Mientras que España y Francia presentan un modelo abierto y accesible (salvo en algunos desarrollos institucionales muy concretos), Finlandia es un país altamente selectivo en el que, comúnmente, se ponen en marcha mecanismos selectivos que permiten valorar la idoneidad de los estudiantes. Si bien, tal y como ya hemos comentado a lo largo de nuestro trabajo, debemos ser cautos a la hora de realizar esta afirmación, ya que la amplia autonomía de las instituciones de educación superior hace que, en muchos casos, también puedan existir itinerarios sumamente flexibles (aunque no es la tendencia más común). Por otro lado, también encontramos grandes diferencias en cuanto a la competencia organizativa del acceso. En España ésta recaerá sobre las CC. AA que, además, contará con la colaboración de las instituciones universitarias de la región. Francia, dada su fuerte centralización, gestiona este proceso de transición desde la administración educativa del gobierno central que se coordina, supervisa y valora desde las Académies. Y, finalmente, en Finlandia, son los propios centros de educación superior los que rigen este proceso de admisión, al igual que en Francia, dada su amplia autonomía, estableciendo aquellos criterios que consideren más oportunos (si bien es cierto que todos parten de un requisito básico, como es el $F M E$ ). Para finalizar, vamos a analizar las características académicas de los alumnos y los centros educativos donde estos se forman. En este sentido no hemos encontrado diferencias significativas ya que, en los tres casos analizados, existe un porcentaje mayoritario de estudiantes que están adscritos a centros de titularidad pública. Donde sí hemos encontrado alguna diferencia es a la hora de valorar el perfil de los estudiantes. Desde el punto de vista analítico, los datos son muy dispares ya que, ni los programas curriculares ni los factores demográficos, guardan similitudes en los tres casos analizados, lo que hace que la comparación sea un tanto dificultosa. Si bien, a grandes rasgos, podemos hablar de una mayor presencia 
de los estudiantes matriculados en programas de formación vocacional en el país nórdico, mientras que en España y Francia predominan los estudiantes que optan por el itinerario más genérico, que serían los estudios de bachillerato en nuestro país y bac general y tecnológico en el país galo.

\section{Tabla 13. Acceso hacia los estudios de educación superior en España, Francia y} Finlandia

\begin{tabular}{|c|c|c|c|c|}
\hline & Modelo de acceso & $\begin{array}{l}\text { Competencia } \\
\text { organizativa }\end{array}$ & $\begin{array}{c}\text { Perfil } \\
\text { estudiante }\end{array}$ & $\begin{array}{l}\text { Titularidad } \\
\text { centros }\end{array}$ \\
\hline España & $\begin{array}{l}\text { Prueba cultural } \\
\text { (flexibilidad) }\end{array}$ & $\begin{array}{c}\text { Administración } \\
\text { Regional + } \\
\text { universidades }\end{array}$ & $\begin{array}{l}\text { Bachillerato } \\
\text { (700.000 } \\
\text { alumnos) } \\
\\
\text { Formación } \\
\text { Profesional de } \\
\text { grado superior } \\
\text { (340.000 } \\
\text { alumnos) } \\
\end{array}$ & $\begin{array}{c}\text { Centros de } \\
\text { titularidad pública } \\
(75 \%) \\
\text { Centros de } \\
\text { titularidad privada } \\
(15 \%) \\
\text { Centros de } \\
\text { titularidad } \\
\text { concertada (10\%) }\end{array}$ \\
\hline Francia & $\begin{array}{c}\text { Prueba } \\
\text { competencial }\end{array}$ & $\begin{array}{l}\text { Administración } \\
\text { regional } \\
\text { (Académies) }\end{array}$ & $\begin{array}{c}\text { Bac general y } \\
\text { tecnológico } \\
(1.600 .000 \\
\text { alumnos) } \\
\text { Bac profesional } \\
\text { (666.000 } \\
\text { alumnos) }\end{array}$ & $\begin{array}{c}\text { Centros de } \\
\text { titularidad pública } \\
(>80 \%) \\
\text { Centros de } \\
\text { titularidad privada } \\
(<20 \%)\end{array}$ \\
\hline Finlandia & $\begin{array}{c}\text { Prueba } \\
\text { competencial }\end{array}$ & $\begin{array}{c}\text { Instituciones de } \\
\text { educación } \\
\text { secundaria superior }\end{array}$ & $\begin{array}{l}\text { Itinerario } \\
\text { profesional } \\
(300.000 \\
\text { alumnos }) \\
\text { Itinerario } \\
\text { general } \\
(100.000 \\
\text { alumnos }) \\
\end{array}$ & $\begin{array}{l}\text { Centros de } \\
\text { titularidad pública } \\
\qquad(>95 \%)\end{array}$ \\
\hline
\end{tabular}

Fuente: Elaboración propia

Por otro lado, junto al acceso, también debemos hacer referencia a la admisión. Como ya hemos explicado al comienzo de nuestro trabajo, frecuentemente, estos términos son utilizados de forme indistinta, pero en realidad tienen 
connotaciones muy diferentes. De este modo, podemos apreciar (tabla 14), cómo tanto el sistema educativo español como el francés, establecen un modelo de admisión que se sustenta en el modelo de acceso, donde la admisión a los centros de educación superior se limita a los requerimientos generales de acceso (prueba de acceso a la universidad en España y Bac en Francia). Si bien es cierto que existen desarrollos formativos concretos en donde, a estos requerimientos, se les añade otros más específicos. Por el contrario, Finlandia si establece un sistema de admisión específico, en donde las universidades, que son las encargadas de regir este proceso de transición, fijan los criterios que crean más oportunos, con el fin de seleccionar los candidatos más idóneos y, además, equilibrar la oferta y la demanda del sistema económico productivo.

\section{Tabla 14. Admisión a los centros de educación superior en España, Francia y Finlandia}

\begin{tabular}{|c|c|c|}
\hline España & $\begin{array}{c}\text { Modelo de } \\
\text { admisión }\end{array}$ & Contenido \\
\hline Flexible & $\begin{array}{c}\text { La admisión se considera implícita en la Selectividad. No obstante, } \\
\text { algunos desarrollos institucionales aplican pruebas de admisión que } \\
\text { complementan el procedimiento de acceso. Por otro lado, también es } \\
\text { posible la admisión sin prueba de acceso. }\end{array}$ \\
\hline Francia & Flexible & $\begin{array}{c}\text { La admisión general a las universidades requiere del curriculum del } \\
\text { estudiante durante su estancia en la educación secundaria. En sectores } \\
\text { académicos "profesionalizantes" se realizan pruebas complementarias } \\
\text { de admisión (altamente selectivas). }\end{array}$ \\
\hline Finlandia & Rígido & $\begin{array}{c}\text { Pruebas específicas de acceso, acreditación de experiencia profesional, } \\
\text { etc. (según los criterios de cada universidad), dependiendo de los } \\
\text { sectores académicos. }\end{array}$ \\
\hline
\end{tabular}

Fuente: Elaboración propia

Por último, vamos a mostrar aquellas semejanzas y diferencias que hemos encontrado en el análisis escolar, en torno a las variables de asesoramiento y acción tutorial (tabla 15). Sin duda, estas son las que presentan un mayor número de semejanzas en los tres sistemas educativos analizados, ya que poseen un objetivo común (asesoramiento y orientación del alumno para una correcta toma de 
decisiones), unos profesionales que han accedido a su puesto tras graduarse en educación superior (educación o psicología), así como un carácter institucionalizado de estos servicios. Por el contrario, encontramos alguna pequeña diferencia en torno al modelo de asesoramiento, que es interno en España y Finlandia, pero no en Francia, que presenta un modelo mixto, en donde intervienen profesionales externos junto a los de la propia institución académica.

Tabla 15. Asesoramiento y acción tutorial en los sistemas educativos de España, Francia y Finlandia

\begin{tabular}{|c|c|c|c|c|}
\hline & Objetivo & Modelo & Carácter & Profesionales \\
\hline España & $\begin{array}{l}\text { Asesorar a los } \\
\text { estudiantes en } \\
\text { las etapas } \\
\text { preuniversitarias } \\
\text { y mejorar los } \\
\text { canales de } \\
\text { información. }\end{array}$ & $\begin{array}{c}\text { Interno } \\
\text { (los servicios } \\
\text { prestados se } \\
\text { proporcionan } \\
\text { desde las propias } \\
\text { instituciones } \\
\text { académicas) } \\
\end{array}$ & Institucionalizada & $\begin{array}{c}\text { Titulados superiores } \\
\text { (Educación o } \\
\text { Psicología) } \\
+ \\
\text { Máster de } \\
\text { capacitación } \\
\text { pedagógica. }\end{array}$ \\
\hline Francia & $\begin{array}{l}\text { Orientar y } \\
\text { asesorar al } \\
\text { alumno en la } \\
\text { toma de } \\
\text { decisiones } \\
\text { académicas, }\end{array}$ & $\begin{array}{c}\text { Mixto } \\
\text { (en colaboración } \\
\text { con los CIO) }\end{array}$ & Institucionalizada & $\begin{array}{c}\text { Titulados superiores } \\
\text { en Psicología (o una } \\
\text { titulación similar) } \\
+ \\
\text { Concurso de } \\
\text { oposición }\end{array}$ \\
\hline Finlandia & $\begin{array}{c}\text { Asesorar y } \\
\text { orientar al } \\
\text { alumno para } \\
\text { favorecer la } \\
\text { toma de } \\
\text { decisiones } \\
\text { académicas y } \\
\text { profesionales. }\end{array}$ & Interno & Institucionalizada & $\begin{array}{c}\text { Titulados superiores } \\
+ \\
\text { Máster }\end{array}$ \\
\hline
\end{tabular}

Fuente: Elaboración propia 

1) INTRODVCCIÓN Y JVSTIFICACIÓN DEL TEMA

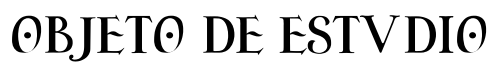

2) CATEGORÎAS $\odot$ VARIABLES DE ANÁLISIS DEL ACCESO/ADMISIÓN A LA EDVCACIÓN SVPERIOR

3) EL ACCESの/ADMISIÓN A LA EDVCACIÓN SVPERIOR EN ESPAÑA, FRANCIA Y

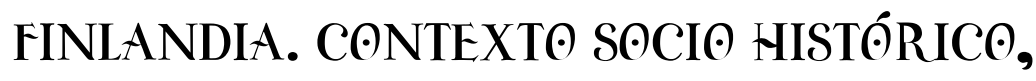
POLÍTICe Y CVLTVRAL

4) ¿¿CEM@ ACTV́AN LOS MODELOS DE ACCES๑/ADMISIÓN HACIA LA EDVCACIÓN SVPERIOR?

\section{5) LA COMPARACIÓN CONTEXTVAL DEL ACCESO/ADMISIÓN A LA EDVCACIÓN SVPERIOR. EL CARÁCTER FVNCIONAL DE LAS TRANSICIONES}

6) CONCLVSI@NES 



\section{5) LA COMPARACI@́N CONTEXTVAL DEL ACCESఠ/ADMISI@́N A LA EDVCACIڤ́N SVPERIOR. LA RACIONALIDAD COMO VEHÍCVIO PARA LA COMPRENSI@́N}

Estamos llegando al final de nuestro trabajo. Nos encontramos ante la última fase del método clásico de comparación, y por ello, nos gustaría comenzar este capítulo realizando una pequeña reflexión acerca de la comparación y, de una forma más específica, acerca de los estudios comparados en educación.

No cabe duda de que la comparación es algo inherente al ser humano. Constantemente estamos comparando. De hecho, sin que seamos conscientes de ello, la comparación forma parte de nuestra vida cotidiana. En este sentido, debemos señalar que, frente a un contexto de comparación, se forman dos escenarios posibles. Por un lado, el de la semejanza y, por el otro, el de la diferencia. Siempre que comparamos algo, lo hacemos porque presenta una serie de semejanzas o diferencias que lo hacen ser susceptible de ser comparado. Ya indicamos al comienzo de nuestro trabajo, durante el desarrollo metodológico, que la comparación no solamente puede darse entre hechos o fenómenos muy similares, sino que aquello que es diferente, también puede ser comparado, ya que en numerosas ocasiones, la riqueza comparativa se encuentra en la diferencia (Farrel,1990; Vega, 2011b). De este modo, cuando nos 
disponemos a realizar un estudio comparado, sea en el ámbito que sea (incluido el educativo), ya presuponemos que vamos a localizar una serie de semejanzas y diferencias. Esto es una obviedad, y es que, es evidente, que frente a un escenario de comparación, siempre van a existir, o bien una serie de semejanzas, cuando los fenómenos comparados sean muy similares, o bien una serie de diferencias, cuando estos fenómenos analizados no presenten rasgos comunes. En nuestro estudio, así lo reflejamos en la hipótesis de partida, cuando indicábamos que los itinerarios de acceso/admisión hacia la educación superior en los sistemas educativos analizados mostraban diferencias desde el punto de vista político, administrativo y pedagógico. Cuando nosotros formulamos esta hipótesis, no habíamos comenzado el desarrollo de nuestra investigación, pero entonces ya comenzábamos a intuir que, al finalizar nuestro estudio, íbamos a localizar una serie de diferencias en el acceso/admisión universitaria de los diferentes sistemas educativos analizados.

Hasta el momento, el trabajo que hemos venido realizando en nuestra investigación, se ha desarrollado a partir de la exposición de una serie de ideas y datos que otros autores han plasmado de una forma brillante. Sin embargo, el mero análisis descriptivo que venimos realizando, no es algo que sea innovador ni susceptible de ser investigado, ya que, como hemos puesto de manifiesto, son muchas y muy diversas las investigaciones que se han realizado, abordando este mismo eje temático. Por ello, debemos ir más allá de la descripción de estos datos, hasta alcanzar su interpretación. Por tanto, el objetivo que pretendemos alcanzar a lo largo de este capítulo es el de explicar, de una forma coherente y racional, las semejanzas y diferencias que hemos presentado de forma analítica en el capítulo anterior, localizando tanto su origen como las causas que han podido provocarlas. Y es que, como puede parecer lógico, tres contextos tan diferentes como los que hemos analizado en nuestro trabajo, presentan grandes diferencias entre sí, en cuanto a su historia, su desarrollo económico, su cultura, su política, etc. Este hecho repercutirá, ineludiblemente, sobre el contexto educativo, y de una forma más específica, sobre el proceso de transición que aquí 
analizamos. Y es que, son muchos los comparatistas que argumentan que el contexto es crucial y tiene una gran influencia sobre el desarrollo, no solo de los sistemas educativos, sino también de sus políticas (Astiz, Wiseman y Baker, 2002; Derqui 2001; Holmes, 1981; Noah, 1986; Phillips y Ochs, 2003, 2004). En este sentido, cobra una especial relevancia la mentalidad política de la educación. Puelles (2010) pone de manifiesto cómo, históricamente, la educación ha sido utilizada como un instrumento al servicio de la política. $\mathrm{Y}$ es que, para el desarrollo de nuestro trabajo, es fundamental que analicemos e interpretemos el enfoque político de la educación, ya que esta «politización» nos permitirá comprender que detrás de toda interpretación histórica y educativa, se esconden elementos políticos (Fernández Soria, 2019).

Por otro lado, frente a estas divergencias, también hemos localizado algunas similitudes, fruto de las nuevas tendencias impulsadas por la globalización y el postmodernismo, que han hecho mella en nuestra sociedad y, de una forma más específica, en el contexto educativo (Carney, 2009; Carnoy, 1999; Steiner, 2010). Y es que, "la globalización, entendida como la intensificación de las relaciones entre contextos distantes en tiempo real" (Vega y Espejo, 2011: 248), ha traído consigo la aparición de un sistema mundial a nivel económico que, con el paso del tiempo, también se ha manifestado en el plano educativo (Dale, 2002; Meyer y Ramírez, 2010).

A continuación, vamos a presentar, de manera individual, cada una de las variables analizadas, donde expondremos las semejanzas y diferencias entre los sistemas educativos objeto de estudio. Este análisis será fundamental para el devenir de nuestro trabajo, ya que nos va a permitir aceptar o refutar las hipótesis planteadas al comienzo de nuestro estudio, que es uno de los grandes objetivos que perseguimos en nuestra investigación. Por último, una vez finalizado este análisis comparativo, y tal y como expusimos en el apartado metodológico de nuestro trabajo, cerraremos este capítulo con un pequeño análisis prospectivo, que nos permita vislumbrar las 
tendencias futuras que los sistemas educativos objeto de análisis presentarán en materia de acceso, en un futuro a corto o medio plazo.

\section{1) Explicación de las semejanzas y diferencias en el acceso/admisión a la educación superior en España, Francia y Finlandia.}

\subsection{1) Características académicas de los alumnos que están en disposición de acceder a los estudios de educación superior}

Comenzaremos examinando las características académicas de los alumnos que están en disposición de acceder a los estudios de educación superior en los tres sistemas educativos objeto de análisis. En este sentido, podemos observar las primeras diferencias de nuestro estudio. No obstante, antes de comenzar el análisis de esta variable, nos gustaría realizar alguna aclaración que debemos tener presente a la hora de interpretar estos datos. Y es que salta a la vista, que existe una gran disparidad en cuanto a las cifras presentadas en cada uno de los sistemas analizados. Esto es algo que, en buena lógica, debe de ser achacado a las grandes diferencias demográficas que presentan cada uno de los países de nuestro estudio. Además, también debemos tener muy presente que los itinerarios formativos seguidos por los estudiantes en cada uno de los sistemas educativos presentan grandes diferencias entre sí. Esto hecho, ha dificultado el análisis comparativo, ya que, en muchas ocasiones, hallar puntos de encuentro ha sido una terea realmente complicada.

A grandes rasgos podemos afirmar que, tanto el sistema educativo español como el sistema educativo francés, guardan ciertas similitudes en cuanto al perfil académico de sus alumnos, ya que ambos presentan un porcentaje mayoritario de estudiantes que acceden a los estudios de educación superior a través de lo que podemos denominar como vía convencional, o lo que es lo mismo, tras superar los estudios de educación secundaria superior -Bachillerato en España y Bac general y tecnológico en Francia-. De este modo, el itinerario profesional, tanto del sistema 
educativo español como del francés, queda relegado a un segundo plano. Este no es un hecho que nos llame especialmente la atención, ya que los estudios de formación profesional en España y Francia, pese al constante crecimiento que han experimentado a lo largo de los últimos años, no han contado con un reconocido prestigio. En nuestro país, son varios los motivos que pueden explicar el escaso protagonismo que, históricamente, ha tenido la formación profesional. En primer lugar, su aparición tardía, ya que estos estudios pasaron, prácticamente, desapercibidos hasta la década de los 80 del pasado siglo, debido, entre otras muchas cosas, al retraso de la industrialización española. Otro de los obstáculos que ha impedido el desarrollo de la formación profesional en España es la escasa coordinación en torno a la competencia organizativa de estos estudios que, durante décadas, han sido regidos desde dos Ministerios, el de Educación y el de Trabajo, poniendo de manifiesto diferentes concepciones en torno a este espacio formativo (Pin y García Lombardía, 2018). Pero, además, a estos factores debemos añadirle otros de corte más cultural y sociológico que tienen que ver con la tradición humanística de nuestra cultura y la infravaloración de determinados trabajos y disciplinas académicas (Escolano, 1982). El estudio que hemos citado anteriormente (Pin y García Lombardía, 2018), muestra cómo, en nuestro país, los estudios de formación profesional son un recurso subsidiario, que sirve como refugio para los alumnos «fracasados». De hecho, en la encuesta realizada para el desarrollo de esta investigación, a la pregunta «¿qué imagen diría que tiene la formación profesional en España?», la puntuación fue de un 4,82 (sobre una puntuación máxima de 10 puntos), frente al 7,61 de los estudios de bachillerato o el 8,32 de los estudios universitarios. Estos datos muestran cómo los estudios de formación profesional poseen imagen social está muy deteriorada, lo que hace que sea una vía académica poco atractiva para los estudiantes y, por tanto, con un menor índice de participación. En lo que se refiere al país galo, la situación es muy similar a la de España, ya que estos estudios tienen una visión un tanto desfigurada, un hecho que contrasta con la magnífica aceptación que, a lo largo de los últimos años, han 
experimentado los estudios profesionales de educación superior (Michel y Cervel, 2019).

Por contra, si nos centramos en el país nórdico, vemos como la tendencia es totalmente opuesta a la de España y Francia, ya que existe un mayor porcentaje de alumnos que acceden a la universidad a través del itinerario profesional, relegando los estudios generales de educación secundaria superior a un segundo plano. Este hecho puede ser motivado, fundamentalmente, por el gran valor que la sociedad finlandesa concede a la formación profesional, cuya matrícula crece año tras año, desde comienzos de siglo. El auge de estos estudios comenzó a mediados del pasado siglo, tras la Segunda Guerra Mundial, cuando se produjo una demanda de trabajadores cualificados en el mercado laboral que le permitiera producir bienes para hacer frente a las reparaciones de la guerra. Si bien, hemos de reconocer que ha sido de forma más reciente, durante la última década del pasado siglo, cuando se ha producido la consolidación absoluta de la formación profesional. Recordemos que durante la década de 1990, Finlandia se vio sumergida en una de las peores crisis económicas de su historia, lo que provocó que la tasa de desempleo incrementara de manera ostensible. Este hecho, obligó a que muchos trabajadores regresaran al sistema educativo en busca de una cualificación que le permitiera reubicarse en el mercado laboral (Kokkonen, 2019; Heath y Winther, 1996).

Si bien, debemos destacar que, frente a estas divergencias, también existen algunas convergencias o puntos de encuentro, que debemos tener presentes para comprender nuestro trabajo. La más destacable es el índice de matriculación en centros públicos de educación secundaria, que es mayoritario en los tres sistemas educativos. Si bien es cierto que existen grandes variaciones entre los tres casos analizados. Finlandia presenta los porcentajes más elevados (próximos al 95\%), gracias a su modelo de Estado de Bienestar, en el que existe un compromiso para ofrecer una cobertura universal frente a las necesidades sociales de la ciudadanía 
(Anttonen y Sipilä, 1996). Estos servicios, entre los que se encuentra la educación, son de carácter público y son proporcionados, mayoritariamente, por la propia administración (Fernández Montaño, 2014; González, 2011). Mientras tanto, Francia y España presentan unos buenos porcentajes de matriculación pública que, sin embargo, están lejos de los datos del país nórdico, con un $80 \%$ y un $75 \%$ de alumnos, respectivamente. De hecho, según el informe Eurostat, el sistema educativo español ostenta uno de los porcentajes más bajos de matriculación pública a nivel europeo (solo superado por países como Bélgica, Reino Unido y Malta). Este hecho debe ser achacado, entre otras muchas cosas, al auge que los centros concertados están experimentando en nuestro país, que se han beneficiado de las nuevas políticas de libre elección de centros (Real Decreto 1635/2009), en las que las familias tienen total libertad para elegir el centro educativo que se adecúe a sus convicciones pedagógicas, religiosas o morales (Díez, 2014; Viñao, 2016).

\subsection{2) Rendimiento competencial en pruebas de acceso}

En el apartado competencial es donde localizamos una de las diferencias más significativas, ya que solamente España establece pruebas de acceso/admisión a la universidad. En este sentido, nos gustaría aclarar, en primer lugar, qué entendemos como prueba de acceso/admisión a la universidad. Nos referimos a aquellas que están reguladas desde la administración educativa (u organismo competente en materia de educación) y, a su vez, están legitimadas en todo el territorio nacional. En este sentido, debemos destacar que España cuenta con una amplia tradición de pruebas de acceso a la universidad, ya que desde mediados del s. XIX existen estos mecanismos, las Reválidas, el Examen de Estado y la Prueba de Madurez, que han sido la antesala a lo que hoy conocemos como Prueba de Acceso a la Universidad, que pese a haber sufrido grandes modificaciones en el apartado organizativo, e incluso en cuanto a su denominación, mantiene la misma esencia que en sus inicios, durante la época tecnocrática del periodo franquista. Pero, además, en España, junto a esta prueba que 
podemos catalogar como ordinaria, también existen otras que gozan de validez administrativa, como son el examen de acceso para mayores de 25 años o el examen de acceso para mayores de 45 años. Estas pruebas, que están enfocadas hacia el acceso universitario de colectivos muy concretos, son un tanto atípicas fuera de nuestras fronteras, donde los países suelen tener tan solo una única vía de acceso o, por el contrario, disponen de varias vías, pero sin un control oficial.

En este sentido, son varios los motivos que pueden explicar el establecimiento de estas pruebas de acceso en nuestro sistema educativo, si bien, desde nuestro punto de vista, hay uno que resalta por encima del resto, que es el arraigo pedagógico. Este arraigo hace que la puesta en marcha de grandes reformas educativas sea una tarea, cuanto menos, complicada. Además, no debemos olvidar que nuestro sistema educativo se sustenta sobre dos principios básicos que, hasta le fecha, son infranqueables, como son el derecho a la educación y la igualdad de oportunidades. En este sentido, debemos destacar que la PAU respeta ambos principios, lo que favorece que exista un cierto consenso social en torno a esta prueba. Y es que la Selectividad, que fue puesta en marcha durante la época tecnocrática del franquismo y legitimada posteriormente por la socialdemocracia, nace en aras de garantizar unos mínimos culturales en los solicitantes de educación superior, y en ningún caso como elemento de selección. De este modo, la administración educativa establece un sistema de acceso en el que todos y cada uno de los estudiantes deben superar un filtro académico pero que, a su vez, es respetuoso con los principios político-educativos a los que hacemos alusión.

Mientras tanto, Francia y Finlandia no presentan esta tipología de pruebas, ya que abogan por poner en marcha otros mecanismos de acceso. Si bien es cierto que tanto en el país galo como en el país nórdico, existe una prueba de ámbito nacional que todos los alumnos han de superar de forma previa al comienzo de sus estudios universitarios (nos referimos al Bac en el caso de Francia y FME en el de Finlandia), 
pero que en ningún caso puede considerarse como una prueba de acceso a la universidad, ya que no están pensadas con ese fin, sino que pretenden acreditar el nivel formativo del estudiante (certificado de estudios de educación secundaria superior). Por tanto, sería este certificado (y no una prueba tal y como ocurren en España) el que operaría como instrumento de acceso tanto en el país galo como en el país nórdico. A él, habría que añadirle otros requisitos complementarios que se encargarían de regular el proceso de admisión, y que analizaremos con un mayor detenimiento más adelante.

Sin embargo, frente a estas diferencias, también hemos encontrado algunas similitudes o puntos de encuentro. $\mathrm{Y}$ es que, tal y como hemos podido apreciar, los tres sistemas educativos analizados establecen procedimientos de admisión a través de sus universidades. Si bien, hemos de reconocer que existen diferencias en cuanto a su aplicación, ya que mientras que en Francia y, especialmente, en España no los utilizan de una forma muy asidua, en Finlandia son muy comunes estos procedimientos, estableciéndose como uno de los grandes criterios de calidad del sistema universitario finlandés. Esto es debido, fundamentalmente, a una cuestión a la que ya hemos aludido en este trabajo, como es la distinción entre acceso y admisión, que está totalmente definida en Finlandia (y también en Francia, aunque los procesos de admisión no sean tan generalizados), pero no en España, donde ambos términos se contemplan de manera indistinta, debido, al carácter sociopolítico de la educación (se evita la selección de los estudiantes en el acceso a las instituciones de educación superior, proporcionando un modelo de transición muy flexible, que respeta el derecho a la educación y la igualdad de oportunidades). En cambio Francia y Finlandia si contemplan un modelo universitario más pragmático (tanto en su acceso como en sus planes de estudio), cuyo fin es el de formar profesionales para el mercado laboral, dejando a un lado el carácter social y humanista de la universidad (OECD, 2015). Y es que, con la llegada del EEES, se ha producido una transformación en el 
seno de las universidades europeas que, con el paso del tiempo, han abandonado ese carácter germánico que les caracterizaba, en favor de una mayor proyección hacia el mercado laboral. Y es que, los diferentes documentos ministeriales que han dado paso a este nuevo contexto educativo de enseñanza superior no discuten la vinculación entre las instituciones universitarias y el desarrollo económico y social y la creación de empleo (Luzón et al., 2009).

\subsection{3) Origen social de los alumnos que están en disposición de acceder a los estudios de educación superior}

Si continuamos analizando al alumno, que es el principal actor educativo dentro de este proceso de transición, no podemos dejar de hacer referencia a su origen social, ya que se trata de una variable que podría condicionar, en gran medida, el proceso educativo que estamos analizando.

En este sentido, uno de los factores en los que hemos prestado una mayor atención, es el logro educativo de los progenitores, ya que hemos considerado que éste es un indicador de impacto sobre los factores sociales y culturales del estudiante; y es que, en muchas ocasiones, las experiencias y aspiraciones de los padres son trasmitidas a sus progenitores. De este modo, los datos analizados en el capítulo anterior ponen de manifiesto cómo los tres sistemas educativos cuentan con un alto porcentaje de alumnos con antecedentes de educación superior, entre los que, sin duda, destaca el país nórdico, que no solamente presenta los mejores datos de nuestro estudio si no que, además, es el líder a nivel europeo, con un porcentaje que oscila en torno al $70 \%$ de los estudiantes. Sin embargo, si nos centramos en el extremo opuesto -alumnos cuyos padres no cuentan con un nivel educativo superior a CINE (0-2)-, la tendencia varía significativamente, ya España cuenta con un porcentaje significativamente mayor al de Francia y Finlandia. Este factor puede ser achacado a muchos elementos, pero nosotros queremos incidir en uno por encima del resto, como 
es la cultura histórica del sistema educativo español. Y es que debemos recordar, que en nuestro país se produjo un desarrollo educativo muy tardío, en donde hasta la década de los ochenta del pasado siglo no se podía hablar de una educación obligatoria y universal real (hablamos de educación real ya que, desde el punto de vista legislativo, la obligatoriedad educativa en España está vigente desde 1857, gracias la ley Moyano), lo que ha generado que un porcentaje significativo de la población adulta no haya conseguido alcanzar el nivel de estudios de educación secundaria. Además, tal y como hemos mostrado, este hecho tiene una gran trascendencia para nuestro trabajo, ya que son muchos los estudios publicados a lo largo de los últimos años que ponen en evidencia que aquellos alumnos cuyos padres tienen un nivel educativo más bajo, presentan serias dificultades en el acceso universitario, produciéndose, además, una ralentización en este proceso de transición. No obstante, debemos destacar que existen excepciones, como la de Finlandia, que presenta unos porcentajes muy altos de ralentización en el acceso/admisión universitaria, pese a contar con la mayor proporción de estudiantes con antecedentes de educación superior de todo el territorio europeo. Esta situación no estaría tan relacionada con el origen social de los estudiantes, sino más bien con otra serie de cuestiones culturales y/o académicas, ya que en Finlandia es muy común que los estudiantes discurran por otros itinerarios formativos o laborales antes de dar comienzo su periplo universitario.

Estos datos, no hacen más que reafirmar el gran acierto de Finlandia a la hora de apostar por la educación como motor de desarrollo. Y es que, no cabe duda, de que la gran inversión que ha realizado el gobierno finlandés en materia educativa -en términos cuantitativos y cualitativos- ha surtido efecto, no solo en lo que a nivel pedagógico se refiere -que evidentemente ha sido un éxito-, sino también en lo que concierne al desarrollo social y económico del país. Sin embargo, la situación difiere en Francia y España, donde no existe una apuesta tan firme por la educación que, históricamente, se ha mantenido en un segundo plano en la agenda política de estos 
países. Este hecho puede estar motivado por los cambios políticos que, a lo largo de las últimas décadas, se han fraguado en ambos países. Y es que, son muchas las investigaciones (Boix, 1997; Busemeyer, 2007; Castles, 1989; Molina, Amate y Guardino, 2011) que ponen sobre la mesa cómo el signo político del gobierno turno tiene una cierta transcendencia en el desarrollo educativo de un país. Si bien, también hay quien defiende que la política, pese a tener una cierta incidencia sobre toda cuestión educativa, no puede considerarse como algo trascendental (Schleicher, 2018). Un ejemplo de ello lo localizamos en nuestro propio país, que pese a los múltiples cambios de gobierno que ha sufrido en los últimos años (muchos de ellos, acompañados de cambios en el apartado legislativo), mantiene un modelo de organización y funcionamiento educativo muy similar al que puso en marcha la LOGSE hace más de 25 años. Y es que las reformas educativas que se han efectuado hasta la fecha son muy superficiales, sin modificaciones de gran envergadura.

Por otro lado, también hemos analizado una variable de gran interés en lo que al origen social de los estudiantes se refiere y que puede repercutir, directa o indirectamente, sobre el acceso/admisión universitaria, como es la forma en la que los alumnos hacen frente a los gastos ocasionados por su situación académica. Y es que dicha situación, puede condicionar su situación académica, ya que no todos los estudiantes tienen facilidades para hacer frente a esta situación académica, debido a los múltiples gastos ocasionados por estos estudios (matricula, alojamiento, transporte, etc.). Es por ello por lo que nosotros hemos querido indagar al respecto, analizando las diferentes situaciones que presentan los alumnos de cada uno de los sistemas educativos analizados en nuestro estudio. De antemano, nos gustaría aclarar que estamos ante tres sistemas educativos totalmente públicos, en donde le corresponde al Estado garantizar este derecho que, recordemos, es universal. Así, mientras que los alumnos españoles tienen como principal fuente de financiación a sus familias, en Francia es la administración central la que presta ayuda a los 
estudiantes mediante becas para el estudio. Por el contrario, en Finlandia, gran parte de sus estudiantes compatibilizan sus estudios superiores con su actividad laboral. Este hecho es un tanto paradójico si tenemos en cuenta que el país nórdico cuenta con un sistema totalmente público (incluso en los niveles postobligatorios), gracias a su Estado democrático de Bienestar.

\subsection{4) Competencia organizativa del acceso, ¿a quién corresponde?}

La competencia organizativa del acceso es otra de las variables en donde podemos encontrar grandes diferencias en los tres sistemas analizados. Sin duda alguna, esta variable estará estrechamente relacionada con uno de los indicadores analizados en el capítulo contextual, como es el modelo de regulación vigente en cada uno de los países objeto de estudio. Este, puede ser definido como el conjunto de normas establecidas por el sector público para garantizar unos niveles mínimos, tanto en la calidad de la formación, como en las condiciones de accesibilidad (Charro, 2016).

De este modo, nos encontramos que en España son las CC. AA, con la colaboración de las universidades públicas, las que se encargan de regular este proceso de transición. Y es que, tal y como hemos podido apreciar a lo largo del trabajo, nuestro país se rige por una fuerte descentralización, que se pone de manifiesto en muchos de los parámetros de la sociedad española, entre los que se encuentra la educación. Desde la aprobación de la CE (1978), la educación ha quedado enmarcada dentro de un sistema de distribución de competencias, donde se diferenciaban, por un lado, las estatales y, por el otro, las delegadas o transferidas. De este modo, mientras que el Estado mantiene la competencia exclusiva sobre aquellas normas básicas que permitan el correcto desarrollo del artículo 27, a las CC. AA les compete todo lo relativo al desarrollo, ejecución y aplicación de la legislación estatal. Por tanto, a la vez que se amplían y refuerzan los procesos de descentralización, se 
sigue delimitando su actuación en función de la del Gobierno Central (Charro, 2016). Así, en el tema que a nosotros nos concierne, mientras que la administración educativa es la encargada de configurar todo lo relativo al currículum de la prueba, a las universidades les compete el desarrollo, ejecución y evaluación de la misma. Además, no debemos obviar que, a lo largo de los últimos años, los centros de educación superior también cuentan con el apoyo de los IES, dado que, en la actualidad, la prueba es llevada a cabo en estos centros educativos.

Mientras tanto, en Francia, como no podía ser de otro modo, es la administración central la que se encarga de regular el acceso a los centros de educación superior, a través del Bac. Ya hemos explicado que, con el objetivo de modernizar el aparato de gestión, han ido apareciendo pequeños atisbos de descentralización, mediante un proceso de desconcentración (Gauthier, 2005). Si bien, el fuerte centralismo que históricamente ha regido el país galo sigue muy presente en muchas vertientes de la sociedad francesa, entre las que se encuentra la educación. De este modo, podemos afirmar, que pese a que Francia ha llevado a cabo una fuerte desconcentración funcional y burocrática, las decisiones básicas, tanto de carácter normativo como ejecutivo, continúan en manos de la administración central (García Garrido, 2005), y entre ellas, se encuentra la educación. Si bien, en Francia, al igual que en España, también existe intervención por parte de las instituciones de educación superior que, en algunos casos concretos, se encargan de regular la admisión de los estudiantes hacia algunos desarrollos institucionales muy concretos.

Finalmente, en Finlandia, es la agencia educativa (FNAE), en colaboración con los centros de educación secundaria, la que se encarga de regular el acceso universitario, a través del FME que, a grandes rasgos, podemos considerarlo como el requisito básico de acceso. Si bien es cierto que los centros de educación superior tienen una gran trascendencia en este proceso de transición, gracias a la amplia autonomía de la que disponen (Meiselao, 2007). No obstante, estos centros se 
encargan de regular el proceso de admisión del alumno, y no del propio acceso que, tal y como acabamos de explicar, es una función que compete a la agencia nacional de educación finlandesa.

Sin embargo, frente a estas marcadas diferencias que presentan los tres sistemas educativos en lo que a la competencia organizativa se refiere, también podemos localizar alguna similitud o punto de encuentro, como es la intervención de las instituciones de educación superior en este proceso de transición. Si bien, hemos de reconocer que el papel desempeñado por estas en cada uno de los sistemas educativos es muy distinto. Mientras que en España la intervención de las universidades adquiere una gran relevancia, ya que son las encargadas de regular junto a la administración educativa- el acceso a la universidad (y también su admisión, tal y como veremos más adelante), en Francia y, especialmente, Finlandia, su papel se limita a regular solamente el proceso de admisión. Especialmente significativo en este último caso, donde las universidades disponen de una amplia autonomía para establecer aquellos mecanismos que consideren más oportunos (Pérez Granados, 2014).

\subsection{5) ¿Qué papel desempeñan los centros de secundaria en el proceso de transición?}

Por otro lado, valoraremos el papel que desempeñan los centros de educación secundaria en el proceso de transición. Y es que, tal y como indicamos al comienzo de nuestro trabajo, este proceso que estamos analizando, no solamente hace referencia a la educación superior sino también a la etapa inmediatamente anterior, la educación secundaria superior, llevándose a cabo, no solamente una transición entre distintos niveles educativos, sino también entre distintos centros. Por ello, creemos que es fundamental analizar el papel que desempeñan estos centros en los que se desarrolla 
esta etapa educativa y que, en cierta medida, condiciona el acceso/admisión universitaria de los estudiantes.

En este sentido, debemos destacar que la certificación competencial del alumno es la principal labor de los centros de educación secundaria en España y Francia. Estos, a través de sus docentes, evalúan al alumnado, que debe demostrar que está en disposición de unas determinadas competencias y conocimientos, que habrán sido determinados previamente por la administración educativa a través del currículum. Sin embargo, en nuestro país existe mucha contrariedad al respecto, ya que los estudiantes que quieran acceder a la universidad, una vez hayan finalizado sus estudios de bachillerato, deberán hacer frente a una prueba de acceso, donde nuevamente serán evaluados acerca del currículum educativo. Por este motivo, desde el colectivo docente siempre se ha puesto en tela de juicio estas pruebas, bajo la premisa de que los conocimientos evaluados ya habían sido verificados previamente por los propios profesores. Así, se entiende que estas pruebas son un mecanismo externo de evaluación, donde no solo se evalúa la capacidad pedagógica de los estudiantes, sino también de los docentes.

Por contra, el sistema educativo finlandés, no se centra tanto en la evaluación competencial del alumno, aunque, como es lógico, también lo hace, sino que lo que pretende es formarlo. De este modo, podemos afirmar que los centros de educación secundaria en el país nórdico desempeñan una labor puramente pedagógica o formativa. Prueba de ello es la escasa presencia de pruebas o exámenes en el sistema educativo y el papel que estos desempeñan, guiando y orientando al estudiante a lo largo del proceso educativo (Enkvist, 2010). De este modo, la evaluación se convierte en una herramienta que estimula y motiva al alumno, a la vez que permite valorar su aprendizaje, dejando a un lado ese carácter sancionador que, en muchas ocasiones, tienen los exámenes. Si lugar a dudas, esta función que desempeñan los centros de educación secundaria finlandeses en este proceso de transición, se muestra en 
consonancia con la pedagogía abierta que desarrollan en sus aulas, en un entorno cercano y familiar, donde prima la flexibilidad y donde los docentes gozan de una amplia autonomía.

Por lo tanto, podemos apreciar como existen diferencias institucionales, tanto en la regulación como en la organización de este proceso de transición. Así, mientras que Francia y Finlandia parten de una interpretación más académica y pedagógica de la educación y, cómo no, de las transiciones, España está encerrada en una interpretación sociopolítica, que hace que los procesos de transición sean sumamente flexibles para que no poner en duda el derecho a la educación y la igualdad de oportunidades.

\subsection{6) Requisitos necesarios para el acceso/admisión a los estudios de educación superior}

Ya hemos podido apreciar a lo largo de este capítulo comparativo, cómo existen grandes diferencias entre los sistemas analizados, en lo que respecta al plano competencial, al modelo de acceso/admisión y regulación, al papel desempeñado por los centros de educación secundaria, etc. Todo ello, va a traer consigo una serie de diferencias en lo que a los requisitos de acceso/admisión se refiere. Y es que, esta variable aúna gran parte de los ejes temáticos examinados hasta el momento.

De este modo, podemos afirmar que existen algunas similitudes entre el sistema educativo francés y finlandés, donde, a grandes rasgos, tan solo existe un único requisito indispensable para el acceso universitario, que es la certificación académica de educación secundaria superior ( $B a c$ en Francia y $F M E$ en Finlandia). Sin embargo, para una mayor y mejor comprensión de esta variable, deberíamos hacer una distinción entre requisitos de acceso y requisitos de admisión, ya que, tal y como hemos explicado, tienen connotaciones distintas. De este modo, a estos requisitos generales de acceso, pueden sumarse otros que regulen la admisión de los estudiantes 
hacia algunos desarrollos institucionales concretos, con especial ahincó, en el país nórdico, donde las instituciones de educación superior gozan de una amplia autonomía. Este hecho, dificulta en gran medida que podamos hablar de homogeneidad en los requisitos de entrada hacia las instituciones de educación superior, ya que cada centro se encarga de fijar, libremente, los requerimientos que considere más oportunos.

Mientras tanto, en España, los alumnos que quieran acceder a los estudios de educación superior deben superar una prueba que, como ya hemos comentado, ha sufrido varias modificaciones a lo largo de su historia, pero que sigue manteniéndose como el requisito indispensable para el acceso ordinario hacia los estudios de educación superior. Por lo tanto, a diferencia de lo que ocurre en Francia y en Finlandia, el certificado de estudios de educación secundaria superior -Bachilleratono les facultaría, por sí mismo, para el acceso universitario. Si bien, esta certificación sí será necesaria para poder realizar la prueba de acceso que, en última instancia, es la encargada de regular este proceso. Si bien es cierto que, algunos colectivos muy concretos, pueden realizar esta prueba sin la necesidad de estar en disposición del título de Bachillerato, como por ejemplo, aquellos alumnos que hayan obtenido el certificado de técnico superior de formación profesional, que pueden realizar la fase específica de la PAU, con el fin de mejorar sus calificaciones. Además, también hemos de tener de tener presente que, frente a este acceso que nosotros hemos catalogado como ordinario, existen otras vías o itinerarios alternativos que también gozan de validez administrativa. Nos estamos refiriendo a las pruebas para alumnos mayores de 25 años, las pruebas para alumnos mayores de 45 años, la acreditación de experiencia profesional o laboral en relación con unas determinadas enseñanzas para aquellos alumnos mayores de 40 años o los alumnos que dispongan del título de técnico superior de formación profesional. Todos estos colectivos, están en disposición de acceder a las instituciones universitarias, sin la necesidad de superar la 
prueba de acceso a la universidad, ya que pueden seguir un itinerario de acceso alternativo. Esto es algo característico de nuestro sistema educativo, pero un tanto inusual fuera de nuestras fronteras, donde tan solo cuentan con una única vía de acceso o, por el contrario, disponen de varias vías, pero que carecen de control oficial (European Commission, 2014). Además, junto a estos requisitos generales de acceso, el sistema educativo español también cuenta con requisitos específicos de admisión, que son establecidos desde las propias universidades. Si bien, estos procedimientos no son muy comunes, ya que tan solo se ponen en marcha en algunos desarrollos formativos específicos.

Estas diferencias las podemos localizar, principalmente, en el binomio acceso/admisión al que tantas veces hemos aludido en nuestro trabajo. De este modo, podemos apreciar como Francia y Finlandia presentan un modelo de acceso y admisión claramente definido, mientras que en España ambos términos se solapan, creando una cierta confusión. Esto puede y debe ser explicado a partir de una idea que ya hemos descrito en reiteradas ocasiones, que es la influencia sociopolítica de la educación en nuestro país, frente al carácter profesionalizante del sistema educativo francés y finlandés. Ese carácter germánico y humanista de la universidad española, muy apegado a lo social y lo cultural, contrasta con el de Francia y Finlandia, que siguiendo las directrices del EEES, han puesto en marcha un modelo formativo con un claro enfoque hacia la profesionalización de sus estudiantes (selección de los mejores candidatos, realización de estudios prospectivos sobre el mercado laboral, etc.).

Por tanto, podemos apreciar cómo existen grandes diferencias en cuanto a los requisitos de acceso, especialmente, entre los del sistema educativo español y los de sus homónimos en este estudio. Sin embargo, también hemos podido localizar algún punto de encuentro, especialmente cuando aludimos a los requisitos de admisión, que son fijados por las propias instituciones de educación superior y que pretenden 
complementar el proceso establecido desde la administración educativa. Este procedimiento, que permite alcanzar el equilibro entre oferta y demanda educativa, puede ser localizado en los tres sistemas analizados, si bien, hemos de reconocer que existen grandes diferencias en cuanto a su aplicación, ya que mientras que el sistema educativo español y francés las ponen en práctica tan solo en algunos desarrollos institucionales muy concretos, el sistema educativo finlandés lo utiliza de una forma más común, como una de sus grandes señas de identidad.

\subsection{7) Sistema educativo y modelos de acceso/admisión}

Otra de las variables analizadas en las que podemos apreciar grandes diferencias es en los modelos de acceso/admisión hacia la formación universitaria. Ya hemos explicado en el apartado descriptivo de nuestro trabajo como, pese a que el EEES ha llevado a cabo múltiples medidas que han favorecido la aparición de un área educativa común de enseñanza superior en el territorio europeo, lo cierto es que uno de los aspectos de mayor relevancia, como es el acceso, se ha dejado en manos de los propios sistemas educativos (Revesado, 2018).

Concretamente, en nuestro trabajo, tanto el sistema educativo español como el francés presentan similitudes al respecto, ya que ambos sistemas presentan un modelo de acceso/admisión abierto, escasamente restrictivo. Como ya hemos explicado, en ambos casos, el itinerario de acceso más común está supeditado a la superación de una prueba de carácter nacional (en el caso de España es una Prueba de Acceso a la Universidad, mientras que en Francia se trata de una prueba que forma parte del currículum educativo de educación secundaria, el $\mathrm{Bac}$ ), que evalúa los conocimientos y las competencias que el alumno ha adquirido durante los últimos años de escolarización. No obstante, pese a la existencia de estas pruebas, no podemos hablar de un modelo de acceso/admisión restrictivo, ya que estas no pueden considerarse selectivas al tener un carácter meramente cultural. Si bien es cierto que, 
frente a este modelo normalizado, existen puntualizaciones en algunos desarrollos institucionales concretos (como por ejemplo, los IUT's o las Grandes Écoles en Francia, o en titulaciones específicas como Traducción e Interpretación o Ciencias de la Actividad Física y del Deporte en España), donde el acceso/admisión es más restringido, ya que se pondrán en marcha procedimientos selectivos de admisión que complementen este proceso educativo. España ha rehusado la inclusión de procedimientos selectivos en el acceso a las instituciones de educación superior para, así, ser respetuoso con los dos principios básicos sobre los que se sustenta el sistema educativo: derecho a la educación e igualdad de oportunidades. Mientras tanto, Francia ha mantenido un modelo de acceso/admisión clásico, a través de una prueba que goza de una gran influencia social en el país galo y que posee una vigencia de más de 200 años. En este sentido, debemos destacar que, pese a que poco a poco van apareciendo pequeñas tendencias descentralizadas, lo cierto es que Francia sigue siendo regida por una fuerte centralización, que hace que la puesta en marcha de reformas educativas sea una tarea, cuanto menos, complicada.

Sin embargo, a la hora de hablar del proceso de admisión a las instituciones de educación superior en el país nórdico, debemos ser más cautos, ya que no podemos enmarcarlo dentro de un modelo concreto, ya que cada centro instaura los requisitos de entrada que crea más oportunos, gracias a la amplia autonomía de la que disponen. De este modo, podemos encontrarnos con instituciones cuyos modelos son altamente restrictivos y otras en la que no lo son tanto; o dentro de una misma institución, titulaciones con un alto grado de restricción y otras en el que el acceso/admisión es más flexible. Esta situación se ha propiciado gracias a la confianza que las autoridades educativas depositan sobre las instituciones de educación superior, que le conceden una libertad absoluta en todo el desarrollo pedagógico (desde la selección de estudiantes, hasta la configuración de los planes de estudio). Si bien es cierto que la tendencia más común es la puesta en marcha de modelos restrictivos, en donde los 
alumnos, además de la certificación del $F M E$, deben superar otra serie de requisitos adicionales de admisión que complementen este proceso educativo. Un ejemplo de ello podemos localizarlo en el acceso hacia los estudios de formación inicial docente, donde solo los alumnos que estén en disposición de los mejores expedientes académicos podrán concurrir a estas plazas. Además, frecuentemente, los estudiantes deben complementar este proceso de admisión con otras pruebas específicas fijadas desde los propios centros de educación superior (lenguaje, matemáticas, TICS, entrevistas personales, etc.).

Por último, para finalizar el análisis de esta variable, nos gustaría volver a incidir en los términos acceso y admisión, así como en la forma en la que estos actúan sobre los diferentes sistemas educativos analizados. En este sentido, queremos resaltar como, tanto en el sistema educativo francés como en el finlandés, existe una mayor nitidez respecto a la forma en la que el acceso y la admisión operan en este proceso de transición. Recordemos que ambos sistemas implementan un procedimiento de acceso que está supeditado a la obtención del certificado académico de educación secundaria y que, además, este es complementado con una serie de requerimientos específicos de admisión que se llevan a cabo desde las propias instituciones de educación superior (que se ven reflejados de una mayor claridad en Finlandia, aunque también tienen una gran presencia en el país galo). En cambio, en España no queda tan claro cuál es la diferencia entre acceso y admisión, y esto es debido, en buena medida, a que solemos utilizar el acceso como una herramienta de admisión. Y es que la nota de acceso a la universidad (obtenida a partir de la media ponderada del expediente académico del alumno y de su calificación en la prueba de acceso a la universidad), es utilizada como mecanismo de admisión, mediante los famosos números clausus. De este modo, para equilibrar la oferta y la demanda, en vez de establecer procedimientos específicos de admisión (tal y como hacen numerosos sistemas educativos del contexto internacional), lo que se hace es utilizar la nota de 
acceso como un elemento de admisión. Esta, sin duda alguna, es otra de las peculiaridades que guarda nuestro sistema educativo, y que sin duda alguna, debemos tener en consideración para una mayor y mejor comprensión de nuestro trabajo.

\subsection{8) Indicadores culturales}

Otra de las variables sobre la que hemos puesto nuestro foco de atención es acerca de algunos indicadores culturales de las sociedades en las que se desarrollan e intervienen estos sistemas educativos. Como ya comentamos, la elección de estos indicadores fue una tarea complicada, ya que teníamos que llevar a cabo un análisis sobre aspectos tangibles, lo cual no ha sido nada sencillo teniendo en cuenta la subjetividad del tema abordado. Fundamentalmente, nos hemos centrado en tres indicadores, que pueden darnos una pequeña visión acerca del nivel cultural de la sociedad española, francesa y finlandesa.

En primer lugar, hemos analizado el tiempo dedicado a la lectura. Son varios los estudios, tanto a nivel nacional como internacional, que se han interesado a lo largo de los últimos años por el tema que aquí presentamos, haciendo hincapié en el papel fundamental que desempeña la lectura, no solo en el proceso educativo de los ciudadanos, sino también en su enriquecimiento cultural. De este modo, podemos catalogar a Francia y Finlandia como países lectores. En el país galo, en torno al 85\% de la población afirma leer frecuentemente, mientras que en Finlandia siete de cada diez personas afirman haber leído un libro en el último año. Y es que Finlandia es uno de los países lectores por excelencia en el contexto internacional, con una red pública de bibliotecas envidiable (amplia disponibilidad horaria, todo tipo de comodidades, servicios gratuitos, etc.). Por el contrario, España se aleja de los datos de sus homónimos en este estudio, siendo uno de los países en los que un menor porcentaje de la población ha leído un libro en los últimos doce meses (cerca del 60\%). Si atendemos a uno de los informes más relevantes sobre lectura en nuestro país, 
"Hábitos de Lectura y Compra de Libros en España" (2018), que es elaborado por la Federación de Gremios de Editores de España (FGEE), podemos localizar algunas de las causas que justifican estos índices tan pobres de lectura: falta de tiempo (por motivos académicos, laborales, familiares, etc.), desinterés frente a la lectura, preferencia por otras alternativas de ocio (especialmente entre los más jóvenes), dificultades para la lectura motivadas por causas de salud (en personas de más de 65 años), etc. Por último, queremos analizar estos datos atendiendo a las variables sexo y edad. En este sentido, hemos podido apreciar muchas similitudes, ya que la tendencia más generalizada en los tres casos es que las mujeres lean más que los hombres, y que sean los más jóvenes (24-35 años), los que dediquen un mayor tiempo a la lectura (con la excepción de Francia, donde la población más lectora supera los 50 años).

En segundo lugar, analizaremos el gasto público cultural. En este sentido, hemos hecho una distinción entre el gasto individual y el gasto o inversión realizada desde los diferentes órganos de gobierno. Si comenzamos analizando la inversión realizada desde los principales órganos de gobierno podemos apreciar como la tendencia es opuesta en Finlandia con respecto a España y Francia, ya que mientras que el gobierno central ha aumentado sus presupuestos en actividades culturales, los entes locales lo han reducido en un 6\%. En España, este hecho puede ser achacado al fuerte impacto que la crisis económica tuvo en nuestro país, que ha generado que el gobierno central realice una mayor inversión sobre distintas áreas que podemos considerar como prioritarias, como son la sanidad, la educación o las pensiones (Bustamante, 2013). En cambio, si analizamos el gasto individual, podemos apreciar cómo, en este caso, la tendencia es opuesta en España con respecto a Francia y Finlandia. La población española, como consecuencia de la ya mencionada recesión económica, redujo casi un 35\% de su gasto en actividades culturales desde el año 2007. Este gasto, también se vio reducido per cápita, en un porcentaje muy similar. 
Mientras tanto, Francia y Finlandia, no solamente mantuvieron una cierta estabilidad en cuanto al gasto en este tipo de actividades, sino que incluso llegaron a aumentarlo en un $13 \%$ y un $7 \%$, respectivamente. De este modo, podemos apreciar como el desarrollo económico de un país puede afectar sobre la inversión que este realice (o no) en actividades culturales. Si bien es cierto que existen otra serie de factores, con una connotación más ideológica que económica, que también pueden tener un cierto impacto sobre esta inversión cultural (Bustamante, 2013).

Por último, hemos analizado el nivel educativo de la población, prestando especial atención a dos colectivos: aquellos que no han alcanzado un nivel superior al CINE 1 y 2 y aquellos que han alcanzado niveles de estudios superiores (CINE 5 y 6). Respecto al primer grupo (alumnos con estudios iguales o inferiores a CINE 1 y 2), vemos como España presenta los porcentajes más altos de los países analizados, con más de un 40\% (superando holgadamente la media de OCDE y U.E). En el lado opuesto, localizamos a Finlandia, con apenas un 12\%. Francia, se encontraría en torno a los parámetros de OCDE, con un $22 \%$. En cambio, si analizamos al segundo grupo (alumnos con estudios superiores), podemos apreciar como España y Francia presentan unos porcentajes muy similares a la media de OCDE, con en torno al $35 \%$. En cambio, Finlandia los supera holgadamente, con cerca de un $45 \%$ de la población. Este hecho no hace más que reafirmar una idea que ya ha sido plasmada en este trabajo, como es la gran apuesta del gobierno finlandés por la educación como motor de desarrollo. Una situación que difiere de la de España -y en menor medida Francia, donde la educación siempre se ha mantenido en un segundo plano en la agenda política de estos países.

Para finalizar, nos gustaría realizar un pequeño comentario acerca de este indicador que estamos analizando y la relación que pueda tener con el tema que estamos trabajando en nuestra investigación. En este sentido, hemos podido evidenciar cómo aquellos países que poseen un nivel cultural más elevado (como por 
ejemplo Finlandia) son, posteriormente, los que se muestran más exigentes en los procesos de transición hacia la educación superior. Por el contrario, los países con un nivel cultural más modesto (como por ejemplo España), presentan un modelo de transición más flexible, con una perspectiva más social. Esta interpretación es fruto de la realidad empírica que hemos analizado, y no atiende a valoraciones o juicos personales.

\subsection{9) Sistemas de orientación en los centros de educación secundaria y su relación con el acceso/admisión a la educación superior}

Para ir poniendo punto y final a este apartado comparativo, vamos a analizar los sistemas de orientación en los centros de educación secundaria que, a través de sus departamentos de orientación, y de una forma más específica, a través de sus orientadores, prestan apoyo y asesoramiento a los estudiantes durante su estancia en la educación secundaria obligatoria y postobligatoria. A simple vista, encontramos muchas similitudes entre los distintos modelos analizados, ya que estamos hablando de un proceso que está plenamente institucionalizado dentro del centro educativo, que presenta unos mismos destinatarios, un mismo objetivo - especialmente durante esta última etapa que estamos analizando-, etc. Una de las hipótesis que manejamos para explicar estas semejanzas, puede localizarse en las medidas llevadas a cabo por la Comisión de la U.E en el año $2004^{45}$ y $2008^{46}$ (anexo 3 y 4), a partir de las cuales se reconoce la orientación educativa como un derecho de los estudiantes para mejorar la calidad de la enseñanza en el seno de las instituciones educativas. Ello explicaría que,

\footnotetext{
${ }^{45}$ Proyecto de Resolución del Consejo y de los Representantes de los Gobiernos de los Estados miembros reunidos en el seno del Consejo, de 18 de mayo de 2004, sobre el fortalecimiento de las políticas, sistemas y prácticas en materia de orientación permanente en Europa.

46 Proyecto de Resolución del Consejo y de los Representantes de los Gobiernos de los Estados miembros, reunidos en Consejo, de 21 de noviembre de 2008, titulada «Incluir mejor la orientación permanente en las estrategias permanentes de educación y formación permanente».
} 
a lo largo de los últimos años, la orientación educativa se haya institucionalizado dentro de los centros educativos de todo el territorio europeo, siendo una herramienta más al servicio de la comunidad educativa y, de una forma más específica, de los propios estudiantes.

Si bien, es curioso apreciar cómo, pese a las múltiples semejanzas que los tres sistemas educativos presentan en materia de orientación académica, los datos relativos a la eficacia de este proceso de transición son muy dispares. Así, mientras que nuestro sistema educativo presenta una de las tasas más elevadas de abandono universitario a nivel internacional -próxima al 35\%- (Pérez y Aldás, 2019), en Finlandia apenas un $5 \%$ de los estudiantes no continúan su formación académica después del primer año, ya bien sea por cambio de titulación o por abandono definitivo del sistema universitario (OECD, 2019). Varios pueden ser los motivos que expliquen esta situación. En primer lugar, que los estudiantes nórdicos presentan varias solicitudes antes de ser aceptados en un programa de educación superior (de hecho, los datos evidencian que solamente el $20 \%$ de los estudiantes acceden a la universidad tras superar los estudios de educación secundaria superior). La gran restricción que existe en numerosos programas de educación superior provoca que muchos alumnos decidan esperar antes de comenzar su periplo universitario hasta ser elegidos en el programa formativo que más se adecúe a sus intereses y capacidades. Por otro lado, también hay quien decide tomarse un año sabático para así esclarecer sus opciones académicas y/o laborales. Esta cuestión, que no solo responde a cuestiones académicas, sino también culturales. Y es que en Finlandia, no se ven tan presionados por comenzar y finalizar los estudios dentro de los plazos establecidos, lo cual parece ser una medida muy positiva para mejorar la eficacia de su sistema universitario.

Si bien es cierto que, frente a estas semejanzas, también existen una serie de especificidades en cada uno de los países, que debemos tener en consideración. En primer lugar, en lo que respecta al plano legislativo. En España, se viene realizando 
un gran esfuerzo a lo largo de los últimos años, por mejorar la coordinación de los servicios de orientación entre centros de educación primaria y educación secundaria, más aún, cuando se pretende abordar la transición entre ambos niveles educativos. Sin embargo, es más complicado encontrar alusiones a estos servicios, cuando la transición se produce entre la secundaria a la universidad. Por el contrario, en Finlandia y, especialmente, en Francia, sí podemos localizar una mayor presencia de estos servicios en el plano normativo y de regulación. El país nórdico mantiene la ley de educación básica de 1998, mediante la cual se estipula que todos los alumnos tienen derecho a recibir una orientación y asesoramiento adecuado, que garantice, entre otras cosas, la recepción de una información útil para acometer su trayectoria académica y/o profesional. Mientras que Francia ha realizado serios esfuerzos por introducir los servicios de orientación como uno de los pilares de su sistema educativo a lo largo de los últimos años. En un primer lugar, mediante la Ley de Educación de 1989 y, especialmente, a partir de la Ley de Orientación y Programación para el Futuro de la Enseñanza (2005). Además, con la nueva reforma de bachillerato que se pondrá en marcha en el año 2021, se apuesta por otorgar un mayor peso curricular a la orientación de los estudiantes, con el único fin de reducir el fracaso durante el tránsito hacia la universidad y la vida activa y dentro de los propios programas universitarios.

Otra de las diferencias que podemos localizar es en lo que se refiere a lo que nosotros hemos denominado como modelo de orientación. Mientras que España y Finlandia presentan un modelo interno, donde la orientación se concibe como una acción plenamente integrada en la programación general del centro y los servicios prestados son proporcionados desde las propias instituciones académicas, en Francia desarrollan un modelo mixto, donde los servicios de orientación no solamente son proporcionados desde las propias instituciones educativas, sino que también lo hacen agencias externas de orientación. Entre estas agencias, debemos destacar, por encima del resto, los denominados Centros de Información y Orientación (CIO), a cuyo frente se encuentras los denominados Conseillers d'Orientation-Psychologues (COP). 
Por otro lado, como es lógico, la regulación de estos servicios también presenta grandes diferencias entre los sistemas analizados. Mientras que en España son las CC. AA las que tienen la responsabilidad de asegurar estos servicios de orientación, en Finlandia es el gobierno central, junto a las corporaciones locales, las que se encargan de esta competencia. En el caso de Francia, como no podía ser de otra forma, es el gobierno central el que se encarga de facilitar estos servicios. Si bien es cierto que, junto a ella, también intervienen un gran número de organismos públicos, semipúblicos y privados (delegaciones locales, centros de información para los jóvenes, etc.).

Por último, haremos una pequeña alusión a los profesionales que se encargan de otorgar estos servicios de orientación. En el caso de España y Finlandia, es requisito indispensable estar en disposición de un título de educación superior y un máster, si bien es cierto que la formación recibida por estos profesionales es distinta. Mientras que en nuestro país los orientadores deben de ser psicólogos o profesionales de la educación, en el país nórdico la formación que reciben durante su periplo universitario varía en función de cada institución; esto debe ser achacado, principalmente, a dos motivos: en primer lugar, a que no existe una normativa que regule esta orientación académico-profesional y, en segundo lugar, a la amplia autonomía de la que disponen las instituciones de educación superior. Por el contrario, en Francia, estos profesionales acceden a su puesto de trabajo mediante un concurso de oposición, tras graduarse en Psicología (o una titulación similar aceptada por la legislación vigente) y tras recibir un periodo de formación de dos años. Por tanto, a diferencia de lo que ocurre en España y en Finlandia, en el país galo no es necesaria una formación específica de máster para intervenir como profesionales de orientación. 


\subsubsection{0) Acción tutorial en los alumnos de educación secundaria y su relación con el acceso/admisión a la educación superior}

Por último, abordaremos los procesos de acción tutorial. Sin duda alguna, esta variable tiene una gran trascendencia en el tema que nosotros trabajamos, ya que uno de los principales actores educativos en este proceso de transición, es el propio docente, siendo mayor su trascendencia, si tenemos en cuenta el nivel educativo en el que nos encontramos, donde el estudiante debe estar capacitado para tomar una serie de decisiones de gran alcance. De este modo, estamos en disposición de afirmar que la acción tutorial se configura como el primer eslabón del sistema de orientación.

En este sentido, hemos de reconocer que esta ha sido una de las variables en donde hemos localizado mayores semejanzas de todas las aquí descritas, si bien es cierto, que también podemos encontrar alguna diferencia significativa, sobre todo en lo que a su ejecución se refiere. En España, pese a que la tutoría llegó a formar parte de los planes de estudio - en la actualidad, no viene contemplada como parte del currículum-, lo cierto es que siempre se ha considerado como una acción insuficiente, lo cual ha limitado el desarrollo de las actividades planificadas y el alcance de los objetivos previstos. En cambio, a diferencia de lo que ocurre en nuestro país, Francia y Finlandia si incluyen la tutoría dentro de sus planes de estudio. En el caso del país galo, forma una parte importante del currículum nacional, tanto en la escolaridad obligatoria como en los niveles postobligatorios, donde los profesores deben guiar y asesorar al alumno, manteniendo una estrecha colaboración con los orientadores del centro y con el Consejero Principal de Educación. Mientras que en Finlandia esta acción va más allá, ya que no solamente forma parte del currículum educativo, como ocurre en Francia, sino que además los alumnos tienen derecho, a un número determinado de sesiones semanales de orientación, lo que favorece un mayor y mejor desarrollo académico y profesional del alumno. 
En este sentido, si volvemos a poner sobre la palestra los datos de abandono universitario analizados en el apartado anterior, podemos apreciar como existe una estrecha relación entre estas acciones de tutoría y una mayor o menor eficacia en el proceso de transición aquí analizado. Y es que es evidente que cuando las acciones de tutoría son insuficientes -como ocurre en nuestro sistema educativo- se corre un mayor riesgo de que el proceso de transición sea menos efectivo que cuando se llevan a cabo procesos de orientación y tutoría de calidad, tal y como ocurre en Francia y en Finlandia.

\section{2) Visión prospectiva}

Para poner punto y final a este apartado comparativo, antes de dar paso a las conclusiones de nuestro estudio, vamos a realizar un pequeño análisis prospectivo, donde pretendemos vislumbrar las tendencias futuras que puedan presentar los sistemas educativos analizados, en lo que a sus políticas de acceso y admisión universitaria se refiere. De este modo, el objetivo que perseguimos a lo largo de los próximos párrafos, no es otro que el de extraer una serie de conclusiones que nos permita realizar previsiones acerca de las tendencias esclarecidas a lo largo del estudio y, en consecuencia, ofrecer propuestas de mejora y líneas de actuación. Desde el punto de vista metodológico, ya hemos explicado cómo este apartado prospectivo puede ser abordado de una manera individual, una vez hayamos finalizado el análisis comparado, o de manera conjunta, introduciéndolo como una parte del mismo. En nuestro caso, hemos creído conveniente incluirlo en esta última fase de la investigación, ya que se trata de la tendencia más normalizada entre los estudios comparado de educación, y a su vez, la que más se acomoda a nuestra investigación.

Comenzaremos analizando la situación del sistema educativo español. En este sentido, prevemos que nuestro país mantendrá una línea continuista, al menos en lo que a las políticas de acceso/admisión se refiere. Y es que, tal y como hemos explicado 
en nuestro trabajo, España es un país que desarrolla una política educativa, con una perspectiva muy social, donde el derecho a la educación y la igualdad de oportunidades se contemplan como dos valores básicos que deben ser respetados de forma escrupulosa. Todos los ciudadanos deben tener la posibilidad de acceder a los distintos niveles educativos (incluidos los postobligatorios), sin limitación alguna, más allá de sus propias capacidades intelectuales. De este modo, pese a los múltiples intentos que se han llevado a cabo los últimos años, España ha rehusado la opción de introducir grandes cambios en materia de acceso hacia el sistema universitario. Además, a todo ello debemos sumarle la fuerte inestabilidad política en la que se ve sumido nuestro país en las últimas fechas, que hace que la puesta en marcha de reformas educativas sea una terea realmente complicada, sin acuerdos de gobierno que favorezcan el progreso y el desarrollo de nuestro sistema educativo. Es decir, el carácter del sistema educativo es más político que pedagógico; de ahí que no sea posible alcanzar un pacto educativo con unos mínimos comunes en la organización y funcionamiento del sistema.

En cambio, si analizamos la situación del país galo, sí prevemos un cambio de tendencia en lo que al acceso/admisión universitaria se refiere. Como ya hemos comentado, el gobierno francés ha puesto en marcha una nueva reforma que afecta al examen de graduación de educación secundaria -Bac- y que se implantará definitivamente el próximo 2021. Esta reforma pretende acabar con la gran complejidad de la prueba que, tras más de doscientos años, necesita impulsar una serie de cambios que le permita adaptarse a las nuevas realidades sociales y pedagógicas de la sociedad francesa. De este modo, se pretende llevar a cabo una modernización del $B a c$ a partir de una nueva organización docente, donde los estudiantes serán evaluados de acuerdo a sus gustos y ambiciones y no atendiendo al itinerario formativo cursado, tal y como se hacía hasta la fecha. Esta reforma repercutirá, ineludiblemente, sobre el acceso hacia las instituciones de educación superior, ya que 

educativos de España, Francia y Finlandia

supondrá una simplificación sobre el tedioso proceso de transición que aquí analizamos. Y es que, la racionalidad de esta reforma puede ser explicada como una forma de conectar el curriculum de secundaria con las opciones académicas de la educación superior, con el fin de reducir el fracaso en las instituciones de educación superior. Es decir, se camina a una mayor flexibilización en la organización curricular de la educación secundaria superior y hacia una mayor conexión curricular entre una y la otra, lo que va a significar una mayor apertura en los procesos de transición con una mayor oferte de itinerarios.

Por último, analizaremos la tendencia del país nórdico, donde todo hace prever que, al igual que en España, mantendrá una línea continuista. Sin embargo, a diferencia de lo que ocurre en nuestro país, esta continuidad responde al buen hacer del sistema educativo nórdico, que pese a haber experimentado un descenso a lo largo de los últimos años en sus puntuaciones en las pruebas internacionales, sigue siendo uno de los grandes referentes del contexto internacional. De este modo, nada hace indicar que Finlandia vaya a desarrollar cambios significativos sobre su sistema educativo y, de una forma más específica, sobre su modelo de acceso/admisión, ya que existe una confianza plena por parte de la sociedad finlandesa sobre este sistema. En Finlandia la estructura política y la función docente están estrechamente unidas. 

1) INTR ODVCCIÓN Y JVSTIFICACIÓN DEL TEMA

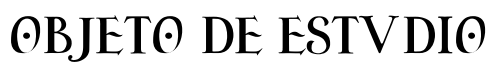

2) CATEG@RÍAS $\odot$ VARIABLES DE ANÁLISIS DEL ACCESค/ADMISIÓN A LA EDVCACIÓN SVPERIOR

3) EL ACCESఠ/ADMISI@́N A LA EDVCACIÓN SVPERIOR EN ESPAN̂A, FRANCIA Y

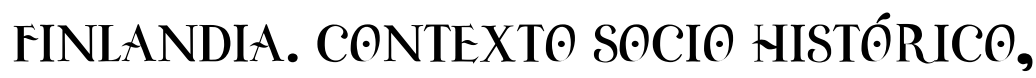
POLÍTICO Y CVLTVRAL

4) ¿СĆMค ACTV́AN LOS MODELOS DE ACCESO/ADMISIÓN A LA EDVCACIÓN SVPERIOR?

5) LA COMPARACIÓN C@NTEXTVAL DEL ACCESO/ADMISIÓN A LA EDVCACIÓN SVPERI@R. EL CARÁCTER FVNCIONAL DE LAS TRANSICIONES 



\section{6) CONCLVSI@NES}

Para poner punto y final a nuestra investigación, pasaremos a explicar, de manera resumida, las conclusiones a las que hemos llegado tras la elaboración de nuestro trabajo. Para ello, no nos detendremos más de lo necesario, ya que entendemos que la lectura integral de este documento apoya y esclarece las ideas que presentaremos a continuación. En este sentido, debemos recordar que estas conclusiones tienen un doble objetivo: por un lado, atender a las aserciones más relevantes de nuestra investigación y, por otro lado, aceptar o refutar las hipótesis planteadas al comienzo de la misma, que no solamente es uno de los grandes objetivos de este capítulo, sino también de nuestro trabajo de investigación.

Una vez realizada esta aclaración, procedemos a exponer las principales conclusiones que hemos alcanzado de nuestro trabajo.

La primera de ellas hace referencia al carácter no solo académico, sino también político, social, cultural, económico, etc. de las transiciones educativas. Y es que tal y como hemos evidenciado en nuestro trabajo, son muchas y muy diversas las variables o factores que intervienen en todo proceso de transición educativa, más aún, cuando esta se produce entre dos instituciones académicas distintas, como es el 
caso que nosotros estamos analizando. En nuestro trabajo, las variables que hemos seleccionado son aquellas que, a nuestro parecer, guardan una mayor trascendencia en el acceso hacia las instituciones de educación superior. Si bien, somos conscientes de que existen muchas otras que aquí no han sido recogidas y que también pueden tener una gran trascendencia en este proceso académico. En este sentido, hemos creído oportuno poner el foco de atención sobre aquellas que son más relevantes, con el único fin de ser lo más exhaustivo posibles en nuestro análisis.

En segundo lugar, hemos podido constatar cómo los tres sistemas educativos analizados se enmarcan dentro de un contexto que presenta grandes diferencias entre sí. No cabe duda de que la segunda etapa del método clásico de comparación, la interpretativa o contextual, tiene una gran trascendencia en nuestro trabajo, y por este motivo, hemos tratado de realizar un análisis lo más exhaustivo posible, entendiendo que gran parte de nuestro trabajo sería desarrollado e interpretado a partir de este contexto. Tal y como hemos podido apreciar, existen varias divergencias entre los tres sistemas objeto de análisis. Así, podemos constatar diferencias desde el punto histórico, con un desarrollo político e institucional más tardío en España, y especialmente en Finlandia, con respecto a Francia, que es uno de los grandes ideólogos de los sistemas nacionales de educación. También existen disimilitudes desde el punto de vista pedagógico, con una metodología más flexible e innovadora en el país nórdico (alumno como epicentro del proceso enseñanza-aprendizaje, ausencia de evaluaciones, mayor autonomía, etc.) con respecto a Francia y España, que presentan una cultura escolar con tintes más tradicionales. El modelo de regulación, que se encarga de establecer quiénes son los encargados de asumir responsabilidades y tomar decisiones en materia de educación, también presenta grandes diferencias entre los tres sistemas analizados. Así, mientras que en Francia existe un marcado centralismo, en España y Finlandia se apuesta por una descentralización educativa, de carácter regional en nuestro país y local en Finlandia. 
Sin duda, todas estas diferencias contextuales que los tres sistemas educativos presentan van a repercutir, ineludiblemente, sobre cualquier proceso educativo que se vaya a llevar a cabo, incluido el acceso hacia las instituciones de educación superior, que es el eje temático sobre el que nosotros estamos indagando.

En relación con el contexto, también nos gustaría hacer una pequeña alusión a una nueva tendencia que está siendo desarrollada por numerosos autores a lo largo de los últimos años y que tiene una gran incidencia en nuestro trabajo, como es el cambio de paradigma experimentado en los estudios de educación comparada, en donde la unidad comparativa «Estado-Nación» ha dejado de ser el principal foco de atención. La irrupción de fenómenos como la globalización, las nuevas tecnologías de la información y la comunicación, los organismos internacionales, etc. han puesto de manifiesto la necesidad de realizar, no solo una revisión, sino también una ampliación de las unidades de comparación. En este sentido, cobra un mayor protagonismo la comparación de contextos -contextual comparison-, donde el método comparado servirá como herramienta para conocer todas aquellas circunstancias que rodean una determinada acción pedagógica (Crossley, 2002; Steiner, 2010). Por este motivo, a lo largo de nuestra investigación, hemos tratado de poner en marcha este nuevo paradigma comparativo, donde el análisis y la interpretación del contexto va a cobrar una especial relevancia, más allá de los propios países y las propias fronteras.

Por otro lado, también hemos podido evidenciar que existen grandes diferencias en el acceso/admisión hacia las instituciones de educación superior en España, Francia y Finlandia. De hecho, ésta podría considerarse, a grandes rasgos, como la principal conclusión de nuestro estudio. Tal es así, que esta afirmación nos va a permitir aceptar la primera hipótesis fijada al comienzo de nuestro proyecto de investigación que, recordemos, es la que se enuncia a continuación: 
Hipótesis 1. Los itinerarios de acceso/admisión a la educación superior en los tres sistemas educativos analizados muestran diferencias desde el punto de vista político, administrativo y pedagógico.

De este modo, hemos podido constatar que existen múltiples diferencias (si bien, también es cierto que existen algunas similitudes) en el acceso/admisión hacia las instituciones de educación superior de los tres sistemas educativos analizados. Sin ánimo de ser exhaustivos, podemos hacer alusión algunas de ellas. En primer lugar, en lo que respecta al plano político, evidenciamos diferencias en los modelos de acceso/admisión, con un mayor grado de restricción en Finlandia (con un claro enfoque profesionalizante de su educación superior), y en menor medida en Francia, que en España, que apuesta por un modelo universitario más germánico y humanista, que trata de garantizar el derecho a la educación, incluso en los niveles postobligatorios. Desde el punto de vista administrativo, podemos observar diferencias en cuanto a la competencia organizativa del acceso, fruto de los distintos modelos de regulación de cada uno de los países analizados; de este modo, mientras que Francia presenta un modelo centralizado - con una amplia autonomía escolar-, en España y Finlandia predomina la descentralización, con la administración regional y los entes locales (respectivamente) al frente de la organización educativa. Por último, desde el punto de vista pedagógico, observamos diferencias en cuanto al papel desempeñado por los centros de educación secundaria (con una dimensión más acreditativa en España y Francia que en Finlandia), así como los requisitos y pruebas de acceso. De este modo, mientras que España presenta una prueba a nivel nacional, que actúa como instrumento de acceso -y de forma indirecta, también como admisión-, en Francia y en Finlandia solamente es necesario el certificado de estudios de educación secundaria superior para el acceso a las universidades. Si bien, este proceso puede ser complementado (especialmente en el país nórdico), con una serie de requisitos específicos adicionales que, en este caso, actuarían como instrumentos de admisión. 
En este sentido, hemos de reconocer que estas diferencias que los tres sistemas educativos presentan en materia de acceso no es algo aleatorio, sino que tienen sus orígenes, tal y como ya hemos comentado, en las variables contextuales en las que estos se enmarcan y que, sin duda alguna, tienen una gran trascendencia sobre el sistema educativo en general y sobre los modelos de acceso en particular. Y es que, son muchos los comparatistas educativos que inciden en la gran importancia que el contexto puede llegar a ejercer, no solamente sobre los sistemas nacionales de educación, sino también sobre el desarrollo de sus políticas.

Por otro lado, también hemos concluido que el establecimiento de pruebas de acceso a la universidad no garantiza, por sí mismo, que este proceso de transición se desarrolle de una manera más eficaz. Recordemos que, en el caso de España, esta prueba se pone en marcha durante los últimos años del franquismo, coincidiendo con la expansión de la escolarización y el incremento de la demanda social de la educación. Como consecuencia de este enorme crecimiento, se produjo una transformación en el contexto universitario, pasando de una universidad de élites a otra de masas, convirtiendo esta institución en un elemento básico para el desarrollo económico de la sociedad (Luzón et al., 2009). Todo ello, trajo consigo un aumento de la flexibilización sobre este proceso de transición que estamos analizando, donde los principios básicos de derecho a la educación e igualdad de oportunidades serían trasladados al contexto universitario. Sin embargo, no hay evidencias de que nuestro sistema educativo presente un modelo de acceso más eficaz que sus homólogos en el estudio. De hecho, podríamos afirmar que ocurre todo lo contrario. Estas pruebas, que en el caso de nuestro país son meramente culturales (aunque poco a poco van adquiriendo tintes competenciales), no suponen un filtro académico para los estudiantes (tal y como ponen de manifiesto los datos), ya que su función se limita a ordenarlos y clasificarlos, especialmente, en aquellas titulaciones en donde la demanda sea superior a la oferta académica. Sin embargo, no hay evidencias que 
garanticen una mayor adecuación del estudiante a los estudios elegidos, lo que puede generar una serie de problemas de carácter pedagógico, como es evidente, pero también económico y social, tal y como veremos más adelante. Por contra, si evidenciamos que instaurar procedimientos específicos de admisión (pruebas competenciales, entrevistas orales, acreditación de experiencia laboral, etc.), surte un mayor efecto a la hora de que el proceso de transición se desarrolle con una mayor eficacia. De hecho, son varios los estudios que ponen de manifiesto que aquellos sistemas educativos que lideran los rankings internacionales, y que nosotros hemos catalogado como los más eficaces, tienden a ser aquellos que utilizan estos procedimientos específicos de admisión como parte de su modelo de transición (Barber y Mourshed, 2007).

De este modo, estamos en disposición de afirmar que para que el proceso de transición se desarrolle de una forma eficaz y exitosa, es necesario llevar a cabo, no solamente un correcto procedimiento de acceso, sino también de admisión, apostando, de una forma vehemente, por la participación de las instituciones de educación superior. De ahí la gran importancia que nosotros hemos otorgado a ambos términos (acceso y admisión) durante el desarrollo de nuestro trabajo, describiéndolos, analizándolos y, sobre todo, diferenciándolos, para una mayor y mejor comprensión de nuestro trabajo.

Otra de las conclusiones que hemos alcanzado una vez finalizada nuestra investigación es el carácter, un tanto especulativo, que adquieren los modelos de transición a la educación superior. Numerosos autores han analizado de forma exitosa este eje temático, haciendo alusión a tres modelos con características propias, que permitían clasificar a los sistemas educativos de una forma sencilla y eficaz. Sin embargo, durante el desarrollo de nuestro trabajo, hemos podido constatar cómo la realidad es otra muy distinta ya que, en numerosas ocasiones, estos sistemas cuentan con una serie de especificidades que impiden que podamos catalogarlos de una 
manera específica. Por este motivo, debemos ser cautos a la hora de hablar de los distintos modelos de acceso/admisión. Y es que no podemos remitirnos tan solo a la normativa vigente que se encarga de regular este proceso de transición, sino que debemos analizarla atendiendo a la realidad en la que se enmarca. De este modo, frente a lo que dictan los textos normativos, también debemos analizar la realidad de los distintos desarrollos institucionales, que pueden traer consigo matices que modifiquen las políticas de acceso. Es decir, los modelos no son puros sino mixtos en su ejercicio institucional y procesual.

En nuestro caso, podemos apreciar cómo pese a que España y Francia disponen de un modelo bastante accesible (abierto), lo cierto es que cuentan con algunos desarrollos institucionales en donde el acceso es más restrictivo; mientras que en Finlandia, la complejidad es mayor aún, dado que la libertad de la que disponen las universidades a la hora de establecer los procedimientos de admisión hace que exista un modelo de acceso para cada centro de educación superior. Si bien, hemos de reconocer que dado el carácter profesionalizante que ha adquirido su sistema universitario, la tendencia más común es la puesta en marcha procedimientos específicos de admisión, lo que otorga un gran valor y unos altos estándares de calidad al sistema universitario finlandés.

Por último, vamos a hacer alusión a una de las conclusiones más relevantes de nuestro estudio, como es que, en algunos casos, a la hora de fijar los criterios transición hacia las instituciones de educación superior, los sistemas educativos no tienen en consideración la situación que presenta el sistema económico productivo. Además, esta afirmación nos va a permitir aceptar la segunda hipótesis de nuestro trabajo que, recordemos, exponía lo siguiente:

Hipótesis 2. Las exigencias y requisitos de acceso/admisión a la educación superior dependen de la estructura y organización de los sistemas educativos, 
de la cultura social y de la tradición escolar, más que de las necesidades y exigencias del sistema productivo.

Hay numerosas evidencias, que ponen de manifiesto cómo determinados sistemas educativos (entre los que, por ejemplo, se encuentran Francia y, sobre todo, España) no establecen una oferta académica de educación superior acorde a las necesidades del su sistema económico productivo. Este hecho trae consigo multitud de problemas que afectan, no solo al ámbito pedagógico, sino también al económico y social. De este modo, aquellos sistemas que establecen un modelo de acceso/admisión abierto y accesible, donde no se toma en consideración la demanda del mercado laboral, deben enfrentarse a situaciones un tanto problemáticas, tanto en el desarrollo académico del estudiante como, sobre todo, en lo que a su empleabilidad se refiere.

Así, podemos observar cómo en aquellos sistemas educativos en donde no se establecen procedimientos adecuados de admisión, las dificultades se van desencadenando de forma paulatina, ejerciendo lo que podemos dominar un «efecto dominó». En primer lugar, podemos mostrar uno de los grandes problemas que, a lo largo de los últimos años, ha presentado la universidad como institución, que es la masificación de estudiantes en sus aulas. Lógicamente, este no es un problema en sí mismo, lo que sí lo es, es la falta de criterios a la hora de seleccionar a los estudiantes, que no siempre son los más adecuados para el perfil de estudios seleccionados, lo que genera numerosos problemas durante el desarrollo académico del estudiante: ralentización en su proceso de graduación, cambio de titulación, abandono prematuro, etc. Numerosos estudios (véase Karras y Wolhuter, 2015; 2018) ponen de manifiesto cómo aquellos sistemas educativos que no utilizan procedimientos específicos de admisión son los que, posteriormente, tienen una mayor proporción de estudiantes que acceden a unos determinados estudios sin que esa haya sido su opción preferencial, desencadenando, en muchas ocasiones, los problemas aquí descritos. De 
este modo, esta situación puede desencadenar una serie de problemas de carácter pedagógico, como es evidente, pero también económico, dado que se está realizando una inversión muy importante para formar a unos estudiantes que, en muchas ocasiones, no van a finalizar su periodo académico. Por otro lado, y continuando con este efecto dominó al que hemos aludido anteriormente, debemos destacar un segundo problema, y es que esta masificación de estudiantes traerá consigo, posteriormente, una masificación de graduados que, como es lógico, no tendrán garantizada su incorporación al mercado laboral al no haberse producido un ajuste entre la oferta académica y la demanda del mercado de trabajo. Esta situación, a su vez, generará otra serie de problemas sobre el sistema económico productivo: sobrecualificación y sobreeducación de los egresados, brain drain o fuga de cerebros, problemas socio afectivos de los estudiantes al verse en una situación laboral controvertida (desmotivación, desasosiego, ansiedad, etc.), etc. Todos estos problemas podemos verlos ejemplificados en nuestro país, que es uno de esos sistemas donde no se restringe la admisión hacia las instituciones de educación superior y en donde no se toma en consideración la situación del sistema económico productivo. Así, podemos apreciar como España presenta los peores datos de sobrecualificación de toda la U.E $(37,6 \%)^{47}$, unos porcentajes de abandono universitario realmente altos (próximos al $35 \%)^{48}$, que generan unas pérdidas económicas próximas a los 1.000 millones de euros anuales, de los cuales, 680 salen de las arcas públicas (Pérez y Aldas, 2019). Además, España también cuenta con el deshonorable honor de encabezar, junto a Italia, el ranking de países con mayor número de migraciones de trabajadores cualificados, que se cifra en casi 90.000 durante la última década (Fries-Tersch,

\footnotetext{
${ }^{47}$ Estos datos han sido recogidos de la decimoquinta edición del informe anual de la Fundación Conocimiento y Desarrollo (2018).

48 Ministerio de Ciencia, Innovación y Universidades [MCIU]. (2018). Datos y Cifras del sistema universitario español. Publicación 2018-2019. Madrid: Secretaría General Técnica.
} 
Tugran, Rossi y Bradley, 2018). Es decir, la relación entre sistema productivo y laboral y la organización institucional del sistema educativo, está mejor acompasada en Finlandia que en España y Francia. Esto es debido, fundamentalmente, al buen hacer del país nórdico, que desde la década de los años 80 del pasado siglo, pone en marcha planes prospectivos, a través de Finnish Society for Future Studies (FSFS), que permiten que el gobierno pueda anticipar decisiones futuras (Heinonen, 2016). En el apartado que a nosotros nos atañe, el acceso/admisión hacia las instituciones de educación superior, estos estudios tienen la finalidad de adecuar el número de estudiantes que deben ser formados atendiendo a la demanda del sistema económico productivo, evitando, de este modo, posibles desajustes.

Por todo ello, y a la luz de estos datos, existen pocos motivos que inviten a defender un sistema abierto, sin restricciones de ningún tipo, en el acceso hacia las instituciones de educación superior. $\mathrm{Y}$ es que ha quedado demostrado que la puesta en marcha de mecanismos específicos de admisión tiene multitud de ventajas, tanto en lo que concierne al ámbito pedagógico, como en el económico y social. Y es que estos procedimientos de admisión nos aportarán muchas facilidades a la hora de identificar a aquellos candidatos con más opciones de convertirse en grandes

profesionales, a localizar estudiantes que con mayores posibilidades de éxito a la hora de finalizar unos determinados estudios, y también, como no, a regular el número de estudiantes hacía unos determinados estudios, impulsando una formación de mayor calidad para los estudiantes (Egido, 2019).

\section{1) Fortalezas y debilidades de nuestro estudio}

Para finalizar, nos gustaría realizar una pequeña autoevaluación de nuestro trabajo, ya que entendemos que esta es la única manera de mejorar y seguir creciendo desde el punto de vista académico. Por ello, vamos a poner sobre la mesa las 
principales fortalezas y debilidades que, desde nuestro parecer, presenta nuestra investigación.

Las principales fortalezas de nuestro trabajo se centran en su trascendencia y desarrollo metodológico. Como ya hemos indicado, estamos ante un eje temático de gran alcance, en el que, a lo largo de los últimos años, numerosos investigadores nacionales e internacionales han puesto su foco de interés. Sin embargo, no localizamos ningún estudio que analice específicamente los sistemas educativos con los que nosotros hemos trabajado, ni mucho menos, la forma en la que nosotros lo hemos hecho, en lo que se refiere a las unidades de análisis descritas, desarrollo contextual, conclusiones alcanzadas, etc. Estamos, por tanto, ante un trabajo de investigación innovador. Y es que, desde nuestra perspectiva, este debe de ser uno de los grandes objetivos que se marque cualquier investigador que se disponga a elaborar una tesis doctoral. Analizar, indagar y examinar hechos, fenómenos, ideas... que nunca antes hayan sido investigados por otros autores, con el único fin de aportar un conocimiento novedoso.

Además, tal y como hemos indicado, estamos ante una investigación de gran alcance metodológico, lo que ha favorecido el desarrollo de una estructura coherente y racional. Ya indicamos al comienzo de nuestra tesis, que íbamos a seguir las líneas del método clásico de comparación, diseñadas por Bereday y Hilker, y redefinidas por numerosos autores a lo largo de los últimos años. En este sentido, hemos tratado de ser consecuentes, y de plasmar este método comparativo a lo largo de nuestro trabajo, dedicando un capítulo a cada una de las fases descritas en el método, con el único fin de favorecer una mayor y mejor comprensión del mismo.

Por último, también nos gustaría hacer referencia a la gran cantidad y, sobre todo, calidad de fuentes utilizadas, como una de las principales virtudes de esta investigación. Hemos tenido la fortuna de trabajar un eje temático que ha sido 
analizado profundamente por otros autores, lo que nos ha facilitado la recogida de información.

Si bien, como en cualquier trabajo de investigación, nos hemos tenido que enfrentar a numerosas dificultades, que hemos tratado de solventar con la mayor eficacia posible. La primera de ellas tiene que ver con el alcance de nuestro trabajo. Y es que, a medida que hemos avanzado en el desarrollo de nuestra investigación, nos hemos visto en la obligación de limitar algunos aspectos, ya que al tratarse de un estudio comparado entre tres sistemas educativos, el trabajo a realizar en cuanto a análisis de variables, desarrollo contextual, etc. se triplicaba. Por este motivo, hemos tenido que seleccionar aquello más relevante en nuestro trabajo, dejando a un lado algunas variables que, si bien no guardaban tanta trascendencia, hubiera sido interesante incorporarlas en nuestra tesis doctoral.

Otro de los problemas al que nos hemos enfrentado es el idioma. Estamos ante tres sistemas educativos con tres idiomas diferentes. Este hecho ha supuesto que, en numerosas ocasiones, hayamos tenido serias dificultades a la hora de analizar e interpretar determinados documentos que guardaban una estrecha relación con nuestro trabajo.

Por último, también hemos encontrado alguna dificultad a la hora de acceder a determinados documentos de análisis. Pese a que el corpus bibliográfico que hemos utilizado es extenso, lo cierto es que, en algunas ocasiones, no hemos podido acceder a algunos documentos de interés o, simplemente, no existía información sobre la que poder respaldar nuestras ideas.

En definitiva, estas son las limitaciones y fortalezas con las que hemos lidiado en nuestro trabajo. Durante el desarrollo de esta investigación, hemos tratado de minimizar al máximo estas debilidades y, sobre todo, potenciar las fortalezas, con el 
único fin de que nuestro trabajo presentase unos índices de calidad científica que, esperamos y deseamos, haya conseguido.

\section{2) Futuras líneas de investigación}

El desarrollo de un proyecto de investigación de tal alcance ha suscitado numerosos intereses científicos que trataremos de abordar en un futuro a corto o medio plazo. Sin duda alguna, esta tesis doctoral ha marcado un antes y un después en mi trayectoria personal, académica y, sobre todo, científica.

En este sentido, nos gustaría enfocar nuestras futuras investigaciones en dos direcciones que, por otro lado, no son excluyentes entre sí. En primer lugar, seguiremos analizando este proceso de transición. Estamos convencidos de que podemos acometer mejoras en nuestro trabajo y, por ello, vamos a continuar hasta alcanzarlas (ampliando unidades de análisis, introduciendo nuevos desarrollos contextuales, nuevas conclusiones, etc.). Como ya hemos indicado durante el apartado introductorio de este trabajo, estamos ante un eje temático que suscita un gran interés personal para nosotros; por este motivo, no queremos limitar nuestra acción investigadora hacia un solo trabajo. Además, también nos planteamos la posibilidad ampliar este proceso de investigación hacia otros sistemas educativos, especialmente en el contexto asiático y latinoamericano, lo cual nos otorgaría una visión más completa respecto al proceso de transición hacia las instituciones universitarias.

Y, por otro lado, también queremos indagar acerca de una coyuntura a la que ya hemos hecho alusión en nuestro trabajo, como son las consecuencias derivadas de los distintos modelos de acceso/admisión. Las cuestiones históricas, políticas, culturales, etc. que llevan a un sistema educativo a establecer un determinado modelo, tiene una serie de consecuencias que deben ser analizadas. Trataremos de hacerlo en futuras investigaciones y, sobre todo, trataremos de dar respuesta desde este proceso de transición que aquí hemos analizado. 


\section{3) Palabras finales}

Y hasta aquí nuestro trabajo. Tal y como ya hemos comentado, estamos ante un tema de gran actualidad, que ha cobrado una especial relevancia entre los investigadores educativos nacionales e internacionales a lo largo de los últimos años. Hemos tratado de realizar un proyecto de investigación coherente y objetivo. Nuestra intención no ha sido, en ningún caso, posicionarnos a favor o en contra de un modelo de acceso/admisión concreto. Simplemente hemos querido dejar constancia de las semejanzas y diferencias que los sistemas educativos analizados presentan en materia de acceso, así como las posibles causas y consecuencias que de ellas derivan. Para ello, nos hemos apoyado en datos empíricos que nos han permitido analizar la realidad académica de estos países. 
REFERENCIAS BIBLIOGRÁFICAS 



\section{REFERENCIAS BIBLIOGRÁFICAS}

ADELMAN, M., HOLLAND, P., y HEIDELK, T. (2017). Increasing Access by Waiving Tuition: Evidence from Haiti. Comparative Education Reviwe, 61 (4), pp. 804-831.

AHO, Ë., PITKÄNEN, K. y SAHLBERG, P. (2006). Policy Development and Reform Principles in Finland since 1968. Washington, DC: World Bank.

ALTBACH, P.G. y KELLY, G.P. (1990). Nuevos enfoques de educación comparada. Madrid: Mondadori

ALEXANDER, K., ENTWISLE, D. y OLSON. L. (2014). The Long Shadow: Family Background, Disadvantaged Urban Youth and the Transition to Adulthood. New York: Russell Sage Foundation.

ALONSO-SAINZ, T. y THOILLIEZ, B. (2020). Acceso a la profesión docente en Francia: una historia de 'Résistance' nacional contra algunas tendencias supranacionales. Revista Española de Educación Comparada, 35, pp. 173196. 
ÁLVAREZ GONZÁLEZ, M. (2004). La acción tutorial como factor de calidad de la educación. EN: A. VALLE LÓPEZ (Ed.). Contextos educativos y acción tutorial (pp. 71-109). Madrid: Ministerio de Educación, Cultura y Deporte.

ÁLVAREZ GONZÁLEZ, M. (2006). Planificación y organización de la acción tutorial (PAT). EN: M. ÁLVAREZ GONZÁLEZ (Ed.). La acción tutorial: Su concepción y su práctica (pp. 27-80). Madrid: Ministerio de Educación y Ciencia.

ÁLVAREZ GONZÁLEZ, M. y BISQUERRA, R. (2012). Orientación educativa. Modelos, áreas, estrategias y recursos. Madrid: Wolters Kluwer España.

ÁlVAREZ GONZÁLEZ, M., FIGUERA, P. y TORRADO, M. (2011). La problemática de la transición Bachillerato-Universidad en la Universidad de Barcelona. Revista Española de Orientación y Psicopedagogía, 22 (1), pp. 1527.

ÁLVAREZ GUISASOLA, J. (2006). Condiciones político-sociales para la escolarización del alumnado en las Comunidades Autónoma. EN: M.A. SANCHO, M.DE ESTEBAN, R. CABALLERO y J.M. RODRIGUEZ DE SANTIAGO. Escolarización del alumnado en el sistema educativo español: cuestiones jurídicas (pp. 21-26). Madrid: Fundación Europea Sociedad y Educación

ANAYA, D., PÉREZ-GONZÁLEZ, J. C. y SUAREZ, J. M. (2011). Los contenidos de formación de los profesionales de la orientación educativa desde la perspectiva de los propios orientadores. Revista de Educación, 356, pp. 607629. 
ANGRIST, J.D., PATHAK, P. A. y WALTERS, C.R. (2013). Explaining charter school effectiveness. American Economic Journal: Applied Economics, Vol. 5 (4), pp. 1-27.

ANTTONEN, A. y SIPILÄ, J. (1996). Servicios europeos de atención social: Is it possible to Identify Models? Journal of European Social Policy, 6 (2), pp. 87100.

ARIÑO, A. y LLOPIS, R. (2011). ¿Universidad sin clases? Condiciones de vida de los estudiantes universitarios en España (Eurostudent IV). Madrid: Ministerio de Educación.

ASTOLA, J. (2001). El sistema constitucional finlandés: una introducción. Revista de estudios políticos (nueva época), 114, pp. 235-249.

ASTIZ, M.F, WISEMAN, A. W. y BAKER, D.P. (2002). Slouching towards Decentralization: Consequences of Globalization for Curricular Control in National Education Systems. Comparative Education Review 46 (1), pp. 6688.

AUDUC, J. L. (2013). Le système éducatif français aujourd'hui. Grenelle (París): Hachette Éducation.

AZORÍN, C. (2019). Las transiciones educativas y su influencia en el alumnado. EDETANIA, 55, pp. 223-248.

BALL, S. J. y YOUDELL, D. (2009). Privatización encubierta de la educación pública. Utopías, II (220), pp. 57-92.

BANDURA, A. (1990). A Perceived self-efficacy in the exercise of personal agency. Revista Española de Pedagogía, 187, pp. 397-424. 
BANKS, A. S. (2001): Cross-national time-series data archive. Binghamton (New York): Computer Systems Unlimited.

BARAÑANO, M. y FINKEL, L. (2014). Transmisión intergeneracional y composición social de la población estudiantil universitaria española: cambios y continuidades. Revista de asociación de Sociología de la Educación, 7 (1), pp. $42-60$.

BARBER, M. y MOURSHED, M. (2007). How the World Best-performing School Systems Come out on Top. McKinsey y Company.

BAUDELOT, C. y ESTABLET, R. (1979). L'école capitaliste en France. Paris: Maspero.

BAYON-CALVO, S. (2019). Una radiografía del abandono escolar temprano en España: Algunas claves para la política educativa en los inicios del siglo XXI. Revista Complutense de Educación, 30 (1), pp. 35-53.

BECKER, G.S. (1964). Human Capital: A Theoretical and Empirical Analysis with Special Reference to Education. New York: National Bureau of Economic Research, Columbia University Press, ( $2^{\mathrm{a}}$ edición).

BEREDAY, G. Z. F. (1968). El método comparativo en pedagogía. Barcelona: Editorial Herder.

BERNAL, J. L., CANO, J. y LORENZO, J. (2014). Organización de los centros educativos. LOMCE y políticas neoliberales. Zaragoza: Mira Editores.

BERNARDI, F. y CEBOLLA, H. (2014). Clase social de origen y rendimiento escolar como predictores de las trayectorias educativas. Revista Española de Investigaciones Sociológicas, 146, pp. 3-22. 
BISQUERRA, R. (2006). Tutoría y desarrollo personal. EN: M. ÁLVAREZ GONZÁLEZ (Ed.). La acción tutorial: Su concepción y su práctica (pp. 81105). Madrid: Ministerio de Educación y Ciencia.

BOIX, C. (1997). Political Parties and the Supply Side of the Economy: the Provision of Physical and Human Capital in Advanced Economies, 1960- 1990. American Journal of Political Science, 41(3), pp. 814-845.

BONAL, X., RAMBLA, X. CALDERÓN, E. y PROS, N. (2005). La descentralización educativa en España. Barcelona: Fundació Carles Pi i Sunyer d'estudis Autonòmics i Locals.

BONAL, X. y TARABINI, A. (2013). The role of PISA in shaping hegemonic educational discourses, policies and practices: the case of Spain. Research in Comparative and International Education, 8 (3), pp. 335-341.

BOURSIN, J. L. (1981). L'administration de l 'Education Nationale. Paris: PUF.

BOWLES, S. y GINTIS, H. (1976). Schooling in Capitalist America: Educational Reform and Contradictions of Economic Life. New York: Basic Books.

BUNK, G. (1994). Teaching Competence in Initial and Continuing Vocational Training in the Federal Republic of Germany. Vocational Training European Journal, 1, pp. 8-14.

BUSEMEYER, M. R. (2007). Determinants of Public Education Spending in 21 OECD Democracies, 1980-2001. Journal of European Public Policy, 14 (4), pp. 582-610.

BUSTAMANTE, E. (2013). España: la cultura en tiempos de crisis. Fuentes financieras y políticas públicas. Madrid: Fundación Alternativas. 
CABALLERO, R. (2014). La regulación de las titulaciones universitarias como límite a la descentralización de la educación superior. Revista de Educación, 366, pp. 43-63.

CABAllero, A., MANSO, J., MATARRANZ, M. y VALlE, J. (2016). Investigación en Educación Comparada: Pistas para investigadores noveles. Revista Latinoamericana de Educación Comparada, 9, pp. 39-56.

CABANEL, P. (2006). De l'école protestante à la laïcité. La Société pour l'encouragement de l'instruction primaire parmi les protestants de France (1829-années 1880). Histoire de l'éducation, 110, pp. 53-90.

CABRERA, L., BETHENCOURT, J., ÁLVAREZ, P. y GONZÁLEZ, M. (2006). El problema del abandono de los estudios universitarios. RELIEVE, 12 (2), pp. 171-203.

CALERO, J. y CHOI, A. (2012). La evaluación como instrumento de política educativa. Presupuestos y Gasto Público, 67, pp. 29-41.

CARNEY, C. (2009). Negotiating policy in an age of globalization: exploring educational "policyscapes" in Denmark, Nepal and China. Comparative Education Review, 53 (1), pp. 63-88.

CARNOY, M. (1999). Globalización y reestructuración de la educación. Revista de Educación, 318, pp. 145-162.

CASQUERO, A. y NAVARRO, M.L. (2010). Determinantes del abandono escolar temprano en España. Un análisis por género. Revista de Educación, Número Extraordinario, pp. 191-223. 
CASTLES, F. G. (1989). Explaining Public Education Expenditure in OECD Nations. European Journal of Political Research, 17, pp. 431-448.

CASTRO, R. B., FERNÁNDEZ, P. y MARTíN, V. (2015). Análisis de la tasa de rendimiento de la educación superior en España. Revista de Educación, 360, pp. 96-120.

CHAPMAN, C. y SALOKANGAS, M. (2012). Independent state-funded schools: Some reflections on recent developments. School Leadership and Management, Vol. 32 (5), pp. 473-486.

CHAPOULIE. J. M. (2005). L'organisation de l'enseignement primaire de la IIIe République: ses origines parisiennes et provinciales, 1850-1880. Histoire de l'éducation, 105, pp. 3-44.

CHARRO, G. A. (2016). Incidencia de la descentralización territorial en la financiación pública de la enseñanza no universitaria en España e impacto de la crisis económica internacional, 2000-2012 (Tesis Doctoral). Universidad Complutense de Madrid, Comunidad de Madrid, España.

CHEETHAM, G. y CHIVERS, G. (2005). Professions, Competence And Informal Learning. Northampton (Massachusetts): Edwars Elgar.

CLAYTON, T. (2004) Competing conceptions of Globalization revisited: Relocating the tension between World-Systems Analysis and Globalization analysis. Comparative Education Review, 48 (3), pp. 274-295.

COROMINAS, E. (2006). Nuevas perspectivas de la orientación profesional para responder a los cambios y necesidades de la sociedad de hoy. Estudios sobre Educación, 11, pp. 91-110. 
CROSSLEY, M. (2002). Comparative and international education: Contemporary challenges, reconceptualization and new directions for the field. Current Issues. Comparative Education, Teachers College, 4 (2), pp. 81-86.

DALE, R. (2002). Globalización: ¿un Nuevo mundo para la educación comparada? EN: J. SCHRIEWER. Formación del discurso en la educación comparada. Barcelona: Pomares.

DALE, R. (2007). Specifying Globalization Effects on National Policy. A focus on the Mechanisms. EN: B. LINGARD y J. OZGA (Eds.). The Routledge Reader in Education Policy and Politics (pp. 48-64). London: Routledge.

DARLING-HAMMOND, L., BURNS, D., CAMPBELL, C., GOODWIN, A. L., HAMMERNESS, K., LOW, E.L., MCINTYRE, A., SATO, M. y ZEICHNER, K. (2017). Empowered educators: Teaching quality around the world. San Francisco: Jossey-Bass

DARCOS, X. (2008). La escuela republicana en Francia: obligatoria, gratuita y laica. La escuela de Jules Ferry, 1880-1905. Zaragoza: Prensas Universitarias de Zaragoza.

DE CARLOS, C. (2014). Del bachillerato a la universidad: la quimera de la prueba acceso. Tarbiya: Revista de investigación e innovación educativa, 43, pp. $165-176$.

DE PABLOS, L. y GIL M. (2007). Análisis de los condicionantes socioeconómicos del acceso a la educación superior. Presupuesto y gasto público, 48, pp. 37-57.

DEL VALLE, A. (2004) Contextos educativos y acción tutorial. Madrid: Subdirección General de Información y Publicaciones del Ministerio de Educación, Cultura y Deporte. 

educativos de España, Francia y Finlandia

DELANNOY, F. y GUZMÁN, M. (2009). Experiencias internacionales en gestión descentralizada de la educación pública. EN: M. MARCEL y D. RACZYNSKI (Eds.). La asignatura pendiente: claves para la revalidación de la educación pública de gestión local en Chile (pp. 225-278). Santiago de Chile: CIEPLAN.

DERQUI, J. M. G. (2001). Educational Decentralization Policies in Argentina and Brazil: Exploring the New Trends. Journal of Education Policy, 16 (6), pp. $561-83$.

DÍEZ, E. J. (2014). Una amenaza para la escuela pública: laicidad, privatización y segregación. Revista Interuniversitaria de Formación de Profesorado, 81 (28.3), pp. 105-117.

DOBBINS, M. y MARTENS, K. (2012). Towards an education approach à la finlandaise? French education policy after PISA. Journal of Education Policy, 27 (1), pp. 23-43.

DOCKETT, S. Y PERRY, B. (2007). Transitions to school: Perceptions, expectations, experiences. Sydney: University of NSW Press

DOMÍNGUEZ, C. (2008). Política y cambio. La legislación educativa de la segunda república. EN: J. JORGANES. (Coord.). La escuela de la II República (pp. 2946). Sevilla: Cajasol Fundación.

DOMÍNGUEZ, G., ÁLVAREZ, F.J. y LÓPEZ, A.M. (2013). Acción tutorial y orientación en el periodo de transición de la Educación Secundaria a la Universidad. La orientación al alumnado de nuevo ingreso. Revista de docencia universitaria, 11(2), pp. 221-241. 
DUBET, F., DURU-BELLAT, M. y VÉRÉTOTU, A. (2010). Les sociétiés et leur école. Emprise dudiplôme et cohesion sociale. Paris: Editions du Seuil.

DUPRIEZ, V., MONSEUR, C., VAN CAMPENHOUDT, M. y LAFONTAINE, D. (2012). Social inequalities of post-secondary educational aspirations: influence of social background, school composition and institutional context. European Educational Research Journal, 11(4), pp. 504-519.

EGIDO, I. (2019). Profesión docente y carrera docente, retos en el marco de la Unión Europea. EN: Consejo Escolar de la Comunidad de Madrid (Ed.): La mejora de la profesión docente en la Comunidad de Madrid (pp. 41-55). Madrid: Comunidad de Madrid.

EGIDO, I. (2020). El acceso a la formación docente inicial en Europa: políticas e investigación. Revista Española de Educación Comparada, 35, pp. 197-211.

ELACQUA, G. (2012). The impact of school choice and public policy on segregation: Evidence from Chile. International Journal of Educational Development, 32 (3), pp. 444-453

ENCISO, M. I. (2013). Origen social de los graduados y la equidad en el acceso a la universidad. Revista de educación superior, 165, 42, pp. 11-29.

ENKVIST, I. (2010). El éxito educativo finlandés. Revista Bordón, 62 (3), pp. 49-67.

ESCOLANO, A. (1982). Economía e Ilustración. El origen de la Escuela Técnica Moderna en España. Revista Interuniversitaria de Historia de la Educación, 1, pp. 169-191. 
ESCOLANO, A. (2001). Las culturas escolares en España en la perspectiva histórica. EN: SOCIEDAD DE ESTUDIOS HISTÓRICOS DE NAVARRA. Primer encuentro sobre Historia de la educación en Navarra (Eds.) (pp. 1132). Pamplona: Gobierno de Navarra.

ESCOLANO, A. (2002). La educación en la España contemporánea. Políticas educativas, escolarización y culturas pedagógicas. Madrid: Biblioteca Nueva.

ESCOLANO, A. (2008). La cultura empírica de la escuela: aproximación etnohistórica y hermenéutica. EN: MAINER, J. (Coord.). Pensar criticamente la Educación escolar (pp. 145-172). Zaragoza: Prensas Universitarias.

ECHEVERRÍA, B. (2002). Gestión de la competencia de acción profesional. Revista de Investigación Educativa, 20 (1), pp. 7-43

ENCISO, M. I. (2013). El origen social de los graduados y la equidad en el acceso a la Universidad. Revista de Educación Superior, vol. 42 (165), pp. 11-29.

EUROPEAN COMMISSION (2008a). La autonomía escolar en Europa. Políticas y medidas. Madrid: Ministerio de Educación, Política Social y Deporte, Subdirección General de Información y Publicaciones

EUROPEAN COMMISSION (2014). Modernisation of Higher Education in Europe: Access, Retention and Employability 2014. Eurydice Report. Luxembourg: Publications Office of the European Union.

EUROPEAN COMMISSION (2015). Modernisation of Higher Education in Europe: Access, Retention and Employability 2014. Eurydice Report. Luxembourg: Publications Office of the European Union. 
EUROPEAN COMMISSION (2016). Culture Statistics. Luxembourg: Publications Office of the European Union.

EUROPEAN COMMISSION (2017a). Compulsory Education in Europe - 2017/18. Eurydice Facts and Figures. Luxembourg: Publications Office of the European Union.

EUROPEAN COMMISSION (2017b). The Organisation of School Time in Europe. Primary and General Secondary Education - 2017/18. Eurydice Facts and Figures. Luxembourg: Publications Office of the European Union.

EUROPEAN COMMISSION (2017c). Support Mechanisms for Evidence-based Policy Making in Education. Eurydice Report. Luxembourg: Publications Office of the European Union.

EUROPEAN COMMISSION (2018a). Compulsory Education in Europe - 2018/19. Eurydice Facts and Figures. Luxembourg: Publications Office of the European Union.

EUROPEAN COMMISSION (2018b). The Organisation of School Time in Europe Primary and General Secondary Education - 2018/19. Eurydice Facts and Figures. Luxembourg: Publications Office of the European Union.

EUROPEAN COMMISSION (2019). The Organisation of School Time in Europe. Primary and General Secondary Education - 2019/20. Eurydice Facts and Figures. Luxembourg: Publications Office of the European Union.

FABIAN, H. y DUNLOP, A. (2007). Outcomes of good practice in transition processes for children entering primary school. La Haya: Bernard van Leer Foundation. 
FARREL, J. P. (1990). La necesidad de la comparación en los estudios sobre la educación. La relevancia de la ciencia y el problema de la comparabilidad. EN: P. ALTBACH y G. KELLY (Ed.). Nuevos enfoques en educación comparada (pp. 229-243). Madrid: Mondadori.

FERNÁNDEZ ENGUITA, M. (2008). Escuela pública y privada en España: La segregación rampante. Revista de la Asociación de Sociología de la Educación, 1(2), pp.42-69.

FERNÁNDEZ - GONZÁLEZ, N. (2015). PISA como instrumento de legitimación de la reforma de la LOMCE. Revista Bordón, 67 (1), pp. 165-178.

FERNÁNDEZ-MACÍAS, E., ANTÓN, J. I., BRAÑA, F. J. Y MUÑOZ DE BUSTILLO, R. (2013). Early schoolleaving in Spain: evolution, intensity and determinants. European Journal of Education, 48(1), pp. 150-164.

FERNÁNDEZ-MIRANDA, A. (2006). El derecho a la educación y libertad de enseñanza en el mercado educativo. EN: M.A. SANCHO, M. DE ESTEBAN, R. CABALLERO y J.M. RODRIGUEZ DE SANTIAGO. Escolarización del alumnado en el sistema educativo español: cuestiones jurídicas (pp. 37-65). Madrid: Fundación Europea Sociedad y Educación

FERNÁNDEZ MONTAÑO, P. (2014). Aproximación al Modelo Nórdico de Estado de Bienestar: La experiencia de una trabajadora social española en Finlandia. Trabajo Social Hoy, 71, pp. 87-96.

FERNÁNDEZ SORIA, J.M. (2005). Influencias nacionales europeas en la política nacional española del s. XX. Historia de la educación. Revista interuniversitaria, 24, pp. 39-95. 
FERNÁNDEZ SORIA. J.M. (2007). Igualdad y libertad de elección de centro docente: una cuestión polémica para un acuerdo necesario. Revista de Educación, 344, 2007, pp. 41-59.

FERNÁNDEZ SORIA, J.M. (2019). Presentación. Historia política de la educación. Educació i Història: Revista d'Història de l'Educació, 32, pp. 11-28.

FERRER, F. (1990). Educación comparada. Fundamentos teóricos, metodología y modelos. Barcelona: PPU.

FERRER, F. (2002). La educación comparada actual. Barcelona: Ariel.

FIGUERA, P. (2006). Transición ESO-secundaria postobligatoria/trabajo. EN: M. ÁLVAREZ GONZÁLEZ (Ed.). La acción tutorial: Su concepción y su práctica (pp. 189-218). Madrid: Ministerio de Educación y Ciencia.

FIGUERA, P., RODRÍGUEZ, M.L. y LLANES, J. (2015). Transición y orientación: Interrelaciones, estrategias y recomendaciones desde la investigación. REIRE, 8 (2), pp. 1-17

FINNISH NATIONAL AGENCY OF EDUCATION [FNAE] (2007). Finnish education system. Helsinki: FNAE.

FREIRE, M. J., TEIJEIRO, M. M. y PAIS, C. (2013). La adecuación entre las competencias adquiridas por los graduados y las requeridas por los empresarios. Revista de Educación, 362, pp. 13-41.

FRIES-TERSCH, E., TUGRAN, T., ROSSI, L. y BRADLEY, H. (2018). 2017 Annual Report on intra-EU Labour Mobility. Luxemburgo: Publications Office of the European Union. 
FRIJHOFF, W. (2011). Influencias francesas en los sistemas nacionales de educación de Europa durante los siglos XIX y XX. Algunas reflexiones metodológicas EN: J. M. HERNÁNDEZ DÍAZ (ED.). Francia en la educación de la España contemporánea (1808-2008) (pp. 29-45). Salamanca: Ediciones Universidad de Salamanca.

GARCÍA ARETIO, L., RUIZ CORBELLA, M. y GARCÍA BLANCO, M. (2011). Claves para la educación. Actores, agentes y escenarios en la sociedad actual. Madrid: UNED.

GARCÍA GARRIDO, J.L. (1986). Fundamentos de educación Comparada. Madrid: Dykinson (2 edición).

GARCÍA GARRIDO, J. L. (2005). Centralización y descentralización en los sistemas educativos. EN: j. GAIRÍN. La descentralización educativa. ¿Una solución o un problema? (pp. 29-83). Madrid: Ciss Praxis.

GARCÍA GARRIDO, J.L., GARCÍA RUÍZ. M. J. y GAVARI, E. (2012). La Educación Comparada en tiempos de Globalización. Madrid: Universidad nacional de Educación a Distancia.

GARCÍA HERNÁNDEZ, M.C. (2018). Respuestas educativas a la exclusión económica y social. Dispositivos existentes en Francia. EN XVI Congreso Nacional de Educación Comparada, Tenerife, España.

GARCÍA PEDRAZA, R. (2015). Comprensividad y diversidad en la educación secundaria de Suecia, Finlandia, Reino unido, Alemania, y España (Tesis Doctoral). Universidad Nacional de Educación a Distancia, Comunidad de Madrid, España. 
GARCÍA PERALES, N. y MARTÍN SÁNCHEZ, M.A. (2012). Algunas notas en perspectiva comparada sobre formación de maestros: el caso de España y Finlandia. El Tejuelo, 13, pp. 70-87.

GARCÍA RUIZ, M. J. (2010). Estudio comparativo de la educación: Finlandia y Comunidad de Madrid. Análisis y Recomendaciones. Madrid: Comunidad de Madrid. Consejería de Educación.

GARCÍA RUIZ, M. J. (2011). Contrastes de las culturas escolares finlandesa y española. Revista española de educación comparada, 18, pp. 157-202.

GAUTHIER, P.L. (1999). Evolución de la educación en Francia. Diez años de reformas: 1990-2000. Revista española de educación comparada, 5, pp. 185208.

GAUTHIER, P.L. (2005). El sistema educativo francés. EN: J. PRATS, F. RAVENTÓS, E. GASÒliBA, R. COWEN, B. P. M. CREEMERS, P. L. GAUTHIER, B. MAES, B. SCHULTE y R. STANDAERT (Eds.), Los sistemas educativos europeos: ¿crisis o transformación? (pp. 29-65). Barcelona: Fundación la Caixa.

GAVARI, E. (2005a). Evolución de la política educativa francesa: de la igualdad a la diversidad. Revista Complutense de Educación, 16 (2), pp. 415-438.

GAVARI, E. (2005b). La educación en Francia y en Italia en la segunda mitad del siglo XX. Madrid: Universidad Nacional de Educación a Distancia.

GIMENO, J. (1996). La transición a la educación secundaria. Madrid: Morata. 
GIMENO, J. (2005). ¿Qué se puede ganar descentralizando la educación? ¿Es posible diferenciarse sin desigualdad? EN: J. GAIRÍN. La descentralización educativa. ¿Una solución o un problema? (pp. 85-134). Madrid: Ciss Praxis.

GIMENO, J. (2014). La LOMCE. ¿Una ley más de educación? Revista Interuniversitaria de Formación de Profesorado, 81 (28.3), pp. 31-44.

GONZÁLEZ, I. (2011). El cambio de orientación de la política social comunitaria. Del estado del bienestar a la sociedad del bienestar (Tesis Doctoral). Universidad de Sevilla, Andalucía, España.

GONZÁLEZ FARACO, J. C., LUZÓN, A. y TORRES, M. (2009). Retos y riesgos en la construcción de un Espacio Europeo de Educación Superior. Revista Electrónica de Investigación Educativa, 11(1), pp. 33-46.

GRAÑERAS, M. y PARRAS, A. (2009). Orientación educativa: fundamentos teóricos, modelos institucionales y nuevas perspectivas. Madrid: CIDE, Servicio Publicaciones M.E.

GRAU, S., ÁlvareZ, J.D., MONCHO, A., RAMOS, M.C., CRESPO, M. y ALONSO, N. (2013). Las transiciones educativas. Necesidades de un proceso de orientación completo. EN XI Jornadas de Redes de Investigación en Docencia Universitaria: Retos de futuro en la enseñanza superior: Docencia e investigación para alcanzar la excelencia académica, Alicante, España.

GREEN, A., LENEY, T. y WOLF, A. (2001). Convergencias y divergencias en los sistemas europeos de educación y formación profesional. Barcelona: Ediciones Pomares. 
GRIPENBERG, M. y LIZARTE, E. J. (2012). El sistema educativo en Finlandia y su éxito en la prueba PISA. Journal for Educators, Teachers and Trainers, 3, pp. $14-24$.

HALINEN, I. y JÄRVINEN, R. (2008): En pos de la educación inclusiva: el caso de Finlandia, Perspectivas, 38, (1), pp. 97-127

HALLS, W.D. (1990) Comparative Education: Contemporary Issues and Trends London: Jessica Kingsley; Paris: UNESCO.

HAUSCHILDT, K., GWOSĆ, C., NETZ, N. y MISHRA, S. (2015). Social and Economic Conditions of Student Life in Europe: Synopsis of indicators, Eurostudent V 2012-2015. Bielefeld: W. Bertelsmann Verlag.

HAUSCHILDT, K., VÖGTLE, E.M. y GWOSĆ, C. (2018). Social and Economic Conditions of Student Life in Europe: Eurostudent VI 2016-2018, Synopsis of indicators. Bielefeld: W. Bertelsmann Verlag

HEATH, W. y WINTHER, P. (1996) Social Policy in Finalnd -an overview-. Luxembourg: European Parlament.

HEINONEN, S. (2016). La Prospectiva y las políticas Públicas: La experiencia de Finlandia. EN Seminario Internacional Prospectiva y Estrategia para el desarrollo del Chile del 2030, Santiago, Chile.

HELLER, G. (2015). Real Finnish Lessons: The true story of an education superpower. Surrey: Centre for Policy Studies.

HILKER, F. (1964). La Pédagogie Comparée. Paris: Institut Pédagogique National.

HILKER, F. (1967) Pedagogía comparata: storia, teoria e prassi. Roma: Armando Armando. 

educativos de España, Francia y Finlandia

HOLMES, B. (1981) Comparative Education: some consideration of method. London: Allen \& Unwin.

ILLERIS, K. (2009). International Perspectives on Competence Development. Nueva York: Routledge.

IÑIGUEZ, T., ELBOJ, C. y VALERO, D. (2016). La universidad del Espacio Europeo de Educación Superior ante el abandono de los estudios de grado. Causas y propuestas estratégicas de intervención. Educar, 52 (2), pp. 258313.

JAKOBI, A. y MARTENS, K. (2007). La influencia de la OCDE en la política educativa nacional. EN: X. BONAL, A. TARABINI y A. VERGER. (Eds.). Globalización Y Educación: Textos Fundamentales (pp. 233-253). Buenos Aires: Miño y Dávila.

JAKKU-SHIVONEN, R. y NIEMI, H. (2011). Aprender de Finlandia. La apuesta por un profesorado investigador. Madrid: Kaleida.

JIMENEZ, E. y PAQUEO, V. (1996). Do local contributions affect the efficiency of public primary schools? Economics of Education Review, Vol. 15 (4), pp. 377 386.

JULIA, D. (1995). La culture scolaire comme objet historique. Paedagogica Historica. International journal of the history of education, 31 (Sup. 1), pp. 353-382.

JULKUNEN, I. (2007). El abandono escolar prematuro en Finlandia - ¿Un problema resuelto? Revista de Estudios de Juventud, 77, pp. 123-138. 
KARRAS, K. G. y WOLHUTER, C. C. (2015). International Handbook of Teacher Training and Re-training Systems in Modern World. Nicosia: Studies and Publishing.

KARRAS, K. G. y WOLHUTER, C. C. (2018). International Handbook on Teacher Education Worldwide, 3 vols. Nicosia: Studies and Publishing.

KAUKO, K. y WERMKE, W. (2018). The Contingent Sense-Making of Contingency: Epistemologies of Change in Comparative Education. Comparative Education Review, 62 (2), pp. 157-177.

KELLY, G.P. y ALBATCH, P.G. (1986). New approaches to comparative education. Chicago: The University of Chicago Press.

KING, K. (2007). Multilateral agencies in the construction of the global agenda on education. Comparative Education, 43 (3), pp. 377-391.

KOKKONEN, V. (2019). The changing nature and role of vocational education and training in Europe. External factors influencing VET - Understanding the National Policy Dimension: Country Case Studies. Luxembourg: CEDEFOP, Publications Office.

KWIEK, M. (2013). From System Expansion to System Contraction: Access to Higher Education in Poland. Comparative Education Review, 57 (3), pp. 553576.

LATIESA, M. (1989). Demanda de educación superior: evaluación y condicionamientos de los estudiantes en la elección de la carrera. Revista Española de Investigaciones Sociológicas, 46, pp. 101-139.

LAUKKANEN, R. (2013): Finland's experiences of compulsory education development, Artseduca, 5, pp. 140-167. 

educativos de España, Francia y Finlandia

LÁZARO, L. (2007). La perspectiva social de la jornada escolar en la Unión Europea. Estudio comparado en Italia, Francia, Portugal y España (Tesis Doctoral). Universidad de Salamanca, Castilla y León, España.

LAZARUS, R.S. y FOLKMAN, S. (1986). Estrés y procesos cognitivos. Barcelona: Martínez Roca.

LELIÈVRE, C. (2002). Les politiques scolaires mises en examen. Douze questions en débat. Issy Les Moulineaux: ESF.

LENT, R. W., HACKETT, G. y BROWN, S. D (1994). A social cognitive view of school-to-work transition. The Career Development Quarterly, 47 (4), pp. $297-$ 311.

LEVIN, H.M., CORNELISZ, I. y HANISCH-CERDA, B. (2013). Does educational privatisation promote social justice? Oxford Review of Education, Vol. 39 (4), pp. 514-532.

LIE, S., LINNAKYLÄ, P. y ROE, A. (2003). Northern lights on PISA: unity and diversity in the Nordic countries in PISA 2000. Oslo: University of Oslo.

LINGARD, B. y RAWOLLE, S. (2010): Globalization and the Rescaling of Education Politics and Policy. Implications for Comparative Education. EN: M. LARSEN (Ed.). New Thinking in Comparative Education. Honouring Robert Cowen (pp. 125-142). Rotterdam: Sense Publishers

LINNAKYLÄ, P. y VÄLIJÄRVI, J. (2006). Rendimiento de los estudiantes finlandeses en PISA. Las claves del éxito en lectura. Revista de Educación, número extraordinario, 227-235. 
LITTLE, A. (2000). Development Studies and Comparative Education: context, content, comparison and contributors. Comparative Education, 36 (3), pp. 279-296.

LLORENT, V.J. (2006). Las reformas de la formación profesional inicial, específica y postobligatoria en los sistemas escolares de Inglaterra, Francia y España, a inicios del siglo XXI. Estudio comparado (Tesis Doctoral). Universidad de Sevilla, Andalucia, España.

LORENZO, M., ARGOS, J., HERNÁNDEZ, J. y VERA, J. (2014). El acceso y la entrada del estudiante a la Universidad: situación y propuestas de mejora facilitadoras del tránsito. Educación XX1, 17 (1), pp. 15-38.

LUQUE, M.F. (2015). La orientación desde la secundaria (Tesis Doctoral). Universidad de Granada, Andalucía, España.

LUZÓN, A., SEVILLA, D. y TORRES, M. (2009). El proceso de Bolonia: Significado, objetivo y controversias. Revista de la Asociación de Inspectores de Educación de España, 10, pp. 1-11.

LUZÓN, A. y TORRES, M. (2011). Visualizing PISA scientific literatura versus PISA public usage. EN M. PEREYRA, H-G. KOTTHOFF y R. COWEN (Eds.), PISA Under Examination. Changing Knowledge, Changing Tests, and Changing Schools (pp. 269-301). Rottderdam: Sense Publishers.

LUZÓN, A. y TORRES, M. (2013). La presencia de PISA en la literatura científica y su tratamiento en la prensa diaria internacional. Profesorado. Revista de currículum y formación del profesorado, 17 (2), pp. 193-224. 
LYNCH, K. y MORAN, M. (2006). Markets, Schools and the Convertibility of Economic Capital: The Complex Dynamics of Class Choice. British Journal of Sociology of Education 27 (2), pp. 221-35.

MAMMARELLA, G. (1996). Historia de Europa contemporánea desde 1945 hasta hoy. Barcelona: Ariel Historia.

MANZON, M. (2011). Comparative Education: The Construction of a Field. Hong Kong: Comparative Education Research Centre.

MARBÁN, V. y RODRÍGUEZ, G. (2014). Políticas sociales en sanidad y educación y el impacto de las políticas de consolidación fiscal. VII Informe sobre exclusión y desarrollo social en España 2014. Madrid: Fundación FOESSA.

MARCENARO, O. D. y NAVARRO, M. L. (2005). Nueva evidencia sobre el rendimiento de capital humano en España. Revista de economía aplicada, 37 (13), pp. 69-88.

MARÍN, J.A. (2004). La Acción Tutorial como elemento de mejora de la calidad de la enseñanza en la Educación Secundaria Obligatoria (E.S.O.): el «Colegio Virgen de Gracia» como estudio de caso (Tesis Doctoral). Universidad de Granada, Andalucia, España.

MARKS, G. y FLEMING, N. (1999). Early school leaving in Australia: findings from the 1995 year 9 LSAY cohort. LSAY Research Report, 11. Victoria: Australian Council for Educational Research

MARQUÉS, I. y GIL, C. J. (2015). Origen social y sobreeducación en los universitarios españoles: ¿es meritocrático el acceso a la clase de servicio? Revista española de investigaciones sociológicas, 150, pp. 89-112. 
MARTíN, E., GONZÁlEZ, M., RODRÍGUEZ, J., PÉREZ, C., Y ÁlVAREZ, P. (2010). El rendimiento académico del alumnado de nuevo ingreso en la Universidad de La Laguna. Tenerife: Servicio de Publicaciones de la Universidad de La Laguna.

MARTÍNEZ, A., CASTRO, M., ZURITA, F. y LUCENA, M. (2015). La elección de estudios superiores universitarios en función de la modalidad de estudios, la nota media y el género. Magister, 27, pp. 18-25.

MARTÍNEZ, A., ZURITA, F., CASTRO, M., CHACÓN, R., HINOJO, M. A. y ESPEJO, T. (2016). La elección de estudios superiores universitarios en estudiantes de último curso de bachillerato y ciclos formativos. Revista Electrónica Educare, 20 (1), pp. 1-18.

MATSUOKA, R. (2018). Inequality in Shadow Education Participation in an Egalitarian Compulsory Education System. Comparative Education Review, $62(4)$, pp. 565-586.

MEISALO, V. (2007). Subject teacher education in Finland: a Research-based approach - The role of Subject didactics and networking in teacher education. EN: R. JAKKU-SIHVONEN y H. NIEMI (Eds.). Education as Societal Contributor (pp. 161-180). Frankfurt am Main: Peter Lang.

MELGAREJO, J. (2006). La selección y formación del profesorado: clave para comprender el excelente nivel de competencia lectora de los alumnos finlandeses. Revista de Educación, número extraordinario, pp. 237-262.

MEYER, J.W. y SCHOFER, E. (2006). La universidad en Europa y en el mundo: expansión en el siglo XX. Revista Española de Educación Comparada, 12, pp. 15-36. 
MEYER, J. W. y RAMÍREZ, F.O. (2010). La educación en la sociedad mundial. Teoría institucional y agenda de investigación de los sistemas educativos contemporáneos. Barcelona: Octaedro: Universitat de Barcelona, Institut de Ciénces de l'Educació.

MICHAVILA, F. y ESTEVE, F. (2011). La llegada a la universidad: ¿oportunidad o amenaza? Participación Educativa, MECD, 17, pp. 69-85.

MICHEL, A. y CERVEL, J.F. (2019). The changing nature and role of vocational education and training in Europe. Main evolutions of higher VET in France. Luxembourg: CEDEFOP, Publications Office.

MINCER, J. (1958). Investment in Human Capital and Personal Income Distribution. Journal of Political Economy, 66, pp. 281-302.

MINCER, J. (1974). Schooling, Experience, and Earnings. New York: Columbia University Press.

Ministerio de Ciencia, Innovación y Universidades [MCIU]. (2018). Datos y Cifras del sistema universitario español. Publicación 2018-2019. Madrid: Secretaria General Técnica.

Ministerio de Educación, Cultura y Deporte [MECD]. (2010a). Datos y Cifras. Curso escolar 2010/2011. Madrid: Secretaría General Técnica.

Ministerio de Educación, Cultura y Deporte [MECD]. (2010b). Datos y Cifras del sistema universitario español. Curso escolar 2010/2011. Madrid: Secretaría General Técnica.

Ministerio de Educación, Cultura y Deporte [MECD]. (2011a). Datos y Cifras. Curso escolar 2011/2012. Madrid: Secretaría General Técnica. 
Ministerio de Educación, Cultura y Deporte [MECD]. (2011b). Datos y Cifras del sistema universitario español. Curso escolar 2011/2012. Madrid: Secretaría General Técnica.

Ministerio de Educación, Cultura y Deporte [MECD]. (2012a). Datos y Cifras. Curso escolar 2012/2013. Madrid: Secretaría General Técnica.

Ministerio de Educación, Cultura y Deporte [MECD]. (2012b). Datos y Cifras del sistema universitario español. Curso escolar 2012/2013. Madrid: Secretaría General Técnica.

Ministerio de Educación, Cultura y Deporte [MECD]. (2013a). Datos y Cifras. Curso escolar 2013/2014. Madrid: Secretaría General Técnica.

Ministerio de Educación, Cultura y Deporte [MECD]. (2013b). Datos y Cifras del sistema universitario español. Curso escolar 2013/2014. Madrid: Secretaría General Técnica.

Ministerio de Educación, Cultura y Deporte [MECD]. (2014a). Datos y Cifras. Curso escolar 2014/2015. Madrid: Secretaría General Técnica.

Ministerio de Educación, Cultura y Deporte [MECD]. (2014b). Datos y Cifras del sistema universitario español. Curso escolar 2014/2015. Madrid: Secretaría General Técnica.

Ministerio de Educación, Cultura y Deporte [MECD]. (2015a). Datos y Cifras. Curso escolar 2015/2016. Madrid: Secretaría General Técnica.

Ministerio de Educación, Cultura y Deporte [MECD]. (2015b). Datos y Cifras del sistema universitario español. Curso escolar 2015/2016. Madrid: Secretaría General Técnica. 

educativos de España, Francia y Finlandia

Ministerio de Educación, Cultura y Deporte [MECD]. (2016a). Datos y Cifras. Curso escolar 2016/2017. Madrid: Secretaría General Técnica.

Ministerio de Educación, Cultura y Deporte [MECD]. (2016b). PISA 2015. Programa para la Evaluación Internacional de los Alumnos. Madrid: Secretaría General Técnica.

Ministerio de Educación, Cultura y Deporte [MECD]. (2017). Datos y Cifras. Curso escolar 2017/2018. Madrid: Secretaría General Técnica.

Ministerio de Educación y Formación Profesional [MEFP]. (2018). Datos y Cifras. Curso Escolar 2018-2019. Madrid: Secretaría General Técnica.

Ministerio de Educación y Formación Profesional [MEFP]. (2019). Datos y Cifras. Curso Escolar 2019-2020. Madrid: Secretaría General Técnica.

MABOKELA, R. O. y MLAMBO, Y. A. (2017). Access and Equity and South African Higher Education: A Review of Policies after 20 Years of Democracy. Comparative Education Review, 61 (4), pp. 780-803.

MOLERO, A. (1985). La Institución Libre de Enseñanza: un proyecto español de renovación pedagógica. Madrid: Anaya.

MOLINA, A., AMATE, I. y GUARDINO, A. (2011). El gasto público en educación en los países de la OCDE: condicionantes económicos e institucionales. Extoikos, 4, pp. 37-45.

MONÉS, J. (1977). El pensament escolar i la renovaciò pedagògica a Catalunya (1833-1938). Barcelona: Edicions de La Magrana. 
MORENO, J.M. (1992). Los exámenes: Un estudio comparativo. Graduación secundaria y acceso a la universidad en seis países occidentales. Madrid: Fondo de Cultura Económica.

MORENO, D., SÁNCHEZ, J. y JIMÉNEZ, J. D. (2014). ¿En los centros privados se inflan las calificaciones de los estudiantes? Revista de Educación, 366, pp. 243-266.

MÜHLECK, K. (2013). Second-generation immigrants in higher education Sketching the European picture. EN: A. F. CAMILLERI, y K. MÜHLECK (Eds.), Evolving diversity II. Participation of students with an immigrant background in European higher education. Bruselas: MENON Network.

MUÑOZ-REPISO, M., MURILLO, F., ARRIMADAS, I., NAVARRO, R., DÍAZCANEJA, P., MARTÍN, ... E. FERNÁNDEZ (1997). El sistema de acceso a la Universidad en España: tres estudios para aclarar el debate. Madrid: CIDE

MUÑOZ VITORIA, F. (1993). El sistema de acceso a la universidad en España 1940-1990. Madrid: CIDE.

MURILLO, F.J., MARTÍNEZ-GARRIDO, C. y BELAVI, G. (2017). Segregación escolar por origen nacional en España. OBETS. Revista de Ciencias Sociales, 12 (2), pp. 395-423.

MURILLO, F.J. y MARTÍNEZ-GARRIDO, C. (2018). Magnitud de la segregación escolar por nivel socioeconómico en España y sus Comunidades Autónomas y comparación con los países de la Unión Europea. Revista de Sociología de la educación, 11 (1), pp. 37-58. 
NIEMI, H., TOOM, A. y KALLIONIEMI, A. (2016). Miracle of education. The principles and practices of teaching and learning in finnish schools. Rotterdam: Sense Publishers.

NOAH, H. (1986) The use and abuse of comparative education. En: P. G. ALTBACH y G. P. KELLY (Eds) New Approaches to Comparative Education (pp. 153166), Chicago: University of Chicago Press.

NOVOA, A. y YARIV-MASHAL, T. (2003). Comparative Research in Education: a mode of governance or a historical journey? Comparative Education, 39 (4), pp. $423-438$.

NUMMINEN, U. y KASURINEN, H. (2003). Evaluation of educational guidance and counselling in Finland. Helsinki: National Board of Education.

OECD (2010). PISA 2009 Results: What Makes a School Successful?Resources, Policies and Practices (Volume IV). PISA, OECD Publishing, Paris.

OECD (2011). PISA in Focus (5). OECD Publishing, Paris.

OECD (2012), Equity and Quality in Education: Supporting Disadvantaged Students and Schools, OECD Publishing.

OECD (2013). PISA 2012 Results: What Makes Schools Successful? Resources, Policies and Practices (Volume IV). OECD Publishing, Paris.

OECD (2015). Education Policy Outlook 2015: Making Reforms Happen. OECD Publishing.

OECD (2016). PISA 2015 Results (Volume II): Policies and Practices for Successful Schools, PISA. OECD Publishing, Paris. 
OECD (2017). Education at a Glance 2017: OECD Indicators. OECD Publishing, Paris.

OECD (2018), Education at a Glance 2018: OECD Indicators. OECD Publishing, Paris

OECD (2019), Education at a Glance 2019: OECD Indicators. OECD Publishing, Paris

OPPENHEIMER, A. (2010). ¡Basta de historias! La obsesión latinoamericana con el pasado y las 12 claves del futuro. Buenos Aires. Debate.

ORR, D., GWOSC, C., y NETZ, N. (2011). Social and Economic Conditions of Student Life in Europe: Synopsis of indicators - Final report - Eurostudent IV 2008-2011. Bielefeld: W. Bertelsmann Verlag.

PAVÍA, J. M. y VILA, E. (2010). ¿Equidad académica en el acceso a la universidad? ¿Enseñanza secundaria pública versus privada? Investigaciones de Economía de la Educación, 4, pp. 87-94.

PEDRÓ, F. (2012). Deconstruyendo los puentes de PISA: del análisis de resultados a la prescripción política. Revista Española de Educación Comparada, 19, pp. 139-172

PEDRÓ, F. y ROLO, J. M. (1998). Los sistemas educativos iberoamericanos en el contexto de la globalización. Interrogantes y oportunidades. Revista Iberoamericana de Educación, 17, pp. 257-289.

PÉREZ GÓMEZ, A. (2014). Evaluación externa de la LOMCE. Reválidas, exclusión y competitividad. Revista Interuniversitaria de Formación de Profesorado, 81 (28.3), pp. 59-71. 

educativos de España, Francia y Finlandia

PÉREZ GRANADOS, L. (2014). La selección de candidatos a la formación docente en Finlandia. La relevancia de las disposiciones personales hacia la actividad docente. Revista Electrónica de Investigación y Docencia (REID), 8, pp. 109132.

PÉREZ, F. y ALDÁS, J. (2019). Indicadores sintéticos de las universidades españolas. Fundación BBVA y el Instituto Valenciano de Investigaciones Económicas.

PHILLIPS, D. y OCHS, K. (2003). Processes of Policy Borrowing in Education: some explanatory and analytical devices. Comparative Education, 39 (4), pp. 451461.

PHILLIPS, D. y OCHS, K. (2004). Researching policy borrowing: some methodological challenges in comparative Education. British Educational Research Journal, 30 (6), pp.773-784.

PONGRATZ, L. (2013). La reforma educativa como estrategia gubernamental. Profesorado. Revista de Currículum y Formación del Profesorado, 17 (2), pp. 141-152.

PRATS, J. y RAVENTÓS, F. (2005): Los sistemas educativos europeos: ¿Crisis o transformación? Barcelona: Fundación La Caixa.

PROST, A. (1995). Les réformes de l'enseignement du second degré en France depuis 50 ans. Educació i història: Revista d'història de l'educació, 2, pp. 78-81.

PUELLES, M. (1992). Informe sobre las experiencias de descentralización educativa en el mundo occidental. Revista de Educación, 299, pp. 353-376. 
PUELLES, M. (2002). Descentralización de la educación en el Estado autonómico. EN: Centro de Estudios del Cambio Social (CECS). Informe España 2002. Una interpretación de su realidad social. Madrid: Fundación Encuentro

PUELLES, M. (2005). La influencia de la nueva derecha inglesa en la política educativa española. Historia de La Educación: Revista Interuniversitaria, 24, pp. 229-253.

PUELLES, M. (2010). Educación e ideología en la España contemporánea (5 edición). Madrid: Tecnos.

PUELLES, M. (2011). Francia y la construcción del sistema público de educación en España (1812-1857). En: J.M. HERNÁNDEZ DÍAZ (Ed.), Francia en la educación de la España contemporánea. (p. 47-61). Salamanca: Ediciones Universidad de Salamanca.

RAIVOLA, R. (1990). ¿Qué es comparación? Consideraciones metodológicas y filosóficas. EN: P.G. ALTBACH. Y G.P KELLY. (1990). Nuevos enfoques de educación comparada (pp. 297-311). Madrid: Mondadori.

RAVENTÓS, F. (1990). Metodología comparativa y pedagogía comparada. Barcelona: Boixareu Universitaria.

REDONDO, A. (2006). La igualdad de oportunidades en el ejercicio del derecho a la educación en libertad. EN: M.A. SANCHO, M. DE ESTEBAN, R. CABALLERO y J.M. RODRIGUEZ DE SANTIAGO. Escolarización del alumnado en el sistema educativo español: cuestiones jurídicas (pp. 69-86). Madrid: Fundación Europea Sociedad y Educación

RENZULLI, L.A. y EVANS, L. (2005). School choice, charter schools, and white flight. Social Problems, 52 (3), pp. 398-418. 
REVESADO, D. (2018). El proceso de Bolonia y la admisión a la universidad. La realidad del sistema universitario español en perspectiva comparada. Revista Española de Educación Comparada, 32, pp. 169-180.

RODRÍGUEZ ESPINAR, S. (2006). Función tutorial y calidad de la educación. EN: M. ÁLVAREZ GONZÁLEZ (Ed.). La acción tutorial: Su concepción y su práctica (pp. 9-25). Madrid: Ministerio de Educación y Ciencia.

RODRÍGUEZ, S., FITA, E. Y TORRADO, M. (2004). El rendimiento académico en la transición secundaria universidad. Revista de Educación, 334, pp. 391-414.

RODRIGUEZ MORENO, L. y GALLEGO, S. (1999). El Proyecto profesional, herramienta de intervención en la función tutorial universitaria. REOP 10 (17), pp. 179-192.

ROGERO-GARCÍA, J. y ANDRÉS-CANDELAS, M. (2014). Gasto público y de las familias en educación en España: diferencias entre centros públicos y concertados. Revista Española de Investigaciones Sociológicas, 147, pp. 121132.

ROIKO-JOKELA, K. (2012). Una historia política de Finlandia. ISTOR, 48, pp. 10-37.

ROMERO, E. y HERNÁNDEZ, M. (2019). Análisis de las causas endógenas y exógenas del abandono escolar temprano: una investigación cualitativa. Educación XX1, 22 (1), pp. 263-293.

ROUTTI, J. y YLÄ-ANTTILA, P. (2006). Finland as a Knowledge Economy. Elements of Success and Lessons Learned. Washington, DC: World Bank.

RUBIO, F. y DARANAS, M. (1997). Constituciones de los Estados de la Unión Europea. Barcelona: Ariel. 
RUST, V. D. (1991). Postmodernism and its comparative education implications. Comparative Education Review, 35 (4), pp. 610-626.

RUST, V. D., SOUMARE, A., PESCADOR, O. y SHIBUYA, M. (1999). Research Strategies in Comparative Education. Comparative Education Review, 43 (1), pp. 86-109.

RUZZI, B. R. (2005). Finland Education Report. National Center on Education and the Economy, New Commission on the Skills of the American Workforce.

SAHLBERG, P. (2006). Subiendo el listón: ¿Cómo responde Finlandia al doble reto de la educación secundaria? Profesorado. Revista de currículum y formación del profesorado, 10 (1), pp. 1-30.

SAHLBERG, P. (2010). Educational change in Finland. EN: A HARGREAVES, M FULLAN, A LIEBERMAN y D. HOPKINGS (Eds.). International handbook of educational change (pp. 323-348). New York: Kluwer.

SAHLBERG, P. (2011a). Finnish lessons. What can the world learn from educational change in Finland? New York; London: Teachers College Press.

SAHLBERG, P. (2011b). Paradoxes of educational improvement: The Finnish experience. Scottish Educational Review, 43 (1), pp. 3-23.

SALMERÓN, H., ORTIZ, L., y RODRÍGUEZ, S. (2005). Evaluación de necesidades de orientación universitaria del alumnado marroquí que pretende acceder a universidades españolas. Revista Española de Orientación y Psicopedagogía 16 (2), pp. 225-256.

SÁNCHEZ, M. F. (2001). La orientación universitaria y las circunstancias de elección de los estudios. Revista de Investigación Educativa, 19 (1), pp. 39-61. 
SANCHIZ, M.L. (2009). Modelos de orientación e intervención psicopedagógica. Castellón de la Plana: Publicaciones de la Universitat Jaume

SANTANA, L.E. y ÁLVAREZ, P. R. (2002). La orientación académica en la universidad. EN: V. ÁLVAREZ y A. LÁZARO (Coord.). Calidad de las universidades y orientación universitaria (pp. 195-214). Archidona (Málaga): Aljibe, D. L.

SANTANA, L.E., FELICIANO, L. y JIMÉNEZ, A. B. (2012). Toma de decisiones y género en Bachillerato. Revista de Educación, 359, pp. 357-387.

SANTANA, L.E., FELICIANO, L. y CRUZ, A. (2010). El Programa de Orientación Educativa y Sociolaboral: un instrumento para facilitar la toma de decisiones en Educación Secundaria. Revista Educación, 351, pp. 73-105.

SAPORITO, S. (2003). Private choices, public consequences: Magnet school choice and segregation by race and poverty. Social Problems, 50 (2), pp. 181-203.

SAURA, G. y LUENGO, J. (2015). Política global más allá de lo nacional. Reforma educativa (LOMCE) y el régimen de estandarización. Revista Bordón, 67 (1), pp. 135-148.

SCHLEICHER, A. (2018). Primera clase. Cómo construir una escuela de calidad para el siglo XXI. Madrid: Fundación Santillana.

SCHLOSSBERG, N. K. (1984). Counseling adults in transition: Linking practice with thery. Nueva York: Springer Publishing Company.

SCHLOSSBERG, N. K. (1989). Overwhelmed: coping with life's ups and downs. Lexington: Lexington Books. 
SCHULTZ, T.W. (1960). Capital Formation by Education. Journal Political Economy, 68, pp. 571-583.

SCHULTZ, T.W. (1963). The Economic Value of Education. New York: Columbia University Press.

SEBASTIÁN, V. (2015). Una reflexión sobre las transiciones educativas. De primaria a secundaria ¿traspaso o acompañamiento? Edetania, 48, pp. 159-183.

SIMOLA, H. (2005). The Finnish miracle of PISA: historical and sociological remarks on teaching and teacher education. Comparative education, 41 (4), pp. 455-470.

SIMOLA, H. (2013). El milagro finlandés de PISA: observaciones históricas y sociológicas sobre la enseñanza y la formación del profesorado. Profesorado. Revista de currículum y formación del profesorado, 17 (2), pp. 153-169.

SIMOLA, H. y RINNE, R. (2013). Política educativa y contingencia: creencias, estatus y confianza detrás del milagro finlandés de PISA. Profesorado. Revista de currículum y formación de profesorado, 17 (2), pp. 171- 192.

SIRIN, S. (2005). Socioeconomic Status and Academic Achievement: A MetaAnalytic Review. Review of Educational Research, 75, pp. 417-453.

SMYTH, E. (2009). Buying Your Way into College? Private Tuition and the Transition to Higher Education in Ireland. Oxford Review of Education 35 (1), pp. 1-22.

SOBE, N.W. (2018). Problematizing Comparison in a Post-Exploration Age: Big Data, Educational Knowledge, and the Art of Criss-Crossing. Comparative Education Review, 62 (3), pp. 325-343. 
STEINER, G. (2010). The politics and economics of comparison. Comparative Education Review, 54 (3), pp. 323-342.

STONE, P. (2013). Access to Higher Education by the Luck of the Draw. Comparative Education Review, 61 (4), pp. 577-599.

TRÖHLER, D. (2009). Armonizar el globo educativo. Política mundial, rasgos culturales y los desafíos investigación educativa. Profesorado. Revista de Currículum y Formación del Profesorado, 13 (2), pp. 1-14

TIANA, A. (2007). A la búsqueda del consenso en educación: la experiencia de la LOE. Revista de Educación, 344, pp. 83-100.

TORRADO, M., RODRÍGUEZ, M. L., FIGUERA, P., FREIXA, M., DORIO, I. Y TRIADÓ, X. (2010). La persistencia y el abandono en el primer año de universidad en ciencias sociales factores explicativos asociados al contexto institucional. Trabajo presentado en el VI Congreso Internacional Docencia Universitaria e Innovación. Barcelona, Universidad de Barcelona.

TORTOSA, M.T., GRAU, S., PELlíN, N., ROIG, R., PERTEGAL, M.L., SABROSO, A., RAMÍREZ, F.J. Y LÓPEZ, A. (2015). La cuarta transición: estado de la cuestión en las dos orillas. EN: XIII Jornadas de Redes de Investigación en Docencia Universitaria: Nuevas estrategias organizativas y metodológicas en la formación universitaria para responder a la necesidad de adaptación y cambio, Alicante, España.

UNESCO. (2005). Hacia las sociedades del conocimiento. Paris: Ediciones Unesco.

UNESCO. (2013). Clasificación Internacional Normalizada de la Educación. Montreal: Instituto de Estadística de la UNESCO. 
URTEAGA, E. (2010a). El debate en torno a las encuestas PISA en Francia. Revista Teoría de la Educación: Educación y Cultura en la Sociedad de la Información, 11 (1), pp. 389-405.

URTEAGA, E. (2010b). Los resultados del estudio PISA en Francia. Revista Complutense de Educación, 21 (2), pp. 231-244.

VALLE, J. M. (2001). Desde la secundaria a la universidad: tentativa de modelos para un problema poliédrico. Revista Española de Educación Comparada, 7, pp. 191-227.

VALLE, J. M. (2008). Hacia el pasaporte europeo universitario: Armonización de los sistemas de acceso a la universidad. EN: J. L. GARCÍA GARRIDO (Ed.). Formar ciudadanos europeos (pp. 99-156). Madrid: Academia Europea de Ciencias y Artes.

VALLE, J. M. y MANSO, J. (2013). Competencias clave como tendencia de la política educativa supranacional de la Unión Europea. Revista de Educación, número extraordinario, pp. 12-33.

VALTONEN, H. y RAUTIAINEN, M. (2012). La educación finlandesa desde 1850 hasta el presente. ISTOR, 48, pp. 129-160.

VAN DER WENDE, M. (2003). Globalisation and Access to Higher Education. Journal of Studies in Internacional Education, 7 (2), pp. 193-206.

VEGA, L. (1995). Moderantismo y educación en España: estudios en torno a la Ley Moyano. Zamora: Instituto de Estudios Zamoranos. 
VEGA, L. (2005). Los sistemas educativos europeos y la formación de profesores. Los casos de Francia, Reino Unido, España y Finlandia. Revista de Educación, 336, pp. 169-187.

VEGA, L. (2011a). Construcción y desarrollo del modelo inglés de "Escuela Comprensiva" en Europa y su influencia en el sistema educativo español. EN J. M HERNÁNDEZ DÍAZ (Coord..), Influencias inglesas en la educación española e iberoamericana (1810-2010) (pp. 89-102). Salamanca: Hergar/Antema

VEGA, L. (2011b). La educación comparada e internacional. Procesos históricos y dinámicas globales. Barcelona: Octaedro.

VEGA, L. (2013). Los cuasi-estados de la educación España en tiempos de crisis y cambios. Las perspectivas históricas y neoliberal de la escuela. EN: M. L. LÁZARO (Ed.). Lecturas de educación comparada e internacional (pp. 5573). Valencia: Universitat de Valencia, Departamento de Educación Comparada e Historia de la Educación, D. L.

VEGA, L. (2016). Los cuasi-estados de la educación en España y la eficacia del sistema escolar, según PISA: reduciendo la equidad y aumentando las diferencias. EN C. DA CUNHA; J. VIEIRA DE SOUSA y M. ABÁDIA DA SILVA (Orgs.), Internacionalizaçáo da Educaçáo: Discursos, Práticas e Reflexos sobre as Políticas Educativas (pp. 197-220). Belo Horizonte: Fino Traço Editora.

VEGA, L. (2017). La globalización en los procesos y programas de formación de maestros en España. Qué podemos aprender y qué debemos mejorar. Hacia una reconsideración del modelo de formación. EN M.V. PIRES; C. MESQUITA; R.P. LOPES; G. SANTOS; M. CARDOSO; J.S. de P.C. SOUSA Y C. 
TEIXEIRA (Eds.), Livro de atas do II Encontro Internacional de Formaçao na Docencia (INCTE) (pp. 27-38). Bragança: Instituto Politécnico de Bragança.

VEGA, L. y ESPEJO, L.B. (2011). Un modelo de análisis de la gobernanza en instituciones públicas de formación de profesores. EN: L. VEGA (Ed.), Gobernanza y políticas de formación inicial de profesores en la Europa Mediterránea (pp. 247-279). Valencia. Tirant Lo Blanch.

VEGA, L. y HERNÁNDEZ, J. C. (2015). Spain and France: Moving from democratization towards elitism in access to higher education. EN: V. STEAD (Ed.), International Perspective on Higher Education Admission Policy. A Reader (pp. 114-127). New York: Peter Lang.

VEGA, L.; HERNÁNDEZ, J. C., y GARCÍA, E. (2016). PISA as a political tool in Spain: Assessment Instrument, Academic Discourse and Political Reform. European Education. Issues and Studies, 48 (2), pp. 89-103.

VEXliARD, A. (1970). Pedagogía comparada. Métodos y Problemas. Buenos Aires: Kapelusz.

VILLAR, A. y HERNÀNDEZ, F. J. (2014). Educación superior, gasto familiar y crisis económica. ¿Existe una estrategia de clase en tiempos de crisis? EN XVII Conferencia de Sociología de la Educació, Bilbao, España.

VILLAR, A. y HERNÁNDEZ, F. J. (2015). ¿Las familias con mayor poder adquisitivo resultan beneficiadas de la inversión pública educativa? ARXIUS, 32, pp. 161-172.

VINCENT-LANCRIN, S. (2008). L'inversion des inégalités entre les sexes dans l'enseignement supérieur: une tendance qui a de l'avenir. L'enseignement supérieur à l'horizon 2030, 1, pp. 291-326. 

educativos de España, Francia y Finlandia

VIÑAO, A. (2002). Sistemas educativos, culturas escolares y reformas. Madrid: Morata.

VIÑAO, A. (2008). La educación en la II República: de la manipulación y el olvido a la recuperación y la memoria. EN: JORGANES, J. (Coord.). La escuela de la II República (pp. 47-72). Sevilla: Cajasol Fundación.

VIÑAO, A. (2016). Ley Orgánica de Mejora de la Calidad Educativa (LOMCE) de 2013: ¿Una reforma más? Historia y Memoria de la Educación, 3, pp. 137-170.

WATTS, A. y FRETWELL, D. (2004). Public Policies for Career Developmen. Washington: World Bank.

WEILL, G. (2006). Historia de la idea laica en Francia en el siglo XIX. SevillaZamora: Comunicación Social.

WOLHUTER, C. (2008). Review of the Review: Constructing the Identity of Comparative Education. Research in Comparative and International Education, 3(4), pp. 323-344.

YANG, L., BORROWMAN, L., TAN, M. Y. y NEW, J. Y (2019). Expectations in Transition: Students' and Teachers' Expectations of University in International Branch Campus. Journal of Studies in Internacional Education. 



\section{WEBGRAFIA}





\section{WEBGRAFIA}

ALMEDA, P. y TATARET, M. (2016). Estudio del gasto cultural de Europa y de los estados miembros durante la crisis 2007-2014. Barcelona: Fundació Catalunya Europa. Recuperado el 15 de junio de 2018 de http://www.catalunyaeuropa.net/img/pdf/ESTUDIO DEL GASTO CULT URAL UE 20160921.pdf

CONSEJO DE EUROPA. (2011). Compendium. Cultural policies and trends in Europe. Recuperado el 15 de junio de 2018, de http://www.culturalpolicies.net/web/statistics-funding.php

CONSULTORA ERNEST and YOUNG. (2014). Creating Growth. Measuring cultural and creative markets in the EU. Recuperado el 15 de junio de 2018, de http://www.ey.com/Publication/vwLUAssets/Measuring_cultural_and_creat ive_markets_in_the_EU/\$FILE/Creating-Growth.pdf 
EUROPEAN COMMISSION (2008b). Orientación académico-profesional en la educación obligatoria a tiempo completo en Europa. Recuperado el 2 de noviembre de 2018, de http://www.mecd.gob.es/dctm/biblioteca/recelec/11997795.pdf?documentId $=0901 \mathrm{e} 72 \mathrm{~b} 8188 \mathrm{c} 1 \mathrm{f} 6$

MAILLET, D. (2007). Aspectos básicos para un estudio comparado de sistemas de educación superior Francia. Recuperado el 25 de octubre de 2018, de http://www.oei.es/salactsi/Francia.pdf

Pasi Sahlberg on Finland's Recent PISA Results. Entrevista publicada en el diario digital Education Week, el pasado 14 de febrero de 2014. Recuperado el 1 de $\begin{array}{llll}\text { octubre de } & 2018 \text { de }\end{array}$ http://blogs.edweek.org/edweek/top_performers/2014/02/pasi_sahlberg_on_ finlands recent pisa results.html

PIN, J.R. y GARCÍA-LOMBARDÍA, P. (2018). Reflexiones sobre la Formación Profesional de Grado Medio y Superior en España. Madrid: Fundación ATRESMEDIA y Fundación MAPFRE. Recuperado el 2 de abril de 2019, de https://www.fundacionmapfre.org/documentacion/publico/i18n/catalogo_im agenes/grupo.cmd?path=1096784

VINCENT-GÉRARD A. Y CHOMET N. (2017). Les Français et la lectura. IPSOS Connect - CNL. Recuperado el 13 de junio de 2018, de http://www.centrenationaldulivre.fr/fr/ressources/etudes_rapports_et_chiffre s/les_francais_et_la_lecture/ 


\section{REPERTORI@ NORMATIVO}





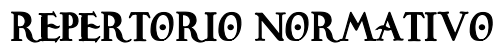

Basic Education Act 628/1998

Declaración de La Sorbona. Declaración conjunta para la armonización del diseño del sistema de educación Superior Europeo, a cargo de los cuatro ministros representantes de Francia, Alemania, Italia y el Reino Unido. La Sorbona, Paris, 25 de mayo de 1998.

El Espacio Europeo de Educación Superior. Declaración conjunta de los ministros europeos de educación, reunidos en Bolonia el 19 de junio de 1999

Ley 14/ 1970, de 4 de agosto, general de Educación y Financiamiento de la Reforma educativa, Boletín Oficial del Estado, 6 de agosto de 1970, Núm. 187, p. 12525-12546.

Ley Orgánica 5/1980, de 19 de junio, por la que se regula el Estatuto de Centros Escolares, Boletín Oficial del Estado, 17 de junio de 1980, Núm. 154, p. 14633-14636. 
Ley Orgánica 8/1985, de 3 de julio, reguladora del Derecho a la Educación, Boletín Oficial del Estado, 4 de julio de 1985, Núm. 159, p. 21015-21022.

Ley Orgánica 1/1990, de 3 de octubre, de Ordenación general del Sistema Educativo. Boletín Oficial del Estado, 4 de octubre de 1990, Núm. 238, p. 28927-28942.

Ley Orgánica 10/2002, de 23 de diciembre, de Calidad de la Educación. Boletín Oficial del Estado, 24 de diciembre de 2002, Núm. 307, p. 45188-45220.

Ley Orgánica 2/2006, de 3 de mayo, de Educación. Boletín Oficial del Estado, de 4 de mayo de 2006, Núm. 106, p. 17158-17207.

Ley Orgánica 8/2013, de 9 de diciembre, para la Mejora de la Calidad Educativa. Boletín Oficial del Estado, de 10 de diciembre de 2013, Núm. 295, p. 97858 97921.

Loi dite Guizot sur l'instruction primaire. (1833). Loi du 28 juin 1833, dite Guizot sur l'instruction primaire (Publiée dans le Journal Officiel de la République Française du 8 juin 1833).

Loi qui établit la gratuité absolue de l'enseignement primaire dans les écoles publiques. (1881). Loi du 16 juin 1881, qui établit la gratuité absolue de l'enseignement primaire dans les écoles publiques. (Publiée dans le Journal Officiel de la République Française du 17 juin 1881).

Loi qui rend l'Enseignement primaire obligatoire. (1882). Loi n 11696 du 28 mars 1882, qui rend l'Enseignement primaire obligatoire. (Publiée dans le Journal Officiel de la République Française du 29 mars 1882). 

educativos de España, Francia y Finlandia

Loi dite Edgar Faure d'orientation de l'enseignement superieur. (1968). Loi $\mathrm{n}^{\circ} 68$ 978 du 12 novembre 1968, dite Edgar Faure d'orientation de l'enseignement superieur. (Publiée dans le Journal Officiel de la République Française du 13 novembre 1968).

Loi relative à l'éducation (Loi Haby). (1975). Loi no 75-620 du 11 juillet 1975, relative à l'éducation (Loi Haby). (Publiée dans le Journal Officiel de la République Française du 12 juillet 1975).

Loi relative à la répartition de compétences entre les communes, les départements, les régions et l'Etat. (1983). Loi $\mathrm{n}^{\circ}$ 83-8 du 7 janvier 1983, relative à la répartition de compétences entre les communes, les départements, les régions et l'Etat. (Publiée dans le Journal Officiel de la République Française du 9 janvier 1983).

Loi dite Savary sur l'enseignement superieur. (1984). Loi n ${ }^{\circ} 84-52$ du 26 janvier 1984, dite Savary sur l'enseignement superieur. (Publiée dans le Journal Officiel de la République Française du 27 janvier 1984).

Loi d'Orientation et de programme pour l'avenir de l'école. (2005). Loi n 2005-380 du 23 avril 2005, d'Orientation et de programme pour l'avenir de l'école. (Publiée dans le Journal Officiel de la République Française du 24 avril 2005)

Loi relative aux libertés et responsabilités des universités (2007). Loi n 2007-1199 du 10 août 2007, relative aux libertés et responsabilités des universités. (Publiée dans le Journal Officiel de la République Française du 10 août 2007.

Loi d'orientation et de programmation pour la refondation de l'école de la République (2013). Loi n ${ }^{\circ} 2013-595$ du 8 juillet 2013, d'orientation et de programmation 
pour la refondation de l'école de la République. (Publiée dans le Journal Officiel de la République Française du 8 juillet 2013).

Loi relative à l'enseignement supérieur et à la recherche (2013). Loi n 2013-660 du 22 juillet 2013 relative à l'enseignement supérieur et à la recherche. Publiée dans le Journal Officiel de la République Française du 22 juillet 2013).

ORDEN EDU/18/2019, de 17 de enero, por la que se crea la comisión organizadora de la evaluación de bachillerato para el acceso a la Universidad de Castilla y León, y se establecen determinados aspectos de la evaluación, para el curso académico 2018-2019. Boletín Oficial de Castilla y León, de 25 de enero de 2019, Núm. 17, pp. 2856-2863.

Proyecto de Resolución del Consejo y de los Representantes de los Gobiernos de los Estados miembros reunidos en el seno del Consejo, de 18 de mayo de 2004, sobre el fortalecimiento de las políticas, sistemas y prácticas en materia de orientación permanente en Europa.

Proyecto de Resolución del Consejo y de los Representantes de los Gobiernos de los Estados miembros, reunidos en Consejo, de 21 de noviembre de 2008, titulada «Incluir mejor la orientación permanente en las estrategias permanentes de educación y formación permanente».

Real Decreto 1635/2009, de 30 de octubre, por el que se regulan la admisión de los alumnos en centros públicos y privados concertados, los requisitos que han de cumplir los centros que impartan el primer ciclo de la educación infantil y la atención al alumnado con necesidad específica de apoyo educativo en el ámbito de gestión del Ministerio de Educación. Boletín Oficial del Estado, de 3 de noviembre de 2009, Núm. 265, pp. 91697-91702. 
ANEXOS 



\section{ANEXO 1. DECLARACIÓN DE LA SORBONA}

\section{Declaración conjunta para la armonización del diseño del Sistema de Educación Superior Europeo (a cargo de los cuatros ministros representantes de Francia, Alemania, Italia y el Reino Unido).}

La Sorbona, París, 25 de mayo de 1998

Recientemente, el proceso europeo ha dado pasos de extremada importancia. A pesar de la relevancia que ello tiene, no deberíamos olvidar que al hablar de Europa no sólo deberíamos referirnos al euro, los bancos y la economía, sino que también debemos pensar en una Europa de conocimientos. Es deber nuestro el consolidar y desarrollar las dimensiones intelectuales, culturales, sociales y técnicas de nuestro continente. Éstas han sido modeladas, en gran medida, por las universidades, quienes todavía desempeñan un papel imprescindible en su desarrollo.

Las universidades se originaron en Europa hace unos tres cuartos de milenio. Nuestros cuatro países poseen algunas de las más antiguas, las cuales celebran actualmente importantes aniversarios, como es hoy el caso de la Universidad de París. En aquellos tiempos, los estudiantes y los académicos solían circular libremente y difundían con rapidez sus conocimientos por todo el continente. En la actualidad, gran número de nuestros estudiantes todavía se gradúa sin haber tenido la oportunidad de realizar un periodo de estudios al otro lado de las fronteras nacionales.

Se aproxima un tiempo de cambios para las condiciones educativas y laborales, una diversificación del curso de las carreras profesionales, en el que la educación y la formación continua devienen una obligación evidente. Debemos a nuestros estudiantes y a la sociedad en su conjunto un sistema de educación superior que les 
ofrezca las mejores oportunidades para buscar y encontrar su propio ámbito de excelencia.

Un área europea abierta a la educación superior trae consigo una gran riqueza de proyectos positivos, siempre respetando nuestra diversidad, pero requiere, por otra parte, el esfuerzo continuo que permita acabar con las fronteras y desarrollar un marco de enseñanza y aprendizaje. Se espera que, de ahora en adelante, éste favorezca una movilidad y una cooperación más estrechas.

El reconocimiento internacional y el atractivo potencial de nuestros sistemas residen en las facilidades de comprensión que éstos ofrecen en lo concerniente tanto a sus aspectos internos como externos. Parece estar emergiendo un sistema compuesto de dos ciclos, universitario y de posgrado, que servirá de piedra angular a la hora de establecer las comparaciones y equivalencias a escala internacional.

Gran parte de la originalidad y flexibilidad de este sistema se conseguirá mediante el sistema de créditos, como en el sistema ECTS, (Sistema Europeo de Transferencia de Créditos) y semestres. Esto permitirá la convalidación de los créditos obtenidos para aquellos que elijan una educación inicial o continua en alguna de las universidades europeas y, asimismo, tengan intención de obtener una titulación. De hecho, los estudiantes deberían ser capaces de acceder al mundo académico en cualquier momento de su vida profesional y desde diversos campos.

Se debería facilitar a los universitarios el acceso a gran variedad de programas, a oportunidades para llevar a cabo estudios multidisciplinares, al perfeccionamiento de idiomas y a la habilidad para utilizar las nuevas tecnologías informativas.

Es importante el reconocimiento internacional de la titulación de primer ciclo como un nivel de cualificación apropiado para el éxito de esta iniciativa, en la que deseamos ofrecer una visión clara de todos nuestros esquemas de educación superior. 
En el ciclo de posgrado cabría la elección entre una titulación de máster de corta duración y una titulación de doctorado más extensa, con la posibilidad de cambiar entre uno y otro. En ambas titulaciones de posgrado, se pondría el énfasis apropiado tanto en la investigación como en el trabajo autónomo.

Tanto en el nivel universitario como en el de posgrado, se animaría a los estudiantes a pasar un semestre, como mínimo, en universidades ubicadas fuera de sus países. A su vez, habría más personal docente y dedicado a la investigación realizando sus actividades profesionales en otros países europeos diferentes a los de origen. El apoyo creciente a la Unión Europea, en lo que a la movilidad de estudiantes y profesores concierne, debería aprovecharse al máximo.

Muchos países, no sólo europeos, han tomado plena conciencia de la necesidad de fomentar dicha evolución. Las conferencias de rectores europeos, presidentes universitarios, y grupos de expertos y académicos de nuestros respectivos países se han embarcado en la tarea de análisis de estos objetivos.

El año pasado, en Lisboa, se acordó una convención que reconoce las cualificaciones obtenidas en educación superior en Europa dentro del campo académico. La convención estableció una serie de requisitos básicos y reconoció a cada país el derecho a tomar parte en un proyecto todavía más constructivo. Apoyándonos en estas conclusiones, podemos llevar a cabo una mejora y llegar más lejos. Actualmente ya existen más puntos en común para el reconocimiento mutuo de las titulaciones de educación superior en cuanto a propósitos profesionales a través de las respectivas directrices de la Unión Europea.

Nuestros gobiernos, sin embargo, todavía tienen que desempeñar un papel significativo mediante la promoción de medios que permitan la convalidación de los conocimientos adquiridos y el mejor reconocimiento de las respectivas titulaciones. Esperamos que todo esto promueva más acuerdos interuniversitarios. La 
armonización progresiva del marco general de nuestras titulaciones y ciclos puede lograrse a través de la consolidación de la experiencia ya existente, las titulaciones conjuntas, las iniciativas piloto y los diálogos en los que nos involucremos todos.

Por la presente, ofrecemos nuestro compromiso para la promoción de un marco común de referencia, dedicado a mejorar el reconocimiento externo y facilitar tanto la movilidad estudiantil como las oportunidades de empleo. El aniversario de la Universidad de París, hoy aquí en La Sorbona, nos ofrece una oportunidad solemne de participar en una iniciativa de creación de una zona Europea dedicada a la Educación Superior, donde las identidades nacionales y los intereses comunes puedan relacionarse y reforzarse para el beneficio de Europa, de sus estudiantes y en general de sus ciudadanos. Nos dirigimos a otros estados miembros de la Unión Europea y a otros países europeos para que se unan a nosotros en esta iniciativa, así como a todas las universidades europeas para que se consolide la presencia de Europa en el mundo a través de la educación continua y actualizada que se ofrece a sus ciudadanos. 


\section{ANEXO 2. ESPACIO EUROPEO DE ENSEÑANZA SUPERIOR}

Declaración conjunta de los ministros europeos de enseñanza

Bolonia, 19 de junio de 1999

El proceso europeo, gracias a los logros extraordinarios de los últimos años, se ha convertido en una realidad cada vez más concreta y determinante en la vida de la Unión y de sus ciudadanos. Las perspectivas de ampliación y de intensificación de las relaciones con otros países europeos proporcionan a esa realidad unas dimensiones aún más amplias. Al mismo tiempo, estamos viendo una creciente concienciación, en muchas partes del mundo político-académico y en la opinión pública, de la necesidad de conferir a la construcción europea una articulación diferenciada y completa, reforzando sobre todo sus dimensiones intelectuales, culturales, sociales, científicas y tecnológicas.

La Europa de los conocimientos está ampliamente reconocida como factor insustituible para el crecimiento social y humano, y como elemento indispensable para consolidar y enriquecer la ciudadanía europea, confiriendo a sus ciudadanos las competencias necesarias para afrontar los retos del nuevo milenio, junto con la concienciación de los valores compartidos y de la pertenencia a un espacio social y cultural común.

Basándose en estos planteamientos, la declaración de La Sorbona del 25 de mayo de 1998 subrayó el papel central de las universidades en el desarrollo de la dimensión cultural europea. Asimismo, hizo hincapié en la construcción del espacio europeo de enseñanza superior como instrumento clave en la promoción de la movilidad de los ciudadanos, su ocupabilidad, y el desarrollo global del continente.

Varios países europeos han aceptado la invitación de comprometerse a conseguir los objetivos expuestos en la declaración, tanto los que la firmaron como los que 
expresaron su acuerdo. La dirección tomada por varias reformas de la enseñanza superior, lanzadas mientras tanto en Europa, es una demostración palpable del compromiso de muchos gobiernos de operar en este sentido.

Por su parte, las instrucciones europeas de enseñanza superior han aceptado el reto y han asumido un papel principal en la construcción del espacio europeo de enseñanza superior, dentro del marco de los principios fundamentales expresados en la Magna Charta Universitatum de Bolonia de 1988. Este hecho es de vital importancia ya que la independencia y autonomía de las universidades garantizan la constante adecuación del sistema de enseñanza superior y de investigación a las necesidades y exigencias de la sociedad y del conocimiento científico.

El rumbo ya está establecido con firmes propósitos. Sin embargo, la consecución de una mayor compatibilidad y comparabilidad de los sistemas de enseñanza superior requiere un impulso constante. Deberíamos apoyarla a través de medidas concretas para realizar avances tangibles. El convenio del 18 de junio, en el cual participaron expertos y estudiosos de todos nuestros países, ha proporcionado indicaciones utilísimas en cuanto a la iniciativa a emprender.

Deberíamos analizar sobre todo el objetivo de incrementar la competitividad internacional del sistema europeo de enseñanza superior. La vitalidad y eficacia de cualquier civilización pueden medirse a través de la atracción que ejerce su cultura sobre otros países. Debemos asegurarnos de que el sistema europeo de enseñanza superior adquiera un grado de atracción que corresponda a nuestras extraordinarias tradiciones culturales y científicas.

Además de consolidar nuestro apoyo a los principios generales expuestos en la declaración de La Sorbona, nos comprometemos a coordinar nuestras políticas para alcanzar a corto plazo, y en cualquier caso antes del final de la primera década del tercer milenio, los siguientes objetivos, los cuales consideramos de máxima 
relevancia para el establecimiento del espacio europeo de enseñanza superior y para la promoción mundial del sistema europeo de enseñanza superior:

- La adopción de un sistema de títulos de sencilla legibilidad y comparabilidad, a través de la introducción del Diploma Supplement, con tal de favorecer la employability (ocupabilidad) de los ciudadanos europeos y la competitividad internacional del sistema europeo de enseñanza superior.

- La adopción de un sistema basado esencialmente en dos ciclos principales, respectivamente de primer y segundo nivel. El acceso al segundo ciclo precisa de la conclusión satisfactoria de los estudios de primer ciclo, que duran un mínimo de tres años. El título otorgado al final del primer ciclo será utilizable como cualificación en el mercado laboral europeo. El segundo ciclo debe conducir a un título de máster o doctorado como en muchos países europeos.

- El establecimiento de un sistema de créditos -como el modelo ECTS- como medio de promover la movilidad de estudiantes. Los créditos también pueden adquirirse en otros contextos, como la formación permanente, siempre que estén reconocidos por las universidades receptoras en cuestión.

- La promoción de la movilidad; mediante la eliminación de los obstáculos para el pleno ejercicio de la libre circulación con especial atención a lo siguiente:

- Para los estudiantes: el acceso a oportunidades de estudio y formación, y a servicios relacionados.

- Para profesores, investigadores y personal técnico-administrativo: el reconocimiento y valorización de períodos de investigación en contextos europeos relacionados con la docencia y la formación, sin perjuicio para los derechos adquiridos.

- La promoción de una colaboración europea en la garantía de calidad con vistas al diseño de criterios y metodologías comparables. 
- La promoción de las dimensiones europeas necesarias en la enseñanza superior, sobre todo en lo que respecta al desarrollo curricular, colaboración interinstitucional, planes de movilidad y programas integrados de estudio, formación e investigación.

Nosotros nos comprometemos a alcanzar estos objetivos -dentro del marco de nuestras competencias institucionales y con pleno respeto a la diversidad de culturas, lenguas, sistemas nacionales de enseñanza y autonomía universitaria- para consolidar el espacio europeo de enseñanza superior. Con este fin, perseguiremos las vías de colaboración intergubernamental y la de organismos europeos no gubernamentales con competencias en asuntos de enseñanza superior. Esperamos que las universidades contesten pronto y de manera positiva, y que contribuyan activamente al éxito de nuestra iniciativa.

Convencidos de que el establecimiento del espacio europeo de enseñanza superior requiere el apoyo, vigilancia y adaptación constante a nuestras necesidades en plena evolución, decidimos volver a reunirnos dentro de dos años para evaluar los avances conseguidos y nuevas medidas a tomar. 


\section{ANEXO 3. PROYECTO DE RESOLUCIÓN DEL CONSEJO Y DE LOS REPRESENTANTES DE LOS GOBIERNOS DE LOS ESTADOS MIEMBROS REUNIDOS EN EL SENO DEL CONSEJO SOBRE EL FORTALECIMIENTO DE LAS POLÍTICAS, SISTEMAS Y PRÁCTICAS EN MATERIA DE ORIENTACIÓN PERMANENTE EN EUROPA.}

El consejo de la Unión Europea y los representantes de los gobiernos de los estados miembros reunidos en el seno del consejo,

\section{CONSCIENTES DE QUE:}

1. En el contexto del aprendizaje permanente, la orientación hace referencia a una gama de actividades que capacita a los ciudadanos de cualquier edad y en cualquier momento de sus vidas a determinar sus capacidades e intereses, a adoptar decisiones educativas, de formación y de empleo, y a gestionar su aprendizaje y la trayectoria individual de sus vidas en cuanto al aprendizaje, el trabajo y otras cuestiones en las que se adquieren o se utilizan competencias.

2. La facilitación de orientación en el marco de los sistemas de educación y formación, especialmente en los centros escolares o a nivel escolar, tienen una función esencial que desempeñar para garantizar que las decisiones individuales relacionadas con la educación y la carrera dispongan de una base sólida, y para ayudarles a desarrollar una autogestión eficaz de sus trayectorias de aprendizaje y de carrera. Es también un instrumento clave para permitir a las instituciones de educación y formación mejorar la calidad y oferta de la enseñanza.

3. La orientación permanente contribuye al logro de los objetivos de desarrollo económico, eficacia del mercado de trabajo y movilidad geográfica y profesional de la Unión Europea, mejorando la eficacia de la inversión en educación y formación 
profesional, de la formación permanente y del desarrollo del capital humano y la mano de obra.

4. Una orientación eficaz desempeña una misión fundamental para fomentar la inclusión social, la equidad social, la igualdad entre los sexos y una ciudadanía activa fomentando y apoyando la participación de las personas en la educación y formación y su elección de carreras realistas y llenas de sentido.

5. En los Estados miembros de la Unión Europea la orientación se facilita mediante una gran variedad de estructuras, regímenes de prestación y prácticas en todos los ámbitos de la educación, la formación, el empleo, el desempleo y los sectores privado y asociativo. Esta diversidad ofrece una base fértil para cooperar y aprender los unos de los otros.

6. La orientación puede aportar un apoyo significativo a las personas en su transición entre niveles y sectores de los sistemas de educación y formación y de la escuela a la vida adulta y profesional; a los jóvenes que reanudan su educación o formación profesional tras haber dejado pronto la escuela; a las personas que se reintegran en el mercado de trabajo después de períodos del desempleo voluntario o involuntario, o de trabajo en el hogar; a los trabajadores a quienes la reestructuración sectorial les exija cambiar el tipo de empleo; así como a los trabajadores de edad avanzada y a los migrantes.

7. La prestación de una orientación permanente de alta calidad es un elemento clave de las estrategias de educación, la formación y la empleabilidad para lograr el objetivo estratégico de que Europa se convierta en la sociedad del conocimiento más dinámica del mundo en 2010. 


\section{RECUERDAN QUE}

1. El informe sobre los futuros objetivos precisos de los sistemas educativos y de formación, refrendado por el Consejo Europeo de Estocolmo en 2001, define el acceso a los servicios de orientación, la garantía de calidad de los servicios, el papel de la orientación en el desarrollo de los recursos humanos y la orientación para facilitar la movilidad, el aprendizaje y el empleo en Europa, como áreas prioritarias de desarrollo a la hora de aplicar el programa de trabajo de Educación y Formación 2010.

2. En la Comunicación de la Comisión sobre aprendizaje permanente (noviembre 2001), "Hacer realidad un espacio europeo del aprendizaje permanente", se destacó la orientación como un tema transversal para el desarrollo y aplicación de estrategias de aprendizaje permanente a nivel nacional y como área prioritaria de actuación, tanto a nivel europeo como nacional.

3. En el Libro Blanco "Un nuevo impulso para la juventud europea" (2001) se hace referencia a la necesidad de los jóvenes de contar con un sistema flexible de orientación y asesoramiento que complemente el acceso actual al aprendizaje durante toda la vida y en todos sus aspectos.

4. En la Resolución del Consejo sobre la educación permanente, de 27 de junio de 2002, se recomendó que los Estados miembros y la Comisión dieran prioridad a los servicios de información, orientación y asesoramiento de buena calidad y al acceso a los mismos, en relación con las oportunidades de educación y formación en Europa, destinados especialmente a distintos grupos.

5. En la Comunicación de la Comisión "Plan de acción sobre las capacidades y la movilidad" (2002) se observó que se puede mejorar la movilidad geográfica y del empleo en Europa y la capacitación de la mano de obra proporcionando un mejor 
acceso de los trabajadores y los empresarios a la información, la orientación y el asesoramiento.

6. La Directiva 2002/73/CE, que modifica la Directiva 76/207/CEE relativa a la aplicación del principio de igualdad de trato entre hombres y mujeres en lo que se refiere al acceso al empleo, a la formación y a la promoción profesionales y a las condiciones de trabajo, incluye el requisito del acceso a todos los tipos y todos los niveles de orientación profesional.

7. En la Resolución del Consejo relativa al fomento de la cooperación reforzada europea en materia de educación y formación profesionales de 19 de diciembre de 2002 se reconoció que es preciso dar prioridad al fortalecimiento de las políticas, sistemas y prácticas relativos a la información, orientación y asesoramiento en los Estados miembros para apoyar la movilidad geográfica y profesional de los ciudadanos europeos.

8. En la comunicación de la Comisión "Invertir eficazmente en educación y formación: un imperativo para Europa" (2003) se observó que debe considerarse la inversión en servicios de orientación como la realización de estrategias de prevención precoz que puedan reducir de manera significativa la falta de adecuación entre la educación y la formación y las necesidades del mercado de trabajo, aumentando la proporción de personas que completan la educación secundaria y superior y facilitando la transición al trabajo y el retorno a los estudios.

9. En las Directrices europeas para el empleo (2003) se recomendó como prioridad facilitar orientación y asesoramiento en fases tempranas para prevenir las incorporaciones al desempleo y en particular al desempleo de larga duración.

10. Las Conclusiones del Consejo del 25 de noviembre de 2003 sobre el desarrollo del capital humano para la cohesión social y la competitividad recalcaron la 
importancia de la coherencia y la complementariedad de las políticas en el ámbito de la educación y la formación y las estrategias económicas y sociales.

11. La Resolución del Consejo del 25 de noviembre de 2003 encaminada a hacer de la escuela un ambiente de aprendizaje abierto para prevenir y luchar contra el abandono de los estudios y el malestar de los jóvenes señaló la necesidad de reforzar el vínculo y la sinergia entre la escuela y el mundo laboral y de promover la inclusión social mediante la implicación de las familias, los organismos juveniles y el voluntariado.

12. Por último, el informe intermedio conjunto (2004) del Consejo y la Comisión sobre la aplicación de la Estrategia de Lisboa, Educación y Formación 2010: Urgen las reformas para coronar con éxito la Estrategia de Lisboa, definió la orientación como una de las cuatro acciones claves para crear entornos de aprendizaje abiertos, atractivos y accesibles, con vistas a "... apoyar el aprendizaje a todas las edades y en diversas estructuras, facilitar a los ciudadanos los medios de gestionar su aprendizaje y su trabajo, en particular allanando su acceso a una extensa gama de posibilidades de aprendizaje y de carreras profesionales y su progresión en dichas formaciones y carreras".

\section{TOMAN NOTA DE LO SIGUIENTE:}

- La transición a una economía y a una sociedad basadas en el conocimiento crea nuevos retos para los responsables políticos en materia de desarrollo de recursos humanos y de políticas, sistemas y prácticas de orientación.

- El surgimiento de una sociedad basada en el conocimiento y la necesidad del aprendizaje permanente exigen que se conceda gran atención a la política de orientación a nivel nacional, sectorial, regional y local. Los servicios deben estar disponibles en momentos y maneras que animen a todos los ciudadanos a continuar desarrollando sus cualificaciones y competencias durante toda su 
vida, en consonancia con las cambiantes necesidades del mercado de trabajo. Estos servicios deben considerarse como un instrumento activo, y es preciso fomentar su uso.

- El aumento de la cooperación en materia de orientación a todos los niveles debe continuar con una perspectiva de aprendizaje permanente, para aprovechar plenamente la diversidad de los sistemas que se encuentran en la actualidad en los Estados miembros de la Unión Europea y para superar la fragmentación entre distintas formas de prestación de esos servicios.

- Las actividades correspondientes que se están realizando en Europa, en particular el trabajo de los grupos de seguimiento de los Objetivos de Lisboa en relación con el desarrollo de conceptos y principios comunes de orientación permanente, las actividades respaldadas por los programas educativos, de formación y empleo de la UE y por el Fondo Social Europeo (FSE) y la necesidad de coordinación y complementariedad entre todas estas actividades.

- El resultado de las revisiones de las políticas en materia de orientación en los países europeos que han emprendido conjuntamente la Comisión Europea (a través del Centro Europeo para el Desarrollo de la Formación Profesional (CEDEFOP)) y la Fundación Europea de la Formación (FEF) y la OCDE, en asociación con el Banco Mundial, muestran que, en muchos países, las políticas, sistemas y prácticas de orientación en Europa no corresponden a las demandas de unas economías y unas sociedades basadas en el conocimiento y exigen una reforma de las políticas y un replanteamiento de la práctica en este sector.

- El Marco de acciones para el desarrollo permanente de competencias y cualificaciones acordado por los interlocutores sociales europeos en el contexto del diálogo social europeo destaca la necesidad de que los trabajadores y los empresarios tengan acceso a servicios de información, orientación y asesoramiento para aplicar una estrategia de mejora de las competencias de los trabajadores individuales. 


\section{DESTACAN:}

- Que, en su caso y teniendo en cuenta las circunstancias locales, todos los ciudadanos europeos deben tener acceso a servicios de orientación en todas las etapas de su vida, prestando particular atención a las personas y grupos en situación de riesgo.

- La función preventiva de los servicios de orientación para fomentar la terminación del ciclo de enseñanza obligatoria, y su contribución a la responsabilización de las personas para gestionar su propia formación y trayectoria profesional, así como a la reintegración de quienes abandonaron la escolaridad en programas adecuados de educación y formación.

- La importancia de la orientación para promover la integración económica y social de los ciudadanos mediante el apoyo al acceso de todos a la educación, la formación y las oportunidades de trabajo, aumentando los índices de terminación de todos los niveles de educación y formación, con inclusión de la enseñanza complementaria y superior y de la educación y formación de adultos, y propiciando la movilidad profesional y geográfica de los alumnos y los trabajadores en Europa.

- La necesidad de flexibilidad y diversidad en la prestación de servicios de orientación inclusive recurriendo a metodologías y tecnologías innovadoras, técnicas de acercamiento y servicios afines para mejorar el acceso de los ciudadanos a estos servicios, especialmente respecto a los jóvenes y adultos de difícil abordaje, y para superar las desigualdades económicas y geográficas.

- El papel central de los beneficiarios de la orientación, tanto en el diseño como en la evaluación de los servicios de orientación para jóvenes y para adultos.

- La participación en el proceso de orientación de todos los agentes pertinentes, incluidos los interlocutores sociales, en línea con los usos nacionales, tanto para garantizar el acceso de los trabajadores a los servicios de orientación como para 
ayudar a los proveedores de educación y formación y a los servicios de orientación aportando, por ejemplo, la posibilidad de una experiencia profesional y de contacto con situaciones reales de trabajo, promoviendo el espíritu empresarial y facilitando el acceso de los trabajadores por cuenta ajena a los servicios de orientación.

\section{REITERAN CON CARÁCTER PRIORITARIO}

- Su empeño en desarrollar unos servicios de orientación de gran calidad para todos los ciudadanos europeos, accesibles en todas las etapas de sus vidas, que los capaciten para gestionar sus trayectorias de aprendizaje y de trabajo y la transición entre una fase y otra.

- La necesidad de una mayor cooperación en materia de orientación mediante acciones y políticas desarrolladas sobre todo en el contexto de las medidas derivadas de la Estrategia de Lisboa en materia de educación y formación, Educación y Formación 2010, y teniendo en cuenta asimismo la Estrategia Europea de Empleo, la Estrategia marco sobre la igualdad entre hombres y mujeres y las políticas europeas de inserción social, movilidad y servicios de interés general.

- La importancia de redirigir los servicios de orientación, en su caso, para mejorar las aptitudes de los ciudadanos en materia de aprendizaje y gestión a lo largo y ancho de su vida, como parte integrante de los programas de educación y formación.

- El desarrollo, a nivel nacional, regional y local, en su caso, de mecanismos que garanticen una mejor calidad de los servicios, la información y los productos de orientación (inclusive los servicios en línea), en particular desde una perspectiva del ciudadano y del consumidor.

- La necesidad de reforzar las estructuras de concepción de políticas y sistemas a nivel nacional y regional, haciendo participar a los principales implicados 
(ministerios, interlocutores sociales, servicios de empleo, prestadores de servicios, orientadores, centros de educación y formación, consumidores, padres y jóvenes).

- La necesidad de un seguimiento de los asuntos de política de orientación dentro del programa de trabajo Educación y Formación 2010.

\section{INVITAN A LA COMISIÓN}

- A que intensifique la cooperación a nivel internacional con las organizaciones correspondientes, la OCDE, la OIT, la UNESCO, en el desarrollo de políticas y acciones concretas de orientación permanente.

\section{INVITAN A LOS ESTADOS MIEMBROS}

- A que revisen, en su caso, los actuales servicios nacionales de orientación en los sectores de la educación y formación y del empleo, en el contexto de las conclusiones de los estudios sobre políticas de orientación de la Comisión, la OCDE y el Banco Mundial.

- A que se esfuercen en conseguir una cooperación y coordinación efectivas en la prestación de servicios de orientación entre los proveedores de orientación a niveles nacional, regional y local, con vistas a conseguir un mayor acceso y garantizar la coherencia entre los servicios, especialmente para los grupos de riesgo.

- A alentar a los orientadores de las escuelas y de los centros de enseñanza complementaria y superior a promover las técnicas de aprendizaje razonado y de aprendizaje autónomo, para que los jóvenes y los adultos puedan gestionar personalmente de un modo eficaz sus propias trayectorias de aprendizaje y actividad profesional. 


\section{INVITAN A LOS ESTADOS MIEMBROS Y A LA COMISIÓN, DENTRO DE SUS COMPETENCIAS RESPECTIVAS}

- A desarrollar y adaptar las estructuras europeas y actividades actuales (redes, grupos de trabajo, programas) relacionadas con la aplicación de las citadas prioridades.

- A determinar, en conjunción con todos los actores pertinentes, incluidos los interlocutores sociales, los sectores en que la cooperación y el apoyo a nivel europeo pueden mejorar los resultados nacionales en el sector de la orientación.

- A que garanticen la máxima rentabilidad en términos de repercusiones en las políticas, sistemas y prácticas, tanto a nivel nacional como comunitario, de las actividades de colaboración entre y con los Estados miembros en materia de orientación permanente financiadas por los instrumentos existentes y futuros de educación y formación y por el Fondo Social Europeo.

- A que velen por la integración de una perspectiva de género en todas las políticas y prácticas relativas a los servicios de orientación.

- A alentar y apoyar a los dispensadores de la enseñanza inicial y permanente de los orientadores a que reflejen en sus programas de formación las mejores prácticas actuales de la Unión.

- A cooperar en la mejora de la calidad de la información con que cuentan los responsables políticos sobre las mejores prácticas a escala nacional e internacional.

- A incluir un examen de las políticas de orientación, en su caso, en los futuros informes sobre el seguimiento del programa Educación y Formación 2010. 


\section{ANEXO 4. PROYECTO DE RESOLUCIÓN DEL CONSEJO Y DE LOS REPRESENTANTES DE LOS GOBIERNOS DE LOS ESTADOS MIEMBROS, REUNIDOS EN CONSEJO, DE 21 DE NOVIEMBRE DE 2008, TITULADA «INCLUIR MEJOR LA ORIENTACIÓN PERMANENTE EN LAS ESTRATEGIAS PERMANENTES DE EDUCACIÓN Y FORMACIÓN PERMANENTE}

(2008/C 319/02)

El consejo de la Unión Europea y los representantes de los gobiernos de los estados miembros reunidos en el seno del consejo

\section{CONSIDERANDO LO SIGUIENTE:}

(1) La globalización creciente de los intercambios y la prolongación de la duración de la vida activa requieren más que nunca una adaptación constante de las competencias individuales para anticiparse mejor a las evoluciones previsibles o necesarias y proteger así la trayectoria profesional;

(2) La ampliación de la Unión Europea aumenta el potencial de movilidad en la educación y la formación, así como en el mercado laboral, creando por lo tanto la necesidad de preparar a los ciudadanos para que desarrollen en su formación y trayectoria profesional en un marco geográfico ampliado;

(3) La vida de los ciudadanos se caracteriza cada vez más por la multiplicación de las transiciones, en concreto de la enseñanza escolar a la educación y formación profesional y a la enseñanza superior o al puesto de trabajo, o entre el empleo y el desempleo, la formación adicional o el cese de actividad laboral. La orientación desempeña un papel determinante en la toma de las importantes decisiones a las que se enfrentan los individuos a lo largo de su vida. Puede contribuir así a la capacitación personal y a la gestión de la propia trayectoria profesional de manera 
más segura en el marco del funciona- miento del mercado laboral y a lograr un mejor equilibrio entre la visa personal y profesional;

(4) el mercado laboral se caracteriza por un desequilibrio entre la persistencia del desempleo y las dificultades de contratación de algunos sectores y la orientación constituye un medio para responder mejor a las necesidades del mercado laboral.

(5) la inclusión social y la igualdad de oportunidades siguen siendo los principales retos de las políticas de educación, formación y empleo.

\section{CONFIRMAN:}

La definición de la orientación como un proceso continuo que permite a los ciudadanos, a cualquier edad y a lo largo de su vida, determinar sus capacidades, sus competencias y sus intereses, tomar decisiones en materia de educación, formación y empleo y gestionar el recorrido de su vida personal en lo que respecta a la educación y la formación, en el trabajo y en otros marcos en los que es posible adquirir o utilizar estas capacidades y competencias. La orientación incluye actividades individuales o colectivas de información, de consultas, de evaluación de competencias, de apoyo y de enseñanza de las competencias necesarias para la toma de decisiones y para la gestión de la carrera.

\section{RECUERDAN QUE:}

1. La Resolución del Consejo del 28 de mayo de 2004 sobre el fortalecimiento de las políticas, sistemas y prácticas en materia de orientación permanente en Europa precisa los grandes objetivos de una política de orientación permanente para todos los ciudadanos de la Unión Europea.

2. La Recomendación del Parlamento Europeo y el Consejo sobre las competencias clave para el aprendizaje permanente del 18 de diciembre de 2006, 
subraya, con referencia a varias competencias clave, que la aptitud para buscar oportunidades de educación y formación es esencial para el desarrollo personal del individuo, su evolución profesional y su integración social.

3. La Resolución del Consejo del 15 de noviembre de 2007 titulada Nuevas cualificaciones para nuevos empleos invita a los Estados miembros y a la Comisión a preparar los trabajadores a los nuevos empleos de la sociedad del conocimiento, gracias a un servicio de orientación profesional que permita a los solicitantes de empleo identificar los módulos de competencia necesarios para acceder a nuevos empleos en los sectores donde existen déficit de competencias.

4. El Informe conjunto de situación 2008 del Consejo y la Comisión sobre la aplicación del programa de trabajo «La Educación y la formación permanente al servicio del conocimiento, la creatividad y la innovación» recuerda que es importante prestar «especial atención» a la orientación a lo largo de la vida.

5. Las Conclusiones del Consejo del 25 de mayo de 2007 sobre un marco coherente de indicadores e índices de referencia para supervisar los avances hacia los objetivos de Lisboa de educación y formación constituyen un importante instrumento para evaluar la realización de los objetivos fijados por la Estrategia de Lisboa y, a este respecto, pueden servir para seguir los progresos de los Estados miembros en materia de orientación en su estrategia de educación y formación permanente.

6. La Recomendación del Parlamento Europeo y el Consejo de 23 de abril de 2008 por la que se establece el marco europeo de certificaciones para la educación y la formación permanentes dispone un marco común de referencia destinado a servir de instrumento de transposición para los distintos sistemas y niveles de certificación. Puede facilitar la movilidad de los activos e integrar la orientación en las políticas y las prácticas de educación y empleo de los Estados miembros. 
7. Las conclusiones del Consejo del 22 de mayo de 2008 sobre la educación y la formación de adultos recuerdan las ventajas económicas, sociales e individuales que conlleva el refuerzo de la educación y la formación de los adultos y hacen hincapié en que corresponde a las autoridades establecer sistemas de información y orientación de calidad, fundados en un enfoque más centrado en el individuo para ayudarle a ser, legítimamente, más activo y autónomo en materia de educación y formación.

\section{OBSERVAN QUE:}

1. Los recientes informes de evaluación, en particular el del Centro Europeo para el Desarrollo de la Formación Profesional (CEDEFOP) de 2008 sobre la aplicación de la Resolución de 2004, destacan que, si bien se han efectuado algunos avances, todavía hay que realizar esfuerzos para prestar servicios de orientación de mejor calidad, ofrecer un acceso más equitativo centrado en las aspiraciones y las necesidades de los ciudadanos y coordinar y construir asociaciones entre las ofertas de servicio existentes.

2. En 2007, los Estados miembros crearon una Red europea para el desarrollo de las políticas de orientación permanente (ELGPN) que incluye representantes de todos los Estados miembros que decidan participar, y aumenta así las posibilidades de aprendizaje mutuo y cooperación para el desarrollo de las políticas, sistemas y prácticas en el ámbito de la orientación permanente entre los Estados miembros.

3. Es necesario consolidar las prioridades destinadas a aplicar activamente una política de orientación en el marco de las estrategias nacionales de educación y formación permanente. Conviene traducir estas prioridades en acciones y utilizar los instrumentos y herramientas europeos. 


\section{INVITAN A LOS ESTADOS MIEMBROS A:}

- reforzar el papel de la orientación permanente en el marco de las estrategias nacionales de educación y formación permanente, de conformidad con la Estrategia de Lisboa y con el marco estratégico para la cooperación europea en el ámbito de la educación y la formación,

- realizar, cuando sea necesario, balances de las políticas y prácticas de orientación a nivel nacional,

- aplicar los siguientes principios rectores (según se detalla en los «Principios» recogidos en el anexo), en función del contexto y legislación nacionales y para acompañar las transiciones a lo largo de la vida de los ciudadanos:

1) favorecer la adquisición permanente de capacidades de orientación;

2) facilitar el acceso de todos los ciudadanos a los servicios de orientación;

3) desarrollar la garantía de calidad de los servicios de orientación;

4) fomentar la coordinación y la cooperación de los distintos protagonistas a niveles nacional, regional y local,

- aprovechar las oportunidades que ofrecen el Programa de acción en el ámbito del aprendizaje permanente (EFTLV) y los Fondos estructurales europeos según las prioridades de los Estados miembros.

\section{INVITAN A LOS ESTADOS MIEMBROS Y A LA COMISIÓN, DENTRO DE SUS RESPECTIVAS COMPETENCIAS, A:}

1 reforzar la cooperación europea en materia de orientación permanente, en particular a través de la red ELGPN, apoyada por el programa Educación y Formación permanente, y junto con el Cedefop. 
En particular:

- facilitar los intercambios entre Estados miembros sobre las políticas que ejecutan, sus prácticas y la evaluación que realizan de las mismas, para que puedan inspirarse de los ejemplos con buenos resultados. 



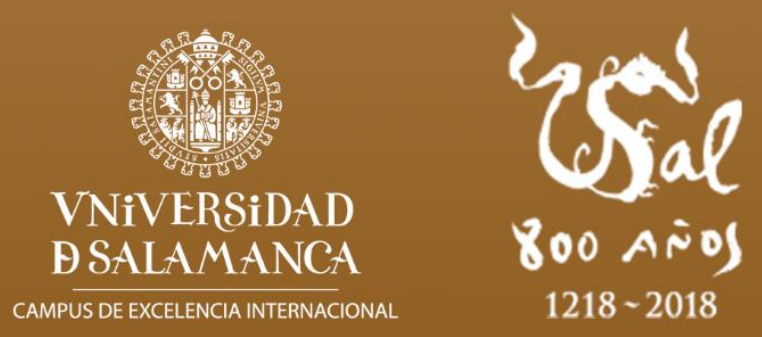

